\title{
Vitamin D in insulin sensitivity and obesity
}

Citation for published version (APA):

Pramono, A. (2020). Vitamin D in insulin sensitivity and obesity: Fact or fiction? [Doctoral Thesis, Maastricht University]. Maastricht University. https://doi.org/10.26481/dis.20200828ap

Document status and date:

Published: 01/01/2020

DOI:

10.26481/dis.20200828ap

Document Version:

Publisher's PDF, also known as Version of record

\section{Please check the document version of this publication:}

- A submitted manuscript is the version of the article upon submission and before peer-review. There can be important differences between the submitted version and the official published version of record.

People interested in the research are advised to contact the author for the final version of the publication, or visit the DOI to the publisher's website.

- The final author version and the galley proof are versions of the publication after peer review.

- The final published version features the final layout of the paper including the volume, issue and page numbers.

Link to publication

\footnotetext{
General rights rights.

- You may freely distribute the URL identifying the publication in the public portal. please follow below link for the End User Agreement:

www.umlib.nl/taverne-license

Take down policy

If you believe that this document breaches copyright please contact us at:

repository@maastrichtuniversity.nl

providing details and we will investigate your claim.
}

Copyright and moral rights for the publications made accessible in the public portal are retained by the authors and/or other copyright owners and it is a condition of accessing publications that users recognise and abide by the legal requirements associated with these

- Users may download and print one copy of any publication from the public portal for the purpose of private study or research.

- You may not further distribute the material or use it for any profit-making activity or commercial gain

If the publication is distributed under the terms of Article $25 \mathrm{fa}$ of the Dutch Copyright Act, indicated by the "Taverne" license above, 
VITAMIN D IN INSULIN SENSITIVITY AND OBESITY:

FACT OR FICTION?

Adriyan Pramono 


\section{NUTRIM}

The studies presented in this thesis were performed within NUTRIM School of Nutrition and Translational Research in Metabolism, Maastricht University.

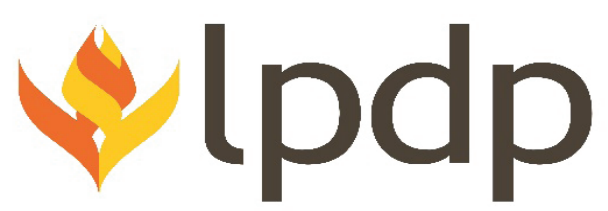

lembaga pengelola dana pendidikan

The PhD program has been supported by Indonesian Endowment Fund for Education (Lembaga Pengelola Dana Pendidikan/LPDP), Indonesia.

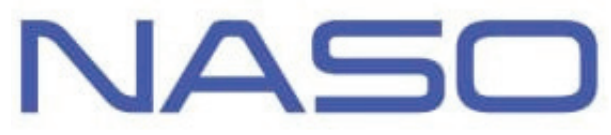

Financial support by the Netherlands Association for the Study of Obesity (NASO) for printing of this thesis is gratefully acknowledge.

$\begin{array}{ll}\text { Cover design } & \text { : Nadia Ayu Lestari } \\ \text { Layout } & \text { : Adriyan Pramono \& Nadia Ayu Lestari } \\ \text { Printed \& Published by } & : \text { Gildeprint } \\ \text { ISBN } & : 978-94-6402-379-4\end{array}$

Copyright (C) Adriyan Pramono, Maastricht 2020

For articles published or accepted for publication, the copyright has been transferred to the respective publisher. No parts of this thesis may be reproduced, store in a retrieval system, or transmitted in any form or by any means without the permission of the author, or when appropriate, from the publishers of the manuscript. 


\title{
VITAMIN D IN INSULIN SENSITIVITY AND OBESITY: FACT OR FICTION?
}

\author{
DISSERTATION
}

to obtain the degree of Doctor at the Maastricht University, on the authority of the Rector Magnificus, Prof. dr. Rianne M. Letschert, in accordance with the decision of the Board of Deans, to be defended in Public on Friday 28 August 2020, at 10:00 hours

by

\section{Adriyan Pramono}

Born July 4, 1985, in Semarang, Indonesia 


\section{Promotor}

Prof. dr. E.E. Blaak

\section{Co-promotor}

Dr. Johan W.E. Jocken

\section{Assessment Committee}

Prof. dr. E.C.M. Mariman, chairman

Prof. dr. L.J.C. van Loon

Dr. Simone J.P.M. Eussen

Prof. dr. C.P.G.M. de Groot (Wageningen University \& Research)

Prof. dr. M. Visser (Vrije Universiteit Amsterdam) 
This thesis is dedicated to my beloved jewels Fadhlan \& Fathima, children of tomorrow. You both will shape the world someday. So be brave, be kind, and be passionate with what you do. 



\section{TABLE OF CONTENTS}

CHAPTER 1 General Introduction

CHAPTER 2 Vitamin D deficiency in the aetiology of obesityrelated insulin resistance

CHAPTER 3 Vitamin D release across abdominal adipose tissue in lean and obese men:

the effect of ß-adrenergic stimulation

CHAPTER 4 Vitamin D and tissue-specific insulin sensitivity in humans with overweight/obesity

CHAPTER 5 The association between vitamin D receptor polymorphisms and tissue-specific insulin resistance in human obesity

CHAPTER 6 The effect of vitamin D supplementation on insulin sensitivity: a systematic review and meta-analysis

CHAPTER 7 General Discussion

Ringkasan

Valorization

Acknowledgements

About the author

PhD portfolio 

CHAPTER 1

General Introduction

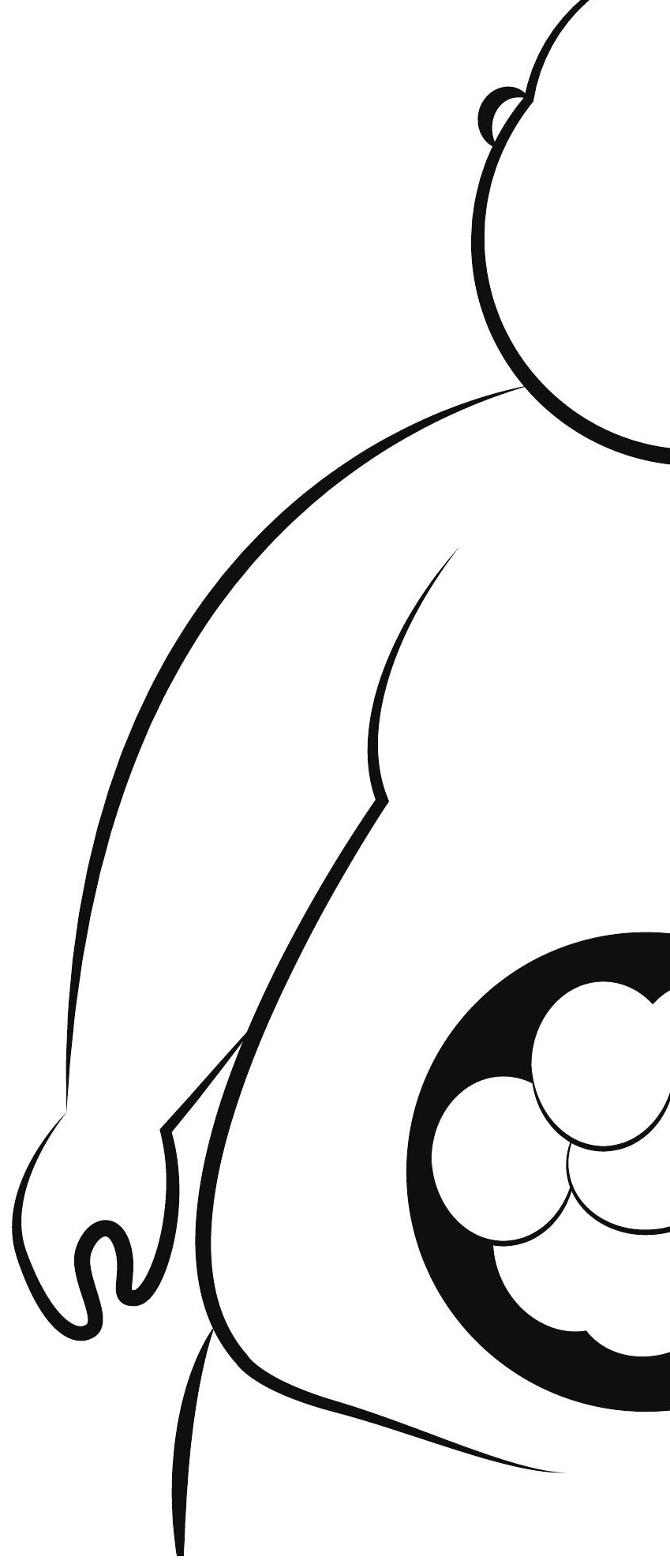




\section{Obesity pandemic}

The World Health Organization (WHO) defines overweight and obesity as abnormal or excessive fat accumulation that presents a risk to human health (1). Currently, in population settings, obesity is defined by body mass index (BMI, calculated as weight in kilograms divided by the square of height in meters $\left.\left(\mathrm{kg} / \mathrm{m}^{2}\right)\right)$, a simple measure of body fatness based on height and weight that applies to adult men and women. A BMI $\geq 25 \mathrm{~kg} /$ $\mathrm{m}^{2}$ is categorized as overweight and a BMI $>30 \mathrm{~kg} / \mathrm{m}^{2}$ is classified as obese (2). Recent findings indicate that BMI might not be considered as an accurate marker to define body fat distribution and cardiometabolic risk $(3,4)$.

Over the last decades, the prevalence of obesity worldwide has risen enormously and reached pandemic proportions. According to World Health Organization report in 2018 , about $39 \%$ of adults aged 18 years and over (39\% of men and $40 \%$ of women) were overweight. Overall, about $13 \%$ of the world's adult population $(11 \%$ of men and $15 \%$ of women) were obese (1). According to a recent report based on data from the Organization for Economic Cooperation and Development (OECD) (5), obesity has reached epidemic proportions in both developed (USA (38.2\%), UK (26.9\%), The Netherlands (12.8\%), and Japan (3.7\%) ) and developing (Brazil (20.8\%), China (7.0\%), India (5.0\%) and Indonesia $(5.7 \%)$ ) countries (6). Taken together, it is now clear that prevalence of obesity expands in all age groups and in both sexes, irrespective of ethnicity, geographical locations and socioeconomic status (7).

Obesity is strongly associated with an increased risk of Type 2 Diabetes Mellitus (T2D), cardiovascular disease (e.g. dyslipidemia, stroke and hypertension), non-alcoholic fatty liver disease (NAFLD), musculoskeletal disorders, certain type of cancers and mental illness (8). Nowadays, not only the Western society is affected by obesity, also many low-middleincome countries have increased morbidity and mortality rates because of the increasing prevalence of obesity (9). Furthermore, obesity and its co-morbidities are associated with increased healthcare costs (particularly secondary health care) and a reduced ability for employment, indicating high impact on social-economic burden (10). Thus obesity and its related co-morbidities have now been well-recognized as a major health problem, and the prevalence of obesity is predicted to still increase in upcoming years thereby having a large impact on future public health (6).

\section{Metabolic interorgan crosstalk in obesity and insulin resistance}

The underlying cause of overweight and obesity is an imbalance between energy intake and energy expenditure, which is influenced by genetic, microbial, neurobiological, behavioral, and environmental factors (11). Obesity is strongly associated with the development of insulin resistance which is defined as an impaired action of insulin on its metabolic target organs such as adipose tissue (AT), liver, skeletal muscle and pancreas $(12,13)$. Figure 1 illustrates the inter-organ crosstalk between these tissues under obesityinduced insulin resistant conditions.

The adipose tissue is not only a passive fat storage organ, but is an active metabolic and endocrine organ $(14,15)$. The adipose tissue has two major functions in lipid metabolism, (1) to store lipid as triacylglycerol (TAG) from the uptake of meal-derived chylomicrons and 
(2) the release of non-esterified fatty acids (NEFA) to supply energy into non-adipose tissue organs during conditions of increased energy demand (16). In the presence of a chronic positive energy balance, the fatty acid supply may exceed the storage capacity. This results in dysfunctional adipose tissue characterized by enlarged adipocytes $(17,18)$, an impaired differentiation of preadipocytes (i.e. adipogenesis) $(19,20)$, decreased adipose tissue blood flow $(16,21,22)$, chronic low-grade local inflammation $(23,24)$ and an impaired lipid buffering capacity $(25,26)$. This impaired lipid buffering capacity is characterized by an reduced insulin-mediated TAG extraction and a reduced insulin-mediated inhibition of endogenous lipolysis. The impaired inhibition of endogenous lipolysis may be (partly) compensated by a relative increase in insulin secretion and thus increased circulating insulin concentrations (25). If the AT buffering capacity is exceeded, fatty acids can spillover in the circulation and will be accumulated in other insulin sensitive tissues such as liver, skeletal muscle, and pancreas, which may relate to impairment in insulin sensitivity and insulin secretion $(12,13)$. Additionally, adipose tissue inflammation may result in systemic low grade inflammation, which has also been linked to the development of insulin resistance (27).

In the liver, lipid accumulation may be explained by (i) an increased spillover of NEFA from subcutaneous adipose tissue (SAT) into circulation (28), (ii) an increased flux of FFA from visceral adipose tissue (VAT) through portal vein directing to the liver ("portal vein hypothesis") (29), and (iii) an increased uptake from lipoprotein remnants (28). An increased lipogenesis due to an increased hepatic lipid supply leads to an increase of very-low-densitylipoprotein (VLDL)-TAG secretion. Hepatic lipid accumulation interferes with insulin signaling in the liver, resulting in a diminished insulin-mediated suppression of VLDL production and secretion (26). Furthermore, hepatic insulin resistance is associated with an increased of endogenous glucose production and a reduced glycogen storage in the liver $(30,31)$.

The skeletal muscle is an important organ in peripheral insulin sensitivity since it contributes to $70-90 \%$ of the total glucose disposal under postprandial conditions (26). An elevated lipid supply from adipose tissue and liver to circulation may result in an increased muscle lipid uptake. The obese, insulin resistant state is characterized by a reduced capacity to adapt fat oxidation to fatty acid supply (32). This leads to an increased intramuscular lipid accumulation, in particular the accumulation of bioactive lipid metabolites, which contributes to impairments in the insulin signalling $(33,34)$, a subsequent reduced glucose transporter-4 (GLUT-4) translocation to the skeletal muscle membrane (35), and a reduced insulin-mediated glucose uptake (36).

In pancreas, chronic exposure to elevated levels of NEFAs results in a decreased insulin gene expression and blunted glucose-stimulated insulin secretion (GSIS) in vitro (37). Using proton-magnetic resonance spectroscopy ( $\left.{ }^{1} \mathrm{H}-\mathrm{MRS}\right)$, it has been demonstrated that pancreatic lipid accumulation was increased in individuals with an impaired glucose metabolism (38). This pancreatic fat accumulation may be associated with a decreased glucose-stimulated insulin secretion by the beta-cells (39).

As a consequence, obesity-related insulin resistance accompanied by impairments in insulin secretion can be progressing towards a prediabetic state and subsequently toward T2DM (40). Prediabetes can be classified as a state of impaired fasting glucose (IFG, fasting glucose $>5.6 \mathrm{mmol} / \mathrm{L}$ ) and/or impaired glucose tolerance (IGT, $2 \mathrm{~h}$ oral glucose tolerance test OGTT)-derived glucose $7.8-11.0 \mathrm{mmol} / \mathrm{L})(41,42)$. These two prediabetic states, may be representing different etiologies towards T2D (43). 


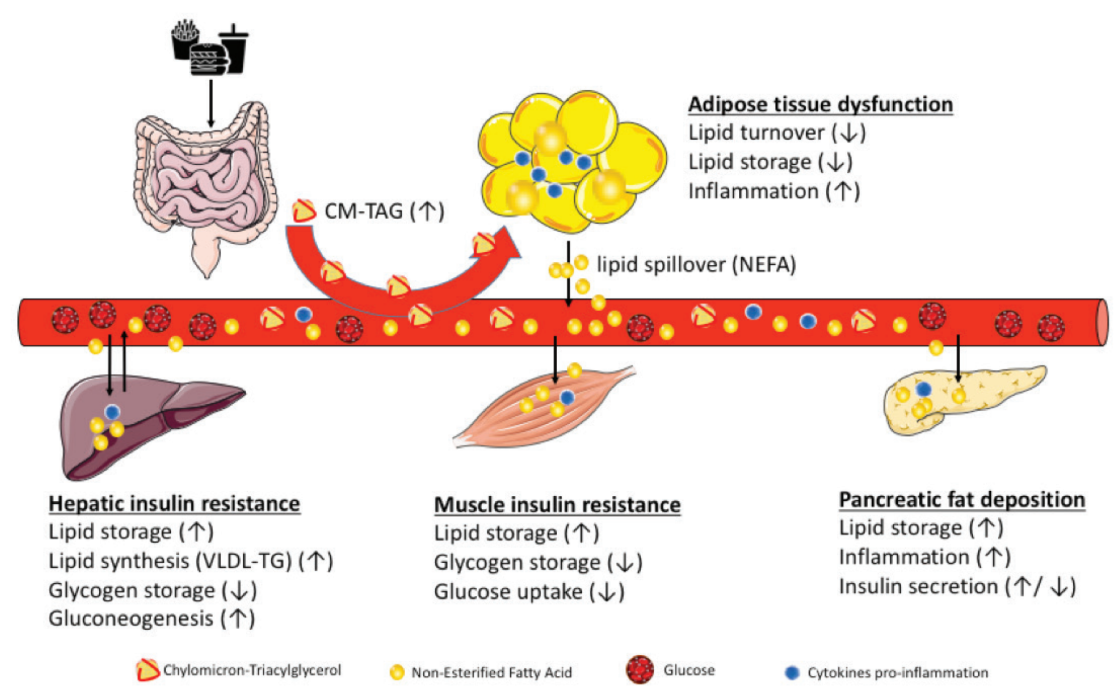

Figure 1. Inter-organ crosstalk in human obesity-related insulin resistance. Long-term positive energy balance results in systemic lipid overload and an increased lipid storage in the adipose tissue. When the buffering capacity in the AT is diminished, fatty acids (NEFA) spillover in non-adipose tissues such as liver, skeletal muscle, and pancreas. An impaired oxidation of lipids in these tissues, directly to increase lipid accumulation within these tissues and induce tissue-specific insulin resistance. Furthermore, cytokines pro-inflammation may also spillover from the AT towards other tissues and potentially decrease whole-body insulin sensitivity. Of note, an increased of insulin secretion has been suggested as an adaptive response to whole-body insulin resistance at the early stage, and it decreases along with chronic insulin resistance and beta-cell dysfunction. $(\uparrow)$ increase; $(\downarrow)$ decrease.

\section{Measurement of insulin resistance}

There are several methodologies for estimating insulin resistance. Homeostasis model assessment of insulin resistance (HOMA-IR) is a common-used surrogate marker describing glucose-insulin homeostasis by mathematically-derived nonlinear equations. It is derived from the use of the fasting insulin (FPI) and glucose (FPG) product, divided by a constant (22.5) (44). The HOMA-IR is a surrogate marker, which may reflect merely hepatic insulin resistance (45). In addition, Matsuda and DeFronzo have developed a model to estimate whole-body insulin sensitivity from the OGTT. Here the OGTT index of insulin sensitivity [ISI (composite)] was calculated using both the data (insulin and glucose) during 2-hours of the test (46).

Furthermore, Abdul-Ghani et al, has developed a model to estimate hepatic insulin resistance and muscle insulin sensitivity based on a multiple sampling points OGTT. The hepatic insulin resistance index (HIRI) is estimated using the square root of the product of the area under curves (AUCS) for glucose and insulin during the first $30 \mathrm{~min}$ of the OGTT, where as muscle insulin sensitivity index (MISI) can be estimated using the rate of decay of plasma glucose concentration during the OGTT (47). Among the tools to determine IR and measure whole-body insulin sensitivity, the hyperinsulinemic euglycemic clamp technique is recognized as the gold-standard method to estimate insulin sensitivity (44). In a two step of hyperinsulinemic euglycemic clamp with a $\left[6,6-{ }^{2} \mathrm{H}_{2}\right]$-glucose tracer infusion both hepatic and peripheral insulin sensitivity as well as adipose tissue insulin sensitivity can be assessed $(48,49)$. 


\section{Obesity, insulin resistance and vitamin D status}

Skin synthesis of vitamin $D_{3}$ stimulated by sun exposure is the major source of vitamin $D$ in humans. Vitamin $D$ can also be ingested from the diet as vitamin $D_{2}$ and $D_{3}$ (50). In form vitamin $D_{2}$ is commonly found in mushroom (51), whereas vitamin $D_{3}$ can be found in oil-rich fish and eggs, meat, fortified foods (most often milk and dairy products, margarine and spreads and some breakfast cereals), as well as supplementation $(50,52)$. The circulating vitamin $D 25$-hydroxyvitamin $\mathrm{D}_{3}\left[25(\mathrm{OH}) \mathrm{D}_{3} /\right.$ calcifediol) is still inactive until this has been hydroxylated (1- $\alpha$-hydroxylase enzyme/CYP27B1) into 1,25-dihydroxyvitamin $\mathrm{D} / 1,25 \mathrm{OH}_{2} \mathrm{D}_{3}$ (calcitriol) in the kidney, which is the active vitamin $\mathrm{D}$ metabolite (53). Both of the active and inactive form of vitamin $D$ have been shown to be lipophilic as indicated by recent studies which were able to detect both vitamin D metabolites in adipose tissue (54, $55)$. Vitamin $D$ deficiency (defined as having $\left[25(\mathrm{OH}) \mathrm{D}_{3}\right.$ ] levels $<50 \mathrm{nmol} / \mathrm{L}$ or $<20 \mathrm{ng} / \mathrm{mL}$ ) (56) often seen in human obesity across age, ethnicity and geographical locations (57).

\section{Vitamin D: skeletal function vs. extra-skeletal role in glucose and lipid metabolism}

The causal role of vitamin D deficiency in bone health is well established. Vitamin D sufficiency is pivotal for normal skeletal development from utero until childhood, and also for maintaining bone health in adults (58). This is due to the fact that sufficient of vitamin $D$ levels lead to adequate calcium-phosphorus concentrations resulting in an effective bone mineralization to prevent vitamin $D$ deficiency and related diseases like rickets (59). In adults, low $25(\mathrm{OH}) \mathrm{D}_{3}$ and high Parathyroid hormone (PTH) also lead to low serum calcium and phosphorus concentrations, resulting in osteomalacia, i.e., a defective mineralization of the collagen matrix causing a reduction of structural support and being associated with an increased risk of fracture (58).

During the last couple decades, studies suggest the link between vitamin $D$ and chronic metabolic diseases or conditions like obesity, insulin resistance and T2DM. Observational human studies have extensively documented an inverse relationship between vitamin D status and obesity-related insulin resistance (60). Vitamin D has been shown to stimulate the expression of insulin receptor substrate in muscle tissue of HFD mice, (61). Vitamin D directly activates peroxisome proliferator activator receptor-d (PPARd) (62), a transcription factor involved in the regulation of fatty acid metabolism in skeletal muscle and adipose tissue. Vitamin D may have an effect on insulin secretion by maintaining extracellular calcium, ensuring normal calcium influx through cell membranes and adequate calcium pool in the pancreatic beta cells (63). The role of of vitamin D in human lipid and glucose metabolism and its deficiency in obesity-associated insulin resistance has been reviewed more extensively in chapter $\mathbf{2}$ of this thesis.

\section{Vitamin D and adipose tissue metabolism}

As indicated above, the obese insulin resistant state is also often associated with low levels of serum vitamin D (Hypovitaminosis D) (64) both in children (65-67) and adult men and women $(60,68)$. Adipose tissue represents a major storage reservoir for 
vitamin $D$, which is not surprising giving its characteristics as a fat-soluble vitamin, although the underlying mechanisms for the circulating deficiency in human obesity is not clearly understood. The enlarged pool of visceral and subcutaneous AT in human obesity probably sequestrates vitamin $D$ and its metabolites, reducing their bioavailability (69). Beside vitamin $D$ uptake by adipose tissue, there also evidence of release both in mice as well as in human adipocytes (70). A recent ex vivo data by Di Nisio et al demonstrated that a blunted adrenaline-mediated lipolytic response, a characteristic of the obese insulin-resistant state, was accompanied by an increased accumulation of $25(\mathrm{OH}) \mathrm{D}_{3}$ in human SAT from obese donors, possibly indicating a blunted vitamin D release (71). However, in vivo data from human is rather limited, as more extensively discussed in chapter $\mathbf{2}$.

\section{Vitamin D-related genes, obesity, and insulin resistance}

Next to environmental (sun exposure, season) and behavioral (food intake) factors, genetic factors may play an important role in determining serum $25(\mathrm{OH}) \mathrm{D}_{3}$ concentrations (72). A study in twin male showed that genetic variation in vitamin D related metabolism genes may explain more than $50 \%$ of the variation in vitamin $D$ metabolite concentrations particularly during winter (73). However, genome-wide association studies have shown that genetic variants in vitamin D-related genes explain a modest $(\sim 10 \%)$ of variations in circulating vitamin D concentrations (74-77). Genetic variations of vitamin D receptor (VDR) is most often associated with vitamin D concentration and metabolic health outcomes (78).

\section{Vitamin D receptor genetic variants}

Human and animal data indicate that VDR is present at the RNA and protein level in adipose tissue (AT) (79) and other insulin sensitive tissues such as liver (80) and skeletal muscle (81), thereby contributing to vitamin D-mediated effects on glucose and lipid metabolism in these tissues. VDR is known as a member of the superfamily of the steroid hormone receptors and is also recognized as a nuclear transcription factor (82). The genomic responses to vitamin $\mathrm{D}$ result from the interactions between its active metabolite $\left[1,25(\mathrm{OH})_{2} D_{3}\right]$ and its intracellular VDR. Then, after the binding of vitamin $D$, VDR forms a heterodimer with the retinoid-X receptor (RXR) that binds to specific vitamin $D$ response elements (VDREs) on DNA sequences leading to expression or trans-repression of several VDR targets genes of which some are involved regulating lipid and glucose metabolism (e.g. PPAR-d, insulin receptor substrate-1) $(82,83)$.

The human VDR gene is located on chromosome 12q, which encodes the fulllength VDR protein. Fokl, Bsml, Apal and Taql (SNPs) have been identified in VDR. Ye et al. (84) found that the VDR Taql T allele was associated with obesity in French Caucasian individuals with early onset of type 2 diabetes. A study conducted in a Saudi Arabian cohort identified that the VDR Taql G allele polymorphisms were significantly more frequent in obese individuals (84). In a Central-European population, it has been suggested that genetic variability in the VDR region (including Fokl and Apal polymorphisms) may be an important factor influencing anthropometric characteristics associated with obesity including BMI, Fat Mass and body fat distribution (85). Furthermore, a study in Poland showed that the Bsml variant may be associated with BMI in men (86), but not in women (87). However, larger 
genome wide studies in UK (men and women) (88) and Chinese women (89) indicate that VDR genetic variants are unlikely a major determinant of obesity related phenotype such as BMI, waist circumference (WC), and waist-to-hip ratio (WHR). In addition, it has been suggested that Fokl variant is related with insulin sensitivity (86). However, is it unknown whether these VDR SNPs are associated with insulin sensitivity and to what extent these SNPs may affect intervention outcome (vitamin D supplementation), as was explored in chapter 2 of this thesis.

\section{Vitamin D supplementation and insulin sensitivity}

The link between obesity, insulin resistance and vitamin D deficiency may give a rational for vitamin D supplementation (90). Therefore, increasing circulating vitamin D levels through either vitamin D fortified foods or drinks (91-93) as well as oral supplementation (94) has been hypothesized to improve glucose metabolism and insulin sensitivity. Numerous randomized controlled trials (RCTs) have been conducted to investigate whether vitamin D supplementation has a causal effect on glucose homeostasis and insulin resistance. However, the results from these RCTs are still inconsistent and next to only fasting glucose measures, as well as indirect markers of insulin sensitivity are used. Some studies suggested a beneficial effect to improve insulin sensitivity (94-96), on the other hand, studies did not find any beneficial effects on glucose homeostasis and/or insulin sensitivity (97-99). Evidence of human interventional studies regarding the effect of vitamin D supplementation on glucose homeostasis and insulin sensitivity is described more detail in chapter $\mathbf{2}$ and chapter 6 of this thesis.

\section{Outline of thesis}

This thesis describes the role of vitamin $D$ in human overweight/obesity and whole body and tissue-specific insulin sensitivity. As described earlier in this thesis, the link between vitamin $D$ deficiency, obesity-related insulin resistance is reviewed in more detail in chapter 2. In addition, this chapter provides and an extensive overview on the etiology of vitamin $D$ deficiency in obesity-related insulin resistance, which covers vitamin D metabolism, the role of vitamin $D$ in (tissue-specific) insulin resistance and in increased adiposity (both human observational and intervention studies). Vitamin $D$ is known as a fat-soluble vitamin that may accumulate in adipose tissue.

In human with overweight/obesity, the expanded adipose tissue mass may take up and store vitamin D thereby representing as a reservoir (metabolic sink) for vitamin D, reducing its bioavailability. To investigate this, in chapter $\mathbf{3}$ we analyzed the uptake and release of vitamin $\mathrm{D}$ metabolites $\left[25(\mathrm{OH}) \mathrm{D}_{3}\right.$ and $\left.1,25(\mathrm{OH})_{2} \mathrm{D}_{3}\right]$ across abdominal subcutaneous adipose tissue in lean and obese men following an overnight fast and beta-adrenergic stimulation (to stimulate lipid hydrolysis) using state-of-the-art arterio-venous difference methodology. In Chapter 4 investigates whether the circulating vitamin $D$ metabolites $\left[25(\mathrm{OH}) \mathrm{D}_{3}\right.$ and $1,25(\mathrm{OH})_{2} \mathrm{D}_{3}$ ] are associated with adipose tissue, muscle and liver insulin sensitivity using the gold standard hyperinsulinemic euglycemic clamp in individuals with overweight/obesity. Furthermore, vitamin D receptor (VDR) and vitamin D-metabolizing enzymes [cytochrome 450 (CYP)] expression in adipose tissue (AT) was studied in relation to AT insulin sensitivity. 
Genetic variants in VDR have been suggested to link with obesity related insulin resistance. In Chapter $\mathbf{5}$ extends the outcome from previous chapter $\mathbf{4}$ and describes the association between genetic variations of VDR, adiposity and (tissue-specific) insulin resistance as well as weight loss and weight regain in human with overweight/obesity from DIOGENES cohort, a Pan-European, randomized, controlled dietary intervention study investigating the effects of dietary protein and glycemic index on weight loss and weight maintenance. Several meta-analyses on effect of vitamin $D$ supplementation only focus on markers related fasting insulin and glucose concentrations.

In chapter 2, we briefly resumed recent meta-analysis study the effect of vitamin D supplementation on glucose metabolism in humans. However, most meta-analyses have been executed with fasting measures of glucose and insulin metabolism. In chapter 6 we conducted a meta-analysis on the effect of vitamin $D$ supplementation on insulin sensitivity derived from Matsuda index, insulin sensitivity index, as well as hyperinsulinemic euglycemic clamp methodologies. Finally, in chapter $\mathbf{7}$ the results of the present thesis are discussed in broader perspective. 


\section{References}

1. World Health Organization. Key Facts Obesity and Overweight 2018 [Available from: https:// www.who.int/news-room/fact-sheets/detail/obesity-and-overweight.

2. Abarca-Gómez L, Abdeen ZA, Hamid ZA, Abu-Rmeileh NM, Acosta-Cazares B, Acuin C, Adams RJ, Aekplakorn W, Afsana K, Aguilar-Salinas CA. Worldwide trends in body-mass index, underweight, overweight, and obesity from 1975 to 2016: a pooled analysis of 2416 populationbased measurement studies in 128. 9 million children, adolescents, and adults. The Lancet. 2017;390(10113):2627-2642.

3. Okorodudu D, Jumean M, Montori VM, Romero-Corral A, Somers V, Erwin P, Lopez-Jimenez F. Diagnostic performance of body mass index to identify obesity as defined by body adiposity: a systematic review and meta-analysis. International journal of obesity. 2010;34(5):791.

4. Nuttall FQ. Body mass index: obesity, BMI, and health: a critical review. Nutrition Today. 2015;50(3):117.

5. The Organisation for Economic Co-operation and Development. OECD: Obesity Update 2017. 2017.

6. Blüher M. Obesity: global epidemiology and pathogenesis. Nature Reviews Endocrinology. 2019:1.

7. Chooi YC, Ding C, Magkos F. The epidemiology of obesity. Metabolism. 2018.

8. Reaven G, Abbasi F, McLaughlin T. Obesity, insulin resistance, and cardiovascular disease. Recent Progress in Hormone Research. 2004;59:207-224.

9. Hruby A, Hu FB. The epidemiology of obesity: a big picture. Pharmacoeconomics. 2015;33(7):673689.

10. Kjellberg J, Larsen AT, Ibsen R, Højgaard B. The socioeconomic burden of obesity. Obesity facts. 2017;10(5):493-502.

11. O'Rahilly S, Farooqi IS. Human obesity: a heritable neurobehavioral disorder that is highly sensitive to environmental conditions. Diabetes. 2008;57(11):2905-2910.

12. Meex RC, Blaak EE, van Loon LJ. Lipotoxicity plays a key role in the development of both insulin resistance and muscle atrophy in patients with type 2 diabetes. Obesity Reviews. 2019;20(9):12051217.

13. Trouwborst I, Bowser SM, Goossens GH, Blaak EE. Ectopic fat accumulation in distinct insulin resistant phenotypes; targets for personalized nutritional interventions. Frontiers in nutrition. 2018;5.

14. Coelho M, Oliveira T, Fernandes R. Biochemistry of adipose tissue: an endocrine organ. Archives of medical science: AMS. 2013;9(2):191.

15. Luo L, Liu M. Adipose tissue in control of metabolism. Journal of Endocrinology. 2016;231(3):R77-R99.

16. Goossens GH. The role of adipose tissue dysfunction in the pathogenesis of obesity-related insulin resistance. Physiol Behav. 2008;94(2):206-218.

17. Muir LA, Neeley CK, Meyer KA, Baker NA, Brosius AM, Washabaugh AR, Varban OA, Finks JF, Zamarron BF, Flesher CG. Adipose tissue fibrosis, hypertrophy, and hyperplasia: correlations with diabetes in human obesity. Obesity. 2016;24(3):597-605.

18. Choe SS, Huh JY, Hwang IJ, Kim JI, Kim JB. Adipose tissue remodeling: its role in energy metabolism and metabolic disorders. Frontiers in endocrinology. 2016;7:30.

19. Gustafson B, Hedjazifar S, Gogg S, Hammarstedt A, Smith U. Insulin resistance and impaired adipogenesis. Trends in Endocrinology \& Metabolism. 2015;26(4):193-200.

20. Hammarstedt A, Gogg S, Hedjazifar S, Nerstedt A, Smith U. Impaired adipogenesis and dysfunctional adipose tissue in human hypertrophic obesity. Physiological reviews. 2018;98(4):1911-1941.

21. Lempesis IG, van Meijel RL, Manolopoulos KN, Goossens GH. Oxygenation of adipose tissue: A human perspective. Acta Physiologica. 2019:e13298. 
22. Frayn K, Karpe F. Regulation of human subcutaneous adipose tissue blood flow. International journal of obesity. 2014;38(8):1019.

23. Goossens GH. The Metabolic Phenotype in Obesity: Fat Mass, Body Fat Distribution, and Adipose Tissue Function. Obesity Facts. 2017;10(3):207-215.

24. Mraz M, Haluzik M. The role of adipose tissue immune cells in obesity and low-grade inflammation. Journal of Endocrinology. 2014;222(3):R113-R127.

25. Frayn KN. Adipose tissue as a buffer for daily lipid flux. Diabetologia. 2002;45(9):1201-1210.

26. Stinkens R, Goossens GH, Jocken JW, Blaak EE. Targeting fatty acid metabolism to improve glucose metabolism. Obesity Reviews. 2015;16(9):715-757.

27. Greenberg AS, Obin MS. Obesity and the role of adipose tissue in inflammation and metabolism. Am J Clin Nutr. 2006;83(suppl):461S-465S.

28. Donnelly KL, Smith Cl, Schwarzenberg SJ, Jessurun J, Boldt MD, Parks EJ. Sources of fatty acids stored in liver and secreted via lipoproteins in patients with nonalcoholic fatty liver disease. The Journal of clinical investigation. 2005;115(5):1343-1351.

29. Item F, Konrad D. Visceral fat and metabolic inflammation: the portal theory revisited. Obesity Reviews. 2012;13:30-39.

30. Perry RJ, Samuel VT, Petersen KF, Shulman GI. The role of hepatic lipids in hepatic insulin resistance and type 2 diabetes. Nature. 2014;510(7503):84-91.

31. Samuel VT, Shulman GI. The pathogenesis of insulin resistance: integrating signaling pathways and substrate flux. The Journal of clinical investigation. 2016;126(1):12-22.

32. Corpeleijn E, Saris WH, Blaak EE. Metabolic flexibility in the development of insulin resistance and type 2 diabetes: effects of lifestyle. obesity reviews. 2009;10(2):178-193.

33. Corcoran MP, Lamon-Fava S, Fielding RA. Skeletal muscle lipid deposition and insulin resistance: effect of dietary fatty acids and exercise. The American journal of clinical nutrition. 2007;85(3):662677.

34. Karlsson HK, Zierath JR, Kane S, Krook A, Lienhard GE, Wallberg-Henriksson H. Insulin-stimulated phosphorylation of the Akt substrate AS160 is impaired in skeletal muscle of type 2 diabetic subjects. Diabetes. 2005;54(6):1692-1697.

35. Samuel VT, Petersen KF, Shulman GI. Lipid-induced insulin resistance: unravelling the mechanism. The Lancet. 2010;375(9733):2267-2277.

36. Emanuel AL, Meijer RI, Muskiet MH, Van Raalte DH, Eringa EC, Serné EH. Role of insulin-stimulated adipose tissue perfusion in the development of whole-body insulin resistance. Arteriosclerosis, thrombosis, and vascular biology. 2017;37(3):411-418.

37. Lupi R, Dotta F, Marselli L, Del Guerra S, Masini M, Santangelo C, Patané G, Boggi U, Piro S, Anello $M$. Prolonged exposure to free fatty acids has cytostatic and pro-apoptotic effects on human pancreatic islets: evidence that $\beta$-cell death is caspase mediated, partially dependent on ceramide pathway, and Bcl-2 regulated. Diabetes. 2002;51(5):1437-1442.

38. van der Zijl NJ, Goossens GH, Moors CC, van Raalte DH, Muskiet MH, Pouwels PJ, Blaak EE, Diamant $\mathrm{M}$. Ectopic fat storage in the pancreas, liver, and abdominal fat depots: impact on $\beta$-cell function in individuals with impaired glucose metabolism. The Journal of Clinical Endocrinology \& Metabolism. 2011;96(2):459-467.

39. Tushuizen ME, Bunck MC, Pouwels PJ, Bontemps S, Van Waesberghe JHT, Schindhelm RK, Mari A, Heine RJ, Diamant M. Pancreatic fat content and $\beta$-cell function in men with and without type 2 diabetes. Diabetes care. 2007;30(11):2916-2921.

40. Shulman GI. Ectopic fat in insulin resistance, dyslipidemia, and cardiometabolic disease. New England Journal of Medicine. 2014;371(12):1131-1141.

41. Nathan DM, Davidson MB, DeFronzo RA, Heine RJ, Henry RR, Pratley R, Zinman B. Impaired fasting glucose and impaired glucose tolerance: implications for care. Diabetes care. 2007;30(3):753-759.

42. Tabák AG, Herder C, Rathmann W, Brunner EJ, Kivimäki M. Prediabetes: a high-risk state for diabetes development. The Lancet. 2012;379(9833):2279-2290. 
43. DeFronzo RA, Abdul-Ghani M. Assessment and treatment of cardiovascular risk in prediabetes: impaired glucose tolerance and impaired fasting glucose. The American journal of cardiology. 2011;108(3):3B-24B.

44. Monzillo LU, Hamdy O. Evaluation of insulin sensitivity in clinical practice and in research settings. Nutrition reviews. 2003;61(12):397-412.

45. Singh B, Saxena A. Surrogate markers of insulin resistance: A review. World journal of diabetes. 2010;1(2):36.

46. Matsuda M, DeFronzo RA. Insulin sensitivity indices obtained from oral glucose tolerance testing: comparison with the euglycemic insulin clamp. Diabetes care. 1999;22(9):1462-1470.

47. Abdul-Ghani MA, Matsuda M, Balas B, DeFronzo RA. Muscle and liver insulin resistance indexes derived from the oral glucose tolerance test. Diabetes Care. 2007;30(1):89-94.

48. Hulzebos CV, Renfurm L, Bandsma RH, Verkade HJ, Boer T, Boverhof R, Tanaka H, Mierau I, Sauer PJ, Kuipers F. Measurement of parameters of cholic acid kinetics in plasma using a microscale stable isotope dilution technique: application to rodents and humans. Journal of lipid research. 2001;42(11):1923-1929.

49. DeFronzo RA, Tobin JD, Andres R. Glucose clamp technique: a method for quantifying insulin secretion and resistance. The American journal of physiology. 1979;237(3):E214-223.

50. Schmid A, Walther B. Natural vitamin D content in animal products. Advances in nutrition. 2013;4(4):453-462.

51. Cardwell G, Bornman JF, James AP, Black LJ. A review of mushrooms as a potential source of dietary vitamin D. Nutrients. 2018;10(10):1498.

52. Spiro A, Buttriss J. Vitamin D: An overview of vitamin D status and intake in E urope. Nutrition bulletin. 2014;39(4):322-350.

53. Christakos S, Dhawan P, Verstuyf A, Verlinden L, Carmeliet G. Vitamin D: metabolism, molecular mechanism of action, and pleiotropic effects. Physiological reviews. 2015;96(1):365-408.

54. Carrelli A, Bucovsky M, Horst R, Cremers S, Zhang C, Bessler M, Schrope B, Evanko J, Blanco J, Silverberg SJ, Stein EM. Vitamin D Storage in Adipose Tissue of Obese and Normal Weight Women. JBMR Plus. 2017;32(2):237-242.

55. Bonnet L, Margier M, Svilar L, Couturier C, Reboul E, Martin JC, Landrier JF, Defoort C. Simple Fast Quantification of Cholecalciferol, 25-Hydroxyvitamin D and 1,25-Dihydroxyvitamin D in Adipose Tissue Using LC-HRMS/MS. Nutrients. 2019;11(9).

56. Lips P, Cashman KD, Lamberg-Allardt C, Bischoff-Ferrari HA, Obermayer-Pietsch BR, Bianchi M, Stepan J, Fuleihan GE-H, Bouillon R. Management of Endocrine Disease: Current vitamin D status in European and Middle East countries and strategies to prevent vitamin D deficiency; a position statement of the European Calcified Tissue Society. European journal of endocrinology. 2019;1(aop).

57. Walsh JS, Bowles S, Evans AL. Vitamin D in obesity. Current opinion in endocrinology, diabetes, and obesity. 2017;24(6):389-394.

58. Bouillon R, Marcocci C, Carmeliet G, Bikle D, White JH, Dawson-Hughes B, Lips P, Munns CF, Lazaretti-Castro M, Giustina A. Skeletal and extra-skeletal actions of vitamin D: current evidence and outstanding questions. Endocrine reviews. 2018.

59. Holick MF. Resurrection of vitamin D deficiency and rickets. The Journal of clinical investigation. 2006;116(8):2062-2072.

60. Wimalawansa SJ. Associations of vitamin D with insulin resistance, obesity, type 2 diabetes, and metabolic syndrome. The Journal of Steroid Biochemistry and Molecular Biology. 2018;175:177189.

61. Alkharfy KM, Al-Daghri NM, Yakout SM, Hussain T, Mohammed AK, Krishnaswamy S. Influence of vitamin D treatment on transcriptional regulation of insulin-sensitive genes. Metabolic syndrome and related disorders. 2013;11(4):283-288.

62. Dunlop TW, Väisänen S, Frank C, Molnar F, Sinkkonen L, Carlberg C. The human peroxisome 
proliferator-activated receptor $\delta$ gene is a primary target of $1 \alpha, 25$-dihydroxyvitamin D3 and its nuclear receptor. Journal of molecular biology. 2005;349(2):248-260.

63. Pittas AG, Lau J, Hu FB, Dawson-Hughes B. The role of vitamin D and calcium in type 2 diabetes. A systematic review and meta-analysis. The Journal of Clinical Endocrinology \& Metabolism. 2007;92(6):2017-2029.

64. Kabadi S, Lee B, Liu L. Joint effects of obesity and vitamin D insufficiency on insulin resistance and type 2 diabetes: results from the NHANES 2001-2006. Diabetes Care 2012;35(10):2048-2054.

65. Zakharova I, Klimov L, Kuryaninova V, Nikitina I, Malyavskaya S, Dolbnya S, Kasyanova A, Atanesyan R, Stoyan M, Todieva A. Vitamin D Insufficiency in Overweight and Obese Children and Adolescents. Frontiers in Endocrinology. 2019;10.

66. Nunlee-Bland G, Gambhir K, Abrams C, Abdul M, Vahedi M, Odonkor W. Vitamin D deficiency and insulin resistance in obese African-American adolescents. Journal of Pediatric Endocrinology and Metabolism. 2011;24(1-2):29-33.

67. Peterson CA, Belenchia AM. Vitamin D deficiency \& childhood obesity: a tale of two epidemics. Missouri medicine. 2014;111(1):49.

68. Saneei P, Salehi-Abargouei A, Esmaillzadeh A. Serum 25-hydroxy vitamin D levels in relation to body mass index: a systematic review and meta-analysis. Obesity Reviews. 2013;14(5):393-404.

69. Gangloff A, Bergeron J, Pelletier-Beaumont E, Nazare J-A, Smith J, Borel A-L, Lemieux I, Tremblay A, Poirier P, Alméras N, Després J-P. Effect of adipose tissue volume loss on circulating 25-hydroxyvitamin $D$ levels: results from a 1-year lifestyle intervention in viscerally obese men. Int J Obes. 2015;39(11):1638-1643.

70. Bonnet L, Karkeni E, Couturier C, Astier J, Dalifard J, Defoort C, Svilar L, Martin JC, Tourniaire F, Landrier JF. Gene Expression Pattern in Response to Cholecalciferol Supplementation Highlights Cubilin as a Major Protein of 25(OH)D Uptake in Adipocytes and Male Mice White Adipose Tissue. Endocrinology. 2018;159(2):957-966.

71. Di Nisio A, De Toni L, Sabovic I, Rocca MS, Filippis VD, Opocher G, Azzena B, Vettor R, Plebani M, Foresta $C$. Impaired release of vitamin $D$ in dysfunctional adipose tissue: new cues on vitamin $D$ supplementation in obesity. J Clin Endocrinol Metab. 2017.

72. Jolliffe DA, Walton RT, Griffiths CJ, Martineau AR. Single nucleotide polymorphisms in the vitamin $D$ pathway associating with circulating concentrations of vitamin $D$ metabolites and non-skeletal health outcomes: review of genetic association studies. The Journal of steroid biochemistry and molecular biology. 2016;164:18-29.

73. Karohl C, Su S, Kumari M, Tangpricha V, Veledar E, Vaccarino V, Raggi P. Heritability and seasonal variability of vitamin $D$ concentrations in male twins. The American journal of clinical nutrition. 2010;92(6):1393-1398.

74. Sapkota BR, Hopkins R, Bjonnes A, Ralhan S, Wander GS, Mehra NK, Singh JR, Blackett PR, Saxena $R$, Sanghera DK. Genome-wide association study of $25(\mathrm{OH})$ vitamin D concentrations in Punjabi Sikhs: results of the Asian Indian diabetic heart study. The Journal of steroid biochemistry and molecular biology. 2016;158:149-156.

75. Zhu H, Wang X, Shi H, Su S, Harshfield GA, Gutin B, Snieder H, Dong Y. A genome-wide methylation study of severe vitamin $D$ deficiency in African American adolescents. The Journal of pediatrics. 2013;162(5):1004-1009. e1001.

76. Ahn J, Yu K, Stolzenberg-Solomon R, Simon KC, McCullough ML, Gallicchio L, Jacobs EJ, Ascherio A, Helzlsouer K, Jacobs KB. Genome-wide association study of circulating vitamin D levels. Human molecular genetics. 2010;19(13):2739-2745.

77. Jiang X, O'Reilly PF, Aschard H, Hsu Y-H, Richards JB, Dupuis J, Ingelsson E, Karasik D, Pilz S, Berry D. Genome-wide association study in 79,366 European-ancestry individuals informs the genetic architecture of 25-hydroxyvitamin D levels. Nature communications. 2018;9(1):260.

78. Ruiz-Ojeda FJ, Anguita-Ruiz A, Leis R, Aguilera CM. Genetic factors and molecular mechanisms of vitamin D and obesity relationship. Annals of Nutrition and Metabolism. 2018;73:89-99. 
79. Mutt SJ, Hypponen E, Saarnio J, Jarvelin MR, Herzig KH. Vitamin D and adipose tissue-more than storage. Front Physiol. 2014;5(228):1-9.

80. Barchetta I, Carotti S, Labbadia G, Gentilucci UV, Muda AO, Angelico F, Silecchia G, Leonetti F, Fraioli A, Picardi A, Morini S, Cavallo MG. Liver vitamin D receptor, CYP2R1, and CYP27A1 expression: relationship with liver histology and vitamin D3 levels in patients with nonalcoholic steatohepatitis or hepatitis C virus. Hepatology. 2012;56(6):2180-2187.

81. Girgis CM, Mokbel N, Cha KM, Houweling PJ, Abboud M, Fraser DR, Mason RS, Clifton-Bligh RJ, Gunton JE. The vitamin D receptor (VDR) is expressed in skeletal muscle of male mice and modulates 25-hydroxyvitamin D (25OHD) uptake in myofibers. Endocrinology. 2014;155(9):32273237.

82. Haussler MR, Jurutka PW, Mizwicki M, Norman AW. Vitamin D receptor (VDR)-mediated actions of $1 \alpha, 25(\mathrm{OH}) 2$ vitamin D3: genomic and non-genomic mechanisms. Best Pract Res Clin Endocrinol Metab. 2011;25(4):543-559.

83. Deeb KK, Trump DL, Johnson CS. Vitamin D signalling pathways in cancer: potential for anticancer therapeutics. Nat Rev Cancer. 2007;7(9):684-700.

84. Al-Daghri NM, Guerini FR, Al-Attas OS, Alokail MS, Alkharfy KM, Draz HM, Agliardi C, Costa AS, Saulle I, Mohammed AK. Vitamin D receptor gene polymorphisms are associated with obesity and inflammosome activity. PloS one. 2014;9(7):e102141.

85. Bienertova-Vasku J, Zlamal F, Pohorala A, Mikes O, Goldbergova-Pavkova M, Novak J, Splichal Z, Pikhart $\mathrm{H}$. Allelic variants in vitamin $\mathrm{D}$ receptor gene are associated with adiposity measures in the central-European population. BMC Med Genet. 2017;18(1):90.

86. Filus A, Trzmiel A, Kuliczkowska-Plaksej J, Tworowska U, Jedrzejuk D, Milewicz A, Medras M. Relationship between vitamin D receptor Bsml and Fokl polymorphisms and anthropometric and biochemical parameters describing metabolic syndrome. The aging male : the official journal of the International Society for the Study of the Aging Male. 2008;11(3):134-139.

87. Tworowska-Bardzinska U, Lwow F, Kubicka E, Laczmanski L, Jedzrzejuk D, Dunajska K, Milewicz A. The vitamin $D$ receptor gene Bsml polymorphism is not associated with anthropometric and biochemical parameters describing metabolic syndrome in postmenopausal women. Gynecological endocrinology : the official journal of the International Society of Gynecological Endocrinology. 2008;24(9):514-518.

88. Vimaleswaran KS, Cavadino A, Berry DJ, Genetic Investigation of Anthropometric Traits C, Whittaker JC, Power C, Järvelin MR, Hyppönen E. Genetic association analysis of vitamin D pathway with obesity traits. International journal of obesity (2005). 2013;37(10):1399-1406.

89. Dorjgochoo T, Shi J, Gao YT, Long J, Delahanty R, Xiang YB, Cai Q, Shu XO. Genetic variants in vitamin $D$ metabolism-related genes and body mass index: analysis of genome-wide scan data of approximately 7000 Chinese women. Int J Obes (Lond). 2012;36(9):1252-1255.

90. Holick MF, Binkley NC, Bischoff-Ferrari HA, Gordon CM, Hanley DA, Heaney RP, Murad MH, Weaver CM. Evaluation, treatment, and prevention of vitamin D deficiency: an Endocrine Society clinical practice guideline. J Clin Endocrinol Metab. 2011;96(7):1911-1930.

91. Shab-Bidar S, Neyestani TR, Djazayery A, Eshraghian M-R, Houshiarrad A, Gharavi Aa, Kalayi A, Shariatzadeh N, Zahedirad M, Khalaji N, Haidari H. Regular consumption of vitamin D-fortified yogurt drink (Doogh) improved endothelial biomarkers in subjects with type 2 diabetes: a randomized double-blind clinical trial. BMC Med. 2011;9(1):125.

92. Nikooyeh B, Neyestani TR, Farvid M, Alavi-Majd H, Houshiarrad A, Kalayi A, Shariatzadeh N, Gharavi Aa, Heravifard S, Tayebinejad N, Salekzamani S, Zahedirad M. Daily consumption of vitamin D-or vitamin D+ calcium-fortified yogurt drink improved glycemic control in patients with type 2 diabetes: a randomized clinical trial. Am J Clin Nutr. 2011;93(4):764-771.

93. Jafari T, Faghihimani E, Feizi A, Iraj B, Javanmard S, Esmaillzadeh A, Fallah A, Askari G. Effects of vitamin D-fortified low fat yogurt on glycemic status, anthropometric indexes, inflammation, and bone turnover in diabetic postmenopausal women: A randomised controlled clinical trial. Clin 
Nutr. 2016;35(1):67-76.

94. Nazarian S, St Peter JV, Boston RC, Jones SA, Mariash CN. Vitamin D3 supplementation improves insulin sensitivity in subjects with impaired fasting glucose. Transl Res. 2011;158(5):276-281.

95. Lemieux P, Weisnagel JS, Caron AZ, Julien AS, Morisset AS, Carreau AM, Poirier J, Tchernof A, Robitaille J, Bergeron J, Marette A, Vohl MC, Gagnon C. Effects of 6-month vitamin D supplementation on insulin sensitivity and secretion: a randomized, placebo-controlled trial. Eur J Endocrinol. 2019.

96. Mitri J, Dawson-Hughes B, Hu FB, Pittas AG. Effects of vitamin D and calcium supplementation on pancreatic $\beta$ cell function, insulin sensitivity, and glycemia in adults at high risk of diabetes: the Calcium and Vitamin D for Diabetes Mellitus (CaDDM) randomized controlled trial. Am J Clin Nutr. 2011;94(2):486-494.

97. Mousa A, Naderpoor N, de Courten MP, Teede H, Kellow N, Walker K, Scragg R, de Courten B. Vitamin D supplementation has no effect on insulin sensitivity or secretion in vitamin Ddeficient, overweight or obese adults: a randomized placebo-controlled trial. Am J Clin Nutr. 2017;105(6):1372-1381.

98. Harris SS, Pittas AG, Palermo NJ. A randomized, placebo-controlled trial of vitamin D supplementation to improve glycaemia in overweight and obese African Americans. Diabetes Obes Metab. 2012;14(9):789-794.

99. Jorde R, Sollid ST, Svartberg J, Schirmer H, Joakimsen RM, Njolstad I, Fuskevag OM, Figenschau Y, Hutchinson MYS. Vitamin D 20,000 IU per Week for Five Years Does Not Prevent Progression From Prediabetes to Diabetes. J Clin Endocrinol Metab. 2016;101(4):1647-1655. 


\section{CHAPTER 2}

Vitamin D deficiency in the aetiology of obesity-related insulin resistance

Adriyan Pramono, Johan W. E. Jocken, and Ellen E. Blaak

Published in:

Diabetes/Metabolism Research and Reviews (2019)35(5):

e3146

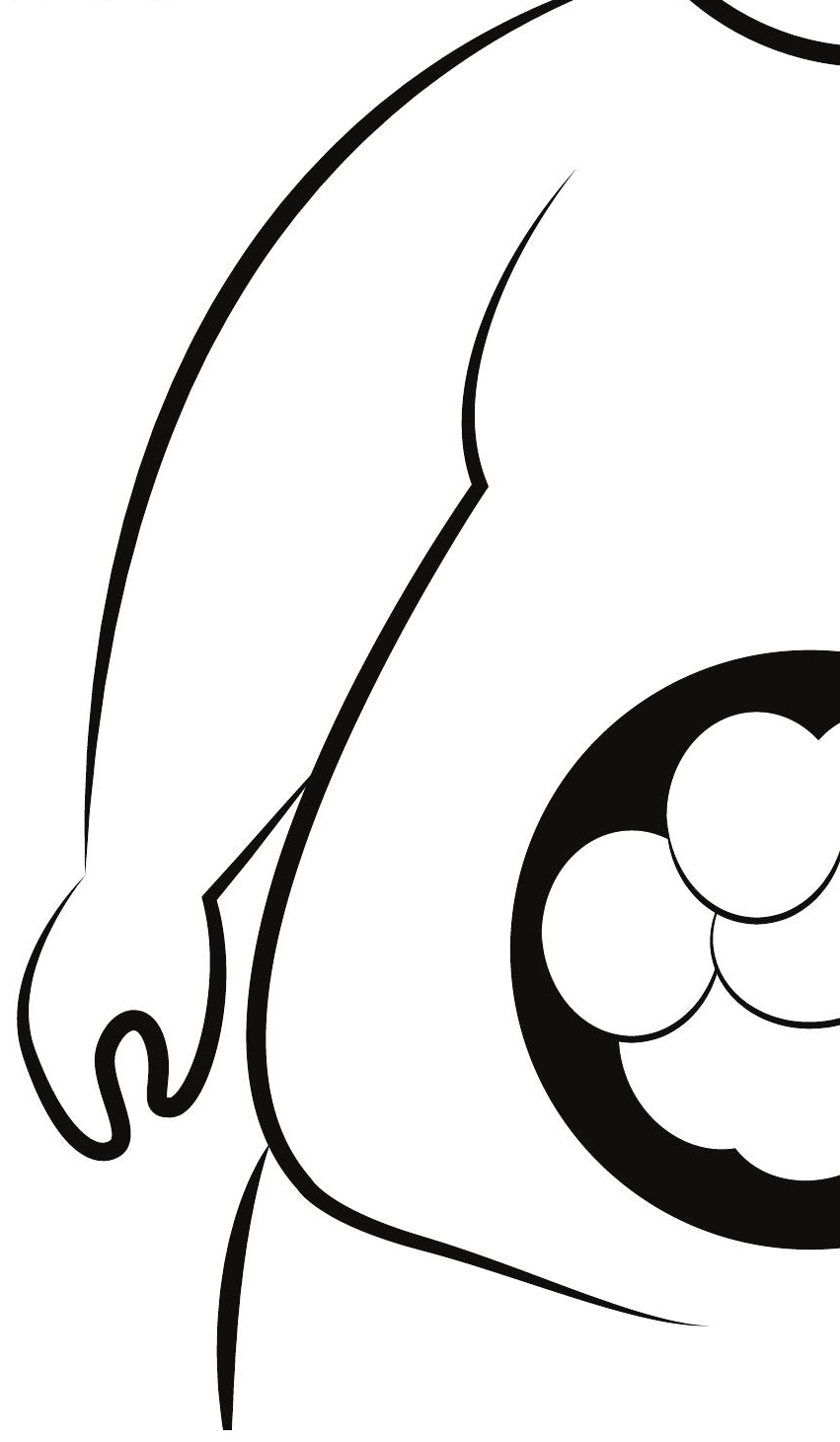




\section{Summary}

The obese insulin resistant state is often associated with low circulating concentration of vitamin $D 25$-hydroxyvitamin $D_{3}\left[25(\mathrm{OH}) \mathrm{D}_{3}\right]$. Fat sequestration of vitamin $D$ in the expanded obese adipose tissue mass has been pointed out as a plausible explanation for this circulating vitamin D deficiency. However, the putative mechanisms behind this hypovitaminosis D remain to be elucidated.

The presence of vitamin $D$ receptor and vitamin D metabolizing enzymes in insulinsensitive organs suggests that vitamin D may be involved in glucose and lipid metabolism and may be related to insulin sensitivity. Indeed, mainly in vitro studies support a role of vitamin $D$ in regulating glucose and lipid metabolism in several insulin sensitive tissues including adipose tissue, skeletal muscle, liver, as well as pancreatic insulin secretion. A potential role of vitamin $D$ in gut barrier function and metabolism has also been suggested. This review summarizes recent knowledge on vitamin D deficiency in the etiology of obesity related insulin resistance, and discusses potential underlying mechanisms. Finally, the role of vitamin D supplementation on insulin sensitivity and glycemic control will be discussed 


\section{Introduction}

Obesity is a main contributor to the development of type 2 diabetes mellitus (T2D) and cardiovascular diseases (CVD) and has become a major public health problem worldwide $(1,2)$. The World Health Organization (WHO) has reported that more than 422 million people suffer from T2D worldwide.(3) In addition, the prevalence of prediabetes, an intermediate condition of fasting and/or postprandial hyperglycemia, has also been indicated to sharply increase in several countries (4-6). Much attention has been given to the prevention of T2D, with emphasis on the prediabetic state. Compared to normal glucose tolerant (NGT) people, $37 \%$ of the pre-diabetic individuals develop T2D within 4 years (7), so maintaining their blood glucose levels in the normal range may reduce the incidence of T2D $(8,9)$.

Obesity is generally described as a condition of excessive fat accumulation, with abdominal obesity being the leading risk factor for insulin resistance and T2D (10). Obesityassociated health complications are often accompanied by dysfunctional adipose tissue (AT) rather than an increased fat mass per se, which is characterized by impairments in lipid storage capacity, particularly in the postprandial state. Hence the surplus energy as triglyceride will flow over into the circulation and result in an increased lipid supply towards non-adipose tissue organs like the liver and the skeletal muscle $(11,12)$. Fat deposition in these non-adipose tissues may result in functional impairments that contribute to the development of whole-body insulin resistance leading to T2D (13).

Originally, the fat-soluble vitamin $\mathrm{D}$ has been well known as major regulator of calcium and phosphate homeostasis related to bone metabolism. There is considerable evidence that vitamin $\mathrm{D} 25$-hydroxyvitamin $\mathrm{D}_{3}(25 \mathrm{OH}) \mathrm{D}_{3}$ ) deficiency (concentration <50 $\mathrm{nmol} / \mathrm{L})$ is associated with osteoporosis and reduced bone health $(14,15)$ On the other hand, evidence is accumulating that vitamin $D$ has much broader non-skeletal roles in the human body than previously thought. In line, vitamin D metabolizing enzymes and vitamin $D$ receptors (VDR) are expressed in several insulin-sensitive tissues, suggesting extrarenal metabolism and activity of vitamin $D(16,17)$. Obesity, insulin resistance and T2D are often characterized by a relative circulating vitamin D deficiency (hypovitaminosis D), suggesting a role for vitamin $D$ in the pathophysiology of obesity-related metabolic disorders (18-20). There is accumulating mechanistic evidence for a role of vitamin D in glucose and lipid metabolism in insulin sensitive tissues like the adipose tissue, skeletal muscle and liver (2123). In this review, we discuss the latest knowledge on vitamin D metabolism as well as its role in glycemic control and lipid metabolism. Firstly, vitamin D metabolism, receptor expression and intracellular signaling will be discussed. Additionally, the role of the active vitamin D metabolite 1,25-dihydroxyvitamin $\mathrm{D}_{3}\left(1,25(\mathrm{OH})_{2} \mathrm{D}_{3}\right)$ and VDR in controlling tissue substrate metabolism and insulin sensitivity will be addressed. Subsequently, data on vitamin D status in the obesity-related insulin resistant will be reviewed. Finally, an overview will be given from recently published meta-analyses on the effect of vitamin D supplementation to improve insulin sensitivity and blood glucose control.

\section{Vitamin D metabolism}

In human, vitamin $D_{3}$ can be synthesized from the skin following ultraviolet $B$ (UVB) 
light exposure (15). Vitamin $D_{2}$ and $D_{3}$ from diet also contribute to circulating levels of vitamin $D(24)$, although their relative contribution to circulating vitamin D levels is still unknown. Vitamin $\mathrm{D}_{3}$ has a higher affinity to bind to vitamin $\mathrm{D}$ binding protein (VDBP) and is therefore more likely to be hydroxylated in the liver (24). In the liver, the hydroxylase enzyme converts vitamin $\mathrm{D}_{3}$ into 25 -hydroxyvitamin $\mathrm{D}_{3}\left(25(\mathrm{OH}) \mathrm{D}_{3}\right)$ at the endoplasmic reticulum (25). The mechanism by which $25(\mathrm{OH}) \mathrm{D}_{3}$ is released from the liver and subsequently bound to VDBP to be transported to the kidneys or extrarenal tissues is not well understood (25).

25-hydroxyvitamin $\mathrm{D}_{3}$ in complex with its plasma carrier, VDBP, is filtered through the glomerulus and reabsorbed in the proximal tubules by the endocytic receptor megalin (26). Subsequently, $25(\mathrm{OH}) \mathrm{D}_{3}$ is converted by the 1 - $\alpha$-hydroxylase enzyme to biologically active $1,25(\mathrm{OH})_{2} \mathrm{D}_{3}$ intracellularly. $(26,27)$ Dysfunction of these receptors, which is commonly found in patients with diabetic nephropathy, even at early stages, may explain why vitamin $D$ deficiency is often observed in these patients (27).

Interestingly, recent in vitro studies have shown that megalin is involved in the uptake and release of vitamin $\mathrm{D} 25(\mathrm{OH}) \mathrm{D}_{3}$ in murine muscle cells (28), whereas cubilin is involved in uptake and release of vitamin $\mathrm{D} 25(\mathrm{OH}) \mathrm{D}_{3}$ in mice white adipocytes (29). The presence of functional VDR and vitamin D metabolizing enzymes was identified at the transcriptional and protein level in murine muscle (30) and adipose tissue (31) indicating extrarenal vitamin D metabolism. Uptake and release of $25(\mathrm{OH}) \mathrm{D}_{3}$, in mice adipose and muscle cells has been investigated $(29,32)$, which was regulated by VDR and its ligand $\left(1,25(\mathrm{OH})_{2} \mathrm{D}_{3}\right)$ in a time dependent-manner (33). Thus, vitamin $\mathrm{D}$ uptake and release in tissues like muscle and adipose tissue might be tightly regulated $(29,34)$.

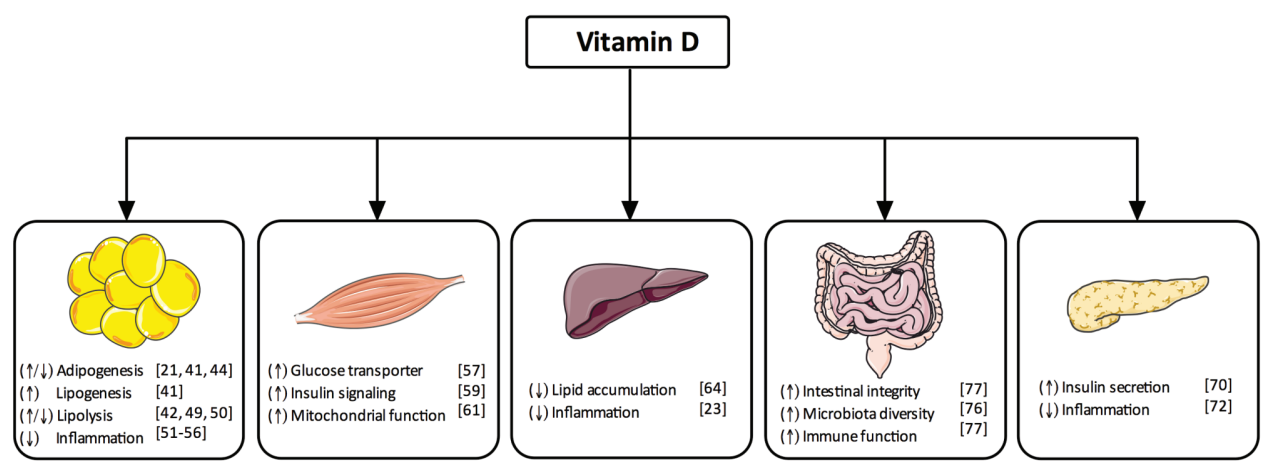

Figure 1. Metabolic effects of Vitamin D on insulin sensitive tissues including adipose tissue metabolism, muscle glucose/lipid metabolism, liver metabolism, pancreatic insulin secretion, and gut-intestinal function. Of note, majority of evidence for these functional effects are derived from in vitro and animal models which warrant further investigations in human. $(\uparrow)$ increase; $(\downarrow)$ decrease; references between brackets [].

The vitamin $D$ receptor belongs to the nuclear receptor family, thereby controlling DNA transcription.(35) Briefly, the cytosolic VDR-1,25(OH) $\mathrm{D}_{3}$ complex translocates to the nucleus where it subsequently interacts with retinoic acid $X$ receptor (RXR) to form RXRVDR complexes that bind to specific DNA regions called vitamin $D$ response element (VDRE) regions, hence regulating VDR-targeted gene expression (36). Although the VDR primarily acts as nuclear transcription factor, it is postulated that non-genomic actions of vitamin $D$ involve rapid binding of $1,25(\mathrm{OH})_{2} \mathrm{D}_{3}$ to both cytosolic and membrane VDR which activates 
several second messenger systems $(37,38)$. Interestingly, a VDRE was identified in the promoter of the human insulin receptor gene, indicating vitamin D might be involved in the transcriptional control of insulin signaling (39).

\section{Role of vitamin D in adipose tissue lipid metabolism}

VDR mRNA expression was identified in visceral adipose tissue (VAT) and subcutaneous adipose tissue (SAT) of lean and obese. In VAT, expression of VDR was higher in obese than in lean, where as no difference of VDR expression in SAT was observed (40). In addition, VDR protein expression has recently been demonstrated in primary adipocytes derived from obese donors (21), indicating the possible involvement of vitamin D in AT development and metabolism. Indeed, recent studies suggest a role of vitamin D in AT adipogenesis, lipogenesis, lipolysis, and inflammation (21, 41-43).

\section{Adipogenesis}

An in vitro study using 3T3-L1 preadipocytes has shown that treatment with $1,25(\mathrm{OH})_{2} \mathrm{D}_{3}(10 \mathrm{nM})$ suppresses the major adipogenic transcription CCAAT enhancer binding protein alpha/beta (CEBP $\alpha / \beta)$ and peroxisome proliferator activated receptor- $\gamma$ (PPAR- $\gamma$ ) in a VDR dependent manner, resulting in inhibition of adipogenic differentiation (44). Of interest $1,25(\mathrm{OH})_{2} \mathrm{D}_{3}$ was added to the medium in the early phase of differentiation. In contrast when $10 \mathrm{nM} 1,25(\mathrm{OH})_{2} \mathrm{D}_{3}$ was added in the late phase of differentiation, there was an increased mRNA expression of adipogenic markers like PPAR- $\gamma, \operatorname{CEBP} \alpha / \beta$, Fatty Acid Binding Protein 4 (FABP4), and Fatty Acid Synthase (FASN) in AT from human multipotent adipose-derived stem cells (hMADS) and subcutaneous pre-adipocytes $(21,41)$. A recent study has suggested $1,25(\mathrm{OH})_{2} \mathrm{D}_{3}(10 \mathrm{nM})$ upregulated CEBP expression after $24 \mathrm{~h}$ of induction of differentiation in human SGBS cells (45). It is likely that treating cell with vitamin $D$ at different stages of differentiation could partly explain these opposite findings in human primary adipocytes $(21,41)$ as compared to murine cell model $(44)$. Nevertheless, taken together, these data suggested that vitamin D might affect adipogenesis (Figure 1) at the transcriptional level, at least in a species specific manner.

\section{Lipogenesis}

Incubation of differentiated subcutaneous human adipocytes derived from male

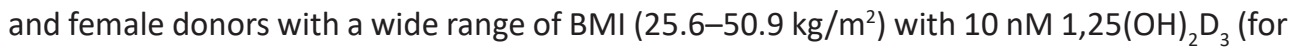
24 hours) increased the protein expression of the lipogenic enzyme fatty acid binding protein 4 (FABP4), the mRNA expression of lipoprotein lipase (LPL), and increased triacylglycerol (TAG) accumulation as compared to control adipocytes (41). Furthermore, incubating

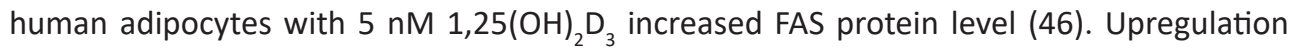
of FAS by $1,25(\mathrm{OH})_{2} \mathrm{D}_{3}$ is likely mediated by the VDR(21) and VDR activity may be necessary for lipid accumulation in the late phase of adipogenesis (47). However, in vivo injection of $1,25(\mathrm{OH})_{2} \mathrm{D}_{3}(1 \mathrm{~g} / \mathrm{kg} /$ day) in Sprague-Dawley rats (16 days) did not increase mRNA expression 
of FAS in AT (48). These findings indicate that vitamin D may modulate lipogenic enzymes expression at least in vitro (Figure 1), therefore human in vivo studies are required to clarify these findings in vitro.

\section{Lipolysis}

A study by Xue et al. showed that $1,25(\mathrm{OH})_{2} \mathrm{D}_{3}(5 \mathrm{nM})$ inhibits basal and betaadrenergically mediated lipolysis in human adipocytes, possibly via increased intracellular calcium levels resulting in decreased cAMP levels and a reduced hormone-sensitive lipase (HSL) phosphorylation $(46,49)$. In contrast, recent data by Chang et al. $(42)$ and Larrick et al(50) showed that $1,25(\mathrm{OH})_{2} \mathrm{D}_{3}$ increased glycerol release both under basal and betaadrenergically stimulated conditions in murine 3T3-L1 adipocytes (42). This increased lipolysis was accompanied by increased mRNA expression of the lipase HSL, and markers of fat oxidation, and mitochondrial biogenesis/function like carnitine palmitoyltransferase 1 (CPT1 $\alpha$ ), PPAR $\alpha$, co-activator proliferator-activated receptor gamma coactivator 1 -alpha (PGC1 $\alpha$ ) and sirtuin 1 (SIRT1) (42). Thus, data on the effect of vitamin D and lipolysis in human primary and murine adipocytes are still inconsistent (Figure 1).

\section{Inflammation: cytokine-adipokine production}

Low-grade circulating inflammation and increased AT infiltration of immune cells are strongly associated with local adipose tissue and whole-body insulin resistance. In vitro studies using murine 3T3-L1 adipocytes and human pre-adipocytes have shown that proinflammatory markers (e.g. IL-6, MCP-1, IL-1 $\beta$ ) and TNF- $\alpha$-derived macrophage activity is reduced following treatment with $10 \mathrm{nM}$ of $1,25(\mathrm{OH})_{2} \mathrm{D}_{3}$, and this effect is partly mediated by $\operatorname{VDR}(51,52)$ In line, recent in vivo findings in Sprague-Dawley male mice following 12-weeks combined High Fat and Low Vitamin D Diet (HFD+LVD) have demonstrated an increase in AT macrophage infiltration, IL- 6 and TNF- $\alpha$ mRNA and protein expression compared to the HFD+1000 IU Vitamin D/Kg group (53). NFKB/MAPK mediated mechanisms have been described to explain the possible anti-inflammatory action of the VDR-ligands in murine adipocytes, $(54,55)$ as well as human preadipocytes $(56)$.

In summary, the current available in vitro and animal data indicate that vitamin $D$ may affect AT lipid buffering capacity by affecting adipogenic differentiation, lipogenesis, intracellular lipolysis, and oxidative capacity (the latter via effects on mitochondrial biogenesis/function). Furthermore, Vitamin D may have beneficial effects on local AT and systemic low-grade inflammation via activation of NFKB/MAPK mediated pathways (Figure 1). Currently, there is a gap between data available from in vitro studies using animal-human derived cell models and well-controlled human intervention studies.

\section{Role of Vitamin D on muscle glucose and lipid metabolism}

As indicated above, vitamin D deficiency may affect AT lipid buffering capacity, thereby altering fatty acid supply to skeletal muscle and indirectly affecting muscle lipid content (preventing lipotoxicity). Additionally, direct effects of vitamin D on skeletal muscle 
metabolism have also been described. For instance, $\mathrm{L} 6$ and $\mathrm{C} 2 \mathrm{C} 12$ myotubes treated with $100 \mathrm{nM}(24 \mathrm{~h})$ and $10 \mathrm{nM}$ of $1,25(\mathrm{OH})_{2} \mathrm{D}_{3}(72 \mathrm{~h})$ showed an elevated glucose transporter 4 (GLUT4), VDR and Insulin Receptor (IR) mRNA expression, but functional effects on glucose uptake were not determined $(57,58)$. In line, C2C12 mouse myotubes treated with $10 \mathrm{nM}$ $1,25(\mathrm{OH})_{2} \mathrm{D}_{3}$ for $48 \mathrm{~h}$ ameliorated lipid-induced insulin resistance, through improved insulin receptor substrate-1 (IRS-1) tyrosine phosphorylation and increased serine phosphorylation of protein kinase $\mathrm{B}(P K B)$, also known as $A k t(59,60)$. Additionally, $1,25(\mathrm{OH})_{2} \mathrm{D}_{3}$ increased mRNA content of Perilipin 2 (PLIN 2,) as well as adipose triglyceride lipase (ATGL) in C2C12 myotubes (22), indicating an involvement of vitamin $D$ in muscle lipolysis and intramuscular lipid catabolism.

Furthermore, treatment of human primary muscle cells from healthy lean donors

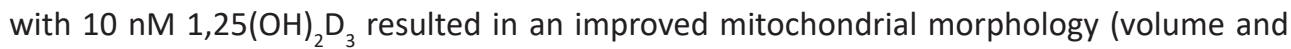
structure) and altered mRNA expression of genes involved in muscle glucose and lipid metabolism like pyruvate dehydrogenase kinase 4 (PDK4) and CPT1 (61), These in vitro animal and human data indicate that vitamin D may affect muscle insulin sensitivity via improvement of mitochondrial function, substrate oxidation, and lipid turnover (Figure 1). However, future investigations are needed to elucidate the physiological importance of vitamin $D$ in muscle substrate handling and insulin sensitivity in humans.

\section{Role of Vitamin D in liver lipid and glucose metabolism}

Obesity is often associated with excessive fat deposition in the liver causing inflammation and hepatic insulin resistance (62). An imbalance between lipid availability (from adipose tissue lipolysis or de novo lipogenesis) and lipid removal (via fatty acid oxidation or triglyceride-rich lipoprotein secretion) in the liver can result in hepatic lipid accumulation, leading to non-alcoholic fatty liver disease (NAFLD) or non-alcoholic steatohepatitis (NASH) (63).

In vivo and in vitro studies in rodents have provided insight into the putative mechanisms through which vitamin D may lower liver lipid accumulation possibly via effects on the enterohepatic circulation and autophagy. Intrahepatic injection of $1,25(\mathrm{OH})_{2} \mathrm{D}_{3}$ ( $5 \mathrm{ng} / \mathrm{g}$ body weight, twice per week) for 4 weeks in HFD+VDD treated mice resulted in an upregulation of bile acids transport, suppressed gene expression related to hepatic lipogenesis and proinflammatory markers, thereby improving the NASH phenotype.(23) In line, intraperitoneal injection of $1,25(\mathrm{OH})_{2} \mathrm{D}_{3}(2.5 \mathrm{ng} / \mathrm{g}$ body weight 3 times per week) for 4 weeks significantly reduced liver lipid accumulation in mice (64). As shown in HepG2 cells, $1,25(\mathrm{OH})_{2} \mathrm{D}_{3}$ may ameliorate hepatic steatosis by upregulating autophagy-related (i.e. ATG16L1) mRNA expression, indicating that vitamin D might induce lipophagy via the autophagy-lysosomal pathway (64).

Nelson and colleagues showed that serum $25(\mathrm{OH}) \mathrm{D}_{3}$ levels are inversely associated with hepatocyte damage, as reflected by hepatocellular ballooning degeneration, in obese men and women with NASH (65). However, another study has reported no correlation between serum vitamin $D$ and liver fat accumulation nor liver insulin sensitivity and inflammation in obese men and women with NASH (66). These data indicate that studies on the association between vitamin D, liver fat and liver insulin sensitivity and inflammation in humans are inconsistent, despite accumulating mechanistic evidence from in vitro and in 
vivo rodent models (Figure 1).

\section{Role of Vitamin D in insulin secretion}

Obesity-associated insulin resistance may chronically elevate glucose and fatty acids in the circulation accompanied by a decline in beta cell function, resulting eventually in a reduced insulin secretion. Therefore, improving beta cell insulin secretion or responsiveness has a major effect on glycemic control $(67,68)$.

Incubation of beta cells derived from VDD mice with $1 \mathrm{nM} 1,25(\mathrm{OH})_{2} \mathrm{D}_{3}$, pretreated with high-glucose, resulted in a reduced mRNA and protein expression of Renin Angiotensin System (RAS) components (69), of which involvement in insulin secretion has been demonstrated in a T2D mice model (70). In addition, incubation of pancreatic cell islets from type 1 diabetic donors with $1,25(\mathrm{OH})_{2} \mathrm{D}_{3}$ increased VDR expression and prevented cytokineinduced FAS expression (mRNA and protein), which is a mediator of beta-cells apoptosis (71). A recent in vitro study has suggested that a VDR-ligand (Calcipotriol/derivative of $1,25(\mathrm{OH})_{2} \mathrm{D}_{3}$ ) may protect human ß-like cells (derived from human induced pluripotent stem cells/iPS) against interleukin $1 ß$-mediated inflammation (72). Together, these data suggest that vitamin D may affect pancreatic insulin secretion in a RAS dependent manner, via induction of beta-cell apoptosis, and may protect beta-cell from local inflammation (Figure 1). Furthermore, the putative underlying mechanisms for the effect of vitamin $D$ on insulin secretion and glycemic control in human pancreatic islets remain to be determined.

\section{Role of Vitamin D in gut}

It is well-known that intestinal calcium balance can be modulated by vitamin $D$ through stimulating intestinal calcium absorption as shown in human and animal studies $(73,74)$. The presence of the VDR and the expression of CYP27B1 in small and large intestinal epithelial and immune cells indicate the biological and metabolic significance of vitamin $D$ in the human gut (75). Interestingly, it has been shown that vitamin $D_{3}$ supplementation for 4 weeks results in an increased microbial diversity and a decrease in relative abundance of Gammaproteobacteria in the upper gastro-intestinal tract in healthy men and women (76). Furthermore, intraperitoneal injection of $1,25(\mathrm{OH})_{2} \mathrm{D}_{3}(5 \mathrm{ng} / \mathrm{g}$ body weight) for one month attenuated metabolic endotoxemia (as evidenced by lower plasma lipopolysaccharides, LPS), and improved intestinal tight junction integrity, as well as Paneth cell defense in HFD+VDD fed mice (77). An elegant review by Zheng and colleagues showed that evidence is accumulating for a role of Vitamin $D$ in improved beta cell function in Type 1 Diabetes (T1D), possibly via effects on the microbiome (78). Nevertheless, the underlying mechanisms still need further investigations. Overall, these findings indicate that vitamin $D$ may have important roles in intestinal barrier function, local inflammation and modulation of microbial composition (Figure 1).

\section{Vitamin D status in the obese insulin resistant state}

Inverse correlations between serum $25(\mathrm{OH}) \mathrm{D}_{3}$ and weight, $\mathrm{BMI}$, and waist circumference have been shown in overweight and obese adults with different ethnic 
backgrounds (79). Low circulating $25(\mathrm{OH}) \mathrm{D}_{3}$ concentrations in human obesity might be due to increased uptake and sequestration of fat-soluble vitamin $D$ in the increased fat mass, though the underlying mechanism is unclear (80). In line, dilution of vitamin $D$ due to a higher volume distribution in obese has been proposed as underlying mechanism for the inverse correlation between body size (body weight) and serum $25(\mathrm{OH}) \mathrm{D}_{3}$ concentrations (81). In addition, obese individuals may spend less time outdoors, which may result in reduced endogenous vitamin $D$ production contributing to the lower circulating vitamin $D$ levels observed in obesity (82). Interestingly, Wamberg and colleagues showed that VDR expression was comparable between VAT and SAT from obese individuals, but higher in VAT from obese individuals compared with VAT from lean individuals (40). The expression of 25-hydroxylase enzymes (CYP2J2, CYP27A1 and CYP27B1) was decreased in SAT from obese individuals (40). These data indicate an impaired adipose tissue vitamin $D$ related metabolism of obese individuals (Figure 2). However, it is still unclear whether this impaired adipose tissue vitamin $\mathrm{D}$ related metabolism is affected by circulating vitamin $\mathrm{D}$ concentrations, insulin resistance or adiposity per se in human obesity.

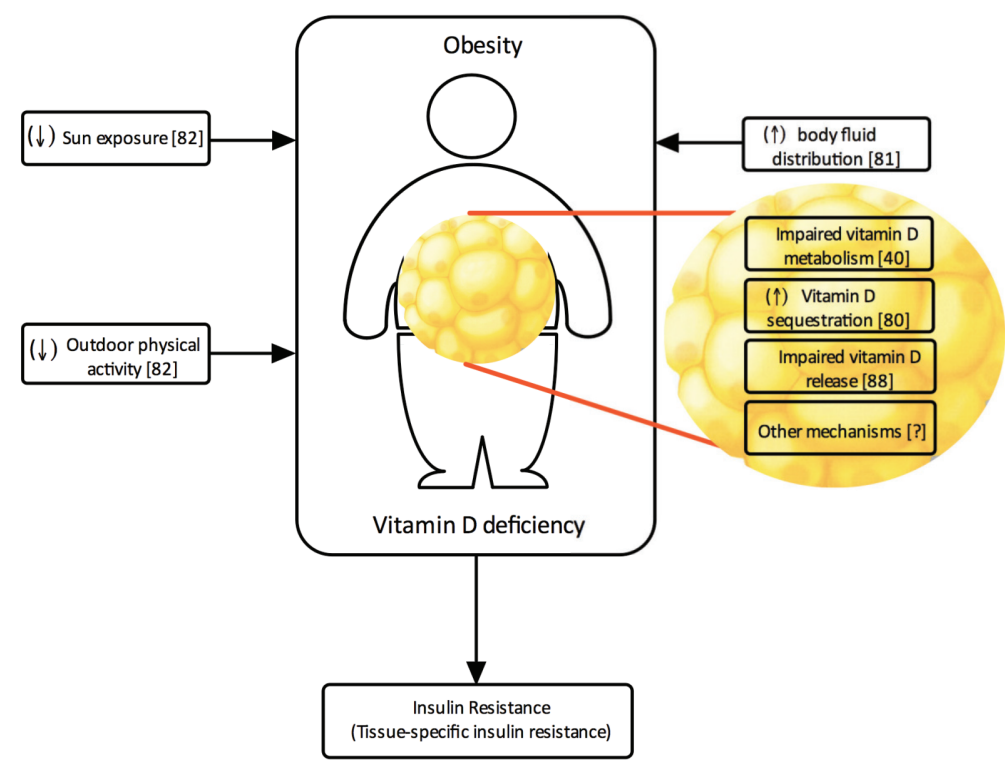

Figure 2. Obesity is often accompanied with low circulating vitamin D levels (vitamin D deficiency). External factors such as less sun exposure and less outdoor physical activity may be associated with low circulating vitamin D levels in human obesity. Furthermore, endogenous mechanisms, including increased body fluid distribution and adipose tissue dysfunction, might also contribute to increased vitamin D sequestration and an impaired vitamin D release in human obesity, which may ultimately lead to the development of insulin resistance. ( $\uparrow$ ) increase; $(\downarrow)$ decrease; references between brackets [].

Fat mass reduction has been considered as a strategy to increase circulating vitamin $D$ in obesity. For instance, energy restriction using a very low-calorie diet (VLCD, $500 \mathrm{kcal}$ per day) combined with physical activity increased plasma $25(\mathrm{OH}) \mathrm{D}_{3}$ levels after 1 year intervention in obese individuals, which was inversely related with the reduction of VAT volume (83). In contrast, the intensive lifestyle Diabetes Prevention Program (DPP) 
showed that a decrease total body fat was not associated with increased plasma $25(\mathrm{OH}) \mathrm{D}_{3}$ concentration in prediabetic individuals (84). In addition to lifestyle intervention, weightreducing surgery using gastric bypass only resulted in a temporal elevation of serum $25(\mathrm{OH})$ $D_{3}$ levels, which decreased again one month after surgery (85). Furthermore, two systematic reviews and one meta-analysis concluded that weight loss interventions showed only marginal changes in serum $25(\mathrm{OH}) \mathrm{D}_{3}$ following significant weight and body fat loss $(86,87)$. Thus, the above studies provide inconsistent evidence on the relation between AT mass and the circulating levels of serum $25(\mathrm{OH}) \mathrm{D}_{3}$. Therefore, it may be that the often observed circulating vitamin $\mathrm{D}$ deficiency in obesity is more complex than previously thought and cannot be solely explained by increased sequestration/dilution in the expanded AT mass.

Of interest, recent ex vivo data by Di Nisio et al (88) demonstrated that a blunted adrenaline mediated lipolytic response, a characteristic of the obese insulin resistant state was accompanied by increased accumulation of $25(\mathrm{OH}) \mathrm{D}_{3}$ in human subcutaneous adipocytes from obese donors, possibly indicating a blunted vitamin $D$ release. Thus, there may be an important link between an impaired lipid mobilization/turnover and an attenuated vitamin $D$ release from the AT in obese-insulin resistant individuals which remains to be investigated in more detail.

\section{Vitamin D, blood glucose control and insulin sensitivity}

The potential effects of vitamin D on glucose homeostasis and insulin sensitivity have been studied in numerous human cross-sectional and intervention studies. The majority of these cross-sectional studies showed a positive association of serum $25(\mathrm{OH}) \mathrm{D}_{3}$ levels with insulin sensitivity measures derived from a hyperinsulinemic euglycemic clamp test $(89,90)$ or indirect markers such as Matsuda index (91), or Quantitative Insulin Sensitivity Index (QUICKI)(92, 93). A negative association was observed with Homeostatic Model Assessment of Insulin Resistance (HOMA-IR)(93) or 2-hour Oral Glucose Tolerance Test (2h OGTT) (94), However, in most studies the relationship between serum $25(\mathrm{OH}) \mathrm{D}_{3}$ and markers of insulin sensitivity/resistance attenuated $(95,96)$ or even disappeared $(94,97)$ after adjustment for markers of adiposity (including BMI, and/or body fat percentage). This indicates that the association between vitamin $D$ deficiency and degree of insulin resistance in obese individuals, may be mediated mainly by the increased body weight and changes in body composition.

\section{Evidence from human intervention studies}

Obesity-associated with circulating vitamin D deficiency may cause a decreased vitamin D bioavailability. Therefore, increasing circulating vitamin D levels by means of supplementation, is expected to affect tissue function and insulin sensitivity in the obese resistant state. As shown in table 1, eight meta-analyses published between 2012 and 2018 (98-105) of human intervention carried out between 1980 and 2017 showed an increased plasma vitamin D $25 \mathrm{OHD}_{3}$ concentration following supplementation, but the majority of these meta-analyses suggested insufficient evidence to no effects on glycemic control and insulin sensitivity/resistance. The included interventions were performed across different ethnicities, in both sexes, and with a broad spectrum of vitamin $D$ doses, modes of administration, treatment duration and most often used surrogate markers of insulin resistance. 
Table 1. Meta-analyses of RCTs regarding the effect of vitamin D supplementation on insulin sensitivity and glucose metabolism

\begin{tabular}{|c|c|c|c|c|}
\hline Investigators (Year) & $\mathrm{N}$ trials included & Study Populations & Markers of glucose \& insulin (effect size) & Outcome \\
\hline George et al. (2012) & 15 RCTs from 1984 to 2010 & $\begin{array}{l}\text { Subjects with NGT and } \\
\text { IFG }\end{array}$ & $\begin{array}{l}\text { - FPG (SMD }-0.02 ; 95 \% \mathrm{Cl}:-0.10 \text { to } 0.06 ; \mathrm{P}=0.59 \text { ) } \\
\text { - HOMA-IR (SMD }-0.07 ; 95 \% \mathrm{Cl}:-0.20 \text { to } 0.06 ; \mathrm{P}=0.30 \text { ) } \\
\text { - HbA1C (SMD } 0.03 ; 95 \% \mathrm{Cl}:-0.18 \text { to } 0.23 ; \mathrm{P}=0.81 \text { ) }\end{array}$ & No effect \\
\hline Jamka et al. (2015) & $\begin{array}{l}12 \text { RCTs between } 2007 \text { and } \\
2014\end{array}$ & Subjects with Obesity & $\begin{array}{l}\text { - FPG (SMD - } 0.10 ; 95 \% \mathrm{Cl}:-0.26 \text { to } 0.07 ; \mathrm{P}=0.25 \text { ) } \\
\text { - HOMA-IR (SMD } 0.04 ; 95 \% \mathrm{Cl}:-0.44 \text { to } 0.52 ; \mathrm{P}=0.86 \text { ) }\end{array}$ & No effect \\
\hline Li et al. (2018) & $\begin{array}{l}20 \text { RCTs between } 2008 \text { and } \\
2017\end{array}$ & Subjects with T2D & $\begin{array}{l}\text { - FPG (WMD -3.59; } 95 \% \mathrm{Cl}:-7.94 \text { to } 0.76 ; \mathrm{P}=0.11) \\
\text { - HOMA-IR (SMD -0.57; } 95 \% \mathrm{Cl}:-1.09 \text { to }-0.04 ; \mathrm{P}=0.03 \text { ) } \\
\text { - HbA1c (WMD -0.11; } 95 \% \mathrm{Cl}:-0.35 \text { to } 0.13 ; \mathrm{P}=0.38 \text { ) }\end{array}$ & $\begin{array}{l}\text { Insufficient } \\
\text { evidence }\end{array}$ \\
\hline Mirhosseini et al.(2017) & $\begin{array}{l}24 \text { RCTs between } 2009 \text { and } \\
2016\end{array}$ & Subjects with $T 2 D$ & $\begin{array}{l}\text { - FPG (SMD -0.27; } 95 \% C l:-8.1 \text { to }-1.6 ; P=0.003) \\
\text { - HOMA-IR (SMD: }-0.66 ; 95 \% C l:-1.06 \text { to }-0.26 ; P=0.001 \text { ) } \\
\text { - HbA1c (SMD: }-0.30 ; 95 \% C l:-0.45 \text { to }-0.15 ; P<0.001 \text { ) }\end{array}$ & $\begin{array}{l}\text { Sufficient } \\
\text { evidence }\end{array}$ \\
\hline Mirhosseini et al.(2018) & $\begin{array}{l}28 \text { RCTs between } 2009 \text { and } \\
2017\end{array}$ & Prediabetes & $\begin{array}{l}\text { - FPG (WMD }-0.46 ; 95 \% \mathrm{Cl}:-0.74 \text { to }-0.19 ; \mathrm{P}=0.001) \\
\text { - HOMA-IR (WMD }-0.39 ; 95 \% \mathrm{Cl}:-0.68 \text { to }-0.11 ; \mathrm{P}=0.007 \text { ) } \\
\text { - HbA1c (WMD }-0.48 ; 95 \% \mathrm{Cl}:-0.79 \text { to }-0.18 ; \mathrm{P}=0.002 \text { ) }\end{array}$ & $\begin{array}{l}\text { Sufficient } \\
\text { evidence }\end{array}$ \\
\hline Poolsup et al. (2016) & $\begin{array}{l}10 \text { RCTs between } 2007 \text { and } \\
2014\end{array}$ & $\begin{array}{l}\text { Subjects with Prediabetes } \\
\text { (based on IFG or IGT) }\end{array}$ & $\begin{array}{l}\text { - FPG (MD - } 0.10 ; 95 \% \mathrm{Cl}:-0.18 \text { to }-0.03 ; \mathrm{P}=0.006) \\
\text { - HbA1C (MD -0.89; } 95 \% \mathrm{Cl}:-1.54 \text { to }-0.23 ; \mathrm{P}=0.008 \text { ) } \\
\text { - HOMA-IR (MD - } 0.06 ; 95 \% \mathrm{Cl}:-0.36 \text { to } 0.24 ; \mathrm{P}=0.69 \text { ) } \\
\text { - 2hOGTT (MD }-0.23 ; 95 \% \mathrm{Cl}:-0.65 \text { to } 0.19 ; \mathrm{P}=0.28 \text { ) }\end{array}$ & $\begin{array}{l}\text { Insufficient } \\
\text { evidence }\end{array}$ \\
\hline Seida et al. (2014) & $\begin{array}{l}36 \text { RCTs between } 1984 \text { and } \\
2013\end{array}$ & $\begin{array}{l}\text { Subjects with NGT, } \\
\text { Prediabetes, T2D }\end{array}$ & $\begin{array}{l}\text { - HOMA-IR (MD }-0.04 ; 95 \% \mathrm{Cl}:-0.03 \text { to } 0.22 ; \mathrm{P}=0.77 \text { ) } \\
\text { - HbA1c (MD }-0.05 ; 95 \% \mathrm{Cl}:-0.12 \text { to } 0.03 ; \mathrm{P}=0.20 \text { ) }\end{array}$ & No effect \\
\hline Wu et al. (2017) & $\begin{array}{l}24 \text { RCTs between } 2007 \text { and } \\
2016\end{array}$ & Subjects with T2D & $\begin{array}{l}\text { - FPG (SMD }-0.14 ; 95 \% \mathrm{Cl}:-0.31 \text { to } 0.03 ; \mathrm{P}=0.10 \text { ) } \\
\text { - } \mathrm{HbA} 1 \mathrm{c}(\mathrm{SMD}-0.25 ; 95 \% \mathrm{Cl}:-0.45 \text { to }-0.05 ; \mathrm{P}=0.001 \text { ) }\end{array}$ & $\begin{array}{l}\text { Insufficient } \\
\text { evidence }\end{array}$ \\
\hline
\end{tabular}

Abbreviations: 2OGTT: 2-hour Oral Glucose Tolerance Test; FPG: Fasting Plasma Glucose; HOMA-IR: Homeostatic Model Assessment of Insulin Resistance; HbA1C: Glycated Haemoglobin; IGT: Impaired Glucose Tolerance; MD: Mean Difference; NGT: Normal Glucose Tolerance; SMD: standardized mean difference; WMD: weighted mean difference; T2D: Type 2 Diabetes.

Focusing on humans with obesity, a meta-analysis in 1181 subjects with overweight/ obesity (100), including sub-analysis based on dosage (high vs. low), duration (long term vs. short term), and group (vitamin D deficient vs. non-deficient) showed no effect of vitamin D supplementation on glucose metabolism and insulin resistance. Furthermore, subgroup analysis suggested that insulin resistance is improved in non-obese as compared to obese subjects (102-104). Together, these data may point towards no direct causality between circulating vitamin D concentration and development of insulin resistance in humans with obesity.

\section{Conclusion and future recommendations}

This review reports that obesity and insulin resistance are often associated with circulating vitamin D deficiency, which may be partly explained by an increased sequestration/dilution in the expanded AT mass. Additionally, vitamin D metabolism within the AT may also be altered as reflected by a down-regulation of vitamin D metabolizing enzymes and the finding of an impaired (lipolysis-mediated) release of vitamin $D 25(O H) D_{3}$. However, further studies are needed to determine the underlying mechanism in humans with obesity.

The role of vitamin D in tissue specific glucose and lipid metabolism is still under debate in humans. Data from mostly murine and in vitro studies indicate that vitamin D possibly contributes to the improvement of AT lipid buffering or fat storage capacity and may reduce the pro-inflammatory state, but data are not entirely consistent and human evidence is lacking. Vitamin D has also been implicated in muscle insulin signaling, intramuscular lipid partitioning as well as liver inflammation and steatosis. However, these (murine) in vitro findings have not been followed by consistent human in vivo evidence on whole-body 
and peripheral (muscle, liver and adipose) insulin sensitivity. Overall, the current published meta-analyses do not support the use of vitamin D supplementation for improving glycemic control and insulin sensitivity in overweight/obese humans. Nevertheless, it should also be noted that a universal approach (one size fits all) for vitamin D deficiency related-insulin resistance may not be appropriate. Perhaps ethnic/geographical location and genetic variations of vitamin D-related metabolism $(106,107)$ may influence responses to, and benefits of, vitamin D supplementation $(104,108)$. Therefore, further evaluation of genetic determinants of vitamin D status among different ethnic/geographical groups and metabolic phenotype may enable the identification of population subgroups, which may benefit from vitamin D supplementation. Finally, combining vitamin D supplementation with other modes of intervention (e.g. diet, exercise, polyphenols, or other micronutrients) might provide new strategies for the treatment and prevention of insulin resistance in humans but this needs to be investigated under well-controlled human settings.

\section{Acknowledgements}

AP is supported by the Indonesia Endowment Fund for Education (LPDP) and Ministry of Research, Technology, and Higher Education (grant number: PRJ-3588/LPDP.3/2016). The funders had no role in the preparation and submission of the manuscript.

\section{Author contributions}

All authors provided a substantial contribution to the discussion of content and approved the final manuscript.

\section{Declaration of interest}

The authors declare that they have no conflict of interest. 


\section{References}

1. Poirier P, Giles TD, Bray GA, et al. Obesity and cardiovascular disease: pathophysiology, evaluation, and effect of weight loss an update of the 1997 American Heart Association Scientific statement on obesity and heart disease from the obesity committee of the council on nutrition, physical activity, and metabolism. Circulation. 2006;113(6):898-918.

2. Prentice AM. The emerging epidemic of obesity in developing countries. Int J Epidemiol. 2006;35(1):93-9.

3. World Health Organization. Global Report on Diabetes. Geneva, Switzerland: World Health Organization; 2016.

4. Mainous AG, Tanner RJ, Baker R, et al. Prevalence of prediabetes in England from 2003 to 2011: population-based, cross-sectional study. BMJ open. 2014;4(6):e005002.

5. Rosella LC, Lebenbaum M, Fitzpatrick T, et al. Prevalence of prediabetes and undiagnosed diabetes in Canada (2007-2011) according to fasting plasma glucose and HbA1c screening criteria. Diabetes Care. 2015;38(7):1299-305.

6. Centers for Disease Control. Awareness of prediabetes--United States, 2005-2010. MMWR Morb Mortal Wkly Rep. 2013;62(11):209.

7. Tuso P. Prediabetes and lifestyle modification: time to prevent a preventable disease. Perm J. 2014;18(3):88 - 93.

8. Tabak AG, Herder C, Rathmann W, et al. Prediabetes: a high-risk state for diabetes development. The Lancet. 2012;379(9833):2279-90.

9. Abraham TM, Fox CS. Implications of rising prediabetes prevalence. Diabetes Care. 2013;36(8):2139-41.

10. Grundy SM. Obesity, metabolic syndrome, and cardiovascular disease. J Clin Endocrinol Metab. 2004;89(6):2595-600.

11. Savage DB, Petersen KF, Shulman GI. Disordered lipid metabolism and the pathogenesis of insulin resistance. Physiol Rev. 2007;87(2):507-20.

12. Goossens GH. The role of adipose tissue dysfunction in the pathogenesis of obesity-related insulin resistance. Physiol Behav. 2008;94(2):206-18.

13. Shulman GI. Ectopic fat in insulin resistance, dyslipidemia, and cardiometabolic disease. N Engl J Med. 2014;371(12):1131-41.

14. Holick MF. Sunlight and vitamin D for bone health and prevention of autoimmune diseases, cancers, and cardiovascular disease. Am J Clin Nutr. 2004;80(6):1678S-88S.

15. Holick MF. Vitamin D deficiency. N Engl J Med. 2007;357.

16. Haussler MR, Jurutka PW, Mizwicki M, et al. Vitamin D receptor (VDR)-mediated actions of $1 \alpha$, 25(OH)2 vitamin D3: genomic and non-genomic mechanisms. Best Pract Res Clin Endocrinol Metab. 2011;25(4):543-59.

17. Clemente-Postigo M, Munoz-Garach A, Serrano M, et al. Serum 25-hydroxyvitamin D and adipose tissue vitamin $\mathrm{D}$ receptor gene expression: relationship with obesity and type 2 diabetes. J Clin Endocrinol Metab. 2015;100(4):E591-5.

18. Botella-Carretero Jl, Alvarez-Blasco F, Villafruela JJ, et al. Vitamin D deficiency is associated with the metabolic syndrome in morbid obesity. Clin Nutr. 2007;26(5):573-80.

19. Earthman C, Beckman L, Masodkar K, et al. The link between obesity and low circulating 25-hydroxyvitamin D concentrations: considerations and implications. Int J Obes. 2012;36(3):38796.

20. Kabadi S, Lee B, Liu L. Joint effects of obesity and vitamin D insufficiency on insulin resistance and type 2 diabetes: results from the NHANES 2001-2006. Diabetes Care 2012;35(10):2048-54.

21. Narvaez CJ, Simmons KM, Brunton J, et al. Induction of STEAP4 correlates with 1,25dihydroxyvitamin D3 stimulation of adipogenesis in mesenchymal progenitor cells derived from human adipose tissue. J Cell Physio. 2013;228(10):2024-36. 
22. Jefferson GE, Schnell DM, Thomas DT, et al. Calcitriol concomitantly enhances insulin sensitivity and alters myocellular lipid partitioning in high fat-treated skeletal muscle cells. Journal of physiology and biochemistry. 2017;73(4):613-21.

23. Kong M, Zhu L, Bai L, et al. Vitamin D deficiency promotes nonalcoholic steatohepatitis through impaired enterohepatic circulation in animal model. Am J Physiol Gastrointest Liver Physiol. 2014;307(9):G883-G93.

24. Houghton LA, Vieth R. The case against ergocalciferol (vitamin D2) as a vitamin supplement. Am J Clin Nutr. 2006;84(4):694-7.

25. DeLuca HF. History of the discovery of vitamin D and its active metabolites. BoneKEy reports. $2014 ; 3$.

26. Nykjaer A, Dragun D, Walther D, et al. An endocytic pathway essential for renal uptake and activation of the steroid 25-(OH) vitamin D 3. Cell. 1999;96(4):507-15.

27. Kaseda R, Hosojima M, Sato H, et al. Role of megalin and cubilin in the metabolism of vitamin D3. Ther Apher Dial. 2011;15(s1):14-7.

28. Abboud M, Puglisi D, Davies B, et al. Evidence for a specific uptake and retention mechanism for 25-hydroxyvitamin D (25OHD) in skeletal muscle cells. Endocrinology. 2013;154(9):3022-30.

29. Bonnet L, Karkeni E, Couturier C, et al. Gene Expression Pattern in Response to Cholecalciferol Supplementation Highlights Cubilin as a Major Protein of 25(OH)D Uptake in Adipocytes and Male Mice White Adipose Tissue. Endocrinology. 2018;159(2):957-66.

30. Girgis CM, Mokbel N, Cha KM, et al. The vitamin D receptor (VDR) is expressed in skeletal muscle of male mice and modulates 25-hydroxyvitamin D (25OHD) uptake in myofibers. Endocrinology. 2014;155(9):3227-37.

31. Li J, Byrne ME, Chang E, et al. 1 $\alpha$, 25-Dihydroxyvitamin D hydroxylase in adipocytes. J Steroid Biochem Mol Biol. 2008;112(1):122-6.

32. Abboud M, Rybchyn MS, Liu J, et al. The effect of parathyroid hormone on the uptake and retention of 25-hydroxyvitamin D in skeletal muscle cells. J Steroid Biochem Mol Biol. 2017;173:173-9.

33. Abboud M, Rybchyn MS, Ning YJ, et al. 1,25-Dihydroxycholecalciferol (calcitriol) modifies uptake and release of 25-hydroxycholecalciferol in skeletal muscle cells in culture. J Steroid Biochem Mol Biol. 2018;177:109-15.

34. Rosenstreich SJ, Rich C, Volwiler W. Deposition in and release of vitamin D3 from body fat: evidence for a storage site in the rat. J Clin Invest. 1971;50(3):679-87.

35. Pike JW, Meyer MB. The vitamin D receptor: new paradigms for the regulation of gene expression by 1,25-dihydroxyvitamin D(3). Endocrinol Metab Clin North Am. 2010;39(2):255-69.

36. Kato S. The function of vitamin D receptor in vitamin D action. J Biochem. 2000;127(5):717-22.

37. Deeb KK, Trump DL, Johnson CS. Vitamin D signalling pathways in cancer: potential for anticancer therapeutics. Nat Rev Cancer. 2007;7(9):684-700.

38. Norman AW. From vitamin $D$ to hormone $D$ : fundamentals of the vitamin $D$ endocrine system essential for good health. Am J Clin Nutr 2008;88((suppl)):491S-9S.

39. Maestro B, Dávila N, Carranza MC, et al. Identification of a Vitamin D response element in the human insulin receptor gene promoter. The Journal of Steroid Biochemistry and Molecular Biology. 2003;84(2-3):223-30.

40. Wamberg L, Christiansen T, Paulsen SK, et al. Expression of vitamin D-metabolizing enzymes in human adipose tissue - the effect of obesity and diet-induced weight loss. Int J Obes (Lond). 2013;37(5):651-7.

41. Nimitphong $H$, Holick MF, Fried SK, et al. 25-hydroxyvitamin D3 and 1,25-dihydroxyvitamin D3 promote the differentiation of human subcutaneous preadipocytes. PLoS One. 2012;7(12):e52171.

42. Chang E, Kim Y. Vitamin D decreases adipocyte lipid storage and increases NAD-SIRT1 pathway in 3T3-L1 adipocytes. Nutrition. 2016;32(6):702-8.

43. Ding C, Wilding JP, Bing C. 1,25-dihydroxyvitamin D3 Protects against Macrophage-Induced Activation of NFKB and MAPK Signalling and Chemokine Release in Human Adipocytes. PLoS One. 
2013;8(4):e61707.

44. Blumberg JM, Tzameli I, Astapova I, et al. Complex role of the vitamin D receptor and its ligand in adipogenesis in 3T3-L1 cells. J Biol Chem. 2006;281(16):11205-13.

45. Felicidade I, Sartori D, Coort SLM, et al. Role of 1 $\alpha, 25$-Dihydroxyvitamin D in Adipogenesis of SGBS Cells: New Insights into Human Preadipocyte Proliferation. Cellular Physiology and Biochemistry. 2018;48(1):397-408.

46. Shi H, Norman AW, Okamura WH, et al. 1 $\alpha, 25$-Dihydroxyvitamin D3 modulates human adipocyte metabolism via nongenomic action. The FASEB journal. 2001;15(14):2751-3.

47. Silvagno F, Pescarmona G. Spotlight on vitamin D receptor, lipid metabolism and mitochondria: Some preliminary emerging issues. Mol Cell Endocrinol. 2017;450((2017)):24-31.

48. Kang EJ, Lee JE, An SM, et al. The effects of vitamin D3 on lipogenesis in the liver and adipose tissue of pregnant rats. Int J Mol Med. 2015;36(4):1151-8.

49. Xue B, Greenberg AG, Kraemer FB, et al. Mechanism of intracellular calcium ([Ca2+] i) inhibition of lipolysis in human adipocytes. The FASEB Journal. 2001;15(13):2527-9.

50. Larrick BM, Kim KH, Donkin SS, et al. 1,25-Dihydroxyvitamin D regulates lipid metabolism and glucose utilization in differentiated 3T3-L1 adipocytes. Nutrition research (New York, NY). 2018;58:72-83.

51. Marcotorchino J, Gouranton E, Romier B, et al. Vitamin D reduces the inflammatory response and restores glucose uptake in adipocytes. Mol Nutr Food Res. 2012;56(12):1771-82.

52. Gao D, Trayhurn P, Bing C. 1, 25-Dihydroxyvitamin D3 inhibits the cytokine-induced secretion of MCP-1 and reduces monocyte recruitment by human preadipocytes. Int J Obes. 2013;37(3):35765.

53. Chang $E$, Kim $Y$. Vitamin D insufficiency exacerbates adipose tissue macrophage infiltration and decreases AMPK/SIRT1 activity in obese rats. Nutrients. 2017;9(4):338.

54. Mutt SJ, Karhu T, Lehtonen S, et al. Inhibition of cytokine secretion from adipocytes by 1,25-dihydroxyvitamin D3 via the NF-KB pathway. The FASEB Journal. 2012;26(11):4400-7.

55. Karkeni E, Bonnet L, Marcotorchino J, et al. Vitamin D limits inflammation-linked microRNA expression in adipocytes in vitro and in vivo: A new mechanism for the regulation of inflammation by vitamin D. Epigenetics. 2018;13(2):156-62.

56. Zhu J, Bing C, Wilding JPH. Vitamin D receptor ligands attenuate the inflammatory profile of IL-1 $\beta$ stimulated human white preadipocytes via modulating the NF-KB and unfolded protein response pathways. Biochemical and biophysical research communications. 2018;503(2):1049-56.

57. Salles J, Chanet A, Giraudet C, et al. 1,25(OH)2-vitamin D3 enhances the stimulating effect of leucine and insulin on protein synthesis rate through Akt/PKB and mTOR mediated pathways in murine C2C12 skeletal myotubes. Mol Nutr Food Res. 2013;57(12):2137-46.

58. Tamilselvan B, Seshadri KG, Venkatraman G. Role of vitamin D on the expression of glucose transporters in L6 myotubes. Indian J Endocrinol Metab. 2013;17(Suppl1):S326.

59. Zhou QG, Hou FF, Guo ZJ, et al. 1,25-Dihydroxyvitamin D improved the free fatty acid-induced insulin resistance in cultured C2C12 cells. Diabetes Metab Res Rev. 2008;24(6):459-64.

60. Girgis CM, Clifton-Bligh RJ, Hamrick MW, et al. The roles of vitamin D in skeletal muscle: form, function, and metabolism. Endocr Rev. 2013;34(1):33-83.

61. Ryan ZC, Craig TA, Folmes CD, et al. 1alpha,25-Dihydroxyvitamin D3 regulates mitochondrial oxygen consumption and dynamics in human skeletal muscle cells. J Biol Chem. 2016;291(3):1514-28.

62. Asrih M, Jornayvaz FR. Inflammation as a potential link between nonalcoholic fatty liver disease and insulin resistance. J Endocrinol. 2013;218(3):R25-R36.

63. Musso G, Gambino R, Cassader M. Recent insights into hepatic lipid metabolism in non-alcoholic fatty liver disease (NAFLD). Prog Lipid Res. 2009;48(1):1-26.

64. Li R, Guo E, Yang J, et al. 1,25(OH)2D3 attenuates hepatic steatosis by inducing autophagy in mice. Obesity (Silver Spring). 2017;25(3):561-71.

65. Nelson JE, Roth CL, Wilson LA, et al. Vitamin D deficiency is associated with increased risk of non- 
alcoholic steatohepatitis in adults with non-alcoholic fatty liver disease: possible role for MAPK and NF-kB? Am J Gastroenterol. 2016;111(6):852-63. .

66. Bril F, Maximos M, Portillo-Sanchez $\mathrm{P}$, et al. Relationship of vitamin $\mathrm{D}$ with insulin resistance and disease severity in non-alcoholic steatohepatitis. J Hepatol. 2015;62(2):405-11.

67. Purrello F, Rabuazzo A. Metabolic factors that affect beta-cell function and survival. Diabetes Nutr Metab. 2000;13(2):84-91.

68. Fonseca VA. Defining and characterizing the progression of type 2 diabetes. Diabetes Care. 2009;32(suppl 2):S151-S6.

69. Cheng $\mathrm{Q}$, Li Y, Boucher B, et al. A novel role for vitamin D: modulation of expression and function of the local renin-angiotensin system in mouse pancreatic islets. Diabetologia. 2011;54(8):207781.

70. Leung PS. The potential protective action of vitamin $D$ in hepatic insulin resistance and pancreatic islet dysfunction in type 2 diabetes mellitus. Nutrients. 2016;8(3):147.

71. Riachy R, Vandewalle B, Moerman E, et al. 1,25-Dihydroxyvitamin D3 protects human pancreatic islets against cytokine-induced apoptosis via down-regulation of the Fas receptor. Apoptosis. 2006;11(2):151-9.

72. Wei Z, Yoshihara E, He N, et al. Vitamin D Switches BAF Complexes to Protect $\beta$ Cells. Cell. 2018;173(5):1135-49.e15.

73. Wasserman R. Vitamin D and the dual processes of intestinal calcium absorption. J Nutr. 2004;134(11):3137-9.

74. Heaney RP. Vitamin D and calcium interactions: functional outcomes. Am J Clin Nutr. 2008;88(2):541S-4S.

75. Li YC, Chen Y, Du J. Critical roles of intestinal epithelial vitamin D receptor signaling in controlling gut mucosal inflammation. J Steroid Biochem Mol Biol. 2015;148:179-83.

76. Bashir M, Prietl B, Tauschmann M, et al. Effects of high doses of vitamin D3 on mucosaassociated gut microbiome vary between regions of the human gastrointestinal tract. Eur J Nutr. 2016;55(4):1479-89.

77. Su D, Nie Y, Zhu A, et al. Vitamin D signaling through induction of paneth cell defens maintains gut microbiota and improves metabolic disorders and hepatic steatosis in animal models. Front Physiol. 2016;7.

78. Zheng P, Li Z, Zhou Z. Gut microbiome in type 1 diabetes: A comprehensive review. Diabetes/ metabolism research and reviews. 2018:e3043.

79. McGill AT, Stewart JM, Lithander FE, et al. Relationships of low serum vitamin D3 with anthropometry and markers of the metabolic syndrome and diabetes in overweight and obesity. Nutr J. 2008;7(1):4.

80. Wortsman J, Matsuoka LY, Chen TC, et al. Decreased bioavailability of vitamin D in obesity. Am J Clin Nutr. 2000;72(3):690-3.

81. Drincic AT, Armas LA, Diest EE, et al. Volumetric dilution, rather than sequestration best explains the low vitamin D status of obesity. Obesity (Silver Spring). 2012;20:1444-48.

82. Florez $\mathrm{H}$, Martinez $\mathrm{R}$, Chacra $\mathrm{W}$, et al. Outdoor exercise reduces the risk of hypovitaminosis $\mathrm{D}$ in the obese. J Steroid Biochem Mol Biol. 2007;103(3-5):679-81.

83. Gangloff A, Bergeron J, Pelletier-Beaumont E, et al. Effect of adipose tissue volume loss on circulating 25-hydroxyvitamin D levels: results from a 1-year lifestyle intervention in viscerally obese men. Int J Obes. 2015;39(11):1638-43.

84. Ceglia L, Nelson J, Ware J, et al. Association between body weight and composition and plasma 25-hydroxyvitamin D level in the Diabetes Prevention Program. Eur J Nutr. 2015:1-10.

85. Lin E, Armstrong-Moore D, Liang Z, et al. Contribution of Adipose Tissue to Plasma 25Hydroxyvitamin D Concentrations During Weight Loss Following Gastric Bypass Surgery. Obesity. 2011;19(3):588-94.

86. Mallard SR, Howe AS, Houghton LA. Vitamin D status and weight loss: a systematic review and 
meta-analysis of randomized and nonrandomized controlled weight-loss trials. Am J Clin Nutr. 2016.

87. Pannu PK, Zhao Y, Soares MJ. Reductions in body weight and percent fat mass increase the vitamin D status of obese subjects: a systematic review and metaregression analysis. Nutr Res. 2016;36(3):201-13.

88. Di Nisio A, De Toni L, Sabovic I, et al. Impaired release of vitamin D in dysfunctional adipose tissue: new cues on vitamin D supplementation in obesity. J Clin Endocrinol Metab. 2017.

89. Chiu KC, Chu A, Go VLW, et al. Hypovitaminosis $D$ is associated with insulin resistance and $\beta$ cell dysfunction. Am J Clin Nutr. 2004;79(5):820-5.

90. Alvarez JA, Ashraf AP, Hunter GR, et al. Serum 25-hydroxyvitamin D and parathyroid hormone are independent determinants of whole-body insulin sensitivity in women and may contribute to lower insulin sensitivity in African Americans. Am J Clin Nutr. 2010;92(6):1344-9.

91. Kayaniyil $S$, Vieth $R$, Retnakaran $R$, et al. Association of vitamin $D$ with insulin resistance and $\beta$-cell dysfunction in subjects at risk for type 2 diabetes. Diabetes care. 2010;33(6):1379-81.

92. Choi HS, Kim K-A, Lim C-Y, et al. Low serum vitamin D is associated with high risk of diabetes in Korean adults. J Nutr. 2011;141(8):1524-8.

93. Heaney RP, French $C B$, Nguyen $S$, et al. A novel approach localizes the association of vitamin $D$ status with insulin resistance to one region of the 25 -hydroxyvitamin D continuum. Adv Nutr. 2013;4(3):303-10.

94. Mousa A, Naderpoor N, de Courten MP, et al. 25-hydroxyvitamin D is associated with adiposity and cardiometabolic risk factors in a predominantly vitamin D-deficient and overweight/obese but otherwise healthy cohort. J Steroid Biochem Mol Biol. 2016.

95. Moore A, Hochner H, Sitlani CM, et al. Plasma vitamin D is associated with fasting insulin and HOMA-IR in young adult males, but not females, of the Jerusalem Perinatal Study. Public Health Nutr. 2015;18(7):1324-31.

96. Marques-Vidal P, Vollenweider P, Guessous I, et al. Serum vitamin D concentrations are not associated with insulin resistance in Swiss adults. J Nutr. 2015;145(9):2117-22.

97. Gulseth HL, Gjelstad IMF, Tierney AC, et al. Serum vitamin D concentration does not predict insulin action or secretion in European subjects with the metabolic syndrome. Diabetes Care. 2010;33(4):923-5.

98. George P, Pearson E, Witham M. Effect of vitamin D supplementation on glycaemic control and insulin resistance: a systematic review and meta-analysis. Diabet Med. 2012;29(8).

99. Seida JC, Mitri J, Colmers IN, et al. Clinical review: effect of vitamin D3 supplementation on improving glucose homeostasis and preventing diabetes: a systematic review and meta-analysis. J Clin Endocrinol Metab. 2014;99(10):3551.

100. Jamka M, Woźniewicz $M$, Jeszka J, et al. The effect of vitamin $D$ supplementation on insulin and glucose metabolism in overweight and obese individuals: systematic review with meta-analysis. Sci Rep. 2015;5:1-12.

101. Poolsup N, Suksomboon N, Plordplong N. Effect of vitamin D supplementation on insulin resistance and glycaemic control in prediabetes: a systematic review and meta-analysis. Diabet Med. 2016;33(3):290-9.

102. Mirhosseini N, Vatanparast H, Mazidi M, et al. The Effect of Improved Serum 25-Hydroxyvitamin D Status on Glycemic Control in Diabetic Patients: A Meta-Analysis. J Clin Endocrinol Metab. 2017;102(9):3097-110.

103. Wu C, Qiu S, Zhu X, et al. Vitamin D supplementation and glycemic control in type 2 diabetes patients: A systematic review and meta-analysis. Metabolism. 2017;73:67-76.

104. Li X, Liu Y, Zheng Y, et al. The Effect of Vitamin D Supplementation on Glycemic Control in Type 2 Diabetes Patients: A Systematic Review and Meta-Analysis. Nutrients. 2018;10(375):1-15.

105. Mirhosseini N, Vatanparast H, Mazidi M, et al. Vitamin D Supplementation, Glycemic Control, and Insulin Resistance in Prediabetics: A Meta-Analysis. Journal of the Endocrine Society. 
CHAPTER 2

Vitamin $\mathrm{D}$ deficiency in the aetiology of obesity-related insulin resistance

2018;2(7):687-709.

106. Han Ff, Lv YI, Gong LI, et al. VDR Gene variation and insulin resistance related diseases. Lipids Health Dis. 2017;16(157):1-12.

107. Zhou T, Sun D, Heianza Y, et al. Genetically determined vitamin D levels and change in bone density during a weight-loss diet intervention: the Preventing Overweight Using Novel Dietary Strategies (POUNDS Lost) Trial. Am J Clin Nutr. 2018;108(5):1129-34.

108. Al-Daghri NM, Mohammed AK, Al-Attas OS, et al. Vitamin D Receptor Gene Polymorphisms Modify Cardiometabolic Response to Vitamin D Supplementation in T2DM Patients. Sci Rep. 2017;7:8280. 


\section{CHAPTER 3}

\section{Vitamin $D$ release across abdominal adipose tissue in lean and obese men: the effect of $ß$-adrenergic stimulation}

Adriyan Pramono, Johan W.E. Jocken, Gijs H. Goossens, Ellen E. Blaak

Published in:

Physiological Reports. (2019) 7: e14308

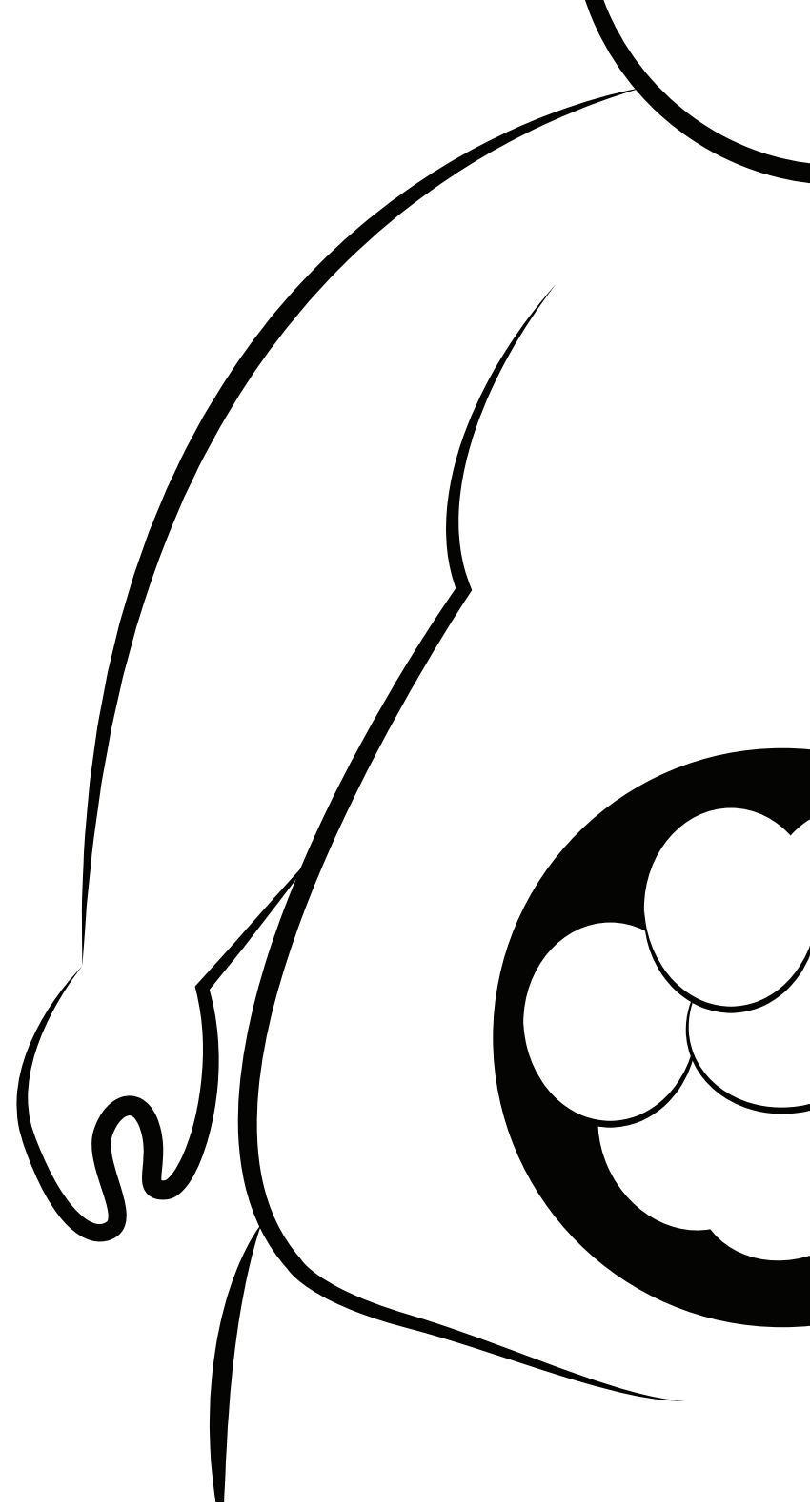




\begin{abstract}
Obesity is characterized by a blunted lipolytic response in abdominal subcutaneous adipose tissue (SAT) and low circulating vitamin D levels. Here, we investigated whether an impaired SAT lipolytic response coincides with an impaired SAT vitamin D release in eight lean and six obese men. 25-hydroxyvitamin $\mathrm{D}_{3}[25(\mathrm{OH}) \mathrm{D} 3]$ and 1,25-dihydroxyvitamin $\mathrm{D}_{3}$ $\left[1,25(\mathrm{OH})_{2} \mathrm{D}_{3}\right]$ fluxes across SAT were measured using arterio-venous blood sampling in combination with AT blood flow measurements after an overnight fast and during 1-hour intravenous infusion of the non-selective ß-adrenergic agonist isoprenaline ( $20 \mathrm{ng} \cdot \mathrm{kg} \mathrm{FFM}^{-1}$. $\left.\mathrm{min}^{-1}\right) .1,25(\mathrm{OH})_{2} \mathrm{D}_{3}$ was released across abdominal SAT during isoprenaline infusion in lean [-0.01 (-0.04 to 0.00$)$ pmol*100g tissue ${ }^{-1 *} \mathrm{~min}^{-1}, \mathrm{P}=0.017 \mathrm{vs}$. zero flux $]$, but not in obese men [0.01 (0.00 to 0.02 ) pmol*100g tissue ${ }^{-1 *} \mathrm{~min}^{-1}, \mathrm{P}=0.116$ vs. zero flux], and accompanied by an impaired isoprenaline-induced lipolytic response in abdominal SAT of obese versus lean men. Isoprenaline had no significant effects on net $25(\mathrm{OH}) \mathrm{D}_{3}$ release across abdominal SAT and plasma vitamin D metabolites in lean and obese men. To conclude, a blunted isoprenaline-mediated lipolysis is accompanied by reduced release of $1,25(\mathrm{OH})_{2} \mathrm{D}_{3}$ vitamin $\mathrm{D}$ across abdominal SAT in obesity.
\end{abstract}




\section{Introduction}

Obesity is associated with adipose tissue (AT) dysfunction, which is characterized by adipocyte hypertrophy, AT inflammation and impaired lipid metabolism, thereby contributing to insulin resistance (1). Noteworthy, obesity is often characterized by low circulating vitamin D levels (2). In line, studies have described an inverse association between body mass index (BMI) and circulating concentration of the inactive vitamin $D$ metabolite 25-hydroxyvitamin $\mathrm{D}_{3}\left(25(\mathrm{OH}) \mathrm{D}_{3}\right)$ (3). Obesity-associated insulin resistance is often accompanied by dysfunctional adipose tissue (AT), which might also contribute to increased vitamin D sequestration and an impaired vitamin D release in human obesity (4).

Uptake and sequestration of vitamin D in the expanded obese AT mass may partly contribute to the relatively low vitamin $D$ concentrations in the circulation in obesity (5), although the underlying mechanism is not yet clearly understood. Furthermore, evidence in rodents suggests that vitamin $D$ may also be released from adipose tissue into the circulation (6). Obesity is characterized by increased lipid storage in the form of triacylglycerol (TAG), mainly in adipose tissue. Catecholamine stimulation leads to an increase in adipose tissue lipolysis, thereby resulting in the hydrolysis of TAG stored in lipid droplets (1). Since vitamin $D$ is a lipophilic vitamin that has been postulated to accumulate in adipose tissue, deliberation of TAG may coincide with release/mobilization of vitamin D metabolites from adipose tissue (7). In line with our hypothesis, Di Nisio et al have shown that adipose tissue derived from obese individuals releases less vitamin $D$ ex vivo when stimulated with adrenaline compared to lean subjects. In the latter study, impaired mobilization of vitamin D coincided with blunted catecholamine-induced lipolytic response, determined by glycerol release into the medium. Nevertheless, other mechanisms like competition between some free fatty acids and vitamin D for binding sites to vitamin D binding protein (DBP) (8) or a role of adipose tissue blood flow (ATBF) in relation to both lipolysis and vitamin $D$ release may possibly be involved. Therefore, it is tempting to speculate that low circulating vitamin $D$ levels in human obesity might be due to an increased uptake and/or a blunted release of vitamin D across abdominal subcutaneous AT (SAT), which may occur concurrently with the often observed blunted catecholamine-mediated lipolysis (9). However, it remains to be determined whether ß-adrenergic stimulation induces vitamin $\mathrm{D} 25(\mathrm{OH}) \mathrm{D}_{3}$ [inactive metabolite] as well as $1,25(\mathrm{OH})_{2} \mathrm{D}_{3}$ [active metabolite] release across human SAT in vivo.

In the present study, using arterio-venous methodology, we investigated (1) the effect of $ß$-adrenergic stimulation on net release of vitamin $D 25(O H) D_{3}$ [inactive] and $1.25(\mathrm{OH})_{2} \mathrm{D}_{3}$ [active metabolite] across abdominal SAT in lean and obese men, and (2) whether an impaired release of vitamin $D$ across obese abdominal SAT is accompanied by a blunted lipolytic response in obese men.

\section{Methods}

\section{Study participants}

The participants of this study were a subset of previous study (Jocken et al, 2008). Eight lean $\left(\mathrm{BMI}<25 \mathrm{~kg} / \mathrm{m}^{2}\right)$ and six obese $\left(\mathrm{BMI}>30 \mathrm{~kg} \mathrm{~kg} / \mathrm{m}^{2}\right)$ men were included in this analysis. Inclusion criteria for both groups were that participants had to be weight-stable (weight change $<3.0 \mathrm{~kg}$ ) for at least 3 months prior to the study, were in good health as 
assessed by medical history, were free of any medication and spent not more than $3 \mathrm{~h}$ of organized sports activities a week. Exclusion criteria were smoking, cardiovascular disease, type 2 diabetes mellitus, liver or kidney malfunction, use of medication known to affect body weight and glucose metabolism, or untreated hypertension. The Medical Ethical Committee of Maastricht University (MEC-03-179) approved the study which was performed according to the procedures set by the latest version of the Declaration of Helsinki, and written informed consent was obtained from all participants.

\section{Study Design}

In this study, participants were allowed to perform only light-intensity physical activity (for examples: walking slowly (in the office), sitting in front of computer/TV, and no sports activities) 2-3 prior to the test day. All participants were asked to refrain from drinking alcohol and to perform no strenuous exercise for $24 \mathrm{~h}$ before the study. Participants came to the university and underwent arterio-venous (A-V) blood sampling across abdominal SAT after an overnight fast and after 1 hour intravenous infusion of the nonselective ß-adrenergic agonist isoprenaline (20 $\left.\mathrm{ng}(\mathrm{kg} \mathrm{FFM})^{-1} \mathrm{~min}^{-1}\right)$, as previously described (9). Circulating concentrations and fluxes across abdominal SAT of glycerol and vitamin D were measured following a 3 hour primed $(3 \mu \mathrm{mol} . \mathrm{kg}-1)$ constant infusion of $\left[{ }^{2} \mathrm{H}_{5}\right]$ glycerol $(0.2$ umol.kg-1.min-1). Blood samples were taken simultaneously from the arterialised venous blood was sampled from a superficial dorsal hand vein and adipose vein at three baseline time points ( $t 90, t 105$ and $t 120 \mathrm{~min}$ ) and at three time points during the last $30 \mathrm{~min}$ of isoprenaline infusion ( $t 150, t 165$ and $t 180 \mathrm{~min}$ ). Adipose tissue blood flow (ATBF) was monitored continuously using the ${ }^{133} \mathrm{Xe}$ wash-out technique. Lean and obese subjects were studied throughout the year in random order, thus the comparison between groups was not confounded by seasonal variation.

\section{Laboratory analysis}

Blood samples were transferred into ice-chilled polypropylene tubes and were centrifuged (1000 g, $4{ }^{\circ} \mathrm{C}, 10 \mathrm{~min}$ ). Plasma was immediately frozen in liquid nitrogen and safely stored at $-80{ }^{\circ} \mathrm{C}$ until analyses. It has been previously demonstrated that when immediately frozen (at $-80^{\circ} \mathrm{C}$ ), vitamin $\mathrm{D}$ metabolites are stable for many years (10-14). Vitamin $\mathrm{D} 25(\mathrm{OH}) \mathrm{D}_{3}$ and $1,25(\mathrm{OH})_{2} \mathrm{D}_{3}$ levels were measured in arterialized and venous plasma samples. Plasma samples at time-points t90, t105 and t120 min (steady state for lipolysis at baseline) and t150, t165 and t180 min (steady state for lipolysis during ISO) were pooled because of a lack of sample material at the same time point for all subjects. There was a steady state at baseline as well as during ISO so that pooling was justified. Vitamin D metabolites were analyzed using liquid-chromatography tandem-mass spectrophotometry (LC-MS/MS) (15). Stable isotope enrichment of glycerol was measured using GC-MS as described previously (9).

\section{Calculations}

Net vitamin $\mathrm{D} 25(\mathrm{OH}) \mathrm{D}_{3}$ and $1,25(\mathrm{OH})_{2} \mathrm{D}_{3}$ fluxes across SAT were calculated by multiplying arterial-venous $(A-V)$ concentration differences by adipose tissue plasma flow, 
as described in other contexts $(9,16)$. Tissue blood flow during baseline is an average of time-points t90, t105, t120 min and during ISO is an averaged of t150, t165 and t180 min. Plasma flow was calculated as tissue blood flow multiplied by ( 1 - haematocrit/100), with haematocrit expressed as a fraction. Positive fluxes indicate net uptake from the circulation, whereas negative fluxes indicate net tissue release into the circulation. The SAT total glycerol uptake was calculated as described previously according to the steady state Steele's equation. Abdominal SAT total glycerol release was calculated by subtracting abdominal SAT net glycerol flux to abdominal SAT total glycerol uptake (9).

\section{Statistical Analysis}

Subjects characteristics were normally distributed, data are presented as mean \pm standard deviation (SD), and differences between lean and obese were tested using Student's unpaired t test. Since vitamin D metabolites, net fluxes, and adipose tissue blood flow were not normally distributed, a non-parametric Mann-Whitney test was used for group comparisons. The effects of $ß$-adrenergic stimulation within groups were tested using the Wilcoxon signed-rank test, and data presented as median (range). Kruskal Wallis test was performed in order to analyze the difference between groups. A Spearman correlation was performed to analyse the relationships between vitamin D fluxes, glycerol, NEFA and circulating vitamin D levels. Statistical calculations were performed with SPSS for Macintosh (version 21.0; SPSS, Chicago, IL, USA).

\section{RESULTS}

\section{Subject characteristics}

Table 1 shows that lean and obese subjects had a comparable age. By definition, BMI, body fat percentage, body fat mass as well as homeostasis model assessment for insulin resistance (HOMA-IR) were significantly higher in obese compared with lean participants (all $\mathrm{P}<0.01)$.

\section{Adipose tissue blood flow (ATBF)}

Table 1. Characteristics of participants

\begin{tabular}{lcc}
\hline Characteristics & Lean $(\mathbf{N}=8)$ & Obese $(\mathbf{N}=6)$ \\
\hline Age (years) & $50 \pm 9$ & $53 \pm 9$ \\
BMI $(\mathrm{kg} / \mathrm{m})$ & $23.7 \pm 1.3$ & $32.3 \pm 2.2^{* *}$ \\
Waist $(\mathrm{cm})$ & $88.9 \pm 3.1$ & $110.2 \pm 7.3^{* *}$ \\
WHR & $0.9 \pm 0.03$ & $1.0 \pm 0.03^{*}$ \\
BF $(\%)$ & $21.5 \pm 3.0$ & $31.8 \pm 1.6^{* *}$ \\
FM (kg) & $16.2 \pm 2.0$ & $31.4 \pm 4.5^{* *}$ \\
HOMA-IR & $1.8 \pm 0.7$ & $3.6 \pm 1.0^{*}$ \\
\hline
\end{tabular}

${ }^{*} P<0.01 ;{ }^{*} P<0.001$, values are mean $\pm S D$

$B F$, body fat; BMI, body mass index; FM, fat mass; HOMA-IR, homeostatic model assessment for insulin resistance; WHR, Waist to Hip Ratio..

Adipose tissue blood flow (ATBF) was comparable between lean and obese individuals at baseline $(P=0.108)$. As expected, Isoprenaline significantly increased ATBF both 


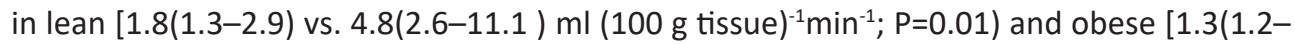

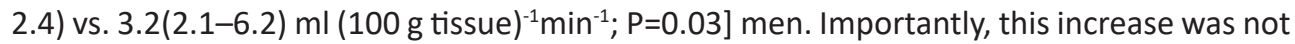
different between groups $(\mathrm{P}=0.245)$.

\section{Systemic (arterialized) concentrations and net vitamin D release across abdominal SAT}

Vitamin D 25(OH) $D_{3}$

Plasma arterialized $25(\mathrm{OH}) \mathrm{D}_{3}$ did not differ between lean and obese individuals at baseline (56.1(16.0-84.5) vs 49.6(33.5-63.4) nmol/L, respectively, $\mathrm{P}=0.852$ ). Additionally, no net $25(\mathrm{OH}) \mathrm{D}_{3}$ release across abdominal SAT was observed at baseline in both lean [0.02(-5.2-5.0) pmol*100g tissue ${ }^{-1 *} \mathrm{~min}^{-1}, \mathrm{P}=1.000$ vs. zero flux] and obese [0.70(-4.9-1.7) pmol $^{*} 100$ g tissue ${ }^{-1 *} \min ^{-1}, \mathrm{P}=0.917$ vs. zero flux].

Following ß-adrenergic stimulation plasma (arterialized) $25(\mathrm{OH}) \mathrm{D}_{3}$ level was not significantly increased in lean [baseline: $56.1(16.0-84.5)$ vs. isoprenaline 55.0(17.4-80.0), $\mathrm{P}=0.499$ ] (Fig.1A) or obese men [baseline: 49.6(33.5-63.4) vs. 49.3(34.6-64.6), $\mathrm{P}=0.917$ ] (Fig.1B). In line, ß-adrenergic stimulation did not significantly induce net $25(\mathrm{OH}) \mathrm{D}_{3}$ release across abdominal SAT in lean $\left[-1.9(-10.8-3.2) \mathrm{pmol}^{*} 100 \mathrm{~g}\right.$ tissue ${ }^{-1 *} \mathrm{~min}^{-1}, \mathrm{P}=0.208$ vs. zero flux] (Fig.1C) and obese [-3.4(-12.1-2.4) pmol*100g tissue ${ }^{-1 *} \min ^{-1}, \mathrm{P}=0.249$ vs. zero flux] (Fig.1D).
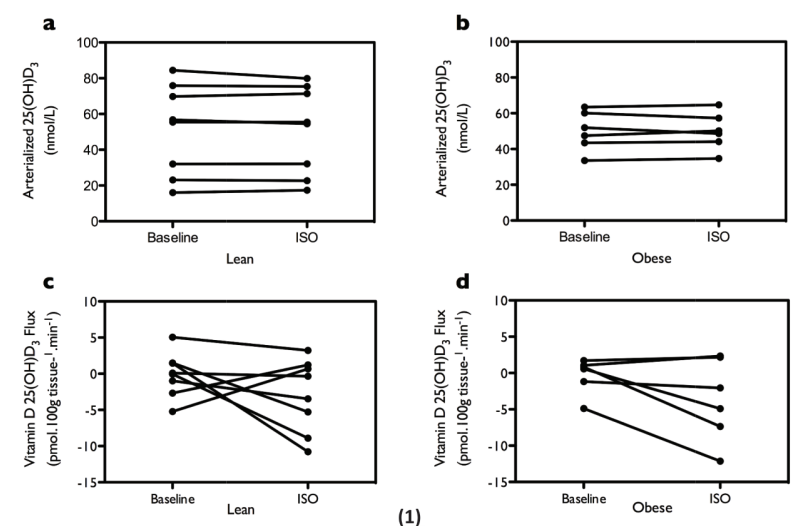

Figure 1. Panel $a$ and $b$ depict plasma (arterialized) Vitamin D 25(OH) D3 concentration at baseline and following ISO in lean $(n=8)$ and obese $(n=6)$. Net vitamin D 25(OH)D3 release (flux) across abdominal SAT in lean (Panel c) and obese (Panel d)

Vitamin $\mathrm{D} 1,25(\mathrm{OH})_{2} \mathrm{D}_{3}$

Plasma arterialized $1,25(\mathrm{OH})_{2} \mathrm{D}_{3}$ did not differ between lean and obese individuals at baseline (96.6(60.7-185.7) vs 108.2(80.5-147.7) pmol/L, respectively, $\mathrm{P}=0.755)$. Furthermore, no net $1,25(\mathrm{OH})_{2} \mathrm{D}_{3}$ release across SAT was observed under baseline conditions in lean [0.00(-0.01-0.03) pmol*100g tissue ${ }^{-1 *} \mathrm{~min}^{-1}, \mathrm{P}=0.889$ vs. zero flux] and obese men [0.00(-0.09-0.00) $\mathrm{pmol}^{*} 100 \mathrm{~g}$ tissue ${ }^{-1 *} \mathrm{~min}^{-1}, \mathrm{P}=0.345$ vs. zero flux]. Following B-adrenergic stimulation plasma (arterialized) $1,25(\mathrm{OH})_{2} \mathrm{D}_{3}$ was not significantly increased in lean [baseline: 96.6(60.7-185.7) vs. isoprenaline 97.0(51.9-165.2), $\mathrm{P}=0.889$ ] (Fig.2A) or obese men [baseline: 108.2(80.5-147.7) vs. 111.1(90.1-139.3), P=0.528] (Fig.2B). However, 
the ISO induced change in $1,25(\mathrm{OH})_{2} \mathrm{D}_{3}$ fluxes was significantly different between groups $(P=0.007)$. An increased net $1,25(\mathrm{OH})_{2} \mathrm{D}_{3}$ release across abdominal SAT was observed in lean [ISO: $-0.01(-0.04-0.00), P=0.017$ vs. zero flux] (Fig.2C), but not in obese men [ISO: $0.01(0.00-0.02), P=0.116$ vs. zero flux] (Fig.2D).
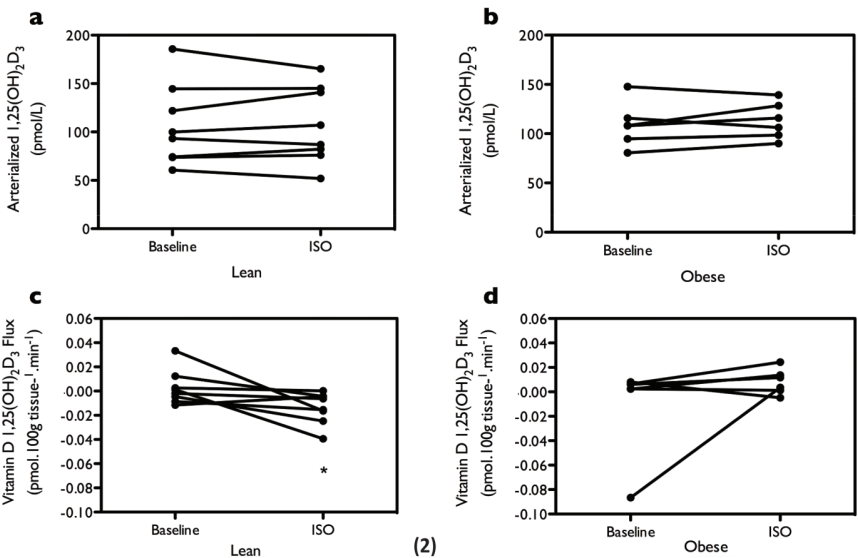

Figure 2. Plasma (arterialized) vitamin $\mathrm{D} 1,25(\mathrm{OH})_{2} \mathrm{D}_{3}$ concentration at baseline and following ISO in lean (Panel a) versus obese (Panel b). Net vitamin D 1,25(OH) $D_{3}$ release (flux) across abdominal SAT in lean (Panel c) and obese (Panel d).

$(*) p<.05$ versus zero flux.

\section{Relationship between AT lipolysis and vitamin D (arterialized) concentrations}
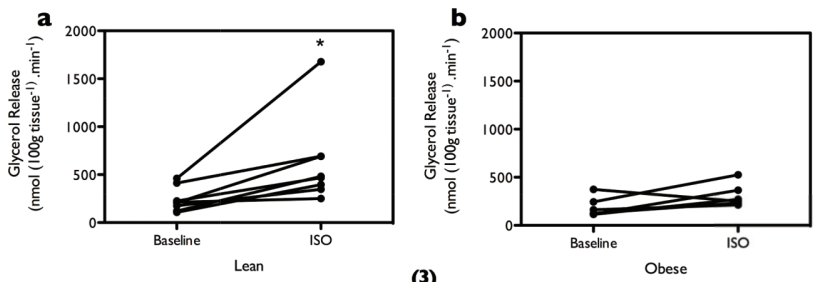

(3)

Figure 3. Total glycerol release across abdominal SAT at baseline and during ß-adrenergic stimulation in lean $(n=8)$ versus obese $(n=6)$. Total glycerol release following ß-adrenergic stimulation was significantly higher in lean (Panel a) versus obese (Panel b). $\left({ }^{*}\right) p<.05$

Next, we investigated whether the observed vitamin D release across SAT was associated with changes in local lipolytic responses and systemic vitamin D concentration. As reported previously, a blunted $B$-adrenergic mediated increase in total glycerol release across abdominal SAT was observed in obese [glycerol baseline vs. ISO obese: 143.9(114.4373.5) vs. $260.5(213.2-526.1) \mathrm{nmol} .100 \mathrm{~g}$ tissue ${ }^{-1} \cdot \mathrm{min}^{-1}$; ( $\mathrm{P}=0.11$, Fig.3B)] compared to lean men [glycerol baseline vs. ISO lean: 209.6(170.8-460.2) vs. 474.8(250.8-1678.2) nmol.100g tissue $\left.{ }^{-1} \cdot \min ^{-1}\right) ;(P=0.01$, Fig.3A)]. However, in present study, net vitamin $D$ $1,25(\mathrm{OH})_{2} \mathrm{D}_{3}$ release (flux) was not correlated with plasma (arterialized) glycerol levels during ß-adrenergic stimulation nor with circulating (arterialized) non-esterified fatty acid (NEFA) and $1,25(\mathrm{OH})_{2} \mathrm{D}_{3}$ levels. ( $\mathrm{P}>0.05$ for all, Supplemental Table S1). 


\section{Discussion}

Obesity is often associated with vitamin D deficiency, which has been suggested to relate to insulin resistance and an impaired metabolic health (4). Recent studies in humans have demonstrated that vitamin D (including its metabolites) accumulates and might be metabolised in adipose tissue (17-19). It has been shown that at least 35\% of circulating vitamin $D$ is likely sequestered in human subcutaneous adipose tissue (20). It was recently demonstrated that beside vitamin $\mathrm{D}$ uptake by adipose tissue there also can be significant release both in mice as well as human adipocytes (21). The latter findings suggest that beside an increased sequestration of vitamin D in AT, also an impaired release (22), may contribute to the accumulation of vitamin $D$ in adipose tissue and to the often observed reduced circulating vitamin $D$ concentrations in obesity.

In the present study, we investigated in vivo fluxes of $25(\mathrm{OH}) \mathrm{D}_{3}$ and $1,25(\mathrm{OH})_{2} \mathrm{D}_{3}$ across abdominal SAT for the first time after an overnight fast and during short-term ß-adrenergic stimulation in lean and obese men using the arterio-venous balance methodology. We observed that net vitamin $\mathrm{D} 1,25(\mathrm{OH})_{2} \mathrm{D}_{3}$ release across abdominal SAT during ß-adrenergic stimulation was significantly higher in lean as compared to obese men, suggesting a blunted vitamin $\mathrm{D} 1,25(\mathrm{OH})_{2} \mathrm{D}_{3}$ release across abdominal SAT in obese men in vivo. In contrast, no significant $25(\mathrm{OH}) \mathrm{D}_{3}$ release across SAT was observed in lean or obese men following an overnight fast or during ß-adrenergic stimulation. The latter findings may be in contrast with recent ex vivo data, which showed a more pronounced reduction in $25(\mathrm{OH}) \mathrm{D}_{3}$ content in SAT derived adipocytes in lean compared to obese donors following adrenaline stimulation, possibly pointing towards a blunted $25(\mathrm{OH}) \mathrm{D}_{3}$ release in obese SAT (22). Unfortunately, in that study only measured vitamin $\mathrm{D} 25(\mathrm{OH}) \mathrm{D}_{3}$ tissue content and not $25(\mathrm{OH}) \mathrm{D}_{3}$ or release in the medium. By using ex vivo cultures, the adipocytes are withdrawn from their natural local hormonal microenvironment, which may also partly explain the differences with the present in vivo findings.

The reason for the blunted SAT release of $1,25(\mathrm{OH})_{2} \mathrm{D}_{3}$ and not $25(\mathrm{OH}) \mathrm{D}_{3}$ in obese individuals remains to be determined. Factors like variation in ATBF theoretically resulting in a differential supply of vitamin D carriers to SAT or differences in circulating NEFA, interfering with the binding of vitamin $D$ to its carrier could possibly explain the difference in vitamin $D$ release. However, the ISO-induced increase in blood flow as well as circulating NEFA were not different between groups. Moreover, the above mechanisms would not explain why the differential release is only observed for $1,25(\mathrm{OH})_{2} \mathrm{D}_{3}$ and not for $25(\mathrm{OH}) \mathrm{D}_{3}$. Vitamin $\mathrm{D}$ $1,25(\mathrm{OH})_{2} \mathrm{D}_{3}$ is a ligand for vitamin $\mathrm{D}$ receptor (VDR), and it has been shown that vitamin $D$ receptor (VDR) expression is increased in SAT of individuals with obesity (23). From the latter, it could be speculated that vitamin $\mathrm{D} 1,25(\mathrm{OH})_{2} \mathrm{D}_{3}$ binds to a higher extent to VDR within SAT in individuals with obesity, resulting in less spillover of vitamin $D 1,25(\mathrm{OH})_{2} \mathrm{D}_{3}$ in the circulation in obese individuals but not in lean, which still needs further investigation.

Of interest, the observed blunted release of $1,25(\mathrm{OH})_{2} \mathrm{D}_{3}$ across abdominal SAT that we found in the present study was accompanied by (but not correlated with) a blunted glycerol release in SAT of obese men. The latter finding as well as the fact that the blunted lipolysis only coincides with a blunted release of $1,25(\mathrm{OH})_{2} \mathrm{D}_{3}$ and not $25(\mathrm{OH}) \mathrm{D}_{3}$ does not support the idea that it is in the obese individuals observed impaired TAG hydrolysis that drives a blunted release of vitamin $D$ metabolites. The exact relationship between the impaired ISO-induced lipolysis and $1,25(\mathrm{OH})_{2} \mathrm{D}_{3}$ release and to what extent they are co- 
regulated remains to be determined.

Furthermore, although net $1,25(\mathrm{OH})_{2} \mathrm{D}_{3}$ release was observed during acute ß-adrenergic stimulation, no changes in plasma vitamin $\mathrm{D} 1,25(\mathrm{OH})_{2} \mathrm{D}_{3}$ (arterialized) concentration were observed. It is likely that following this short-term (1 hour) ISO infusion, the contribution of $1,25(\mathrm{OH})_{2} \mathrm{D}_{3}$ release per unit adipose tissue may be relatively too small to induce significant changes in circulating vitamin $\mathrm{D}$ concentrations. We have estimated this based on several assumptions for the amount of total body water ( $72 \%$ of fat free mass and $10 \%$ of fat mass is water) and extra cellular water (38\% of total body water) (24) and we took into account the half-life of $1,25(\mathrm{OH})_{2} \mathrm{D}_{3}(25)$. Based on these assumptions, the estimated percentage contribution of total vitamin $\mathrm{D} 1,25(\mathrm{OH})_{2} \mathrm{D}_{3}$ release across adipose tissue to plasma concentrations during isoprenaline stimulation ranged between 0 and $4 \%$. This relatively small contribution might partly explain why no significant increase in plasma vitamin $\mathrm{D} 1,25(\mathrm{OH}) \mathrm{D}_{3}$ after $ß$-adrenergic stimulation was observed in the present study.

We have measured vitamin $\mathrm{D} 25(\mathrm{OH}) \mathrm{D}_{3}$ and $1,25(\mathrm{OH})_{2} \mathrm{D}_{3}$ metabolites based on their proposed importance in human metabolism and health (26). However, there are several other vitamin $\mathrm{D}$ metabolites such as 24,25-dihydroxyvitamin $\mathrm{D}\left[24,25(\mathrm{OH})_{2} \mathrm{D}_{3}\right]$ (27) and 3-epi-25(OH)D (28). The role of the latter vitamin D metabolite (29) in human is currently unknown and warrants investigation. A limitation of the study is that we were, unfortunately, unable to measure adipose tissue vitamin D content, which would be interesting to take into account in future studies. Whether long-term interventions that activate SAT lipolysis and vitamin D release (e.g. weight loss (30) and exercise (7)) might affect circulating vitamin D concentrations needs to be investigated in more detail. In conclusion, our unique in vivo data show that $ß$-adrenergic stimulation induces release of active vitamin $D$ metabolite across abdominal SAT. In the present study, a blunted catecholamine-mediated lipolysis was accompanied by a decreased $1,25(\mathrm{OH})_{2} \mathrm{D}_{3}$ (active metabolite) release across abdominal SAT in obese men. Future studies are warranted to elucidate to what extent this blunted vitamin D release may affect circulating vitamin D concentrations in obese humans.

\section{Acknowledgments}

The authors would like to thank the participants for their contribution to the study. We also thank the Laboratory of Endocrinology (VU Medical Center, Amsterdam) for the execution of the vitamin D metabolites analysis. The authors also would like to thank Yvonne Essers for technical support. A.P is supported by Indonesia Endowment Fund for Education Scholarship (LPDP). The funder had no role in the preparation, study design and analysis or the publication of the manuscript.

\section{Disclosure statement}

The authors declare that they have no conflict of interest.

\section{Author Contributions}

A.P. and J.W.E.J. designed the study and collected data. A.P. analyzed data. Data interpretation was performed by A.P., J.W.E.J., G.H.G., and E.E.B. The manuscript was written by A.P. and was revised by J.W.E.J., G.H.G., and E.E.B. All authors reviewed and approved the final manuscript. 


\section{References}

1. Stinkens R, Goossens GH, Jocken JW, et al. Targeting fatty acid metabolism to improve glucose metabolism. Obesity Reviews. 2015;16(9):715-57.

2. Vanlint S. Vitamin D and obesity. Nutrients. 2013;5(3):949-56.

3. Pourshahidi LK. Vitamin D and obesity: current perspectives and future directions. Proceedings of the Nutrition Society. 2015;74(2):115-24.

4. Pramono A, Jocken J, Blaak E. Vitamin D deficiency in the etiology of obesity related insulin resistance. Diabetes/metabolism research and reviews. 2019;35(5):e3146.

5. Wortsman J, Matsuoka LY, Chen TC, et al. Decreased bioavailability of vitamin D in obesity. Am J Clin Nutr. 2000;72(3):690-3.

6. Rosenstreich SJ, Rich C, Volwiler W. Deposition in and release of vitamin D3 from body fat: evidence for a storage site in the rat. J Clin Invest. 1971;50(3):679-87.

7. Hengist A, Perkin O, Gonzalez J, et al. Mobilising vitamin D from adipose tissue: The potential impact of exercise. Nutrition Bulletin. 2019.

8. Bouillon R, Xiang DZ, Convents R, et al. Polyunsaturated fatty acids decrease the apparent affinity of vitamin $D$ metabolites for human vitamin D-binding protein. The Journal of steroid biochemistry and molecular biology. 1992;42(8):855-61.

9. Jocken J, Goossens G, van Hees A, et al. Effect of beta-adrenergic stimulation on whole-body and abdominal subcutaneous adipose tissue lipolysis in lean and obese men. Diabetologia. 2008;51(2):320-7.

10. Colak A, Toprak B, Dogan N, et al. Effect of sample type, centrifugation and storage conditions on vitamin D concentration. Biochemia medica: Biochemia medica. 2013;23(3):321-5.

11. Müller MJ, Stokes CS, Lammert F, et al. Chemotyping the distribution of vitamin D metabolites in human serum. Scientific reports. 2016;6:21080-.

12. Ocké MC, Schrijver J, Obermann-De Boer GL, et al. Stability of blood (pro) vitamins during four years of storage at- $20 \mathrm{C}$ : consequences for epidemiologic research. Journal of clinical epidemiology. 1995; 48(8):1077-85.

13. Agborsangaya* C, Toriola* AT, Grankvist $\mathrm{K}$, et al. The effects of storage time and sampling season on the stability of serum 25 -hydroxy vitamin $\mathrm{D}$ and androstenedione. Nutrition and cancer. 2009;62(1):51-7.

14. El-Khoury JM, Wang S. Stability of 1, 25-dihydroxyvitamin D2 and 1,25-dihydroxyvitamin D3 in human serum. Clinical biochemistry. 2012;9(45):707-8.

15. Ter Horst KW, Versteeg RI, Gilijamse PW, et al. The vitamin D metabolites 25(OH)D and 1,25(OH)2D are not related to either glucose metabolism or insulin action in obese women. Diabetes Metab. 2016;42(6):416-23.

16. Goossens $\mathrm{G}$, Jocken J, Van Baak $M$, et al. Short-term $\beta$-adrenergic regulation of leptin, adiponectin and interleukin- 6 secretion in vivo in lean and obese subjects. Diabetes, Obesity and Metabolism. 2008;10(11):1029-38.

17. Didriksen A, Burild A, Jakobsen J, et al. Vitamin D3 increases in abdominal subcutaneous fat tissue after supplementation with vitamin D3. European Journal of Endocrinology. 2015;172(3):235-41.

18. Carrelli A, Bucovsky M, Horst R, et al. Vitamin D Storage in Adipose Tissue of Obese and Normal Weight Women. JBMR Plus. 2017;32(2):237-42.

19. Wamberg L, Christiansen T, Paulsen SK, et al. Expression of vitamin D-metabolizing enzymes in human adipose tissue - the effect of obesity and diet-induced weight loss. Int J Obes (Lond). 2013;37(5):651-7.

20. Heaney RP, Horst RL, Cullen DM, et al. Vitamin D3 Distribution and Status in the Body. J Am Coll Nutr. 2009;28(3):252-6.

21. Bonnet L, Karkeni E, Couturier C, et al. Gene Expression Pattern in Response to Cholecalciferol Supplementation Highlights Cubilin as a Major Protein of 25(OH)D Uptake in Adipocytes and 
Male Mice White Adipose Tissue. Endocrinology. 2018;159(2):957-66.

22. Di Nisio A, De Toni L, Sabovic I, et al. Impaired release of vitamin D in dysfunctional adipose tissue: new cues on vitamin D supplementation in obesity. J Clin Endocrinol Metab. 2017.

23. Jonas MI, Kuryłowicz A, Bartoszewicz Z, et al. Vitamin D Receptor Gene Expression in Adipose Tissue of Obese Individuals is Regulated by miRNA and Correlates with the Pro-Inflammatory Cytokine Level. International journal of molecular sciences. 2019;20(21):5272.

24. McArdle W. Exercise physiology : nutrition, energy, and human performance. Baltimore MD: Lippincott Williams Wilkins; 2010.

25. Lips P. Relative value of 25(OH)D and 1,25(OH)2D measurements. J Bone Miner Res. 2007;22(11):1668-71.

26. DeLuca HF. History of the discovery of vitamin D and its active metabolites. BoneKEy reports. 2014;3.

27. Bosworth CR, Levin G, Robinson-Cohen C, et al. The serum 24, 25-dihydroxyvitamin D concentration, a marker of vitamin $\mathrm{D}$ catabolism, is reduced in chronic kidney disease. Kidney international. 2012;82(6):693-700.

28. Lensmeyer $G$, Poquette $M$, Wiebe $D$, et al. The $C-3$ epimer of 25 -hydroxyvitamin $D 3$ is present in adult serum. The Journal of Clinical Endocrinology \& Metabolism. 2012;97(1):163-8.

29. Zheng J-S, Imamura F, Sharp SJ, et al. Association of plasma vitamin D metabolites with incident type 2 diabetes: EPIC-InterAct case-cohort study. The Journal of Clinical Endocrinology \& Metabolism. 2018;104(4):1293-303.

30. Gangloff A, Bergeron J, Pelletier-Beaumont E, et al. Effect of adipose tissue volume loss on circulating 25 -hydroxyvitamin $D$ levels: results from a 1-year lifestyle intervention in viscerally obese men. Int J Obes. 2015;39(11):1638-43. 
CHAPTER 3

Vitamin D release across abdominal adipose tissue in lean and obese men: the effect of $ß$-adrenergic stimulation

Supplemental Table S1. Spearman correlation coefficient between net vitamin D release and arterialized glycerol, arterialized NEFA levels, arterialized vitamin $\mathrm{D} 1,25(\mathrm{OH})_{2} \mathrm{D}_{3}$ during ISO concentrations.

\begin{tabular}{llll}
\hline & Arterialized Glycerol & Arterialized NEFA & $\begin{array}{l}\text { Arterialized } \\
\mathbf{1 , 2 5}(\mathbf{O H})_{2} \mathbf{D}_{\mathbf{3}}\end{array}$ \\
\hline $\begin{array}{l}1.25(\mathrm{OH})_{2} \mathrm{D}_{3} \text { flux during } \\
\text { ISO-stimulation }\end{array}$ & $0.402(\mathrm{P}=0.154)$ & $0.341(\mathrm{P}=0.233)$ & $0.240(\mathrm{P}=0.409)$ \\
\hline
\end{tabular}

Data are presented as correlation coefficient ( $\mathrm{P}$ value). 


\section{CHAPTER 4}

\section{Vitamin D and tissue-specific insulin sensitivity in humans with overweight/ obesity}

Adriyan Pramono, Johan W.E. Jocken, Yvonne P.G. Essers, Gijs H. Goossens, Ellen E. Blaak

\section{Published in:}

J Clin Endocrinol Metab (2019) 104(1):49-56

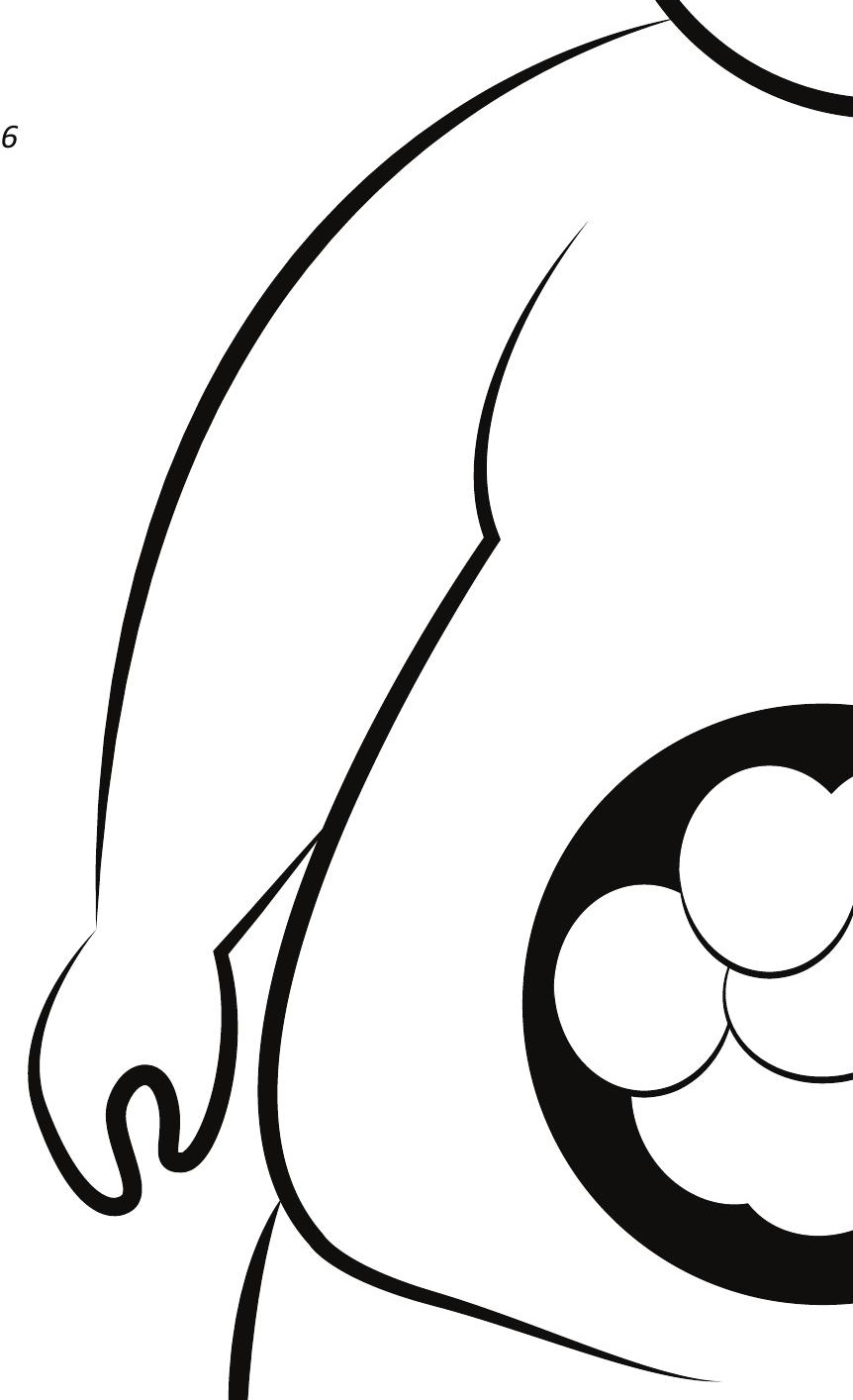




\begin{abstract}
Context: Vitamin D deficiency in obesity has been linked to insulin resistance. However, studies that examined the association between plasma 25 -hydroxyvitamin $\mathrm{D}_{3}\left[25(\mathrm{OH}) \mathrm{D}_{3}\right]$ as well as plasma 1,25 -dihydroxyvitamin $\mathrm{D}_{3}\left[1,25(\mathrm{OH})_{2} \mathrm{D}_{3}\right]$ and tissue-specific insulin sensitivity are scarce. Furthermore, vitamin D receptor (VDR) and vitamin D-metabolizing enzymes (CYPs) expression in adipose tissue (AT) might affect AT insulin sensitivity.
\end{abstract}

Objective: To investigate the association between $\mathrm{BMI}$ and plasma $25(\mathrm{OH}) \mathrm{D}_{3}$, plasma $1,25(\mathrm{OH})_{2} \mathrm{D}_{3}$, and AT VDR; between plasma $25(\mathrm{OH}) \mathrm{D}_{3}, 1,25(\mathrm{OH})_{2} \mathrm{D}_{3^{\prime}}$, and AT VDR and tissuespecific insulin sensitivity in overweight/obese individuals.

Design and Patients: This analysis included 92 adult individuals (BMI: $>25 \mathrm{~kg} / \mathrm{m}^{2}$ ). A twostep hyperinsulinemic-euglycemic clamp with a $\left[6,6-{ }^{2} \mathrm{H}_{2}\right]$-glucose tracer was performed to assess tissue-specific insulin sensitivity. Abdominal subcutaneous AT (SAT) mRNA expression of VDR and CYP was determined using QRT-PCR.

Setting: University Medical Centre.

Main Outcome Measures: Plasma $25(\mathrm{OH}) \mathrm{D}_{3}, 1,25(\mathrm{OH})_{2} \mathrm{D}_{3}, 1,25(\mathrm{OH})_{2} \mathrm{D}_{3} / 25(\mathrm{OH}) \mathrm{D}_{3}$ ratio, SAT AT VDR and CYPs mRNA, and tissue-specific insulin sensitivity.

Results: $\mathrm{BMI}$ was inversely associated with plasma $25(\mathrm{OH}) \mathrm{D}_{3}(\beta=-0.274, \mathrm{P}=0.011)$ but not with plasma $1,25(\mathrm{OH})_{2} \mathrm{D}_{3}$. Plasma $25(\mathrm{OH}) \mathrm{D}_{3}$ was not related to CYPs or VDR expression in SAT. Plasma $1,25(\mathrm{OH})_{2} \mathrm{D}_{3}$ and $25(\mathrm{OH}) \mathrm{D}_{3}$ were not related with tissue-specific insulin sensitivity. Interestingly, SAT VDR mRNA was negatively associated with AT insulin sensitivity ( $ß=-0.207$, $\mathrm{P}=0.025)$,

Conclusions: $\mathrm{BMI}$ was inversely associated with $25(\mathrm{OH}) \mathrm{D}_{3}$ concentrations, which could not be explained by alterations in SAT VDR and CYP enzymes. Plasma vitamin D metabolites were not related to tissue-specific insulin sensitivity. However, VDR expression in SAT was negatively associated with AT insulin sensitivity. 


\section{Introduction}

Obesity has reached epidemic proportions in both developed and developing countries (1). Body fat accumulation and in particular an impaired adipose tissue (AT) function, which is commonly observed in obesity, has been linked to the development of metabolic syndrome, insulin resistance, type 2 diabetes and cardiovascular diseases $(2,3)$. Of interest, obesity is often characterized by low plasma 25 -hydroxyvitamin $\mathrm{D}_{3}\left[25(\mathrm{OH}) \mathrm{D}_{3}\right]$ levels $(<50 \mathrm{nmol} / \mathrm{L}$ ). This plasma vitamin $D$ deficiency in obese individuals has been suggested to contribute to obesity-related metabolic disorders such as insulin resistance and type 2 diabetes $(4,5)$. However, evidence from human observational data is not consistent. Recent studies have shown a negative association between plasma or serum vitamin $D 25(\mathrm{OH}) \mathrm{D}_{3}$ levels and whole-body insulin resistance, as estimated from the Homeostatic Model for Insulin Resistance (HOMA-IR), which was independent of body mass index (BMI) in both men and women $(6,7)$. In contrast, other studies have shown no association between serum $25(\mathrm{OH}) \mathrm{D}_{3}$ and insulin resistance (HOMA-IR) in obese humans $(8,9)$. It has been hypothesized that mainly adiposity itself may determine the observed relationship between plasma vitamin $D$ deficiency and insulin resistance, due to sequestration of vitamin $D$ in the enlarged AT mass (10). Furthermore, it has been proposed that the difference in vitamin $D$ concentrations between lean and obese individuals may be explained by volumetric dilution in obesity, with body weight explaining $13 \%$ of the variance in vitamin D concentrations (11). Finally, it has been postulated that an altered vitamin D metabolism in AT may contribute to vitamin $D$ deficiency and insulin resistance (12).

Indeed, AT is actively involved in vitamin D metabolism, which is underlined by the expression of vitamin D-metabolizing enzymes (CYP) and the vitamin D receptor (VDR) in AT (13). The vitamin D receptor (VDR) belongs to the nuclear receptor family and mediates effects of vitamin $D$ at the gene transcription level (14). In murine adipocytes, the active vitamin $\mathrm{D}$ metabolite $\left(1,25(\mathrm{OH})_{2} \mathrm{D}_{3}\right)$ may increase sirtuin 1 (SIRT1) and the NAD $/ \mathrm{NADH}$, thereby affecting cellular energy metabolism (15). Furthermore, it has previously been reported that VDR expression is comparable in visceral AT (VAT) and subcutaneous AT (SAT) of obese individuals (16), although the expression of vitamin D-metabolizing enzymes (CYP) was decreased in SAT of obese individuals (16). Currently, it is not clear whether VDR expression is altered in the obese insulin resistant state and whether alterations in AT expression of VDR or vitamin D metabolizing enzymes relate to vitamin D deficiency and/or AT insulin resistance. Recent meta-analyses have shown that vitamin D supplementation had no significant effects on whole-body insulin resistance and insulin secretion in overweight/ obese individuals $(17,18)$. Taken together, the contribution of vitamin $D$ deficiency to whole-body and tissue-specific insulin resistance remains to be established, and it is unclear whether a possible association is independent of body mass index (BMI) and/or body fat percentage $(19,20)$. Moreover, most studies that examined the association between vitamin $D$ and insulin sensitivity did not use the gold-standard hyperinsulinemic euglycemic clamp to determine insulin sensitivity (21). Additionally, most of the studies on the relationship between vitamin $D$ and insulin sensitivity have measured the inactive metabolite of vitamin D, $25(\mathrm{OH}) \mathrm{D}_{3}(7,9,22)$, instead of its active metabolite, $1,25(\mathrm{OH})_{2} \mathrm{D}_{3}$ or the active/inactive metabolite ratio. Finally, data on AT vitamin D metabolism in the obese insulin resistant state is scarce.

Therefore, in the present study, we investigated vitamin D metabolites (both inactive 
and active forms) as well as AT expression of genes involved in vitamin D metabolism in overweight/obese men and women who underwent a 2-step hyperinsulinemic euglycemic clamp with a $\left[6,6-{ }^{2} \mathrm{H}_{2}\right]$-glucose tracer to investigate adipose tissue, liver and skeletal muscle insulin sensitivity. Firstly, we investigated whether obesity (BMI) is related to plasma active, inactive vitamin $D$ concentrations or the ratio between both. Subsequently, we investigated whether putative alterations in plasma vitamin $D$ metabolites in obesity may be mediated by an altered expression of AT VDR or vitamin D-metabolizing enzymes. Secondly, we investigated whether plasma vitamin $D$ and AT expression of VDR relates to tissue-specific insulin sensitivity and, if so, whether these relationships are independent of BMI, age and sex. Finally, we investigated whether an altered AT vitamin metabolism may relate to AT insulin sensitivity.

\section{Subjects and Methods}

\section{Subjects}

The study participants were men and women with Caucasian ethnicity, recruited at the Maastricht University Medical Center ${ }^{+}$, Maastricht, The Netherlands. Inclusion and exclusion criteria of these participants are described elsewhere in more detail $(23,24)$. The subjects gave written informed consent for their participation, and the study was reviewed and approved by the local Medical Ethical Committee of Maastricht University Medical Center ${ }^{+}$.

\section{Two-step hyperinsulinemic-euglycemic Clamp}

A two-step hyperinsulinemic-euglycemic clamp combined with a $\left[6,6-{ }^{2} \mathrm{H}_{2}\right]$-glucose tracer (Cambridge Isotope Laboratories) was performed to analyze the insulin-mediated suppression of Free Fatty Acids (FFAs; representing AT insulin sensitivity) (25), insulinstimulated rate of disappearance (Rd) of glucose (peripheral/muscle insulin sensitivity), and insulin-mediated suppression of Endogenous Glucose Production (EGP) (hepatic insulin sensitivity) (26). A bolus injection of $2.4 \mathrm{mg}\left[6,6-{ }^{2} \mathrm{H}_{2}\right]$-glucose $/ \mathrm{kg}$ was administered, continued with $\left[6,6-{ }^{2} \mathrm{H}_{2}\right]$-glucose infusion at $0.04 \mathrm{mg} /(\mathrm{kg} \times \mathrm{min})$. After $2 \mathrm{hr}$, low-dose insulin was infused at $10 \mathrm{mU} / \mathrm{m}^{2} / \mathrm{min}$ for $2 \mathrm{hr}(27)$, followed by high-dose insulin at $40 \mathrm{mU} / \mathrm{m}^{2} / \mathrm{min}$ for $2 \mathrm{hr}$ (28). By variable co-infusion of a $17.5 \%$ glucose solution, enriched by $1.1 \%$ tracer, plasma glucose concentrations were maintained at $5.0 \mathrm{mmol} / \mathrm{l}$. For calculation of steadystate kinetics, additional blood samples were taken in the last $30 \mathrm{~min}$ of each step $(0,10$, and $40 \mathrm{mU} / \mathrm{m} 2 / \mathrm{min}$ insulin) (23). The Rd was calculated during the 0 and $40 \mathrm{mU} / \mathrm{m}^{2} / \mathrm{min}$ insulin infusion, whereas calculations for insulin-mediated suppression of EGP and free fatty acids was performed during 0 and $10 \mathrm{mU} / \mathrm{m}^{2} / \mathrm{min}$ insulin infusion, as relative percentage (\%) of suppression during 10 compared with $0 \mathrm{mU} / \mathrm{m}^{2} / \mathrm{min}$ (24). Blood samples were taken from a superficial dorsal hand vein, which was arterialized by using a hot-box $\left(\sim 50^{\circ} \mathrm{C}\right)$.

\section{Adipose Tissue Biopsy and Analysis}

An abdominal subcutaneous AT biopsy was taken under local anesthesia following an overnight fast, as described before (23). The AT sample was washed in sterile saline, 
immediately frozen in liquid nitrogen, and maintained at $-80^{\circ} \mathrm{C}$ until further analysis. For RNA isolation, the tissue was placed in Trizol (Qiagen) and then mixed by means of an ultra turrax homogenizer. Total RNA was extracted using phenol-chloroform extraction method and described in more detail elsewhere (16).

\section{Adipose tissue gene expression}

For real-time quantitative PCR, CDNA was generated using an iScript CDNA synthesis kit, according to the instructions of the manufacturer (Bio-Rad Laboratories). PCR-master $\mathrm{mix}$, containing the specific primers, was added and real-time quantification of genes was performed by SYBR-green real-time reverse transcription PCR assay (Bio-Rad iQ SYBR green mix) using a MylQ Real time PCR cycler (Bio-Rad). The primer pairs that were used are described in Supplemental Table S1. 18S was used as a housekeeping gene and data were calculated using delta CT method (16).

\section{Biochemical analysis}

Blood was collected into pre-chilled tubes and centrifuged at $1,000 \mathrm{~g}$, and plasma was snap-frozen and stored at $\sim 80^{\circ} \mathrm{C}$ until analyses. Tracer enrichment of rate of disappearance (Rd) and endogenous glucose production (EGP) were determined using gas chromatography-mass spectrometry (26). Plasma glucose and FFA were determined using commercial available colorimetric assays on a Cobas Fara auto-analyzer (Roche, Switzerland). Plasma insulin was measured with a double-antibody radioimmunoassay (Millipore). Plasma concentrations of vitamin $\mathrm{D} 25(\mathrm{OH}) \mathrm{D}_{3}$ and $1,25(\mathrm{OH})_{2} \mathrm{D}_{3}$ were determined using liquid-chromatography tandem-mass spectrophotometry (LC-MS/MS), as described before (29).

\section{Statistical Analysis}

All continuous variables were checked for normal distribution. Variables with a skewed distribution were square root transformed (plasma vitamin $D$ concentration and SAT VDR mRNA) or natural logarithmic (In) transformed (SAT vitamin D enzymes, CYP2J2, CYP27A1, CYP27B1, and CYP24A1) to satisfy condition of normality.

First, simple regression analysis was performed with plasma vitamin D metabolites or VDR and vitamin D-metabolizing enzymes as dependent variables, and BMI as independent variable. Subsequently, multiple regression analysis was performed with age and sex added as independent variables.

Secondly, simple regression analysis was performed with hepatic, peripheral, or AT insulin sensitivity as dependent variables, and plasma $25(\mathrm{OH}) \mathrm{D}_{3}, 1,25(\mathrm{OH})_{2} \mathrm{D}_{3}$ or $1,25(\mathrm{OH})_{2} \mathrm{D}_{3} / 25(\mathrm{OH}) \mathrm{D}_{3}$ ratio as independent variables (Model 1 ). Next, $\mathrm{BMI}$, age, and sex were added to the model as independent variables (Model 2). Finally, simple regression analysis was performed to relate SAT VDR gene expression and AT insulin sensitivity. Subsequently, multiple regression analysis was conducted to test whether SAT VDR gene expression might relate to AT insulin sensitivity, independent of age, BMI and sex. Interaction between covariates in the multiple regression analyses was also tested, and no interaction was found. All data were analyzed using SPSS for Mac version 22.0 (SPSS, Chicago, IL, USA) 
and statistical significance was set at $p<0.05$.

\section{Results}

\section{Characteristics of study participants}

Anthropometric and metabolic characteristics for all participants are presented in Table 1. The majority of study participants were men (78.3\%), with age ranged between 19 and 69 years, and BMI ranged between 25.4 and $38.6 \mathrm{~kg} / \mathrm{m}^{2}$. The mean plasma $25(\mathrm{OH})$ $\mathrm{D}_{3}$ (inactive metabolite) concentration was $56.0 \mathrm{nmol} / \mathrm{L}$ (range: 12.6 - $122.6 \mathrm{nmol} / \mathrm{L}$ ), with $45.7 \%$ of all participants $(n=42)$ classified as vitamin $D$ deficient, based on the Endocrine Society cut off (<50 nmol/L) (30).

Table 1. Characteristics of the Study Participants $(n=92)$

\begin{tabular}{lcc}
\hline Variable & Mean \pm SD & Range \\
\hline Age (years) & $50.3 \pm 13.6$ & $19-69$ \\
Sex (Males/Females) & $72 \mathrm{M} / 20 \mathrm{~F}$ & \\
$\mathrm{BMI}\left(\mathrm{kg} / \mathrm{m}^{2}\right.$ ) & $30.6 \pm 2.9$ & $25.4-38.6$ \\
Waist circumference (cm) & $103 \pm 12$ & $77-126$ \\
W/H ratio & $0.9 \pm 0.1$ & $0.7-1.2$ \\
Fasting insulin (mU/l) & $13.9 \pm 6.8$ & $2.8-30.3$ \\
Fasting glucose (mmol/I) & $5.6 \pm 0.6$ & $4.4-7.5$ \\
2h-glucose (mmol/I) & $6.5 \pm 1.8$ & $3.4-11.2$ \\
HOMA-IR & $3.6 \pm 1.9$ & $0.7-8.8$ \\
Insulin-mediated suppression of EGP (\%) & $50.6 \pm 18.9$ & $5.2-97.9$ \\
Insulin-mediated suppression of FFA (\%) & $52.9 \pm 20.3$ & $6.1-90.6$ \\
Insulin-stimulated Rd ( $\mu$ mol kg ${ }^{-1}$ min -1$)$ & $27.0 \pm 10.8$ & $9.8-53.9$ \\
25(OH) $\mathrm{D}_{3}$ (nmol/L, inactive metabolite) & $56.0 \pm 21.6$ & $12.6-122.6$ \\
$1,25(\mathrm{OH})_{2} \mathrm{D}_{3}$ (pmol/L, active metabolite) & $106.3 \pm 26.4$ & $54.9-205.0$ \\
The active/inactive metabolite ratio & $2.2+0.9$ & $1.0-6.5$ \\
\hline
\end{tabular}

Unless otherwise noted, values are the mean 6 SD. All participants were Caucasian. Abbreviations: EGP, endogenous glucose production; FFA, free fatty acid; HOMA-IR, homeostasis model assessment insulin resistance; Rd, rate of glucose disappearance.

\section{Association between BMI and plasma vitamin D concentration}

Table 2. Determinants of plasma $25(\mathrm{OH}) \mathrm{D}_{3}, 1,25(\mathrm{OH})_{2} \mathrm{D}_{3}$ and the $1,25(\mathrm{OH})_{2} \mathrm{D}_{3} / 25(\mathrm{OH}) \mathrm{D}_{3}$ ratio

\begin{tabular}{|c|c|c|c|c|c|c|c|c|c|c|c|c|}
\hline \multirow[t]{2}{*}{$\begin{array}{l}\text { Dependent } \\
\text { Variables }\end{array}$} & \multicolumn{3}{|c|}{$\begin{array}{c}\text { Plasma 25(OH)D } \\
\text { (inactive metabolite) }\end{array}$} & \multirow[b]{2}{*}{ Adj. $R^{2}$} & \multicolumn{3}{|c|}{$\begin{array}{c}\text { Plasma } 1,25(\mathrm{OH})_{2} \mathrm{D}_{3} \\
\text { (active metabolite) }\end{array}$} & \multirow[b]{2}{*}{ Adj. $R^{2}$} & \multicolumn{3}{|c|}{$1,25(\mathrm{OH})_{2} \mathrm{D}_{3} / 25(\mathrm{OH}) \mathrm{D}_{3}$} & \multirow[b]{2}{*}{ Adj. $R^{2}$} \\
\hline & B & $95 \% \mathrm{Cl}$ & $P$ value & & B & $95 \% \mathrm{Cl}$ & $P$ value & & B & $95 \% \mathrm{Cl}$ & $P$ value & \\
\hline \multicolumn{13}{|l|}{ Model 1} \\
\hline BMI & -0.234 & $-0.44(-0.02)$ & 0.031 & 0.043 & -0.095 & $-0.31(0.12)$ & 0.386 & -0.003 & 0.140 & $-0.08(0.36)$ & 0.201 & 0.008 \\
\hline \multicolumn{13}{|l|}{ Model 2} \\
\hline BMI & -0.274 & $-0.48(-0.06)$ & 0.011 & 0.104 & -0.088 & $-0.31(0.13)$ & 0.434 & -0.023 & 0.056 & $-0.01(0.12)$ & 0.099 & 0.067 \\
\hline Age & 0.321 & $0.07(0.57)$ & 0.012 & & 0.046 & $-0.22(0.31)$ & 0.734 & & -0.101 & $-0.18(-0.02)$ & 0.014 & \\
\hline \multicolumn{13}{|l|}{ Sex: } \\
\hline Men & 0 & 0 & & & 0 & 0 & & & 0 & 0 & & \\
\hline Women & 0.172 & $-0.43(0.77)$ & 0.570 & & 0.185 & $-0.45(0.83)$ & 0.576 & & -0.060 & $-0.25(0.13)$ & 0.536 & \\
\hline
\end{tabular}

BMI was negatively associated with plasma $25(\mathrm{OH}) \mathrm{D}_{3}$ (std $\beta=-0.234,95 \% \mathrm{Cl}$ $-0.44(-0.02), \mathrm{P}=0.031)$, but did not relate with plasma $1,25(\mathrm{OH})_{2} \mathrm{D}_{3}$ and the ratio. Multiple regression analysis showed that the relationship between $\mathrm{BMI}$ and plasma $25(\mathrm{OH}) \mathrm{D}_{3}$ 
remained significant after adjustment for age and sex (std $\beta=-0.274, P=0.011)$ (Table 2).

\section{Association between BMI and vitamin D-related gene expression in SAT}

BMI was positively associated with SAT VDR gene expression (std $\beta=0.223,95 \% \mathrm{Cl}$ 0.00 (0.44), $P=0.047$, Table 3 ). It is well established that VDR expression is regulated by $1,25(\mathrm{OH})_{2} \mathrm{D}_{3}$ (31). However, the strength of the association between BMI and AT VDR gene expression did not change (std $\beta=0.213,95 \% \mathrm{Cl}-0.11(0.44), \mathrm{P}=0.062$ ) after adjustment for plasma $1,25(\mathrm{OH})_{2} \mathrm{D}_{3}$ (active metabolite), age and sex. No significant associations were found between BMI and SAT expression of vitamin D metabolizing enzymes (CYP2J2, CYP27A1, CYP27B1, CYP24A1) (Supplemental Table S2).

Table 3. Determinants of vitamin D receptor expression in abdominal SAT

\begin{tabular}{|c|c|c|c|c|}
\hline & \multicolumn{3}{|c|}{ SAT VDR gene expression } & \multirow[b]{2}{*}{ Adj. $R^{2}$} \\
\hline & $\beta$ & $95 \% \mathrm{Cl}$ & $P$ value & \\
\hline $\begin{array}{l}\text { Model } 1 \\
\text { BMI }\end{array}$ & 0.223 & $0.00(0.44)$ & 0.047 & 0.036 \\
\hline \multicolumn{5}{|l|}{ Model 2} \\
\hline BMI & 0.213 & $-0.11(0.44)$ & 0.062 & 0.138 \\
\hline Plasma $1,25(\mathrm{OH})_{2} \mathrm{D}_{3}$ & 0.019 & $-0.19(0.23)$ & 0.855 & \\
\hline Age & 0.251 & $-0.01(0.51)$ & 0.057 & \\
\hline \multicolumn{5}{|l|}{ Sex : } \\
\hline Men & 0 & 0 & & \\
\hline Women & -0.327 & $-0.99(0.34)$ & 0.332 & \\
\hline
\end{tabular}

Plasma vitamin D 25(OH)D and SAT expression of VDR and vitamin D enzymes

Table 4. Relationship between plasma vitamin D deficiency and SAT expression of VDR and Vitamin D-Metabolizing enzymes

\begin{tabular}{|c|c|c|c|c|}
\hline & \multicolumn{4}{|c|}{$\begin{array}{c}\text { Plasma 25(OH)D } \\
\text { (inactive metabolite) }\end{array}$} \\
\hline & $\beta$ & $95 \% \mathrm{Cl}$ & P Value & Adj. $\mathrm{R}^{2}$ \\
\hline Model 1 & & & & \\
\hline BMI & -0.234 & $-0.44(-0.02)$ & 0.031 & 0.043 \\
\hline Model 2 & -0.234 & $-0.48(0.09)$ & 0059 & 0.028 \\
\hline SAT VDR mRNA & 0.142 & $-0.09(0.38)$ & 0.232 & \\
\hline $\begin{array}{l}\text { Model } 3 \\
\text { BMI }\end{array}$ & -0.252 & $-0.54(0.03)$ & 0.083 & 0.018 \\
\hline $\begin{array}{l}\text { CYP2J2 mRNA } \\
\text { Model } 4\end{array}$ & 0.022 & $-0.23(0.28)$ & 0.861 & \\
\hline BMI & -0.254 & $-0.52(0.01)$ & 0.061 & 0.029 \\
\hline CYP27A1 mRNA & 0.105 & $-0.13(0.34)$ & 0.373 & \\
\hline BMI & -0.189 & $-0.48(0.10)$ & 0.203 & 0.009 \\
\hline CYP27B1 mRNA & 0.139 & $-0.12(0.39)$ & 0.282 & \\
\hline BMI & -0.248 & $-0.54(0.04)$ & 0.092 & 0.021 \\
\hline CYP24A1 mRNA & 0.079 & $-0.18(0.33)$ & 0.539 & \\
\hline
\end{tabular}

Next, we investigated the relationship between plasma $25(\mathrm{OH}) \mathrm{D}_{3}$ levels and the expression of VDR and enzymes related to vitamin D metabolism in SAT. Abdominal SAT expression of VDR and vitamin D-metabolizing enzymes was not associated with plasma $25(\mathrm{OH}) \mathrm{D}_{3}$ level (Supplemental Table S3). Additionally, we investigated whether the negative relationship between $\mathrm{BMI}$ and plasma $25(\mathrm{OH}) \mathrm{D}_{3}$ may be mediated by alteration in AT expression of VDR or vitamin D-metabolizing enzymes. As indicated in Table 4, 
further adjustment for SAT VDR expression or SAT vitamin D metabolizing enzymes did not significantly alter the relationship between $\mathrm{BMI}$ and plasma $25(\mathrm{OH}) \mathrm{D}_{3}$.

\section{Plasma vitamin D metabolite levels and tissue-specific insulin sensitivity}

Neither plasma $25(\mathrm{OH}) \mathrm{D}_{3}$ (inactive metabolite) nor plasma $1,25(\mathrm{OH})_{2} \mathrm{D}_{3}$ (active metabolite) or the active/inactive metabolite ratio were associated with hepatic, peripheral or AT insulin sensitivity, as shown in Table $\mathbf{5}$.

Table 5. Relationship between plasma vitamin D metabolites and hepatic, peripheral, adipose tissue insulin sensitivity

\begin{tabular}{|c|c|c|c|c|c|c|c|c|c|c|c|c|}
\hline \multirow[t]{2}{*}{ Dependent variables: } & \multicolumn{4}{|c|}{ Hepatic IS } & \multicolumn{4}{|c|}{ Peripheral IS } & \multicolumn{4}{|c|}{ Adipose Tissue IS } \\
\hline & B & $95 \% \mathrm{Cl}$ & $\mathbf{P}$ & Adj. $R^{2}$ & B & $95 \% \mathrm{Cl}$ & $\mathbf{P}$ & Adj. $R^{2}$ & B & $95 \% \mathrm{Cl}$ & $\mathbf{P}$ & Adj. $R^{2}$ \\
\hline \multicolumn{13}{|l|}{ Model 1} \\
\hline Plasma $25(\mathrm{OH}) \mathrm{D}_{3}$ & 0.073 & $-0.15(0.29)$ & 0.512 & -0.007 & 0.138 & $-0.08(0.36)$ & 0.219 & 0.007 & -0.027 & $-0.26(0.20)$ & 0.816 & -0.012 \\
\hline Plasma $1,25(\mathrm{OH})_{2} \mathrm{D}_{3}$ & 0.059 & $-0.17(0.29)$ & 0.614 & -0.009 & 0.041 & $-0.19(0.27)$ & 0.727 & -0.011 & 0.135 & $-0.10(0.37)$ & 0.264 & 0.003 \\
\hline Ratio plasma Vitamin $\mathrm{D}$ & -0.214 & $-0.92(0.50)$ & 0.551 & -0.008 & -0.373 & $-1.09(0.34)$ & 0.304 & 0.001 & 0.393 & $-0.35(1.13)$ & 0.293 & 0.002 \\
\hline \multicolumn{13}{|l|}{ Model 2} \\
\hline Plasma $25(\mathrm{OH}) \mathrm{D}_{3}$ & 0.106 & $-0.11(0.32)$ & 0.322 & 0.195 & 0.091 & $-0.11(0.29)$ & 0.362 & 0.318 & -0.015 & $-0.21(0.18)$ & 0.876 & 0.385 \\
\hline BMI & -0.126 & $-0.34(0.08)$ & 0.236 & & -0.429 & $-0.62(-0.23)$ & $<0.001$ & & -0.224 & $-0.41(-0.03)$ & 0.022 & \\
\hline Age & -0.101 & $-0.36(0.15)$ & 0.433 & & -0.064 & $-0.30(0.17)$ & 0.596 & & -0.030 & $-0.26(0.20)$ & 0.799 & \\
\hline \multicolumn{13}{|l|}{ Sex } \\
\hline Men & 0 & 0 & & & 0 & 0 & & & 0 & 0 & & \\
\hline Women & 0.847 & $0.26(1.43)$ & 0.005 & & 0.639 & $0.09(1.18)$ & 0.022 & & 1.319 & $0.78(1.85)$ & $<0.001$ & \\
\hline \multicolumn{13}{|l|}{ Model 3} \\
\hline Plasma $1,25(\mathrm{OH})_{2} \mathrm{D}_{3}$ & 0.001 & $-0.21(0.21)$ & 0.992 & 0.184 & -0.050 & $-0.25(0.15)$ & 0.613 & 0.312 & 0.051 & $-0.14(0.24)$ & 0.593 & 0.387 \\
\hline BMI & -0.152 & $-0.36(0.05)$ & 0.145 & & -0.457 & $-0.65(0.27)$ & $<0.001$ & & -0.214 & $-0.40(-0.03)$ & 0.025 & \\
\hline Age & -0.065 & $-0.31(0.18)$ & 0.604 & & -0.029 & $-0.26(0.20)$ & 0.805 & & -0.039 & $-0.26(0.18)$ & 0.730 & \\
\hline \multicolumn{13}{|c|}{$-0.20(0.10)$} \\
\hline Men & 0 & 0 & & & 0 & 0 & & & 0 & 0 & & \\
\hline Women & 0.866 & $0.28(1.46)$ & 0.005 & & 0.669 & $0.12(1.22)$ & 0.018 & & 1.302 & $0.77(1.84)$ & $<0.001$ & \\
\hline \multicolumn{13}{|l|}{ Model 4} \\
\hline Ratio plasma Vitamin D & -0.390 & $-1.06(0.28)$ & 0.249 & 0.198 & -0.397 & $-1.02(0.22)$ & 0.207 & 0.325 & 0.263 & $-0.34(0.87)$ & 0.392 & 0.391 \\
\hline BMI & -0.136 & $-0.34(0.07)$ & 0.190 & & -0.435 & $-0.62(-0.24)$ & $<0.001$ & & -0.231 & $-0.42(-0.05)$ & 0.015 & \\
\hline Age & -0.105 & $-0.36(0.15)$ & 0.411 & & -0.074 & $-0.31(0.16)$ & 0.535 & & -0.008 & $-0.24(0.22)$ & 0.949 & \\
\hline \multicolumn{13}{|l|}{ Sex } \\
\hline Men & 0 & 0 & & & 0 & 0 & & & 0 & 0 & & \\
\hline Women & 0.845 & $0.26(1.43)$ & 0.005 & & 0.633 & $0.09(1.18)$ & 0.023 & & 1.331 & $0.80(1.86)$ & $<0.001$ & \\
\hline
\end{tabular}

Models 2 to 4 include BMI, age, and sex; model 2 includes plasma $25(\mathrm{OH}) \mathrm{D}_{3}$; model 3 includes plasma 1,25( $\left.\mathrm{OH}\right)_{2} \mathrm{D}_{3}$; Model 4 includes ratio vitamin $D$ instead of plasma $25(\mathrm{OH}) \mathrm{D}_{3}$ and $1,25(\mathrm{OH})_{2} \mathrm{D}_{3}$ in addition to independent variables $\mathrm{BMI}$, age, and sex. Abbreviation: IS, insulin sensitivity.

\section{Subcutaneous AT VDR, vitamin D-metabolizing enzyme expression and adipose tissue insulin sensitivity}

Table 6. Relationship between SAT VDR expression and adipose tissue insulin sensitivity

\begin{tabular}{lcccc}
\hline & \multicolumn{4}{c}{ Adipose Tissue Insulin Sensitivity } \\
\cline { 2 - 5 } & B & $\mathbf{9 5 \% ~ C l}$ & $\begin{array}{c}\mathbf{P} \\
\text { Value }\end{array}$ & Adj. $^{\mathbf{2}}$ \\
\hline Model 1 & & & \\
SAT VDR mRNA & -0.366 & $-0.56(-0.17)$ & $<0.001$ & 0.140 \\
Model 2 & & & & \\
SAT VDR mRNA & -0.207 & $-0.39(-0.03)$ & 0.025 & $0.369^{b}$ \\
BMI & -0.169 & $-0.34(0.05)$ & 0.057 & \\
Age & 0.036 & $-0.17(0.25)$ & 0.729 & \\
Sex: & 0 & 0 & & \\
$\quad$ Men & 1.176 & $0.64(1.71)$ & $<0.001$ & \\
$\quad$ Women & & &
\end{tabular}

Finally, the association between AT VDR gene expression and AT insulin sensitivity was examined. SAT VDR expression was negatively correlated with AT insulin sensitivity (std 
$B=-0.207,95 \% \mathrm{Cl}-0.39(-0.03), P=0.025)$, which was independent of age, sex, and BMI (Table 6). No associations were found between SAT expression of vitamin D-metabolizing enzymes and AT insulin sensitivity (data not shown).

\section{Discussion}

In the present study, we demonstrated for the first time that (1) BMI was negatively associated with of plasma $25(\mathrm{OH}) \mathrm{D}_{3}$ but not with plasma $1,25(\mathrm{OH})_{2} \mathrm{D}_{3}$, nor its ratio; (2) Plasma vitamin $\mathrm{D} 25(\mathrm{OH}) \mathrm{D}_{3}$ deficiency was neither related to changes in SAT vitamin D-metabolizing enzymes nor SAT VDR gene expression; (3) plasma $25(\mathrm{OH}) \mathrm{D}_{3}, 1,25(\mathrm{OH})_{2} \mathrm{D}_{3}$, and the active/ inactive metabolite ratio were not significantly associated with hepatic, peripheral or AT insulin sensitivity, (4) SAT VDR gene expression was negatively associated with AT insulin sensitivity.

We found that BMI was one of the major determinants of plasma $25(\mathrm{OH}) \mathrm{D}_{3}$ concentration (inactive metabolite), whilst BMI was neither associated with plasma $1,25(\mathrm{OH})_{2} \mathrm{D}_{3}$ concentration (active metabolite) nor with the active/inactive metabolite ratio. This might be explained by the increased leptin concentrations in obese individuals, which may suppress renal conversion of vitamin $\mathrm{D} 25(\mathrm{OH}) \mathrm{D}_{3}$ to $1,25(\mathrm{OH})_{2} \mathrm{D}_{3}$ indirectly by stimulation of osteoblast and/or osteocyte FGF23 production (32). In line, a recent large meta-analysis, which included 21 adult cohorts, clearly demonstrated that a higher $\mathrm{BMI}$ is accompanied by lower $25(\mathrm{OH}) \mathrm{D}_{3}$ status (33). In addition, previous data in morbidly obese women has also shown that $\mathrm{BMI}$ was inversely related with $25(\mathrm{OH}) \mathrm{D}_{3}$ level but not with $1,25(\mathrm{OH})_{2} \mathrm{D}_{3}(29)$. It has been postulated that these low plasma $25(\mathrm{OH}) \mathrm{D}_{3}$ levels in obese may be partly explained by increased blood volume due to the larger body size(i.e. volumetric dilution) or sequestration of vitamin $D$ in the expanded body fat depot $(10,11)$. However, vitamin D may affect skeletal muscle mass (34) as well as bone mass (35). Therefore, it is important to distinguish between the relationship between vitamin $\mathrm{D}$ and $\mathrm{BMI}$ or adipose tissue mass. Unfortunately, in the present study we did not assess body composition. Therefore, it is unclear whether the observed association between Vitamin D and BMI reflects the relationship with adipose tissue mass per se. The latter needs to be investigated in more detail in future research.

Alterations in AT vitamin D metabolism might be implicated in plasma vitamin $D$ deficiency (36). However, in the present study, we did not find a significant association between SAT VDR gene expression and plasma $25(\mathrm{OH}) \mathrm{D}_{3}$ concentration. Furthermore, the expression of the vitamin D-metabolizing enzymes (CYP) in SAT was not significantly related to plasma $25(\mathrm{OH}) \mathrm{D}_{3}$ levels. In contrast, previous finding have shown a positive correlation between CYP27A1 expression in VAT and plasma $25(\mathrm{OH}) \mathrm{D}_{3}(16)$ In addition, Wamberg et al.(16) showed that obesity is characterized by a decreased expression of the 25-hydroxylase CYP2J2 and the 1a-hydroxylase CYP27B1 in SAT. Whereas the catabolic CYP24A1 does not differ between lean and obese women. However, the expression of catabolic CYP24A1 increased after weight loss (16), suggesting a higher vitamin D turnover in the SAT of obese subjects following weight loss. We cannot exclude that gene expression of vitamin D-metabolizing enzymes may be different between the SAT and VAT (16), which might partly explain the lack of association between plasma $25(\mathrm{OH}) \mathrm{D}_{3}$ with SAT gene expression in the present study. In the present study, SAT VDR expression was positively associated with BMI which is in line with previous findings in VAT (7), indicating that VDR expression is increased 
in both SAT and VAT in obesity. However, the physiological relevance of this upregulation needs to be elucidated in future research. The SAT is by far the body's largest fat depot, and an important mass effect on vitamin D metabolism, is therefore, more likely compared to the VAT.

Recent meta-analyses have shown no effect of oral vitamin D3 supplementation on glucose metabolism and insulin resistance/secretion $(17,37)$. Here, we found that plasma $25(\mathrm{OH}) \mathrm{D}_{3}, 1,25(\mathrm{OH})_{2} \mathrm{D}_{3}$ concentration, and the $1,25(\mathrm{OH})_{2} \mathrm{D}_{3} / 25(\mathrm{OH}) \mathrm{D}_{3}$ ratio were not significantly associated with hepatic, peripheral, or AT insulin sensitivity in overweight/ obese men and women. Taken together, our data suggest that plasma vitamin D deficiency is not related to insulin resistance in overweight/obese men and women, assessed using the gold-standard hyperinsulinemic-euglycemic clamp. Finally, we observed that higher SAT VDR gene expression was associated with lower AT insulin sensitivity independent of BMI, age, and sex, and explained $14 \%$ of the variance in AT insulin sensitivity. Recent study has suggested that the association between insulin resistance related diseases and VDR polymorphisms was more pronounced in dark-pigmented Caucasians and Asians but not in white-pigmented Caucasian (38). However, it needs to be investigated whether these genetic and our observed transcriptional differences also translate into functional changes at the protein level. Furthermore, it has been shown that VDR mRNA expression is positively associated with local inflammation in human SAT and VAT (39). However, further studies are needed to investigate whether the observed association between SAT VDR expression and AT insulin sensitivity is at least partly explained by AT inflammation.

In conclusion, obesity is associated with lower plasma $25(\mathrm{OH}) \mathrm{D}_{3}$ (inactive metabolite), but not with plasma $1,25(\mathrm{OH})_{2} \mathrm{D}_{3}$ (active metabolite) nor $1,25(\mathrm{OH})_{2} \mathrm{D}_{3} / 25(\mathrm{OH})$ $D_{3}$ ratio. This plasma vitamin $D$ deficiency was not related changes in AT expression of vitamin $D$ metabolizing enzymes (CYP) nor VDR. Neither plasma $25(\mathrm{OH}) \mathrm{D}_{3}, 1,25(\mathrm{OH})_{2} \mathrm{D}_{3}$ concentration or $1,25(\mathrm{OH})_{2} \mathrm{D}_{3} / 25(\mathrm{OH}) \mathrm{D}_{3}$ ratio were associated with hepatic, adipose tissue, and peripheral insulin sensitivity in overweight/obese men and women. Interestingly, SAT VDR gene expression was negatively associated with AT insulin sensitivity, and future studies are needed to unravel the molecular mechanisms by which nuclear and membrane-bound VDR interact with insulin action in abdominal SAT.

\section{Acknowledgments}

The authors thank all participants for participation in this study. We also thank the Laboratory of Endocrinology (VU Medical Center, Amsterdam, Netherlands) for the execution of the vitamin D metabolites analysis. Financial Support: A.P. is supported by the Indonesia Endowment Fund for Education (LPDP) and Ministry of Research, Technology and Higher Education (RISTEKDIKTI). The funders had no role in study design, data collection and analysis, decision to publish, or preparation of the manuscript. Correspondence and Reprint Requests: Ellen E. Blaak, PhD, Department of Human Biology, NUTRIM School of Nutrition and Translational Research in Metabolism, Maastricht University, P.O. Box 616, 6200 MD Maastricht, Netherlands. E-mail: e.blaak@maastrichtuniversity.nl.

\section{Disclosure Summary:}

The authors have nothing to disclose. 


\section{References}

1. Hruby A, Hu FB. The epidemiology of obesity: a big picture. Pharmacoeconomics. 2015;33(7):673689.

2. Han TS, Lean ME. A clinical perspective of obesity, metabolic syndrome and cardiovascular disease. JRSM Cardiovasc Dis. 2016;5:1-13.

3. Després J-P. Body fat distribution and risk of cardiovascular disease an update. Circulation. 2012;126(10):1301-1313.

4. Gagnon C, Lu ZX, Magliano DJ, Dunstan DW, Shaw JE, Zimmet PZ, Sikaris K, Grantham N, Ebeling PR, Daly RM. Serum 25-hydroxyvitamin D, calcium intake, and risk of type 2 diabetes after 5 years. Diabetes care. 2011;34(5):1133-1138.

5. Kabadi S, Lee B, Liu L. Joint effects of obesity and vitamin D insufficiency on insulin resistance and type 2 diabetes: results from the NHANES 2001-2006. Diabetes Care 2012;35(10):2048-2054.

6. Esteghamati A, Aryan Z, Esteghamati A, Nakhjavani M. Vitamin D deficiency is associated with insulin resistance in nondiabetics and reduced insulin production in type 2 diabetics. Horm Metab Res. 2015;47(04):273-279.

7. Clemente-Postigo M, Munoz-Garach A, Serrano M, Garrido-Sanchez L, Bernal-Lopez MR, Fernandez-Garcia D, Moreno-Santos I, Garriga N, Castellano-Castillo D, Camargo A, FernandezReal JM, Cardona F, Tinahones FJ, Macias-Gonzalez M. Serum 25-hydroxyvitamin D and adipose tissue vitamin $\mathrm{D}$ receptor gene expression: relationship with obesity and type 2 diabetes. J Clin Endocrinol Metab. 2015;100(4):E591-595.

8. Marques-Vidal P, Vollenweider P, Guessous I, Guessous I, Henry H, Boulat O, Waeber G, Jornayvaz FR. Serum vitamin D concentrations are not associated with insulin resistance in Swiss adults. J Nutr. 2015;145(9):2117-2122.

9. Al Masri M, Romain AJ, Boegner C, Maimoun L, Mariano-Goulart D, Attalin V, Leprieur E, Picandet $\mathrm{M}$, Avignon A, Sultan A. Vitamin D status is not related to insulin resistance in different phenotypes of moderate obesity. Appl Physiol Nutr Metab. 2017;42(4):438-442.

10. Wortsman J, Matsuoka LY, Chen TC, Lu Z, Holick MF. Decreased bioavailability of vitamin D in obesity. Am J Clin Nutr. 2000;72(3):690-693.

11. Drincic AT, Armas LA, Diest EE, Heaney RP. Volumetric dilution, rather than sequestration best explains the low vitamin D status of obesity. Obesity (Silver Spring). 2012;20:1444-1448.

12. Mutt SJ, Hypponen E, Saarnio J, Jarvelin MR, Herzig KH. Vitamin D and adipose tissue-more than storage. Front Physiol. 2014;5(228):1-9.

13. Abbas MA. Physiological functions of Vitamin D in adipose tissue. J Steroid Biochem Mol Biol. 2016;165(Pt B):369-381.

14. Silvagno F, Pescarmona G. Spotlight on vitamin D receptor, lipid metabolism and mitochondria: Some preliminary emerging issues. Mol Cell Endocrinol. 2017;450((2017)):24-31.

15. Chang E, Kim Y. Vitamin D decreases adipocyte lipid storage and increases NAD-SIRT1 pathway in 3T3-L1 adipocytes. Nutrition. 2016;32(6):702-708.

16. Wamberg L, Christiansen T, Paulsen SK, Fisker S, Rask P, Rejnmark L, Richelsen B, Pedersen SB. Expression of vitamin D-metabolizing enzymes in human adipose tissue - the effect of obesity and diet-induced weight loss. Int J Obes (Lond). 2013;37(5):651-657.

17. Jamka M, Woźniewicz M, Jeszka J, Mardas M, Bogdański P, Stelmach-Mardas M. The effect of vitamin $D$ supplementation on insulin and glucose metabolism in overweight and obese individuals: systematic review with meta-analysis. Sci Rep. 2015;5:1-12.

18. Mirhosseini N, Vatanparast H, Mazidi M, Kimball SM. The Effect of Improved Serum 25-Hydroxyvitamin D Status on Glycemic Control in Diabetic Patients: A Meta-Analysis. J Clin Endocrinol Metab. 2017;102(9):3097-3110.

19. Mousa A, Naderpoor N, de Courten MP, Teede H, Kellow N, Walker K, Scragg R, de Courten B. Vitamin D supplementation has no effect on insulin sensitivity or secretion in vitamin D- 
deficient, overweight or obese adults: a randomized placebo-controlled trial. Am J Clin Nutr. 2017;105(6):1372-1381.

20. Wagner H, Alvarsson M, Mannheimer B, Degerblad M, Östenson CG. No effect of high-dose vitamin $D$ treatment on $\beta$-cell function, insulin sensitivity, or glucose homeostasis in subjects with abnormal glucose tolerance: A randomized clinical trial. Diabetes Care. 2016;39(3):345-352.

21. Alvarez JA, Ashraf A. Role of vitamin $D$ in insulin secretion and insulin sensitivity for glucose homeostasis. Int J Endocrinol. 2009;2010:1-18.

22. Abbasi F, Blasey C, Feldman D, Caulfield MP, Hantash FM, Reaven GM. Low circulating 25-hydroxyvitamin $D$ concentrations are associated with defects in insulin action and insulin secretion in persons with prediabetes. J Nutr. 2015;145(4):714-719.

23. Reijnders D, Goossens GH, Hermes GD, Neis E, van der Beek C, Most J, Holst J, Lenaerts K, Kootte R, Nieuwdorp M, Groen A, Olde Damink S, Boekschoten M, Smidt H, Zoetendal E, Dejong C, Blaak $E$. Effects of gut microbiota manipulation by antibiotics on host metabolism in obese humans: a randomized double-blind placebo-controlled trial. Cell Metab. 2016;24(1):63-74.

24. Most J, Timmers S, Warnke I, Jocken J, van Boekschoten M, de Groot P, Bendik I, Schrauwen P, Goossens G, Blaak E. Combined epigallocatechin-3-gallate and resveratrol supplementation for $12 \mathrm{wk}$ increases mitochondrial capacity and fat oxidation, but not insulin sensitivity, in obese humans: a randomized controlled trial. Am J Clin Nutr. 2016;104(1):215-227.

25. DeFronzo RA, Tobin JD, Andres R. Glucose clamp technique: a method for quantifying insulin secretion and resistance. The American journal of physiology. 1979;237(3):E214-223.

26. Hulzebos CV, Renfurm L, Bandsma RH, Verkade HJ, Boer T, Boverhof R, Tanaka H, Mierau I, Sauer PJ, Kuipers F, Stellaard F. Measurement of parameters of cholic acid kinetics in plasma using a microscale stable isotope dilution technique: application to rodents and humans. J Lipid Res. 2001;42(11):1923-1929.

27. Kotronen A, Seppala-Lindroos A, Bergholm R, Yki-Jarvinen H. Tissue specificity of insulin resistance in humans: fat in the liver rather than muscle is associated with features of the metabolic syndrome. Diabetologia. 2008;51(1):130-138.

28. Brehm A, Krssak M, Schmid Al, Nowotny P, WaldhausI W, Roden M. Increased lipid availability impairs insulin-stimulated ATP synthesis in human skeletal muscle. Diabetes. 2006;55(1):136-140.

29. Ter Horst KW, Versteeg RI, Gilijamse PW, Ackermansb MT, Heijboerc AC, Romijnd JA, la Fleura $\mathrm{SE}$, Trinkoe R, DiLeonee RJ, Serlie MJ. The vitamin D metabolites 25(OH)D and 1,25(OH)2D are not related to either glucose metabolism or insulin action in obese women. Diabetes Metab. 2016;42(6):416-423.

30. Holick MF, Binkley NC, Bischoff-Ferrari HA, Gordon CM, Hanley DA, Heaney RP, Murad MH, Weaver CM. Evaluation, treatment, and prevention of vitamin D deficiency: an Endocrine Society clinical practice guideline. J Clin Endocrinol Metab. 2011;96(7):1911-1930.

31. Kamei $Y$, Kawada T, Kazuki R, Ono T, Kato $S$, Sugimoto E. Vitamin D receptor gene expression is upregulated by 1, 25-dihydroxyvitamin D3 in 3T3-L1 preadipocytes. Biochem Biophys Res Commun. 1993;193(3):948-955.

32. Tsuji K, Maeda T, Kawane T, Matsunuma A, Horiuchi N. Leptin stimulates fibroblast growth factor 23 expression in bone and suppresses renal 1 $\alpha$, 25-dihydroxyvitamin D3 synthesis in leptindeficient ob/ob Mice. JBMR. 2010;25(8):1711-1723.

33. Vimaleswaran KS, Berry DJ, Lu C, Tikkanen E, Pilz S, Hiraki LT, Cooper JD, Dastani Z, Li R, Houston DK, Wood AR, Michaëlsson K, Vandenput L, Zgaga L, Yerges-Armstrong LM, McCarthy MI, Dupuis J, Kaakinen M, Kleber ME, Jameson K, Arden N, Raitakari O, Viikari J, Lohman KK, Ferrucci L, Melhus $H$, Ingelsson E, Byberg L, Lind L, Lorentzon M, Salomaa V, Campbell H, Dunlop M, Mitchell BD, Herzig K-H, Pouta A, Hartikainen A-L, Streeten EA, Theodoratou E, Jula A, Wareham NJ, Ohlsson C, Frayling TM, Kritchevsky SB, Spector TD, Richards JB, Lehtimäki T, Ouwehand WH, Kraft P, Cooper C, März W, Power C, Loos RJF, Wang TJ, Järvelin M-R, Whittaker JC, Hingorani AD, Hyppönen E, the Genetic Investigation of Anthropometric Traits c. Causal Relationship between Obesity and 
Vitamin D Status: Bi-Directional Mendelian Randomization Analysis of Multiple Cohorts. PLoS Med. 2013;10(2):e1001383.

34. Marantes I, Achenbach SJ, Atkinson EJ, Khosla S, Melton III LJ, Amin S. Is vitamin D a determinant of muscle mass and strength? JBMR. 2011;26(12):2860-2871.

35. Bischoff-Ferrari HA, Dietrich T, Orav EJ, Dawson-Hughes B. Positive association between 25-hydroxy vitamin $D$ levels and bone mineral density: a population-based study of younger and older adults. Am J Med. 2004;116(9):634-639.

36. Cordeiro A, Santos A, Bernardes M, Ramalho A, Martins MJ. Vitamin D metabolism in human adipose tissue: could it explain low vitamin $D$ status in obesity? Hormone molecular biology and clinical investigation. 2017;33(2):20170003.

37. Poolsup N, Suksomboon N, Plordplong N. Effect of vitamin D supplementation on insulin resistance and glycaemic control in prediabetes: a systematic review and meta-analysis. Diabet Med. 2016;33(3):290-299.

38. Han Ff, Lv Yl, Gong Ll, Liu H, Wan Z-r, Liu L-h. VDR Gene variation and insulin resistance related diseases. Lipids Health Dis. 2017;16(157):1-12.

39. Nguyen VT, Li X, Elli EF, Ayloo SM, Castellanos KJ, Fantuzzi G, Freels S, Braunschweig CL. Vitamin D, inflammation, and relations to insulin resistance in premenopausal women with morbid obesity. Obesity. 2015;23(8):1591-1597. 


\section{Supplemental Tables}

Supplemental Table S1. Primer sets used for real time PCR

\begin{tabular}{lll}
\hline Genes & Primers (forward) & Primers (reverse) \\
\hline VDR & 5'-GGCCCAACTCCAGACACACT-3' & 5'-GGGTCACAGAAGGGTCATCTGA-3' \\
CYP2J2 & 5'-TCCATCCTCGGACTCTCCTAC-3' & 5'-GCGCCGTCTTTTGAGAAAGT-3' \\
CYP27A1 & 5'-CGGCAACGGAGCTTAGAGG-3' & 5'-GGCATAGCCTTGAACGAACAG-3' \\
CYP27B1 & 5'-GAGACTGGGACCAGATGTTTG-3' & 5'-CAGGCAACTCTTCCCGGAAC-3' \\
CYP24A1 & 5'-GGTGGCGAGACTCAGAACG-3' & 5'-GTCGTGCTGTTTCTTGAGACC-3' \\
18S & 5'-AGTTAGCATGCCAGAGTCTGG-3' & 5'-TGCATGGCCGTTCTTAGTTG-3' \\
\hline
\end{tabular}

Supplemental Table S2. Determinants of subcutaneous AT vitamin D-metabolizing enzymes mRNA

\begin{tabular}{|c|c|c|c|c|c|c|c|c|c|c|c|c|c|c|c|}
\hline & \multicolumn{4}{|c|}{ CYP2J2 expression } & \multicolumn{3}{|c|}{ CYP27A1 expression } & \multicolumn{4}{|c|}{ CYP27B1 expression } & \multicolumn{4}{|c|}{ CYP24A1 expression } \\
\hline & B & $95 \% \mathrm{Cl}$ & P Value & Adj. $R^{2}$ & B & $95 \% \mathrm{Cl}$ & $P$ Value Adj. $R^{2}$ & B & $95 \% \mathrm{Cl}$ & $P$ Value & Adj. $R^{2}$ & B & $95 \% \mathrm{Cl}$ & $P$ Value & Adj. $R^{2}$ \\
\hline BMI & 0.058 & $=0.22(0.33)$ & 0.674 & 0.002 & 0.01 & $-0.28(0.29)$ & 0.968 & 0.02 & $0.25(0.29)$ & 0.885 & 0.002 & 0.01 & $0.27(0.29$ & 0.943 & 0.011 \\
\hline Age & 0.152 & $=0.14(0.44)$ & 0.302 & & 0.37 & $0.07(0.68)$ & 0.018 & 0.252 & $0.04(0.54)$ & 0.086 & & 0.28 & $0.15(0.58$ & 3 0.063 & \\
\hline \multicolumn{16}{|l|}{ Sex: } \\
\hline Men & 0 & 0 & & & 0 & 0 & & 0 & 0 & & & 0 & 0 & & \\
\hline Women & 0.283 & $=0.63(1.12)$ & 0.538 & & 0.51 & $-0.45(1.48)$ & 0.29 & 0.465 & $0.44(1.37)$ & 0.308 & & 0.4 & $0.53(1.33$ & $\begin{array}{l}30.395 \\
\end{array}$ & \\
\hline
\end{tabular}

Supplemental Table S3. Relationship between SAT vitamin D metabolizing enzymes and plasma inactive vitamin D concentration

\begin{tabular}{lccc}
\hline & \multicolumn{3}{c}{$\begin{array}{c}\text { Plasma 25(OH)D } \\
\text { (inactive metabolite) }\end{array}$} \\
\cline { 2 - 4 } & $\boldsymbol{B}$ & $\mathbf{9 5 \%} \mathrm{Cl}$ & $\mathbf{P}$ \\
\hline CYP2J2 mRNA & -0.011 & $-0.27(0.24)$ & 0.930 \\
CYP27A1 mRNA & 0.080 & $-0.16(0.32)$ & 0.506 \\
CYP27B1 mRNA & 0.122 & $-0.13(0.38)$ & 0.345 \\
CYP24A1 mRNA & 0.077 & $-0.18(0.34)$ & 0.555 \\
\hline
\end{tabular}




\section{CHAPTER 5}

The association between vitamin $D$ receptor polymorphisms and tissue-specific insulin resistance in human obesity

Adriyan Pramono, Johan W.E. Jocken, Michiel E. Adriaens, Mads F.

Hjorth, A. Astrup, Wim H. Saris and Ellen E. Blaak

Submitted

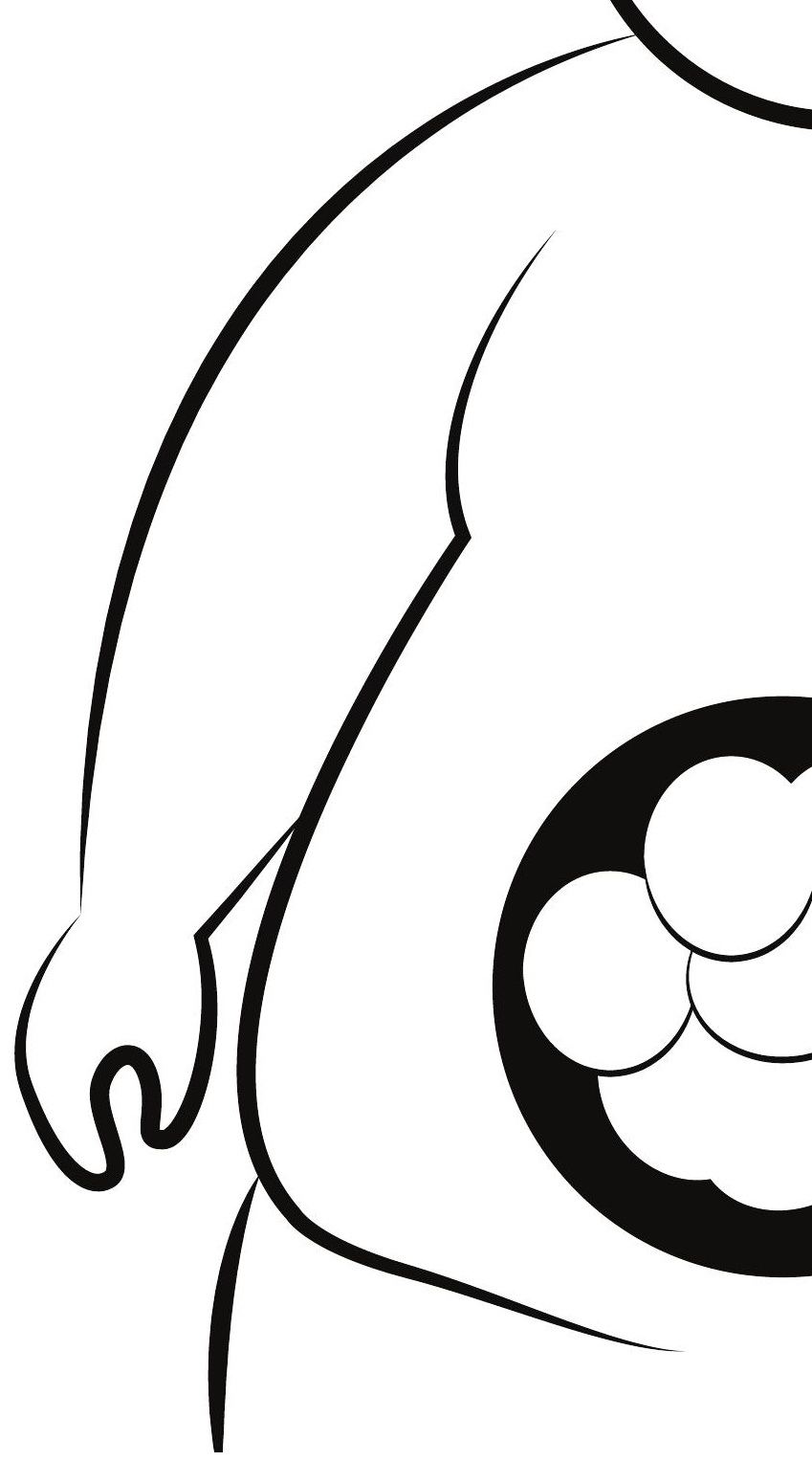




\begin{abstract}
Aims/hypothesis: This study aimed to: (1) investigate the association of four singlenucleotide polymorphisms (SNPs) in the VDR gene (Taql/rs731236, Apal/rs7975232, Fokl/ rs10735810, and Bsml/rs1544410) with adiposity, insulin sensitivity indexes at baseline; (2) identify the effect of the VDR SNPs in the SAT transcriptome in overweight/obese Caucasians of the DiOGenes cohort; and (3) determine the association of the VDR SNPs with change of body weight and insulin sensitivity indexes after weight loss and weight maintenance (regain) intervention.
\end{abstract}

Methods: We included 553 adult obese individuals (mean BMI $\left.34.8 \mathrm{~kg} / \mathrm{m}^{2}\right)$, men $(n=197)$ and women $(n=356)$, which were studied at baseline, following an 8-week weight loss intervention and 26-weeks weight maintenance (regain). Genotyping was performed using an Illumina 660W-Quad SNP chip on the Illumina iScan Genotyping System. Tissue-specific insulin sensitivity was determined using Hepatic Insulin Resistance Index (HIRI), Muscle Insulin Sensitivity Index (MISI) and Adipose Tissue Insulin Resistance Index (Adipo-IR). Expression quantitative trait loci (eQTL) analysis was performed using SAT gene sequencing data to determine the effect of SNPs on SAT gene expression.

Results: The genetic variants, AG and GG in the VDR Taql or CA and AA in the VDR Apal were associated with higher $\mathrm{BMI}$, waist and fat mass $(\mathrm{P}<0.05$ for all), even after adjustment for age, sex, and center. None of the VDR polymorphisms were associated with HIRI or MISI. Interestingly, carriers of the G-allele of VDR Fokl showed higher Adipo-IR (GG+GA $7.8 \pm 0.4$ vs. AA $5.6 \pm 0.5, P=0.010$ ) and higher systemic Free Fatty Acids (FFA) (GG+GA: $637.8 \pm 13.4$ vs. $A A: 547.9 \pm 24.7 \mu \mathrm{mol} / \mathrm{L}, \mathrm{P}=0.011$ ) as compared to non-carriers, even after adjustment with age, sex, center and fat mass. However, eQTL analysis showed minor to no effect of these genotypes on the transcriptional level in SAT. Also, VDR polymorphisms were not related to changes in body weight and insulin resistance as result of dietary intervention ( $P>$ 0.05 for all parameters).

Conclusions/interpretation: the VDR Taql and Apal variants are associated with markers of adiposity at baseline. The VDR Fokl variant is associated with elevated circulating FFA and Adipo-IR in obese Caucasians at baseline. Nevertheless, the VDR SNPs had minor to no effect on the transcriptional level, at least in SAT, indicating that the putative mechanisms of action remain to be determined. The VDR polymorphisms did not relate to body weight and insulin resistance as result of dietary intervention.

DiOGenes was registered at clinicaltrials.gov as NCT00390637. 


\section{Introduction}

The obesity prevalence has increased dramatically reaching epidemic proportions worldwide (1). Overweight and obesity have been shown as major risk factors for the development of insulin resistance, type 2 diabetes mellitus (T2D), and cardiovascular diseases (CVDs) (2). Next to economic, social, and physical environment, genetic factors play an important role in obesity development and its comorbidities (3). Previous studies have shown that human obesity is often characterized by vitamin $D$ deficiency (circulating vitamin 25 -hydroxyvitamin $\mathrm{D}_{3} / 25 \mathrm{OHD}<50 \mathrm{nmol} / \mathrm{L}$ ) (4) and increased vitamin $D$ receptor (VDR) expression within subcutaneous adipose tissue (SAT) (5). Interestingly, it has been suggested that 1,25-dihydroxyvitamin D3 (hydroxylated form of 25OHD in the kidney), the active form of vitamin $D$, has independent effects on features of the metabolic syndrome (6).

The actions of 1,25-dihydroxyvitamin D3 are mediated through VDR, a ligandactivated nuclear receptor that drives gene transcription involved in bone metabolism and also extra-skeletal cell cycle regulation (7). Interestingly, VDR is expressed not only in the kidney, but also in major insulin-sensitive tissues such as adipose (8), muscle and liver (9). Additionally, adipose tissue overexpression of human VDR in mice leads to an increased fat mass, a decreased glucose tolerance and energy expenditure (10). Of interest, our recent data indicated that VDR mRNA expression in subcutaneous adipose tissue (SAT) was positively related with body mass index (BMI) (5) and adipose tissue insulin resistance (Adipo-IR) derived from a hyperinsulinemic euglycemic clamp (5), indicating a possible role for VDR in regulating adipose tissue function.

Genetic variations of VDR (Apal, Taql, Bsml, and Fokl) have previously been related with measures of adiposity. Some studies have shown that the Apal, Taql, Bsml, and Fokl VDR variants are associated with markers of adiposity (11-13). In contrast, others reported a lack of association between VDR variants and adiposity $(14,15)$. Thus, evidence for the relationship between VDR genetic variants and obesity remains inconclusive. Of note, the majority of these studies determined adiposity based only on body mass index (BMI) (1114), and therefore did not take a more precise determination of body composition into account. Furthermore, it has been shown that VDR genetic variants may be associated with whole body insulin resistance (16-18) and the development of T2D(19). Interestingly, it has been shown that the effects of vitamin $D$ supplementation on insulin sensitivity (i.e. HOMAIR) are affected by VDR genetic variation $(20,21)$. The latter may suggest that metabolic effects of vitamin $D$ and intervention outcome, particularly insulin sensitivity, may also be influenced by genetic variation in the VDR.

Studies investigate the relationship between VDR polymorphisms, adiposity and tissue-specific insulin sensitivity (including muscle, liver and adipose tissue) are currently lacking. Also, whether these VDR variants may also affect human SAT at the transcriptional level is unknown. Here, we investigated the possible association of the VDR Taql, Apal, Bsml and Fokl polymorphisms with markers of adiposity including body composition and tissue-specific insulin resistance in the adult Caucasian obese/overweight population of the DiOGenes study. Additionally, we investigated in the DIOGenes study whether these polymorphisms affected body weight loss as well as change in (tissue-specific) insulin sensitivity after an 8-week weight loss intervention followed by 26 -weeks weight maintenance. To gain mechanistic insight, we also determined whether these VDR variants 
affect abdominal subcutaneous adipose tissue (SAT) at the transcriptional level.

\section{Methods}

\section{Study Design}

The DiOGenes study is a Pan-European multicenter, randomized, controlled dietary intervention study, designed to assess the efficacy of moderate fat diets that vary in protein content and glycemic index for preventing weight regain and obesity related risk factors after weight loss (for details see Larsen et al (22)). The study involved 8 European countries (8 centers: Denmark, Netherlands, United Kingdom, Germany, Spain, Bulgaria, Czech Republic, and Greece). In total, 938 overweight or obese, nondiabetic adults free of cardiovascular disease [age 18-65 years, body mass index (BMI) $27-45 \mathrm{~kg} / \mathrm{m}^{2}$ ] were recruited. More details on recruitment, inclusion and exclusion criteria, and study design are described elsewhere (22).

The analyses described here mainly focusses baseline data of 553 participants (men=197 and women=356), prior to any intervention, for whom VDR polymorphisms (Taql/rs731236, Apal/rs7975232, Fokl/rs10735810, and Bsml/rs1544410) and detailed information of body composition such as body mass index (BMI), waist circumference (WC), and fat mass (FM), as well as glucose and insulin concentrations during an oral glucose tolerance test (OGTT) were available. Subsequently, we analyzed how the indicated VDR polymorphisms related to changes in body weight and (tissue-specific) insulin sensitivity during a weight loss and subsequent weight maintenance period.

For this, after the first clinical investigation day (pre-low-calorie diet) with baseline measurements (CID1), eligible adults followed an 8-week low calorie diet (Modifast, Nutrition et Sante', France) consisting of $800 \mathrm{kcal} / \mathrm{d}$. Adults who achieved a weight loss of $\geq 8 \%$ after 8 -weeks underwent the second clinical investigation day (post-low-calorie diet), was randomized to ad libitum diets for 26 weeks of weight maintenance (22). After weight loss and weight maintenance the clinical investigation day was repeated (CID2 and CID3, respectively) The Medical Ethical Committees of the respective countries approved the study protocol. All participants gave written informed consent and the study was conducted in accordance with the principle of the Declaration of the Helsinki II.

\section{Body composition and blood sampling}

Body composition was determined and blood samples were collected after an overnight fast. We included the following baseline anthropometric parameters: body weight, body mass index (BMI), waist circumference (WC), and fat mass (FM). BMI was calculated by dividing the mass in $\mathrm{kg}$ by squared height (in meter). Body composition was determined by Bioimpedance analysis. Additionally, glucose, free fatty acids (FFA) (automatic spectrophotometric enzymatic techniques) and insulin (radioimmunoassay) were measured from fasting blood samples (22). 


\section{Estimates of insulin resistance indexes}

Participants underwent a standard 5-point oral glucose tolerance test (OGTT) at baseline. Briefly, after an overnight fast, venous blood was collected before (t0) and after a $75 \mathrm{~g}$ glucose load was ingested. Blood samples were taken at 0, 30, 60, 90 and 120 minutes to determine glucose and insulin concentrations (22). Muscle insulin sensitivity index (MISI) and hepatic insulin resistance index (HIRI) were estimated using the methods of AbdulGhani et al (23).

The muscle insulin sensitivity index (MISI) was calculated according to the following formula: $\mathrm{MISI}=(\mathrm{dG} / \mathrm{dt}) /$ mean plasma insulin concentrations during the OGTT. Here, $\mathrm{dG} / \mathrm{dt}$ is the rate of decay of plasma glucose concentrations during the OGTT, calculated as the slope of the least square fit to the decline in plasma glucose concentration from peak to nadir (23). The decline in plasma glucose concentration after 60 minute primarily reflects glucose uptake by peripheral tissue mainly skeletal muscle.

The hepatic insulin resistance index (HIRI) was calculated using the square root of the product of the area under curves (AUCs) for glucose and insulin during the first 30 minute of the OGTT. The formula of HIRI's calculation was SQRT (glucose ${ }_{0-30}$ [AUC in $\mathrm{mg} / \mathrm{d} x$ h] $x$ insulin $_{0-30}[A U C$ in $\mu \mathrm{U} / \mathrm{mL} x \mathrm{~h}$ ]). This index has been developed and validated against the product of fasting plasma insulin and endogenous glucose production in hyperinsulinemic euglycemic clamp studies in a Mexican-American population (non-Caucasian) (23).

The Adipose tissue insulin resistance index (Adipo-IR) was calculated for 485 participants (FFA data available) using the method of Søndergaard et al (24). The Adipo-IR was calculated using fasting insulin and fasting free fatty acid (FFA) concentrations (fasting insulin $[\mu \mathrm{IU} / \mathrm{mL}] \times$ fasting FFA $[\mu \mathrm{mol} / \mathrm{L}] / 1000)$. This formula has been strongly associated with suppression of lipolysis derived from palmitate flux $\left(\mathrm{IC}_{50}\right)$ as measured by the multistep pancreatic clamp technique (24).

\section{SNP selection and genotyping}

Buffy coats were collected for DNA extraction and genetic single nucleotide polymorphisms (SNPs) analysis. The four VDR SNPs: Taql(rs731236), Apal(rs7975232), Bsml(rs1544410), and Fokl(rs10735810) were evaluated by allelic discrimination realtime PCR using an Illumina 660W-Quad SNP chip on the Illumina iScan Genotyping System (Illumina, San Diego, CA, USA).

\section{Abdominal SAT RNAseq analysis}

Total RNA was extracted from abdominal SAT biopsies as described before (25). Gene expression was examined by using 100-nucelutide long paired-end RNA sequencing with an Illumina HiSeq 2000 of libraries prepared by using the Illumina TruSeq kit following the manufacturer's standard protocols. Sequencing was performed using baseline SAT prior to any weight-loss intervention. For each sample, the number of reads mapping onto genes was retrieved by using Genomic Alignments as previously described (26). 


\section{Statistical analysis}

All continuous variables were checked for normal distribution. Variables with a skewed distribution were natural logarithmically transformed (BMI, WC, FM, MISI, HIRI, and Adipo-IR) to satisfy the condition of normality. The data were back-transformed and presented as mean $\pm \mathrm{SE}$.

Allele frequency and Hardy-Weinberg Equilibrium (HWE) were calculated for all VDR SNPs. The non-random association of alleles at different loci of VDR polymorphisms (pairwise linkage disequilibrium (LD)) analysis was analyzed using SNPStat (27) (available online at https://www.snpstats.net/start.htm). Coefficient D' was used to describe pairwise $L D$, where a $D^{\prime}$ value close to 1 indicated high LD and D' value close to 0 suggested weak LD.

Analysis of covariance (ANCOVA) was performed to examine the differences in body composition (BMI, waist, and fat mass) between the genotypes adjusted for age, sex, and center. The changes in body weight between genotypes following weight loss intervention were adjusted for initial body weight, while the differences in body weight between genotypes following weight maintenance were corrected for weight loss during LCD and mean body weight pre and post LCD. Furthermore, ANCOVA was also conducted to analyze the differences in tissue-specific insulin resistance index (MISI, HIRI, and AdipoIR) between the genotypes adjusted for age, sex, center and FM at baseline. The changes in MISI, HIRI, and Adipo-IR between the genotypes following weight loss intervention were adjusted for MISI, HIRI, and Adipo-IR at baseline, respectively. The changes in MISI, HIRI, and Adipo-IR between the genotypes following weight maintenance were adjusted for the changes MISI, HIRI, and Adipo-IR during LCD and mean of MISI, HIRI, Adipo-IR pre and post $L C D$, respectively. In addition, dominant, recessive, over and co-dominant models were selected. Briefly, a dominant model compares homozygote dominant versus heterozygotehomozygote recessive, whereas the recessive model compares heterozygote-homozygote dominant versus homozygote recessive. An over-dominant model compares homozygote dominant-recessive versus heterozygote where this model assumes the heterozygote has the strongest impact on the outcome. On the other hand, co-dominant models hypothesize that each genotype may be associated with the outcomes (28).

Expression quantitative trait loci (eQTL) analysis (29) was conducted to analyze the association between the VDR gene variants and abdominal SAT tissue gene expression (RNA-seq). We considered three sets of genes for the eQTL analysis: (i) the VDR gene (cis), (ii) all VDR target genes (trans) and (iii) all genes in cis, defined as any gene within $1 \mathrm{Mb}$ upstream or downstream of the genomic location of the respective SNP. To test for eQTL associations, we first recoded the genotype of each SNP to the alternative allele dosage (i.e. 0,1 or 2 copies). To construct the set of VDR target genes, we manually performed a search using PubMed (search criteria combined with Boolean operators AND/OR: Vitamin D, Vitamin D receptor (VDR), target genes, obesity). From the list of articles retrieved (10, 3044), abstracts were scanned, and only those that reported vitamin $D$, gene name and obesity and/or insulin resistance were further analyzed resulting in a list of VDR target genes. Next, for each gene in a set, a linear additive model was created with gene expression as the dependent variable and the alternative allele dosage as the independent variable, while correcting for age, sex and center. Correction for multiple testing was performed by means of a Bonferroni correction and for eQTL analysis we performed the false discovery rate (FDR) correction. All analyses were performed in the statistical programming language $\mathrm{R}$ (version 


\subsection{1) (45).}

\section{Results}

The main demographic, anthropometric and clinical characteristics of participants are presented in Table 1. In our population genotypes of Taql rs731236, Apal rs7975232, Bsml rs1544410, and Fokl rs10735810 were predominantly heterozygous and all SNPs were compatible with HWE as shown in Supplemental table S1.

Table 1. Participants' demographic, anthropometric and clinical characteristics.

\begin{tabular}{|c|c|c|c|c|c|c|}
\hline & $\begin{array}{l}\text { Baseline } \\
\text { (CID1) } \\
(\mathrm{N}=553)\end{array}$ & & $\begin{array}{l}\text { After weight } \\
\text { loss (CID2) } \\
(\mathrm{N}=491)\end{array}$ & & $\begin{array}{l}\text { After weight } \\
\text { maintenance } \\
\text { (regain) } \\
\text { (CID3) } \\
(\mathrm{N}=356)\end{array}$ & \\
\hline & Mean \pm SE & Range & Mean \pm SE & Range & Mean \pm SE & Range \\
\hline Age (years) & $41.5 \pm 0.3$ & $24-63$ & $41.7 \pm 0.3$ & $24-63$ & $42.5 \pm 0.3$ & $24-63$ \\
\hline $\operatorname{Sex}(M / F)$ & $197 / 356$ & & $178 / 313$ & & $120 / 236$ & \\
\hline Weight (kg) & $100.6 \pm 0.8$ & $66.6-168.6$ & $89.4 \pm 0.9$ & $59-150$ & $89.7 \pm 0.7$ & $57-154$ \\
\hline BMI $\left(\mathrm{kg} / \mathrm{m}^{2}\right)$ & $34.8 \pm 0.2$ & $26.7-52.0$ & $30.9 \pm 0.2$ & $22.2-45.7$ & $30.9 \pm 0.2$ & $21.8-43.9$ \\
\hline$W C(\mathrm{~cm})$ & $109 \pm 0.6$ & $64.0-155.0$ & $98.8 \pm 0.7$ & $70.0-133.0$ & $99.3 \pm 0.6$ & $71.0-138.0$ \\
\hline $\mathrm{FM}(\mathrm{kg})$ & $40.8 \pm 0.5$ & $15.6-82.6$ & $32.2 \pm 0.6$ & $9.9-58.8$ & $33.2 \pm 0.5$ & $11.9-68.7$ \\
\hline Fasting glucose (mmol/L) & $5.2 \pm 0.1$ & $3.4-8.7$ & $4.9 \pm 0.0$ & $4.0-8.0$ & $5.0 \pm 0.0$ & $4.0-7.0$ \\
\hline Fasting insulin $\mu \mathrm{IU} / \mathrm{mL}$ & $11.9 \pm 0.4$ & $2.0-134.0$ & $8.3 \pm 0.3$ & $2.0-87.0$ & $9.3 \pm 0.5$ & $2.0-100.0$ \\
\hline Fasting FFA ( $\mu \mathrm{mol} / \mathrm{L})$ & $627 \pm 12^{+}$ & $162-2226$ & $712 \pm 11^{++}$ & $153-1727$ & $555 \pm 12^{t+t}$ & $109-1419$ \\
\hline HIRI & $33.4 \pm 0.5^{f}$ & $11.9-94.3$ & $26.4 \pm 0.7^{f f}$ & $7.4-73.3$ & $32.0 \pm 0.9^{\mathrm{fff}}$ & $6.5-89.6$ \\
\hline MISI & $0.06 \pm 0.00^{9}$ & $0.01-0.53$ & $0.06 \pm 0.00$ ตा & $0.01-0.30$ & $0.07 \pm 0.00$ ภาศๆ & $0.01-0.36$ \\
\hline Adipo-IR & $7.0 \pm 0.2^{+}$ & $1.0-39.3$ & $5.8 \pm 0.3^{+t}$ & $0.7-43.9$ & $5.1 \pm 0.3^{t+t}$ & $0.4-58.5$ \\
\hline
\end{tabular}

Abbreviations: Adipo-IR, adipose tissue insulin resistance index; BMI, body mass index; F, female; FM, fat mass; FFA, free fatty acid; HIRI, hepatic insulin resistance index; HOMA-IR, homeostatic model assessment for insulin resistance; $\mathrm{M}$, male; $\mathrm{MISI}$, muscle insulin sensitivity index. ${ }^{+} \mathrm{N}=485 ;{ }^{++} \mathrm{N}=420 ;{ }^{+++} \mathrm{N}=281 ;{ }^{\mathrm{f}} \mathrm{N}=539 ;$ ff $\mathrm{N}=383$; fff $\mathrm{N}=303$;

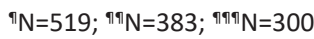

\section{VDR variants and anthropometry measurements at baseline}

Variants in VDR Taql in the dominant model (AA versus $A G+G G$ ) were related to $\mathrm{BMI}, \mathrm{WC}$, and $\mathrm{FM}(\mathrm{P}=0.007 ; \mathrm{P}=0.08 ; \mathrm{P}=0.006$, respectively) (Table 2). Furthermore, variants in VDR Taql were associated with $B M I, W C$, and $F M(P=0.009, P=0.013, P=0.006$, respectively) in the over-dominant model ( $A A+G G$ versus $A G)$. Overall, $G$ allele carriers $(A G+G G)$ of the VDR Taql had higher BMI, WC, and FM as compared to non-carriers (AA) (Table 2).

In the dominant model VDR Apal (CC versus $\mathrm{CA}+\mathrm{AA}$ ) was associated with higher $\mathrm{BMI}$ and $F M(P=0.023 ; P=0.028$, respectively) (Table 2). Further analysis in the over-dominant model showed that $C C+A A$ variants in VDR Apal were related to $B M I$ and $F M(P=0.012$; $P=0.008$, respectively) as compared to the $C A$ variant. Overall, $A$ allele carriers $(C A+A A)$ of VDR Apal had higher BMI and FM compared to non-carriers (CC). However, neither VDR 
CHAPTER 5

The association between vitamin $\mathrm{D}$ receptor polymorphisms and tissue-specific insulin resistance in human obesity

Bsml nor Fokl were related to $\mathrm{BMI}, \mathrm{WC}$, and $\mathrm{FM}$ in this cohort ( $\mathrm{P}>0.05$ for all parameters).

Table 2. The relationship between VDR polymorphisms and body composition.

\begin{tabular}{|c|c|c|c|c|c|c|c|c|c|c|c|}
\hline Taql rs731236 & Genotype & $\mathbf{N}$ & Mean & SE & $\begin{array}{l}P \text { - } \\
\text { value }\end{array}$ & Mean & SE & $\begin{array}{l}P \text { - } \\
\text { value }\end{array}$ & Mean & SE & $\begin{array}{l}P \text { - } \\
\text { value }\end{array}$ \\
\hline & $A A$ & 209 & 34.1 & 0.3 & \multirow{3}{*}{0.017} & 107 & 0.9 & \multirow{3}{*}{0.045} & 39.1 & 0.7 & \multirow{3}{*}{0.012} \\
\hline \multirow[t]{2}{*}{ Co-dominant } & $A G$ & 251 & 35.4 & 0.3 & & 110 & 0.9 & & 42.1 & 0.8 & \\
\hline & GG & 93 & 34.9 & 0.5 & & 107 & 1.4 & & 41.1 & 1.2 & \\
\hline \multirow[t]{2}{*}{ Dominant } & AA & 209 & 34.1 & 0.3 & \multirow{2}{*}{0.007} & 107 & 0.9 & \multirow{2}{*}{0.08} & 39.1 & 0.7 & \multirow{2}{*}{$0.00 €$} \\
\hline & $\mathrm{AG}+\mathrm{GG}$ & 344 & 35.3 & 0.3 & & 109 & 0.7 & & 41.8 & 0.7 & \\
\hline \multirow[t]{2}{*}{ Recessive } & $A A+A G$ & 460 & 34.8 & 0.2 & \multirow{2}{*}{0.99} & 109 & 0.6 & \multirow{2}{*}{0.17} & 40.8 & 0.5 & \multirow{2}{*}{0.74} \\
\hline & GG & 93 & 34.9 & 0.5 & & 107 & 1.4 & & 41.1 & 1.2 & \\
\hline \multirow[t]{2}{*}{ Over-dominant } & $A A+G G$ & 302 & 34.3 & 0.3 & \multirow{2}{*}{0.009} & 107 & 0.7 & \multirow{2}{*}{0.013} & 39.7 & 0.6 & \multirow{2}{*}{0.006} \\
\hline & $\mathrm{AG}$ & 251 & 35.4 & 0.3 & & 110 & 0.9 & & 42.1 & 0.8 & \\
\hline \multirow[t]{2}{*}{ Apal rs7975232 } & Genotype & $\mathbf{N}$ & Mean & SE & $\begin{array}{l}p \text { - } \\
\text { value }\end{array}$ & Mean & SE & $\begin{array}{l}p- \\
\text { value }\end{array}$ & Mean & SE & $\begin{array}{l}p- \\
\text { value }\end{array}$ \\
\hline & $\mathrm{CC}$ & 206 & 34.1 & 0.3 & \multirow{3}{*}{0.033} & 107 & 0.9 & \multirow{3}{*}{0.11} & 39.4 & 0.7 & \multirow{3}{*}{0.026} \\
\hline \multirow[t]{2}{*}{ Co-dominant } & $\mathrm{CA}$ & 250 & 35.4 & 0.3 & & 110 & 0.9 & & 42.1 & 0.8 & \\
\hline & $\mathrm{AA}$ & 97 & 34.8 & 0.5 & & 106 & 1.3 & & 40.5 & 1.2 & \\
\hline \multirow[t]{2}{*}{ Dominant } & $\mathrm{CC}$ & 206 & 34.1 & 0.3 & \multirow{2}{*}{0.023} & 107 & 0.9 & & 39.4 & 0.7 & \\
\hline & $C A+A A$ & 347 & 35.3 & 0.3 & & 109 & 0.8 & 0.36 & 41.7 & 0.6 & 0.028 \\
\hline Recessive & $C C+C A$ & 456 & 34.9 & 0.2 & & 109 & 0.6 & & 40.9 & 0.5 & 038 \\
\hline & AA & 97 & 34.8 & 0.5 & 0.56 & 106 & 1.3 & 0.15 & 40.5 & 1.2 & 0.38 \\
\hline Over-dominant & $\mathrm{CC}+\mathrm{AA}$ & 303 & 34.3 & 0.3 & & 107 & 0.7 & & 39.8 & 0.6 & \\
\hline & $\mathrm{CA}$ & 250 & 35.4 & 0.3 & 0.012 & 110 & 0.9 & 0.056 & 42.1 & 0.8 & 0.008 \\
\hline Bsml rs1544410 & Genotype & $\mathbf{N}$ & Mean & SE & $\begin{array}{l}P \text { - } \\
\text { value }\end{array}$ & Mean & SE & $\begin{array}{l}P \text { - } \\
\text { value }\end{array}$ & Mean & SE & $\begin{array}{l}P \text { - } \\
\text { value }\end{array}$ \\
\hline & $\pi$ & 166 & 34.9 & 0.4 & & 108 & 1.0 & & 41.1 & 0.9 & \\
\hline Co-dominant & TC & 263 & 35.1 & 0.3 & 0.18 & 110 & 0.9 & 0.40 & 41.2 & 0.7 & 0.44 \\
\hline & $\mathrm{CC}$ & 124 & 34.1 & 0.4 & & 108 & 1.1 & & 39.6 & 1.0 & \\
\hline Dominant & $\mathrm{TT}$ & 166 & 34.9 & 0.4 & & 108 & 1.0 & & 41.1 & 0.9 & \\
\hline & $\mathrm{TC}+\mathrm{CC}$ & 387 & 34.8 & 0.3 & 0.78 & 109 & 0.7 & 0.43 & 40.7 & 0.6 & 0.87 \\
\hline Recessive & $\mathrm{TT}+\mathrm{TC}$ & 429 & 35.1 & 0.2 & & 109 & 0.7 & & 41.2 & 0.6 & \\
\hline & $\mathrm{CC}$ & 124 & 34.1 & 0.4 & 0.07 & 108 & 1.1 & 0.45 & 39.6 & 1.0 & 0.21 \\
\hline Over-dominant & $\mathrm{TT}+\mathrm{CC}$ & 290 & 34.6 & 0.3 & 01 & 108 & 0.8 & 018 & 40.5 & 0.7 & 037 \\
\hline & $\mathrm{TC}$ & 263 & 35.1 & 0.3 & 0.21 & 110 & 0.9 & 0.18 & 41.2 & 0.7 & 0.31 \\
\hline Fokl rs10735810 & Genotype & $\mathbf{N}$ & Mean & SE & $\begin{array}{l}P \text { - } \\
\text { value }\end{array}$ & Mean & SE & $\begin{array}{l}P \text { - } \\
\text { value }\end{array}$ & Mean & SE & $\begin{array}{l}P \text { - } \\
\text { value }\end{array}$ \\
\hline & GG & 227 & 34.9 & 0.3 & & 109 & 0.9 & & 40.5 & 0.8 & \\
\hline Co-dominant & GA & 259 & 34.9 & 0.3 & 0.94 & 109 & 0.8 & 0.85 & 41.6 & 0.7 & 0.14 \\
\hline & $\mathrm{AA}$ & 67 & 34.8 & 0.6 & & 108 & 1.5 & & 39.2 & 1.4 & \\
\hline Dominant & GG & 227 & 34.9 & 0.3 & & 109 & 0.9 & & 40.5 & 0.8 & \\
\hline & $\mathrm{GA}+\mathrm{AA}$ & 326 & 34.8 & 0.3 & 0.96 & 109 & 0.7 & 0.76 & 41.1 & 0.6 & 0.57 \\
\hline Recessive & GG-GA & 486 & 34.9 & 0.2 & & 109 & 0.6 & & 41.1 & 0.5 & \\
\hline & $\mathrm{AA}$ & 67 & 34.8 & 0.6 & 0.76 & 108 & 1.5 & 0.73 & 39.2 & 1.4 & 0.10 \\
\hline Over-dominant & $G G+A A$ & 294 & 34.8 & 0.3 & & 109 & 0.8 & & 40.2 & 0.7 & \\
\hline & $\mathrm{GA}$ & 259 & 34.9 & 0.3 & 0.80 & 109 & 0.8 & 0.59 & 41.6 & 0.7 & 0.11 \\
\hline
\end{tabular}

Abbreviations: BMI, body mass index; FM, fat mass; WC, waist circumference. P-value was corrected for age, sex, and center.

\section{Linkage disequilibrium of VDR variants and haplotype analysis}

Pairwise Linkage Disequilibrium (LD) between SNPs was assessed, and LD analysis revealed strong LD between VDR Taql, Apal, and Bsml $\left(D^{\prime}=0.9754, D^{\prime}=0.9944, D^{\prime}=0.9943\right.$, 
respectively see Figure 1 ). In contrast, weak LD ( $D^{\prime}$ values close to 0 , see Figure 1 ) was observed between these variants (Taql, Apal, Bsml) and Fokl. However, subsequent haplotype analysis revealed no significant associations between different haplotypes and BMI, WC and FM, even after adjustment for age, sex, and center (except uncommon haplotypes (frequency <1\%) (Supplemental Table S2). Further haplotype analysis showed no association with HIRI, MISI or Adipo-IR (data not shown).

\section{Chromosome 12}
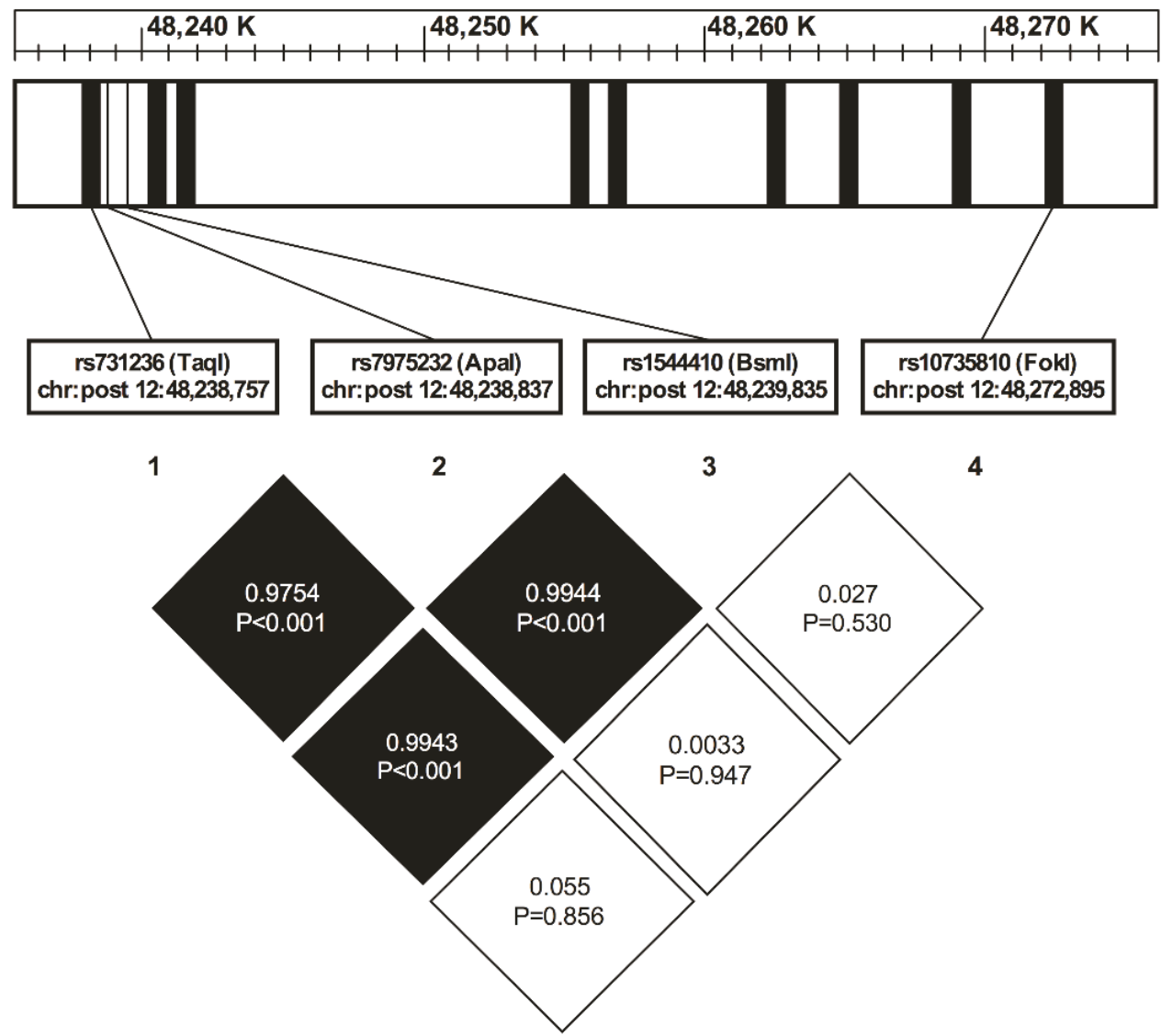

Figure 1. The VDR gene on chromosome 12. The approximate locations of the observed polymorphisms are indicated by arrows. The blocks represented pairwise linkage disequilibrium (LD) pattern. Each squares described the $D^{\prime}$ values and the $p$ values between the pairs of VDR polymorphisms. The black blocks are proportional to $D^{\prime}$ values which indicates high LD between polymorphisms. The white blocks indicate low LD between polymorphisms.

\section{VDR variants and tissue-specific insulin resistance index}

The analysis of tissue-specific insulin resistance according to VDR genotypes as described in Table 3, shows no significant associations between VDR variants, hepatic insulin 
CHAPTER 5

The association between vitamin D receptor polymorphisms and tissue-specific insulin resistance in human obesity

resistance (HIRI) and muscle insulin sensitivity (MISI) ( $p>0.05$ for all). Of interest, $G$ allele carriers of VDR Fokl showed higher Adipo-IR (GG+GA $7.8 \pm 0.4$ vs. AA $5.6 \pm 0.5, P=0.010$ ) even after adjustment for age, sex, center and FM.

Moreover, circulating FFA but not fasting insulin, were significantly higher in $\mathrm{G}$ allele carriers of VDR Fokl as compared to non-carriers (GG+GA: $637.8 \pm 13.4$ ( $\mu \mathrm{mol} / \mathrm{L})$ vs. AA: $547.9 \pm 24.7$, $\mathrm{P}=0.011$ ) (Supplemental Table S3).

Table 3. The association between VDR polymorphisms and tissue-specific insulin resistance index.

\begin{tabular}{|c|c|c|c|c|c|c|c|c|c|c|c|c|c|}
\hline & & HIRI $^{+}$ & & & & & MISI $^{\ddagger}$ & & & & Adipo- & & \\
\hline Taql rs731236 & Genotype & $\mathbf{N}$ & Mean & SE & $\begin{array}{l}P \text { - } \\
\text { value }\end{array}$ & $\mathbf{N}$ & Mean & SE & $\begin{array}{l}P \text { - } \\
\text { value }\end{array}$ & $\mathbf{N}$ & Mean & SE & $\begin{array}{l}P \text { - } \\
\text { value }\end{array}$ \\
\hline \multirow{3}{*}{ Co-dominant } & $\mathrm{AA}$ & 205 & 32.6 & 0.7 & \multirow{3}{*}{0.89} & 200 & 0.05 & 0.0 & \multirow{3}{*}{0.54} & 183 & 6.7 & 0.3 & \multirow{3}{*}{0.81} \\
\hline & $\mathrm{GA}$ & 243 & 33.8 & 0.7 & & 233 & 0.06 & 0.0 & & 225 & 8.1 & 0.5 & \\
\hline & GG & 91 & 34.1 & 1.5 & & 86 & 0.05 & 0.0 & & 77 & 7.7 & 1.2 & \\
\hline \multirow[t]{2}{*}{ Dominant } & $\mathrm{AA}$ & 205 & 32.6 & 0.7 & \multirow{2}{*}{0.64} & 200 & 0.05 & 0.0 & \multirow{2}{*}{0.31} & 183 & 6.7 & 0.3 & \multirow{2}{*}{0.63} \\
\hline & $\mathrm{GA}+\mathrm{GG}$ & 334 & 33.9 & 0.7 & & 319 & 0.06 & 0.0 & & 302 & 8.0 & 0.5 & \\
\hline \multirow[t]{2}{*}{ Recessive } & $\mathrm{AA}+\mathrm{GA}$ & 448 & 33.3 & 0.5 & \multirow{2}{*}{0.90} & 433 & 0.06 & 0.0 & \multirow{2}{*}{0.44} & 408 & 7.5 & 0.3 & \multirow{2}{*}{0.80} \\
\hline & GG & 91 & 34.1 & 1.5 & & 86 & 0.05 & 0.0 & & 77 & 7.7 & 1.2 & \\
\hline \multirow[t]{2}{*}{ Over-dominant } & $A A+G G$ & 296 & 33.1 & 0.7 & \multirow{2}{*}{0.72} & 286 & 0.05 & 0.0 & \multirow{2}{*}{0.68} & 260 & 6.9 & 0.4 & \multirow{2}{*}{0.52} \\
\hline & GA & 243 & 33.8 & 0.7 & & 233 & 0.06 & 0.0 & & 225 & 8.1 & 0.5 & \\
\hline Apal rs7975232 & Genotype & $\mathbf{N}$ & Mean & SE & $\begin{array}{l}P \text { - } \\
\text { value }\end{array}$ & $\mathbf{N}$ & Mean & SE & $\begin{array}{l}P \text { - } \\
\text { value }\end{array}$ & $\mathbf{N}$ & Mean & SE & $\begin{array}{l}P \text { - } \\
\text { value }\end{array}$ \\
\hline \multirow{3}{*}{ Co-dominant } & $\mathrm{CC}$ & 201 & 32.6 & 0.7 & \multirow{3}{*}{0.71} & 200 & 0.05 & 0.0 & \multirow{3}{*}{0.73} & 181 & 6.7 & 0.4 & \multirow{3}{*}{0.83} \\
\hline & CA & 243 & 33.7 & 0.7 & & 233 & 0.06 & 0.0 & & 223 & 8.0 & 0.5 & \\
\hline & $\mathrm{AA}$ & 95 & 34.2 & 1.4 & & 86 & 0.05 & 0.0 & & 81 & 7.8 & 1.1 & \\
\hline \multirow[t]{2}{*}{ Dominant } & $\mathrm{CC}$ & 201 & 32.6 & 0.7 & \multirow{2}{*}{0.41} & 200 & 0.05 & 0.0 & ר) & 181 & 6.7 & 0.4 & 056 \\
\hline & $\mathrm{CA}+\mathrm{AA}$ & 338 & 33.9 & 0.7 & & 319 & 0.06 & 0.0 & 0.42 & 304 & 7.9 & 0.5 & 0.56 \\
\hline Recessive & $\mathrm{CC}+\mathrm{CA}$ & 444 & 33.2 & 0.5 & 065 & 433 & 0.06 & 0.0 & 076 & 404 & 7.4 & 0.3 & 71 \\
\hline & $\mathrm{AA}$ & 95 & 34.2 & 1.4 & 0.65 & 86 & 0.05 & 0.0 & 0.16 & 81 & 7.8 & 1.1 & 0.71 \\
\hline Over-dominant & $C C+A A$ & 296 & 33.1 & 0.7 & 013 & 286 & 0.05 & 0.0 & 058 & 262 & 7.1 & 0.4 & ר7 ח \\
\hline & $\mathrm{CA}$ & 243 & 33.7 & 0.7 & 0.43 & 233 & 0.06 & 0.0 & 0.58 & 223 & 8.0 & 0.5 & 0.17 \\
\hline Bsml rs1544410 & Genotype & $\mathbf{N}$ & Mean & SE & $\begin{array}{l}P \text { - } \\
\text { value }\end{array}$ & $\mathbf{N}$ & Mean & SE & $\begin{array}{l}P \text { - } \\
\text { value }\end{array}$ & $\mathbf{N}$ & Mean & SE & $\begin{array}{l}P \text { - } \\
\text { value }\end{array}$ \\
\hline & $\pi$ & 163 & 34.3 & 1.1 & & 154 & 0.05 & 0.0 & & 141 & 8.5 & 0.9 & \\
\hline Co-dominant & $\mathrm{TC}$ & 255 & 33.2 & 0.7 & 0.59 & 246 & 0.06 & 0.0 & 0.52 & 236 & 7.2 & 0.3 & 0.59 \\
\hline & $\mathrm{CC}$ & 121 & 32.6 & 0.9 & & 119 & 0.06 & 0.0 & & 108 & 6.8 & 0.5 & \\
\hline Dominant & $\pi$ & 163 & 34.3 & 1.1 & 027 & 154 & 0.05 & 0.0 & 0 & 141 & 8.5 & 0.9 & 27 0 \\
\hline & $\mathrm{TC}+\mathrm{CC}$ & 376 & 33.0 & 0.6 & 0.31 & 365 & 0.06 & 0.0 & 0.41 & 344 & 7.1 & 0.3 & 0.32 \\
\hline Recessive & $\mathrm{TT}+\mathrm{TC}$ & 418 & 33.6 & 0.6 & 0 & 400 & 0.06 & 0.0 & 0 & 377 & 7.7 & 0.4 & 0.56 \\
\hline & $\mathrm{CC}$ & 121 & 32.6 & 0.9 & 0.43 & 119 & 0.06 & 0.0 & 0.30 & 108 & 6.9 & 0.5 & 0.56 \\
\hline Over-dominant & $\pi+C C$ & 284 & 33.6 & 0.7 & 7 & 273 & 0.06 & 0.0 & م 0 0 & 249 & 7.8 & 0.6 & 067 \\
\hline & $\mathrm{TC}$ & 255 & 33.2 & 0.7 & 0.87 & 246 & 0.06 & 0.0 & 0.90 & 236 & 7.2 & 0.3 & 0.67 \\
\hline $\begin{array}{l}\text { Fokl } \\
\text { rs10735810 }\end{array}$ & Genotype & $\mathbf{N}$ & Mean & SE & $\begin{array}{l}P \text { - } \\
\text { value }\end{array}$ & $\mathbf{N}$ & Mean & SE & $\begin{array}{l}P \text { - } \\
\text { value }\end{array}$ & $\mathbf{N}$ & Mean & SE & $\begin{array}{l}P \text { - } \\
\text { value }\end{array}$ \\
\hline & GG & 219 & 33.8 & 0.8 & & 213 & 0.06 & 0.0 & & 202 & 7.7 & 0.5 & \\
\hline Co-dominant & GA & 254 & 33.5 & 0.7 & 0.54 & 244 & 0.06 & 0.0 & 0.60 & 225 & 7.8 & 0.5 & 0.038 \\
\hline & $\mathrm{AA}$ & 66 & 31.8 & 1.4 & & 62 & 0.07 & 0.0 & & 58 & 5.6 & 0.5 & \\
\hline Dominant & GG & 219 & 33.8 & 0.8 & 060 & 213 & 0.06 & 0.0 & 0.49 & 202 & 7.7 & 0.5 & 0 \\
\hline & $\mathrm{GA}+\mathrm{AA}$ & 320 & 33.2 & 0.7 & 0.64 & 306 & 0.06 & 0.0 & & 283 & 7.4 & 0.4 & 0.69 \\
\hline Recessive & $\mathrm{GG}+\mathrm{GA}$ & 473 & 33.6 & 0.5 & בר ח & 457 & 0.06 & 0.0 & 0.36 & 427 & 7.8 & 0.4 & 010 \\
\hline & $\mathrm{AA}$ & 66 & 31.8 & 1.4 & 0.21 & 62 & 0.07 & 0.0 & & 58 & 5.6 & 0.5 & 0.010 \\
\hline Over-dominant & $\mathrm{GG}+\mathrm{AA}$ & 285 & 33.3 & 0.7 & & 275 & 0.06 & 0.0 & 0.92 & 260 & 7.2 & 0.4 & ? 20 \\
\hline & GA & 254 & 33.5 & 0.7 & 0.80 & 244 & 0.06 & 0.0 & & 225 & 7.8 & 0.5 & 0.29 \\
\hline
\end{tabular}

Abbreviations: Adipo-IR, adipose tissue insulin resistance index; HIRI, hepatic insulin resistance index; MISI, muscle insulin sensitivity index. P-value was corrected for age, sex, center, and fat mass. $\left.{ }^{\dagger}\right) \mathrm{N}=539 ;(\ddagger) \mathrm{N}=519 ;(\#) \mathrm{N}=485$. 


\section{Association between VDR polymorphisms and SAT gene transcription level}

Expression quantitative trait loci (eQTL) analysis was conducted to analyze the association between the VDR gene variants and abdominal SAT tissue gene expression. Hoverer, cis and trans eQTL analysis showed that VDR gene expression did not significantly differ between genotypes of any of the VDR SNPs (Taql, Apal, Bsml, and Fokl). We observed no significance difference of the VDR SNPs with gene expression of VDR target genes in cis and trans after FDR correction ( $p>0.05$ ) (Supplemental Table S4 and S5).

\section{VDR polymorphisms and change of body weight, change of tissue-specific IR following weight loss and maintenance}

No effects of VDR genetic variants on the change of body weight following weight loss and weight maintenance were observed (Supplemental Table S6). Furthermore, there were no effects of VDR polymorphisms on the change of tissue-specific insulin resistance indexes (HIRI, MISI, and Adipo-IR) following weight loss intervention and weight maintenance (regain) (Supplemental Table S7 and S8).

\section{Discussion}

In this study, we showed that variants in VDR Taql and Apal are associated with elevated BMI (contributing $0.9 \mathrm{~kg} / \mathrm{m} 2$ per risk allele), WC ( $3 \mathrm{~cm}$ per risk allele), or $\mathrm{FM}$ at baseline ( $2 \mathrm{~kg}$ per risk allele) at baseline. Secondly, variants in FokI VDR were associated with Adipo-IR as well as elevated circulating FFA at baseline $(79 \mu \mathrm{mol} / \mathrm{L}$ per risk allele). Thirdly, cis and trans eQTL analysis demonstrated no major effects of these VDR polymorphisms on the SAT transcriptome at baseline. Finally, there was no relationship between VDR polymorphisms and changes in body weight and tissue-specific insulin resistance during weight loss and weight maintenance.

In the present study, we found that BMI, WC, and FM were significantly higher in individuals that carried the VDR Taql $G$ allele ( $A G$ and GG genotype) compared to non- carriers (AA genotype). In addition, BMI and FM of VDR Apal A allele carriers were considerably higher than those of non-carriers (CC genotype). In line with this, Al Daghri et al. showed that Taql ( $G$ allele) and Apal (A allele) were associated with higher BMI in a dark-pigmented Caucasian population (11). Additionally, the Taql polymorphism was also associated with higher BMI in a Greek population (12). In contrast, Vimaleswaran et al. and Walsh et al. showed no association between variants in VDR Taql,, BMI (46) and FM (47) in male and female, lean/overweight and obese Caucasians. Regarding Bsml and Fokl, we did not find any association with BMI, WC, or FM, which is in line with a previous finding by Dorjgochoo et al. and Walsh et al. showing no relationship between Bsml and Fokl variants and markers of body composition (BMI (48) or FM (47)) in a Caucasian population.

Furthermore, pairwise LD analysis showed strong LD between Taql, Apal, and Bsml in our obese/overweight Caucasian population. However, haplotype analysis revealed no significantly associations with BMI, FM and tissue-specific insulin resistance, even after adjustment for age, sex, and center. These results, are in contrast with Al-Daghri et al. showing that in Dark-pigmented Caucasian individuals carriers of both $\mathrm{G}$ allele (Taql) and 
A allele (Apal) had significantly higher BMI independent from age and sex (11). Differences in study populations (i.e. broader BMI vs. overweight/obese BMI) and ethnic-pigmentation (Dark-pigmented versus White-pigmented Caucasian) might partly explain this discrepancy (16), which still needs further investigation.

With respect to tissue specific insulin resistance, we did not find any associations between VDR polymorphisms (Taql, Apal, Bsml, and FokI), HIRI or MISI estimated from 5 time-points OGTT. Of interest, G-allele Carriers of VDR Fokl showed a significant higher Adipo-IR and elevated fasting FFA concentrations, independent of age and sex. Moreover, recent studies in Asian populations with dyslipidemia suggested an association between Fokl variants elevated triglyceride (TG) (49) and low-density lipoprotein (LDL) (50). These findings may indicate that VDR Fokl variants are merely related to dyslipidemia and an impaired liver lipid metabolism (51), which needs to be investigated in more detail. Furthermore, the Fokl polymorphism is located on the exon in the coding region of the VDR gene, resulting in different translation initiation sites (TIS) and giving rise to a full-length VDR protein or a three amino acid shorter VDR protein variant (52), having higher transcriptional activity $(53,54)$. Therefore, we studied whether variants in VDR Fokl were associated with changes in the abdominal SAT transcriptome (targeted gene expression related to adipose tissue glucose, and lipid metabolism as well as inflammation). However, our cis and trans eQTL analysis suggested no effect of VDR Fokl variants on SAT gene transcription, suggesting a minor contribution of VDR polymorphisms on adipose tissue function in overweight/obese men and women.

Further analysis, showed no effect of Taql, Apal and FokI VDR genetic variants on the change of body weight and tissue specific insulin resistance following weight loss and weight regain. Thus although these polymorphisms significantly contribute to adiposity and Adipo-IR in a cross sectional analysis they are apparently of less importance in determining dietary intervention outcome. This seems to be in contrast to another study in a T2D Saudi population showing that VDR genetic variants (i.e., Taql and Bsml) affect intervention outcome (i.e., insulin sensitivity measured by HOMA-IR) following vitamin D supplementation (21).

In conclusion, our findings indicate that variants in VDR Taql and Apal are associated with markers of adiposity. In addition, the VDR Fokl G-allele is associated with elevated circulating FFA and Adipo-IR in overweight/obese Caucasians. These VDR SNPs were not related changes in body weight and insulin sensitivity as result of dietary intervention. Nevertheless, these VDR SNPs had no effect on the transcriptional level, at least in abdominal SAT, indicating that the putative mechanisms of action remain to be determined. 


\section{References}

1. Chooi YC, Ding C, Magkos F. The epidemiology of obesity. Metabolism. 2018.

2. Eckel RH, Kahn SE, Ferrannini E, Goldfine AB, Nathan DM, Schwartz MW, Smith RJ, Smith SR. Obesity and type 2 diabetes: what can be unified and what needs to be individualized? The Journal of Clinical Endocrinology \& Metabolism. 2011;96(6):1654-1663.

3. Albuquerque D, Nóbrega C, Manco L, Padez C. The contribution of genetics and environment to obesity. British medical bulletin. 2017;123(1):159-173.

4. Holick MF, Binkley NC, Bischoff-Ferrari HA, Gordon CM, Hanley DA, Heaney RP, Murad MH, Weaver CM. Evaluation, treatment, and prevention of vitamin D deficiency: an Endocrine Society clinical practice guideline. J Clin Endocrinol Metab. 2011;96(7):1911-1930.

5. Pramono A, Jocken JWE, Essers YPG, Goossens GH, Blaak EE. Vitamin D and Tissue-Specific Insulin Sensitivity in Humans With Overweight/Obesity. J Clin Endocrinol Metab. 2019;104(1):49-56.

6. Bea JW, Jurutka PW, Hibler EA, Lance P, Martínez ME, Roe DJ, Molmenti CLS, Thompson PA, Jacobs ET. Concentrations of the vitamin D metabolite 1, $25(\mathrm{OH}) 2 \mathrm{D}$ and odds of metabolic syndrome and its components. Metabolism. 2015;64(3):447-459.

7. Haussler MR, Jurutka PW, Mizwicki M, Norman AW. Vitamin D receptor (VDR)-mediated actions of $1 \alpha, 25(\mathrm{OH}) 2$ vitamin D3: genomic and non-genomic mechanisms. Best Pract Res Clin Endocrinol Metab. 2011;25(4):543-559.

8. Clemente-Postigo M, Munoz-Garach A, Serrano M, Garrido-Sanchez L, Bernal-Lopez MR, Fernandez-Garcia D, Moreno-Santos I, Garriga N, Castellano-Castillo D, Camargo A, Fernandez-Real JM, Cardona F, Tinahones FJ, Macias-Gonzalez M. Serum 25-hydroxyvitamin D and adipose tissue vitamin D receptor gene expression: relationship with obesity and type 2 diabetes. J Clin Endocrinol Metab. 2015;100(4):E591-595.

9. Bikle DD. Extrarenal synthesis of 1,25-dihydroxyvitamin D and its health implications. Clinic Rev Bone Miner Metab. 2010(7).

10. Wong KE, Kong J, Zhang W, et al. Targeted expression of human vitamin $\mathrm{D}$ receptor in adipocytes decreases energy expenditure and induces obesity in mice. J Biol Chem. 2011;286(39):3380433810.

11. Al-Daghri NM, Guerini FR, Al-Attas OS, Alokail MS, Alkharfy KM, Draz HM, Agliardi C, Costa AS, Saulle I, Mohammed AK. Vitamin D receptor gene polymorphisms are associated with obesity and inflammosome activity. PloS one. 2014;9(7):e102141.

12. Vasilopoulos Y, Sarafidou T, Kotsa K, Papadimitriou M, Goutzelas Y, Stamatis C, Bagiatis V, Tsekmekidou X, Yovos JG, Mamuris Z. VDR Taql is associated with obesity in the Greek population. Gene. 2013;512(2):237-239.

13. Ochs-Balcom HM, Chennamaneni R, Millen AE, Shields PG, Marian C, Trevisan M, Freudenheim $\mathrm{JL}$. Vitamin D receptor gene polymorphisms are associated with adiposity phenotypes. Am J Clin Nutr. 2011;93(1):5-10.

14. Khan RJ, Riestra P, Gebreab SY, Wilson JG, Gaye A, Xu R, Davis SK. Vitamin D Receptor Gene Polymorphisms Are Associated with Abdominal Visceral Adipose Tissue Volume and Serum Adipokine Concentrations but Not with Body Mass Index or Waist Circumference in African Americans: The Jackson Heart Study-3. The Journal of nutrition. 2016;146(8):1476-1482.

15. Maria CR, Carrillo-Avila JA, Jacqueline SR, Emilio GJ, Sofia V, Javier M, Blanca RM. Genetic association analysis of vitamin $D$ receptor gene polymorphisms and obesity-related phenotypes. Gene. 2018;640:51-56.

16. Han Ff, Lv YI, Gong LI, Liu H, Wan Z-r, Liu L-h. VDR Gene variation and insulin resistance related diseases. Lipids Health Dis. 2017;16(157):1-12.

17. Mook-Kanamori DO, Geelhoed JM, Steegers EA, Witteman JC, Hofman A, Moll HA, van Duijn CM, Hokken-Koelega AC, Jaddoe VW. Insulin gene variable number of tandem repeats is not associated with weight from fetal life until infancy: the Generation R Study. European journal of endocri- 
nology. 2007;157(6):741-748.

18. Wehr E, Trummer O, Giuliani A, Gruber H-J, Pieber TR, Obermayer-Pietsch B. Vitamin D-associated polymorphisms are related to insulin resistance and vitamin $D$ deficiency in polycystic ovary syndrome. European Journal of Endocrinology. 2011;164(5):741-749.

19. Angel B, Lera L, Márquez C, Albala C. The association of VDR polymorphisms and type 2 diabetes in older people living in community in Santiago de Chile. Nutrition \& diabetes. 2018;8(1):31.

20. Jain R, von Hurst PR, Stonehouse W, Love DR, Higgins CM, Coad J. Association of vitamin D receptor gene polymorphisms with insulin resistance and response to vitamin D. Metabolism. 2012;61(3):293-301.

21. Al-Daghri NM, Mohammed AK, Al-Attas OS, Ansari MGA, Wani K, Hussain SD, Sabico S, Tripathi G, Alokail MS. Vitamin D Receptor Gene Polymorphisms Modify Cardiometabolic Response to Vitamin D Supplementation in T2DM Patients. Sci Rep. 2017;7:8280.

22. Larsen TM, Dalskov S, van Baak M, Jebb S, Kafatos A, Pfeiffer A, Martinez JA, Handjieva-Darlenska T, Kunesova M, Holst C, Saris WH, Astrup A. The Diet, Obesity and Genes (Diogenes) Dietary Study in eight European countries - a comprehensive design for long-term intervention. Obes Rev. 2010;11(1):76-91.

23. Abdul-Ghani MA, Matsuda M, Balas B, DeFronzo RA. Muscle and liver insulin resistance indexes derived from the oral glucose tolerance test. Diabetes Care. 2007;30(1):89-94.

24. Søndergaard E, Espinosa De Ycaza AE, Morgan-Bathke M, Jensen MD. How to Measure Adipose Tissue Insulin Sensitivity. J Clin Endocrinol Metab. 2017;102(4):1193-1199.

25. Viguerie N, Montastier E, Maoret JJ, Roussel B, Combes M, Valle C, Villa-Vialaneix N, lacovoni JS, Martinez JA, Holst C, Astrup A, Vidal H, Clement K, Hager J, Saris WH, Langin D. Determinants of human adipose tissue gene expression: impact of diet, sex, metabolic status, and cis genetic regulation. PLoS genetics. 2012;8(9):e1002959.

26. Lawrence M, Huber W, Pages H, Aboyoun P, Carlson M, Gentleman R, Morgan MT, Carey VJ. Software for computing and annotating genomic ranges. PLoS computational biology. 2013;9(8):e1003118.

27. Sole X, Guino E, Valls J, Iniesta R, Moreno V. SNPStats: a web tool for the analysis of association studies. Bioinformatics (Oxford, England). 2006;22(15):1928-1929.

28. Horita N, Kaneko T. Genetic model selection for a case-control study and a meta-analysis. Meta gene. 2015;5:1-8.

29. Cookson W, Liang L, Abecasis G, Moffatt M, Lathrop M. Mapping complex disease traits with global gene expression. Nature reviews Genetics. 2009;10(3):184-194.

30. Vukić M, Neme A, Seuter S, Saksa N, de Mello VDF, Nurmi T, Uusitupa M, Tuomainen T-P, Virtanen $\mathrm{JK}$, Carlberg C. Relevance of vitamin D receptor target genes for monitoring the vitamin D responsiveness of primary human cells. PloS one. 2015;10(4):e0124339.

31. Maruyama R, Aoki F, Toyota M, Sasaki Y, Akashi H, Mita H, Suzuki H, Akino K, Ohe-Toyota M, Maruyama Y. Comparative genome analysis identifies the vitamin $D$ receptor gene as a direct target of p53-mediated transcriptional activation. Cancer research. 2006;66(9):4574-4583.

32. Narvaez CJ, Simmons KM, Brunton J, Salinero A, Chittur SV, Welsh JE. Induction of STEAP4 correlates with 1,25-dihydroxyvitamin D3 stimulation of adipogenesis in mesenchymal progenitor cells derived from human adipose tissue. J Cell Physio. 2013;228(10):2024-2036.

33. Ryynänen J, Neme A, Tuomainen TP, et al. Changes in vitamin D target gene expression in adipose tissue monitor the vitamin $D$ response of human individuals. Mol Nutr Food Res. 2014;58(10):2036-2045.

34. Nimitphong H, Holick MF, Fried SK, Lee MJ. 25-hydroxyvitamin D3 and 1,25-dihydroxyvitamin D3 promote the differentiation of human subcutaneous preadipocytes. PLoS One. 2012;7(12):e52171.

35. Larrick BM, Kim KH, Donkin SS, Teegarden D. 1,25-Dihydroxyvitamin D regulates lipid metabolism and glucose utilization in differentiated 3T3-L1 adipocytes. Nutrition research (New York, NY). 2018;58:72-83. 
36. Carlberg C, Seuter S, de Mello VD, et al. Primary vitamin D target genes allow a categorization of possible benefits of vitamin D3 supplementation. PLoS One. 2013;8(7):e71042.

37. Marcotorchino J, Gouranton E, Romier B, Tourniaire F, Astier J, Malezet C, Amiot M-J, Landrier J-F. Vitamin $D$ reduces the inflammatory response and restores glucose uptake in adipocytes. Mol Nutr Food Res. 2012;56(12):1771-1782.

38. Chang E, Kim Y. Vitamin D decreases adipocyte lipid storage and increases NAD-SIRT1 pathway in 3T3-L1 adipocytes. Nutrition. 2016;32(6):702-708.

39. Sabir MS, Khan Z, Hu C, Galligan MA, Dussik CM, Mallick S, Stone AD, Batie SF, Jacobs ET, Whitfield GK, Haussler MR, Heck MC, Jurutka PW. SIRT1 enzymatically potentiates 1,25-dihydroxyvitamin D3 signaling via vitamin D receptor deacetylation. J Steroid Biochem Mol Biol. 2017;172:117-129.

40. Ding C, Wilding JP, Bing C. 1,25-dihydroxyvitamin D3 Protects against Macrophage-Induced ACtivation of NFKB and MAPK Signalling and Chemokine Release in Human Adipocytes. PLoS One. 2013;8(4):e61707.

41. Moreno-Santos I, Castellano-Castillo D, Lara MF, Fernandez-Garcia JC, Tinahones FJ, Macias-Gonzalez M. IGFBP-3 Interacts with the Vitamin D Receptor in Insulin Signaling Associated with Obesity in Visceral Adipose Tissue. International journal of molecular sciences. 2017;18(11).

42. Issa LL, Leong GM, Barry JB, Sutherland RL, Eisman JA. Glucocorticoid receptor-interacting protein-1 and receptor-associated coactivator-3 differentially interact with the vitamin $D$ receptor (VDR) and regulate VDR-retinoid $X$ receptor transcriptional cross-talk. Endocrinology. 2001;142(4):1606-1615.

43. Asano L, Watanabe M, Ryoden Y, Usuda K, Yamaguchi T, Khambu B, Takashima M, Sato SI, Sakai J, Nagasawa K, Uesugi M. Vitamin D Metabolite, 25-Hydroxyvitamin D, Regulates Lipid Metabolism by Inducing Degradation of SREBP/SCAP. Cell chemical biology. 2017;24(2):207-217.

44. Bandera Merchan B, Tinahones FJ, Macías-González M. Commonalities in the Association between PPARG and Vitamin D Related with Obesity and Carcinogenesis. PPAR research. 2016;2016.

45. Team RC. R: A language and environment for statistical computing. 2013.

46. Vimaleswaran KS, Cavadino A, Berry DJ, Genetic Investigation of Anthropometric Traits C, Whittaker JC, Power C, Järvelin MR, Hyppönen E. Genetic association analysis of vitamin D pathway with obesity traits. International journal of obesity (2005). 2013;37(10):1399-1406.

47. Walsh S, Ludlow AT, Metter EJ, Ferrucci L, Roth SM. Replication study of the vitamin D receptor (VDR) genotype association with skeletal muscle traits and sarcopenia. Aging clinical and experimental research. 2016;28(3):435-442.

48. Dorjgochoo T, Shi J, Gao Y-T, Long J, Delahanty R, Xiang Y-B, Cai Q, Shu XO. Genetic variants in vitamin $D$ metabolism-related genes and body mass index: analysis of genome-wide scan data of approximately 7000 Chinese women. International journal of obesity. 2012;36(9):1252.

49. Xia Z, Hu Y, Han Z, Gao Y, Bai J, He Y, Zhao H, Zhang H. Association of vitamin D receptor gene polymorphisms with diabetic dyslipidemia in the elderly male population in North China. Clinical interventions in aging. 2017;12:1673-1679.

50. Jia J, Tang Y, Shen C, Zhang N, Ding H, Zhan Y. Vitamin D receptor polymorphism rs2228570 is significantly associated with risk of dyslipidemia and serum LDL levels in Chinese Han population. Lipids in health and disease. 2018;17(1):193.

51. Keane JT, Elangovan H, Stokes RA, Gunton JE. Vitamin D and the Liver-Correlation or Cause? Nutrients. 2018;10(4):496.

52. Whitfield GK, Remus LS, Jurutka PW, Zitzer H, Oza AK, Dang HT, Haussler CA, Galligan MA, Thatcher ML, Dominguez CE. Functionally relevant polymorphisms in the human nuclear vitamin $D$ receptor gene. Molecular and cellular endocrinology. 2001;177(1-2):145-159.

53. Colin EM, Weel AE, Uitterlinden AG, Buurman CJ, Birkenhager JC, Pols HA, van Leeuwen JP. Consequences of vitamin $D$ receptor gene polymorphisms for growth inhibition of cultured human peripheral blood mononuclear cells by 1, 25-dihydroxyvitamin D3. Clin Endocrinol (Oxf). 2000;52(2):211-216. 


\section{CHAPTER 5}

The association between vitamin $\mathrm{D}$ receptor polymorphisms and tissue-specific insulin resistance in human obesity

54. Alimirah F, Peng X, Murillo G, Mehta RG. Functional significance of vitamin D receptor Fokl polymorphism in human breast cancer cells. PloS one. 2011;6(1):e16024. 
Supplemental Table S1. Minor allele frequencies (MAFs) and Hardy-Weinberg equilibrium (HWE) of VDR genotype prevalence in overweight/obese Caucasians.

\begin{tabular}{lcccccc}
\hline \multicolumn{1}{c}{ SNP } & Location & MAF & \multicolumn{3}{c}{ Genotype prevalence } & HWE* \\
\hline $\begin{array}{l}\text { Study subjects } \\
(\mathrm{N}=553)\end{array}$ & & & Homozygote & Heterozygote & Homozygote & \\
\hline Taql (rs731236 A>G) & Exon 9 & 0.168 & AA (37.8\%) & AG (45.4\%) & GG (16.8\%) & 0.25 \\
Apal (rs7975232 C>A) & Intron 8 & 0.175 & CC (37.3\%) & CA (45.2\%) & AA (17.5\%) & 0.16 \\
Bsml (rs1544410 C>T) & Intron 8 & 0.224 & TT (30.0\%) & TC (47.6\%) & CC (22.4\%) & 0.31 \\
Fokl (rs10735810 A>G) & $\begin{array}{c}\text { Exon 2 } \\
\text { (start codon) }\end{array}$ & 0.121 & GG (41.0\%) & GA (46.8\%) & AA (12.1\%) & 0.64 \\
\hline
\end{tabular}

HWE, Hardy-Weinberg equilibrium; MAF, Minor allele frequencies; SNP, single nucleotide polymorphisms; VDR, Vitamin D receptor. $\left({ }^{*}\right)$ P value of HWE equilibrium test.

Supplementary Table S2. Haplotype frequencies and association with BMI, WC, and FM.

\begin{tabular}{|c|c|c|c|c|c|c|}
\hline & & & & BMI & WC & FM \\
\hline Haplotype & Taql & Apal & Frequency (\%) & P-value & P-value & P-value \\
\hline $\mathrm{H} 1$ & $A$ & C & 59.58 & - & - & - \\
\hline $\mathrm{H} 2$ & G & A & 39.24 & 0.10 & 0.76 & 0.12 \\
\hline H3* & $A$ & $A$ & 0.91 & 0.11 & 0.02 & 0.44 \\
\hline $\mathrm{H} 4 *$ & G & $\mathrm{C}$ & 0.27 & 0.11 & 0.02 & 0.44 \\
\hline Haplotype & Taql & Bsml & Frequency (\%) & P-value & P-value & P-value \\
\hline $\mathrm{H} 1$ & $A$ & $\mathrm{C}$ & 46.10 & - & - & - \\
\hline $\mathrm{H} 2$ & G & $\mathrm{T}$ & 39.41 & 0.097 & 0.77 & 0.13 \\
\hline H3 & A & $\mathrm{T}$ & 14.39 & 0.79 & 0.43 & 0.51 \\
\hline $\mathrm{H} 4 *$ & G & $\mathrm{C}$ & 0.10 & 0.83 & 0.98 & 0.023 \\
\hline Haplotype & Apal & Bsml & Frequency (\%) & P-value & P-value & P-value \\
\hline $\mathrm{H} 1$ & $\mathrm{C}$ & $\mathrm{C}$ & 46.10 & - & - & - \\
\hline $\mathrm{H} 2$ & A & $\mathrm{T}$ & 40.04 & 0.16 & 0.90 & 0.26 \\
\hline H3 & $\mathrm{C}$ & $\mathrm{T}$ & 13.75 & 0.84 & 0.81 & 0.80 \\
\hline $\mathrm{H} 4 *$ & A & C & 0.11 & $<0.001$ & 0.42 & 0.037 \\
\hline
\end{tabular}

Abbreviations: BMI, body mass index; FM, fat mass; WC, waist circumference. P-value is age, sex, and center adjusted. $\left({ }^{*}\right)$ rare haplotypes which are indicated by $\%$ frequency in this population close to zero.

Supplementary Table S3. The association between FokI VDR variants and circulating FFA.

\begin{tabular}{|c|c|c|c|c|c|}
\hline \multirow[b]{2}{*}{ Fokl rs10735810 } & \multicolumn{4}{|c|}{ Circulating FFA } & \multirow[b]{2}{*}{$P$-value } \\
\hline & Genotypes & $\mathrm{N}$ & Mean & SE & \\
\hline \multirow{3}{*}{ Co-dominant } & GG & 202 & 617.2 & 15.1 & \multirow{3}{*}{$0.039 *$} \\
\hline & GA & 225 & 656.2 & 21.4 & \\
\hline & $A A$ & 58 & 547.9 & 24.7 & \\
\hline \multirow[t]{2}{*}{ Dominant } & GG & 202 & 617.2 & 15.1 & \multirow{2}{*}{0.31} \\
\hline & $G A+A A$ & 283 & 634.0 & 17.9 & \\
\hline \multirow[t]{2}{*}{ Recessive } & $G G+G A$ & 427 & 637.8 & 13.4 & \multirow{2}{*}{$0.011 *$} \\
\hline & $\mathrm{AA}$ & 58 & 547.9 & 24.7 & \\
\hline \multirow[t]{2}{*}{ Over-dominant } & $G G+A A$ & 260 & 601.8 & 13.0 & \multirow{2}{*}{0.51} \\
\hline & GA & 225 & 656.2 & 21.4 & \\
\hline
\end{tabular}

$\left({ }^{*}\right) P$-value are age, sex, center, and fat mass adjusted. 
CHAPTER 5

The association between vitamin $\mathrm{D}$ receptor polymorphisms and tissue-specific insulin resistance in human obesity

\section{Supplemental Table S4. Cis eQTL analysis for the association between VDR SNPs and abdominal SAT transcriptome}

\begin{tabular}{|c|c|c|c|}
\hline External Gene Name & Ensemble Gene ID & SNPs ID & $\begin{array}{l}\text { Uncorrected } \\
\text { p-value }\end{array}$ \\
\hline AC004241.1 & ENSG00000257433 & rs731236 & 0.99469 \\
\hline AC004241.1 & ENSG00000257433 & rs1544410 & 0.88040 \\
\hline AC004466.1 & ENSG00000268069 & rs731236 & 0.93225 \\
\hline AC004466.1 & ENSG00000268069 & rs1544410 & 0.98856 \\
\hline AC004801.1 & ENSG00000226138 & rs731236 & 0.30670 \\
\hline AC004801.1 & ENSG00000226138 & rs1544410 & 0.72247 \\
\hline AC004801.2 & ENSG00000240399 & rs731236 & 0.42504 \\
\hline AC004801.2 & ENSG00000240399 & rs1544410 & 0.35540 \\
\hline AC008014.1 & ENSG00000257261 & rs731236 & 0.48353 \\
\hline AC008014.1 & ENSG00000257261 & rs1544410 & 0.93297 \\
\hline AC008083.2 & ENSG00000257925 & rs731236 & 0.20447 \\
\hline AC008083.2 & ENSG00000257925 & rs1544410 & 0.12114 \\
\hline AC008083.3 & ENSG00000258181 & rs731236 & 0.26733 \\
\hline AC008083.3 & ENSG00000258181 & rs1544410 & 0.20223 \\
\hline AC024257.3 & ENSG00000269514 & rs731236 & 0.25634 \\
\hline AC024257.3 & ENSG00000269514 & rs1544410 & 0.39731 \\
\hline AC090115.1 & ENSG00000257735 & rs731236 & 0.87932 \\
\hline AC090115.1 & ENSG00000257735 & rs1544410 & 0.83515 \\
\hline AC119044.1 & ENSG00000258352 & rs731236 & 0.44192 \\
\hline AC119044.1 & ENSG00000258352 & rs1544410 & 0.31780 \\
\hline$A D C Y 6$ & ENSG00000174233 & rs731236 & 0.39809 \\
\hline$A D C Y 6$ & ENSG00000174233 & rs1544410 & 0.28094 \\
\hline AMIGO2 & ENSG00000139211 & rs731236 & 0.37283 \\
\hline AMIGO2 & ENSG00000139211 & rs1544410 & 0.90822 \\
\hline ASB8 & ENSG00000177981 & rs731236 & 0.02566 \\
\hline ASB8 & ENSG00000177981 & rs1544410 & 0.03282 \\
\hline C12orf54 & ENSG00000177627 & rs731236 & 0.61907 \\
\hline C12orf54 & ENSG00000177627 & rs1544410 & 0.40474 \\
\hline CACNB3 & ENSG00000167535 & rs731236 & 0.91111 \\
\hline CACNB3 & ENSG00000167535 & rs1544410 & 0.76199 \\
\hline CCDC184 & ENSG00000177875 & rs731236 & 0.48553 \\
\hline CCDC184 & ENSG00000177875 & rs1544410 & 0.48287 \\
\hline CCNT1 & ENSG00000129315 & rs731236 & 0.52803 \\
\hline CCNT1 & ENSG00000129315 & rs1544410 & 0.38410 \\
\hline$D D \times 23$ & ENSG00000174243 & rs731236 & 0.70691 \\
\hline$D D \times 23$ & ENSG00000174243 & rs1544410 & 0.50571 \\
\hline ENDOU & ENSG00000111405 & rs731236 & 0.09196 \\
\hline ENDOU & ENSG00000111405 & rs1544410 & 0.23893 \\
\hline H1FNT & ENSG00000187166 & rs731236 & 0.63911 \\
\hline
\end{tabular}


CHAPTER 5

The association between vitamin $\mathrm{D}$ receptor polymorphisms and tissue-specific insulin resistance in human obesity

\begin{tabular}{|c|c|c|c|}
\hline H1FNT & ENSG00000187166 & rs1544410 & 0.26691 \\
\hline HDAC7 & ENSG00000061273 & rs731236 & 0.60242 \\
\hline HDAC7 & ENSG00000061273 & rs1544410 & 0.84823 \\
\hline KANSL2 & ENSG00000139620 & rs731236 & 0.01986 \\
\hline KANSL2 & ENSG00000139620 & rs1544410 & 0.15509 \\
\hline LINC02156 & ENSG00000257906 & rs731236 & 0.74041 \\
\hline LINC02156 & ENSG00000257906 & rs1544410 & 0.67127 \\
\hline MIR4701 & ENSG00000264201 & rs731236 & 0.80517 \\
\hline MIR4701 & ENSG00000264201 & rs1544410 & 0.50309 \\
\hline OR10AD1 & ENSG00000172640 & rs731236 & 0.81170 \\
\hline OR10AD1 & ENSG00000172640 & rs1544410 & 0.66316 \\
\hline OR5BK1P & ENSG00000257763 & rs731236 & 0.87842 \\
\hline OR5BK1P & ENSG00000257763 & rs1544410 & 0.75369 \\
\hline OR5BT1P & ENSG00000258024 & rs731236 & 0.80873 \\
\hline OR5BT1P & ENSG00000258024 & rs1544410 & 0.91078 \\
\hline OR8T1P & ENSG00000226413 & rs731236 & 0.11767 \\
\hline OR8T1P & ENSG00000226413 & rs1544410 & 0.56028 \\
\hline PCED1B & ENSG00000179715 & rs731236 & 0.11442 \\
\hline PCED1B & ENSG00000179715 & rs1544410 & 0.53613 \\
\hline PCED1B-AS1 & ENSG00000247774 & rs731236 & 0.42487 \\
\hline PCED1B-AS1 & ENSG00000247774 & rs1544410 & 0.48036 \\
\hline PFKM & ENSG00000152556 & rs731236 & 0.14653 \\
\hline PFKM & ENSG00000152556 & rs1544410 & 0.16194 \\
\hline RAPGEF3 & ENSG00000079337 & rs731236 & 0.45454 \\
\hline RAPGEF3 & ENSG00000079337 & rs1544410 & 0.50054 \\
\hline RPAP3 & ENSG00000005175 & rs731236 & 0.17424 \\
\hline RPAP3 & ENSG00000005175 & rs1544410 & 0.11689 \\
\hline SENP1 & ENSG00000079387 & rs731236 & 0.32878 \\
\hline SENP1 & ENSG00000079387 & rs1544410 & 0.44986 \\
\hline SLC48A1 & ENSG00000211584 & rs731236 & 0.80739 \\
\hline SLC48A1 & ENSG00000211584 & rs1544410 & 0.73488 \\
\hline SNORA2A & ENSG00000206612 & rs731236 & 0.81513 \\
\hline SNORA2A & ENSG00000206612 & rs1544410 & 0.37916 \\
\hline SNORA2C & ENSG00000221491 & rs731236 & 0.54230 \\
\hline SNORA2C & ENSG00000221491 & rs1544410 & 0.16198 \\
\hline TEX49 & ENSG00000257987 & rs731236 & 0.94032 \\
\hline TEX49 & ENSG00000257987 & rs1544410 & 0.21053 \\
\hline TMEM106C & ENSG00000134291 & rs731236 & 0.98853 \\
\hline TMEM106C & ENSG00000134291 & rs1544410 & 0.79571 \\
\hline$V D R$ & ENSG00000111424 & rs731236 & 0.96896 \\
\hline$V D R$ & ENSG00000111424 & rs1544410 & 0.86894 \\
\hline ZNF641 & ENSG00000167528 & rs731236 & 0.65912 \\
\hline ZNF641 & ENSG00000167528 & rs1544410 & 0.44825 \\
\hline
\end{tabular}

Abbreviation: SNPs, single-nucleotide polymorphisms 
CHAPTER 5

The association between vitamin $\mathrm{D}$ receptor polymorphisms and tissue-specific insulin resistance in human obesity

\section{Supplemental Table S5. Trans eQTL analysis for the association between VDR SNPs and abdominal SAT transcriptome}

\begin{tabular}{|c|c|c|c|}
\hline Gene Symbol / Name & Ensemble Gene ID & SNPs ID & $\begin{array}{l}\text { Uncorrected } \\
\text { p-value }\end{array}$ \\
\hline$A D I P O Q$ & ENSG00000181092 & rs731236 & 0.455771 \\
\hline$A D I P O Q$ & ENSG00000181092 & rs1544410 & 0.583178 \\
\hline$A D I P O Q$ & ENSG00000181092 & rs7975232 & 0.547899 \\
\hline$A D I P O Q$ & ENSG00000181092 & rs10735810 & 0.471824 \\
\hline ADRB2 & ENSG00000169252 & rs731236 & 0.554752 \\
\hline ADRB2 & ENSG00000169252 & rs1544410 & 0.758225 \\
\hline ADRB2 & ENSG00000169252 & rs7975232 & 0.568370 \\
\hline ADRB2 & ENSG00000169252 & rs10735810 & 0.291999 \\
\hline AGPAT2 & ENSG00000169692 & rs731236 & 0.709753 \\
\hline AGPAT2 & ENSG00000169692 & rs1544410 & 0.679197 \\
\hline AGPAT2 & ENSG00000169692 & rs7975232 & 0.666850 \\
\hline AGPAT2 & ENSG00000169692 & rs10735810 & 0.991221 \\
\hline$A K T$ & ENSG00000142208 & rs731236 & 0.745880 \\
\hline$A K T$ & ENSG00000142208 & rs1544410 & 0.702942 \\
\hline$A K T$ & ENSG00000142208 & rs7975232 & 0.903707 \\
\hline$A K T$ & ENSG00000142208 & rs10735810 & 0.161249 \\
\hline$A M P K$ & ENSG00000132356 & rs731236 & 0.842185 \\
\hline$A M P K$ & ENSG00000132356 & rs1544410 & 0.711332 \\
\hline$A M P K$ & ENSG00000132356 & rs7975232 & 0.664204 \\
\hline$A M P K$ & ENSG00000132356 & rs10735810 & 0.984760 \\
\hline ASAP2 & ENSG00000151693 & rs731236 & 0.321611 \\
\hline$A S A P 2$ & ENSG00000151693 & rs1544410 & 0.367287 \\
\hline$A S A P 2$ & ENSG00000151693 & rs7975232 & 0.389561 \\
\hline ASAP2 & ENSG00000151693 & rs10735810 & 0.655794 \\
\hline$B C L 6$ & ENSG00000113916 & rs731236 & 0.325408 \\
\hline$B C L 6$ & ENSG00000113916 & rs1544410 & 0.188299 \\
\hline$B C L 6$ & ENSG00000113916 & rs7975232 & 0.383846 \\
\hline$B C L 6$ & ENSG00000113916 & rs10735810 & 0.681122 \\
\hline CD14 & ENSG00000170458 & rs731236 & 0.564831 \\
\hline CD14 & ENSG00000170458 & rs1544410 & 0.949605 \\
\hline CD14 & ENSG00000170458 & rs7975232 & 0.552160 \\
\hline CD14 & ENSG00000170458 & rs10735810 & 0.764573 \\
\hline
\end{tabular}


CHAPTER 5

The association between vitamin $\mathrm{D}$ receptor polymorphisms and tissue-specific insulin resistance in human obesity

\begin{tabular}{|c|c|c|c|}
\hline$C D 274$ & ENSG00000120217 & rs731236 & 0.508695 \\
\hline$C D 274$ & ENSG00000120217 & rs1544410 & 0.519024 \\
\hline$C D 274$ & ENSG00000120217 & rs7975232 & 0.544318 \\
\hline$C D 274$ & ENSG00000120217 & rs10735810 & 0.734286 \\
\hline CD36/GP4/FAT & ENSG00000135218 & rs731236 & 0.564701 \\
\hline CD36/GP4/FAT & ENSG00000135218 & rs1544410 & 0.768725 \\
\hline CD36/GP4/FAT & ENSG00000135218 & rs7975232 & 0.670100 \\
\hline CD36/GP4/FAT & ENSG00000135218 & rs10735810 & 0.179631 \\
\hline CEBP alpha & ENSG00000245848 & rs731236 & 0.710341 \\
\hline CEBP alpha & ENSG00000245848 & rs1544410 & 0.879930 \\
\hline CEBP alpha & ENSG00000245848 & rs7975232 & 0.726116 \\
\hline CEBP alpha & ENSG00000245848 & rs10735810 & 0.443595 \\
\hline CEBP beta & ENSG00000172216 & rs731236 & 0.120219 \\
\hline CEBP beta & ENSG00000172216 & rs1544410 & 0.863106 \\
\hline CEBP beta & ENSG00000172216 & rs7975232 & 0.129213 \\
\hline CEBP beta & ENSG00000172216 & rs10735810 & 0.944037 \\
\hline CGI58/ABHD5 & ENSG00000011198 & rs731236 & 0.480435 \\
\hline CGI58/ABHD5 & ENSG00000011198 & rs1544410 & 0.394122 \\
\hline CGI58/ABHD5 & ENSG00000011198 & rs7975232 & 0.572882 \\
\hline CGI58/ABHD5 & ENSG00000011198 & rs10735810 & 0.364466 \\
\hline cGMP & ENSG00000164430 & rs731236 & 0.554868 \\
\hline cGMP & ENSG00000164430 & rs1544410 & 0.534201 \\
\hline cGMP & ENSG00000164430 & rs7975232 & 0.674139 \\
\hline cGMP & ENSG00000164430 & rs10735810 & 0.289114 \\
\hline ChREBP & ENSG00000009950 & rs731236 & 0.877966 \\
\hline ChREBP & ENSG00000009950 & rs1544410 & 0.847874 \\
\hline ChREBP & ENSG00000009950 & rs7975232 & 0.999319 \\
\hline ChREBP & ENSG00000009950 & rs10735810 & 0.849390 \\
\hline CPT1 alpha & ENSG00000110090 & rs731236 & 0.075466 \\
\hline CPT1 alpha & ENSG00000110090 & rs1544410 & 0.367426 \\
\hline CPT1 alpha & ENSG00000110090 & rs7975232 & 0.117869 \\
\hline CPT1 alpha & ENSG00000110090 & rs10735810 & 0.586946 \\
\hline CYP27A1 & ENSG00000135929 & rs731236 & 0.888183 \\
\hline CYP27A1 & ENSG00000135929 & rs1544410 & 0.628180 \\
\hline CYP27A1 & ENSG00000135929 & rs7975232 & 0.797584 \\
\hline CYP27A1 & ENSG00000135929 & rs10735810 & 0.294358 \\
\hline
\end{tabular}


CHAPTER 5

The association between vitamin $\mathrm{D}$ receptor polymorphisms and tissue-specific insulin resistance in human obesity

\begin{tabular}{|c|c|c|c|}
\hline CYP27B1 & ENSG00000111012 & rs731236 & 0.764641 \\
\hline CYP27B1 & ENSG00000111012 & rs1544410 & 0.482150 \\
\hline CYP27B1 & ENSG00000111012 & rs7975232 & 0.844958 \\
\hline CYP27B1 & ENSG00000111012 & rs10735810 & 0.864502 \\
\hline DUSP10 & ENSG00000143507 & rs731236 & 0.581689 \\
\hline DUSP10 & ENSG00000143507 & rs1544410 & 0.716124 \\
\hline DUSP10 & ENSG00000143507 & rs7975232 & 0.471904 \\
\hline DUSP10 & ENSG00000143507 & rs10735810 & 0.659463 \\
\hline ELOVL3 & ENSG00000119915 & rs731236 & 0.353104 \\
\hline ELOVL3 & ENSG00000119915 & rs1544410 & 0.128534 \\
\hline ELOVL3 & ENSG00000119915 & rs7975232 & 0.346517 \\
\hline ELOVL3 & ENSG00000119915 & rs10735810 & 0.565609 \\
\hline ELOVL5 & ENSG00000012660 & rs731236 & 0.764295 \\
\hline ELOVL5 & ENSG00000012660 & rs1544410 & 0.996432 \\
\hline ELOVL5 & ENSG00000012660 & rs7975232 & 0.676255 \\
\hline ELOVL5 & ENSG00000012660 & rs10735810 & 0.986764 \\
\hline ELOVL6 & ENSG00000170522 & rs731236 & 0.280761 \\
\hline ELOVL6 & ENSG00000170522 & rs1544410 & 0.642418 \\
\hline ELOVL6 & ENSG00000170522 & rs7975232 & 0.302517 \\
\hline ELOVL6 & ENSG00000170522 & rs10735810 & 0.239844 \\
\hline$F A B P 4 / a P 2$ & ENSG00000170323 & rs731236 & 0.252726 \\
\hline$F A B P 4 / a P 2$ & ENSG00000170323 & rs1544410 & 0.114612 \\
\hline$F A B P 4 / a P 2$ & ENSG00000170323 & rs7975232 & 0.311057 \\
\hline$F A B P 4 / a P 2$ & ENSG00000170323 & rs10735810 & 0.414575 \\
\hline FASN & ENSG00000169710 & rs731236 & 0.643663 \\
\hline FASN & ENSG00000169710 & rs1544410 & 0.904114 \\
\hline FASN & ENSG00000169710 & rs7975232 & 0.564575 \\
\hline FASN & ENSG00000169710 & rs10735810 & 0.474491 \\
\hline FBP1 & ENSG00000165140 & rs731236 & 0.988056 \\
\hline FBP1 & ENSG00000165140 & rs1544410 & 0.589106 \\
\hline FBP1 & ENSG00000165140 & rs7975232 & 0.851003 \\
\hline FBP1 & ENSG00000165140 & rs10735810 & 0.203295 \\
\hline FUCA1 & ENSG00000179163 & rs731236 & 0.761917 \\
\hline FUCA1 & ENSG00000179163 & rs1544410 & 0.902608 \\
\hline FUCA1 & ENSG00000179163 & rs7975232 & 0.811523 \\
\hline FUCA1 & ENSG00000179163 & rs10735810 & 0.921394 \\
\hline
\end{tabular}


CHAPTER 5

The association between vitamin $\mathrm{D}$ receptor polymorphisms and tissue-specific insulin resistance in human obesity

\begin{tabular}{|c|c|c|c|}
\hline GOS2 & ENSG00000123689 & rs731236 & 0.400351 \\
\hline GOS2 & ENSG00000123689 & rs1544410 & 0.900682 \\
\hline GOS2 & ENSG00000123689 & rs7975232 & 0.378927 \\
\hline GOS2 & ENSG00000123689 & rs10735810 & 0.986559 \\
\hline$G C R / N R 3 C 1$ & ENSG00000113580 & rs731236 & 0.899442 \\
\hline$G C R / N R 3 C 1$ & ENSG00000113580 & rs1544410 & 0.709112 \\
\hline GCR/NR3C1 & ENSG00000113580 & rs7975232 & 0.974601 \\
\hline$G C R / N R 3 C 1$ & ENSG00000113580 & rs10735810 & 0.328819 \\
\hline G6PDH & ENSG00000160211 & rs731236 & 0.951515 \\
\hline G6PDH & ENSG00000160211 & rs1544410 & 0.386809 \\
\hline G6PDH & ENSG00000160211 & rs7975232 & 0.865034 \\
\hline G6PDH & ENSG00000160211 & rs10735810 & 0.045936 \\
\hline GLUT4 & ENSG00000181856 & rs731236 & 0.490177 \\
\hline GLUT4 & ENSG00000181856 & rs1544410 & 0.937162 \\
\hline GLUT4 & ENSG00000181856 & rs7975232 & 0.436036 \\
\hline GLUT4 & ENSG00000181856 & rs10735810 & 0.821755 \\
\hline HIF-2 & ENSG00000135245 & rs731236 & 0.205890 \\
\hline HIF-2 & ENSG00000135245 & rs1544410 & 0.065505 \\
\hline HIF-2 & ENSG00000135245 & rs7975232 & 0.148536 \\
\hline HIF-2 & ENSG00000135245 & rs10735810 & 0.518143 \\
\hline IGFBP3 & ENSG00000146674 & rs731236 & 0.482403 \\
\hline IGFBP3 & ENSG00000146674 & rs1544410 & 0.637022 \\
\hline IGFBP3 & ENSG00000146674 & rs7975232 & 0.595182 \\
\hline IGFBP3 & ENSG00000146674 & rs10735810 & 0.903709 \\
\hline IL-6 & ENSG00000136244 & rs731236 & 0.140935 \\
\hline IL-6 & ENSG00000136244 & rs1544410 & 0.807286 \\
\hline$I L-6$ & ENSG00000136244 & rs7975232 & 0.094911 \\
\hline IL-6 & ENSG00000136244 & rs10735810 & 0.332016 \\
\hline IL10 & ENSG00000136634 & rs731236 & 0.715458 \\
\hline IL10 & ENSG00000136634 & rs1544410 & 0.403498 \\
\hline IL10 & ENSG00000136634 & rs7975232 & 0.717372 \\
\hline IL10 & ENSG00000136634 & rs10735810 & 0.116512 \\
\hline$I L 1 b$ & ENSG00000125538 & rs731236 & 0.881061 \\
\hline$I L 1 b$ & ENSG00000125538 & rs1544410 & 0.731165 \\
\hline$I L 1 b$ & ENSG00000125538 & rs7975232 & 0.766322 \\
\hline$I L 1 b$ & ENSG00000125538 & rs10735810 & 0.291848 \\
\hline
\end{tabular}


CHAPTER 5

The association between vitamin $\mathrm{D}$ receptor polymorphisms and tissue-specific insulin resistance in human obesity

\begin{tabular}{|c|c|c|c|}
\hline IL4 & ENSG00000113520 & rs731236 & 0.432480 \\
\hline IL4 & ENSG00000113520 & rs1544410 & 0.535233 \\
\hline IL4 & ENSG00000113520 & rs7975232 & 0.412625 \\
\hline IL4 & ENSG00000113520 & rs10735810 & 0.235396 \\
\hline IRF/8 & ENSG00000140968 & rs731236 & 0.857759 \\
\hline IRF/8 & ENSG00000140968 & rs1544410 & 0.317458 \\
\hline IRF/8 & ENSG00000140968 & rs7975232 & 0.689645 \\
\hline IRF/8 & ENSG00000140968 & rs10735810 & 0.336422 \\
\hline IRS-1 & ENSG00000169047 & rs731236 & 0.237335 \\
\hline IRS-1 & ENSG00000169047 & rs1544410 & 0.708163 \\
\hline IRS-1 & ENSG00000169047 & rs7975232 & 0.203457 \\
\hline IRS-1 & ENSG00000169047 & rs10735810 & 0.468792 \\
\hline$J A K$ & ENSG00000162434 & rs731236 & 0.999467 \\
\hline$J A K$ & ENSG00000162434 & rs1544410 & 0.617411 \\
\hline$J A K$ & ENSG00000162434 & rs7975232 & 0.868002 \\
\hline$J A K$ & ENSG00000162434 & rs10735810 & 0.888699 \\
\hline KLF5 & ENSG00000102554 & rs731236 & 0.263342 \\
\hline KLF5 & ENSG00000102554 & rs1544410 & 0.498447 \\
\hline KLF5 & ENSG00000102554 & rs7975232 & 0.340295 \\
\hline KLF5 & ENSG00000102554 & rs10735810 & 0.986493 \\
\hline LEPTIN gene & ENSG00000174697 & rs731236 & 0.455041 \\
\hline LEPTIN gene & ENSG00000174697 & rs1544410 & 0.635911 \\
\hline LEPTIN gene & ENSG00000174697 & rs7975232 & 0.571979 \\
\hline LEPTIN gene & ENSG00000174697 & rs10735810 & 0.273339 \\
\hline Lipolysis Gene (HSL) & ENSG00000079435 & rs731236 & 0.618543 \\
\hline Lipolysis Gene (HSL) & ENSG00000079435 & rs1544410 & 0.721577 \\
\hline Lipolysis Gene (HSL) & ENSG00000079435 & rs7975232 & 0.624253 \\
\hline Lipolysis Gene (HSL) & ENSG00000079435 & rs10735810 & 0.629081 \\
\hline Lipolysis Gene (ATGL/PNPLA2) & ENSG00000177666 & rs731236 & 0.225928 \\
\hline Lipolysis Gene (ATGL/PNPLA2) & ENSG00000177666 & rs1544410 & 0.728314 \\
\hline Lipolysis Gene (ATGL/PNPLA2) & ENSG00000177666 & rs7975232 & 0.282723 \\
\hline Lipolysis Gene (ATGL/PNPLA2) & ENSG00000177666 & rs10735810 & 0.902261 \\
\hline LPGAT1 & ENSG00000153395 & rs731236 & 0.705962 \\
\hline LPGAT1 & ENSG00000153395 & rs1544410 & 0.742170 \\
\hline LPGAT1 & ENSG00000153395 & rs7975232 & 0.689354 \\
\hline LPGAT1 & ENSG00000153395 & rs10735810 & 0.285120 \\
\hline
\end{tabular}


CHAPTER 5

The association between vitamin $\mathrm{D}$ receptor polymorphisms and tissue-specific insulin resistance in human obesity

\begin{tabular}{|c|c|c|c|}
\hline LPIN1 & ENSG00000134324 & rs731236 & 0.983600 \\
\hline LPIN1 & ENSG00000134324 & rs1544410 & 0.742501 \\
\hline LPIN1 & ENSG00000134324 & rs7975232 & 0.890749 \\
\hline LPIN1 & ENSG00000134324 & rs10735810 & 0.805104 \\
\hline$L P L$ & ENSG00000175445 & rs731236 & 0.716027 \\
\hline$L P L$ & ENSG00000175445 & rs1544410 & 0.318743 \\
\hline$L P L$ & ENSG00000175445 & rs7975232 & 0.579031 \\
\hline$L P L$ & ENSG00000175445 & rs10735810 & 0.955493 \\
\hline$L R R C 25$ & ENSG00000175489 & rs731236 & 0.652329 \\
\hline LRRC25 & ENSG00000175489 & rs1544410 & 0.993398 \\
\hline LRRC25 & ENSG00000175489 & rs7975232 & 0.733143 \\
\hline LRRC25 & ENSG00000175489 & rs10735810 & 0.133150 \\
\hline LRRC8A & ENSG00000136802 & rs731236 & 0.718964 \\
\hline LRRC8A & ENSG00000136802 & rs1544410 & 0.744592 \\
\hline$\angle R R C 8 A$ & ENSG00000136802 & rs7975232 & 0.622977 \\
\hline LRRC8A & ENSG00000136802 & rs10735810 & 0.587621 \\
\hline MAPK1 & ENSG00000100030 & rs731236 & 0.416836 \\
\hline MAPK1 & ENSG00000100030 & rs1544410 & 0.408182 \\
\hline MAPK1 & ENSG00000100030 & rs7975232 & 0.328973 \\
\hline MAPK1 & ENSG00000100030 & rs10735810 & 0.334360 \\
\hline MARRS/PDIA3 & ENSG00000167004 & rs731236 & 0.529960 \\
\hline MARRS/PDIA3 & ENSG00000167004 & rs1544410 & 0.927959 \\
\hline MARRS/PDIA3 & ENSG00000167004 & rs7975232 & 0.527661 \\
\hline MARRS/PDIA3 & ENSG00000167004 & rs10735810 & 0.860993 \\
\hline$M C P-1 / C C L 2$ & ENSG00000108691 & rs731236 & 0.169003 \\
\hline$M C P-1 / C C L 2$ & ENSG00000108691 & rs1544410 & 0.184940 \\
\hline$M C P-1 / C C L 2$ & ENSG00000108691 & rs7975232 & 0.133740 \\
\hline$M C P-1 / C C L 2$ & ENSG00000108691 & rs10735810 & 0.920663 \\
\hline MEK & ENSG00000169032 & rs731236 & 0.334461 \\
\hline MEK & ENSG00000169032 & rs1544410 & 0.882005 \\
\hline MEK & ENSG00000169032 & rs7975232 & 0.569745 \\
\hline MEK & ENSG00000169032 & rs10735810 & 0.410889 \\
\hline MGLL & ENSG00000074416 & rs731236 & 0.449126 \\
\hline MGLL & ENSG00000074416 & rs1544410 & 0.765235 \\
\hline MGLL & ENSG00000074416 & rs7975232 & 0.456461 \\
\hline MGLL & ENSG00000074416 & rs10735810 & 0.582794 \\
\hline
\end{tabular}


CHAPTER 5

The association between vitamin $\mathrm{D}$ receptor polymorphisms and tissue-specific insulin resistance in human obesity

\begin{tabular}{|c|c|c|c|}
\hline NFATC $/ 2$ & ENSG00000101096 & rs731236 & 0.790467 \\
\hline NFATC/2 & ENSG00000101096 & rs1544410 & 0.651108 \\
\hline NFATC/2 & ENSG00000101096 & rs7975232 & 0.674252 \\
\hline NFATC/2 & ENSG00000101096 & rs10735810 & 0.663359 \\
\hline NFKB1 & ENSG00000109320 & rs731236 & 0.600707 \\
\hline NFKB1 & ENSG00000109320 & rs1544410 & 0.689101 \\
\hline NFKB1 & ENSG00000109320 & rs7975232 & 0.570783 \\
\hline NFKB1 & ENSG00000109320 & rs10735810 & 0.236408 \\
\hline NFKB2 & ENSG00000077150 & rs731236 & 0.589044 \\
\hline NFKB2 & ENSG00000077150 & rs1544410 & 0.741047 \\
\hline NFKB2 & ENSG00000077150 & rs7975232 & 0.561895 \\
\hline NFKB2 & ENSG00000077150 & rs10735810 & 0.300123 \\
\hline$N P R(A)$ & ENSG00000169418 & rs731236 & 0.791393 \\
\hline$N P R(A)$ & ENSG00000169418 & rs1544410 & 0.894629 \\
\hline$N P R(A)$ & ENSG00000169418 & rs7975232 & 0.900030 \\
\hline$N P R(A)$ & ENSG00000169418 & rs10735810 & 0.838292 \\
\hline$N P R(C)$ & ENSG00000113389 & rs731236 & 0.357951 \\
\hline$N P R(C)$ & ENSG00000113389 & rs1544410 & 0.125813 \\
\hline$N P R(C)$ & ENSG00000113389 & rs7975232 & 0.359934 \\
\hline$N P R(C)$ & ENSG00000113389 & rs10735810 & 0.047163 \\
\hline NRIP1 & ENSG00000180530 & rs731236 & 0.484102 \\
\hline NRIP1 & ENSG00000180530 & rs1544410 & 0.792344 \\
\hline NRIP1 & ENSG00000180530 & rs7975232 & 0.531864 \\
\hline NRIP1 & ENSG00000180530 & rs10735810 & 0.331990 \\
\hline P38/MAPK14 & ENSG00000112062 & rs731236 & 0.972425 \\
\hline P38/MAPK14 & ENSG00000112062 & rs1544410 & 0.680897 \\
\hline P38/MAPK14 & ENSG00000112062 & rs7975232 & 0.893236 \\
\hline P38/MAPK14 & ENSG00000112062 & rs10735810 & 0.340913 \\
\hline$p 53$ & ENSG00000141510 & rs731236 & 0.770322 \\
\hline$p 53$ & ENSG00000141510 & rs1544410 & 0.701156 \\
\hline$p 53$ & ENSG00000141510 & rs7975232 & 0.728798 \\
\hline$p 53$ & ENSG00000141510 & rs10735810 & 0.198160 \\
\hline PDK4 & ENSG00000004799 & rs731236 & 0.356615 \\
\hline PDK4 & ENSG00000004799 & rs1544410 & 0.215324 \\
\hline PDK4 & ENSG00000004799 & rs7975232 & 0.294460 \\
\hline PDK4 & ENSG00000004799 & rs10735810 & 0.225928 \\
\hline
\end{tabular}


CHAPTER 5

The association between vitamin $\mathrm{D}$ receptor polymorphisms and tissue-specific insulin resistance in human obesity

\begin{tabular}{|c|c|c|c|}
\hline РізK & ENSG00000121879 & rs731236 & 0.319843 \\
\hline РізК & ENSG00000121879 & rs1544410 & 0.411791 \\
\hline РізК & ENSG00000121879 & rs7975232 & 0.240937 \\
\hline PiзK & ENSG00000121879 & rs10735810 & 0.322286 \\
\hline PKA-cAMP & ENSG00000072062 & rs731236 & 0.080860 \\
\hline PKA-cAMP & ENSG00000072062 & rs1544410 & 0.246549 \\
\hline PKA-сAMP & ENSG00000072062 & rs7975232 & 0.077146 \\
\hline PKA-СAMP & ENSG00000072062 & rs10735810 & 0.618250 \\
\hline PKG, PRKG1 & ENSG00000185532 & rs731236 & 0.792431 \\
\hline PKG, PRKG1 & ENSG00000185532 & rs1544410 & 0.861508 \\
\hline PKG, PRKG1 & ENSG00000185532 & rs7975232 & 0.881917 \\
\hline PKG, PRKG1 & ENSG00000185532 & rs10735810 & 0.885963 \\
\hline PLIN1 & ENSG00000166819 & rs731236 & 0.493276 \\
\hline PLIN1 & ENSG00000166819 & rs1544410 & 0.487446 \\
\hline PLIN1 & ENSG00000166819 & rs7975232 & 0.422464 \\
\hline PLIN1 & ENSG00000166819 & rs10735810 & 0.320787 \\
\hline PPARG & ENSG00000132170 & rs731236 & 0.214866 \\
\hline PPARG & ENSG00000132170 & rs1544410 & 0.164932 \\
\hline PPARG & ENSG00000132170 & rs7975232 & 0.280887 \\
\hline PPARG & ENSG00000132170 & rs10735810 & 0.570991 \\
\hline$R A F$ & ENSG00000157764 & rs731236 & 0.892289 \\
\hline$R A F$ & ENSG00000157764 & rs1544410 & 0.669877 \\
\hline$R A F$ & ENSG00000157764 & rs7975232 & 0.791940 \\
\hline RAF & ENSG00000157764 & rs10735810 & 0.790475 \\
\hline RXR (also known as NR2B1) & ENSG00000186350 & rs731236 & 0.497599 \\
\hline RXR (also known as NR2B1) & ENSG00000186350 & rs1544410 & 0.706210 \\
\hline RXR (also known as NR2B1) & ENSG00000186350 & rs7975232 & 0.416367 \\
\hline RXR (also known as NR2B1) & ENSG00000186350 & rs10735810 & 0.766505 \\
\hline SIRT1 & ENSG00000096717 & rs731236 & 0.918472 \\
\hline SIRT1 & ENSG00000096717 & rs1544410 & 0.616911 \\
\hline SIRT1 & ENSG00000096717 & rs7975232 & 0.751828 \\
\hline SIRT1 & ENSG00000096717 & rs10735810 & 0.211152 \\
\hline SIRT2 & ENSG00000068903 & rs731236 & 0.916038 \\
\hline SIRT2 & ENSG00000068903 & rs1544410 & 0.601722 \\
\hline SIRT2 & ENSG00000068903 & rs7975232 & 0.853919 \\
\hline SIRT2 & ENSG00000068903 & rs10735810 & 0.996848 \\
\hline
\end{tabular}


CHAPTER 5

The association between vitamin $\mathrm{D}$ receptor polymorphisms and tissue-specific insulin resistance in human obesity

\begin{tabular}{|c|c|c|c|}
\hline SIRT3 & ENSG00000142082 & rs731236 & 0.872985 \\
\hline SIRT3 & ENSG00000142082 & rs1544410 & 0.824033 \\
\hline SIRT3 & ENSG00000142082 & rs7975232 & 0.891138 \\
\hline SIRT3 & ENSG00000142082 & rs10735810 & 0.868598 \\
\hline SREBP1 & ENSG00000072310 & rs731236 & 0.699367 \\
\hline SREBP1 & ENSG00000072310 & rs1544410 & 0.890846 \\
\hline SREBP1 & ENSG00000072310 & rs7975232 & 0.621155 \\
\hline SREBP1 & ENSG00000072310 & rs10735810 & 0.492756 \\
\hline STAT5B & ENSG00000173757 & rs731236 & 0.276236 \\
\hline STAT5B & ENSG00000173757 & rs1544410 & 0.157144 \\
\hline STAT5B & ENSG00000173757 & rs7975232 & 0.292999 \\
\hline STAT5B & ENSG00000173757 & rs10735810 & 0.904678 \\
\hline STEAP4 & ENSG00000127954 & rs731236 & 0.714747 \\
\hline STEAP4 & ENSG00000127954 & rs1544410 & 0.986450 \\
\hline STEAP4 & ENSG00000127954 & rs7975232 & 0.776424 \\
\hline STEAP4 & ENSG00000127954 & rs10735810 & 0.498933 \\
\hline STS & ENSG00000101846 & rs731236 & 0.237906 \\
\hline STS & ENSG00000101846 & rs1544410 & 0.229482 \\
\hline STS & ENSG00000101846 & rs7975232 & 0.277679 \\
\hline STS & ENSG00000101846 & rs10735810 & 0.298352 \\
\hline TNF alpha & ENSG00000232810 & rs731236 & 0.670245 \\
\hline TNF alpha & ENSG00000232810 & rs1544410 & 0.352961 \\
\hline TNF alpha & ENSG00000232810 & rs7975232 & 0.683853 \\
\hline TNF alpha & ENSG00000232810 & rs10735810 & 0.945494 \\
\hline TLR4 & ENSG00000136869 & rs731236 & 0.435463 \\
\hline TLR4 & ENSG00000136869 & rs1544410 & 0.819043 \\
\hline TLR4 & ENSG00000136869 & rs7975232 & 0.471708 \\
\hline TLR4 & ENSG00000136869 & rs10735810 & 0.100343 \\
\hline TREM1 & ENSG00000124731 & rs731236 & 0.649246 \\
\hline TREM1 & ENSG00000124731 & rs1544410 & 0.566640 \\
\hline TREM1 & ENSG00000124731 & rs7975232 & 0.622751 \\
\hline TREM1 & ENSG00000124731 & rs10735810 & 0.672667 \\
\hline TRPV & ENSG00000196689 & rs731236 & 0.114610 \\
\hline TRPV & ENSG00000196689 & rs1544410 & 0.344408 \\
\hline TRPV & ENSG00000196689 & rs7975232 & 0.126326 \\
\hline TRPV & ENSG00000196689 & rs10735810 & 0.697008 \\
\hline
\end{tabular}


CHAPTER 5

The association between vitamin $\mathrm{D}$ receptor polymorphisms and tissue-specific insulin resistance in human obesity

\begin{tabular}{|l|l|l|r|}
\hline$U C P 1$ & ENSG00000109424 & rs731236 & 0.168400 \\
\hline$U C P 1$ & ENSG00000109424 & rs1544410 & 0.498550 \\
\hline$U C P 1$ & ENSG00000109424 & rs7975232 & 0.228401 \\
\hline$U C P 1$ & ENSG00000109424 & rs10735810 & 0.591485 \\
\hline$U C P 2$ & ENSG00000175567 & rs731236 & 0.699806 \\
\hline$U C P 2$ & ENSG00000175567 & rs1544410 & 0.535526 \\
\hline$U C P 2$ & ENSG00000175567 & rs7975232 & 0.770138 \\
\hline$U C P 2$ & ENSG00000175567 & rs10735810 & 0.483619 \\
\hline$U C P 3$ & ENSG00000175564 & rs731236 & 0.651331 \\
\hline$U C P 3$ & ENSG00000175564 & rs1544410 & 0.811421 \\
\hline$U C P 3$ & ENSG00000175564 & rs7975232 & 0.604212 \\
\hline$U C P 3$ & ENSG00000175564 & rs10735810 & 0.388739 \\
\hline$V D R$ & ENSG00000111424 & rs731236 & 0.968960 \\
\hline$V D R$ & ENSG00000111424 & rs1544410 & 0.868942 \\
\hline$V D R$ & ENSG00000111424 & rs7975232 & 0.961647 \\
\hline$V D R$ & ENSG00000111424 & rs10735810 & 0.584302 \\
\hline
\end{tabular}

Abbreviation: SNPs, single-nucleotide polymorphisms 
CHAPTER 5

The association between vitamin $\mathrm{D}$ receptor polymorphisms and tissue-specific insulin resistance in human obesity

Supplemental Table S6. The relationship between VDR polymorphisms and weight lossweight maintenance (regain).

\begin{tabular}{|c|c|c|c|c|c|c|c|c|c|}
\hline \multirow[b]{2}{*}{ Taql rs731236 } & \multirow[b]{2}{*}{ Genotype } & \multicolumn{5}{|c|}{ Weight loss (kg)* } & \multicolumn{3}{|c|}{ Weight maintenance/regain (kg) } \\
\hline & & $\mathbf{N}$ & Mean & SE & $P$-value** & $\mathbf{N}$ & Mean & SE & $P$-value $\#$ \\
\hline \multirow{3}{*}{ Co-dominant } & AA & 182 & -10.6 & 0.4 & \multirow{3}{*}{0.97} & 141 & 0.7 & 0.4 & \multirow{3}{*}{0.68} \\
\hline & AG & 228 & -11.3 & 0.2 & & 156 & 0.1 & 0.5 & \\
\hline & GG & 81 & -11.0 & 0.4 & & 59 & 0.9 & 0.7 & \\
\hline \multirow[t]{2}{*}{ Dominant } & AA & 182 & -10.6 & 0.4 & \multirow{2}{*}{0.80} & 141 & 0.7 & 0.4 & \multirow{2}{*}{0.75} \\
\hline & $A G+G G$ & 309 & -11.3 & 0.2 & & 215 & 0.3 & 0.4 & \\
\hline \multirow[t]{2}{*}{ Recessive } & $A A+A G$ & 410 & -11.0 & 0.2 & \multirow{2}{*}{0.89} & 297 & 0.4 & 0.3 & \multirow{2}{*}{0.51} \\
\hline & GG & 81 & -11.0 & 0.4 & & 59 & 0.9 & 0.7 & \\
\hline \multirow[t]{2}{*}{ Over-dominant } & $A A+G G$ & 263 & -10.7 & 0.3 & \multirow{2}{*}{0.89} & 200 & 0.8 & 0.4 & \multirow{2}{*}{0.42} \\
\hline & AG & 228 & -11.3 & 0.2 & & 156 & 0.1 & 0.5 & \\
\hline Apal rs7975232 & Genotype & $\mathbf{N}$ & Mean & SE & $P$-value** & $\mathbf{N}$ & Mean & SE & $P$-value \\
\hline \multirow{3}{*}{ Co-dominant } & $\mathrm{CC}$ & 179 & -10.6 & 0.4 & \multirow{3}{*}{0.95} & 138 & 0.7 & 0.4 & \multirow{3}{*}{0.73} \\
\hline & CA & 228 & -11.3 & 0.2 & & 157 & 0.1 & 0.5 & \\
\hline & AA & 84 & -11.0 & 0.4 & & 61 & 0.9 & 0.7 & \\
\hline \multirow[t]{2}{*}{ Dominant } & CC & 179 & -10.6 & 0.4 & \multirow{2}{*}{0.76} & 138 & 0.7 & 0.4 & \multirow{2}{*}{0.82} \\
\hline & $C A+A A$ & 312 & -11.2 & 0.2 & & 218 & 0.4 & 0.4 & \\
\hline \multirow[t]{2}{*}{ Recessive } & $\mathrm{CC}+\mathrm{CA}$ & 407 & -11.0 & 0.2 & \multirow{2}{*}{0.83} & 295 & 0.4 & 0.3 & 052 \\
\hline & AA & 84 & -11.0 & 0.4 & & 61 & 0.9 & 0.7 & 0.53 \\
\hline Over-dominant & $C C+A A$ & 263 & -10.7 & 0.3 & & 199 & 0.8 & 0.4 & \\
\hline & $\mathrm{CA}$ & 228 & -11.3 & 0.2 & 0.90 & 157 & 0.1 & 0.5 & 0.48 \\
\hline Bsml rs1544410 & Genotype & $\mathbf{N}$ & Mean & SE & $P$-value** & $\mathbf{N}$ & Mean & SE & $P$-value ${ }^{\# \#}$ \\
\hline & $\mathrm{TT}$ & 146 & -11.2 & 0.3 & & 104 & 0.9 & 0.5 & \\
\hline Co-dominant & $\mathrm{TC}$ & 238 & -10.9 & 0.3 & 0.48 & 172 & 0.4 & 0.4 & 0.48 \\
\hline & $\mathrm{CC}$ & 107 & -10.9 & 0.5 & & 80 & 0.1 & 0.6 & \\
\hline Dominant & TT & 146 & -11.2 & 0.3 & & 104 & 0.9 & 0.5 & \\
\hline & $\mathrm{TC}+\mathrm{CC}$ & 345 & -10.9 & 0.2 & 0.55 & 252 & 0.3 & 0.4 & 0.29 \\
\hline Recessive & $\mathrm{TT}+\mathrm{TC}$ & 384 & -11.0 & 0.2 & & 276 & 0.6 & 0.3 & \\
\hline & $\mathrm{CC}$ & 107 & -10.9 & 0.5 & 0.43 & 80 & 0.1 & 0.6 & 0.36 \\
\hline Over-dominant & $\mathrm{TT}+\mathrm{CC}$ & 253 & -11.1 & 0.3 & & 184 & 0.6 & 0.4 & \\
\hline & $\mathrm{TC}$ & 238 & -10.9 & 0.3 & 0.23 & 172 & 0.4 & 0.4 & 0.84 \\
\hline Fokl rs10735810 & Genotype & $\mathbf{N}$ & Mean & SE & $P$-value** & $\mathbf{N}$ & Mean & SE & $P$-value ${ }^{\# \#}$ \\
\hline & GG & 206 & -11.1 & 0.3 & & 147 & -0.1 & 0.5 & \\
\hline Co-dominant & GA & 225 & -11.0 & 0.3 & 0.45 & 165 & 1.0 & 0.5 & 0.22 \\
\hline & $\mathrm{AA}$ & 60 & -10.8 & 0.6 & & 44 & 0.4 & 0.6 & \\
\hline Dominant & GG & 206 & -11.1 & 0.3 & & 147 & -0.1 & 0.5 & \\
\hline & $\mathrm{GA}+\mathrm{AA}$ & 285 & -10.9 & 0.3 & 0.34 & 209 & 0.9 & 0.4 & 0.14 \\
\hline Recessive & GG-GA & 431 & -11.0 & 0.2 & & 312 & 0.5 & 0.3 & \\
\hline & AA & 60 & -10.8 & 0.6 & 0.62 & 44 & 0.4 & 0.6 & 0.67 \\
\hline Over-dominant & $\mathrm{GG}+\mathrm{AA}$ & 266 & -11.1 & 0.3 & 20 & 191 & 0.1 & 0.4 & 0 \\
\hline & $\mathrm{GA}$ & 225 & -11.0 & 0.3 & 0.20 & 165 & 1.0 & 0.5 & 0.09 \\
\hline
\end{tabular}

*Weight loss is absolute change of body weight after weight loss intervention and initial body weight (baseline). "Weight regain is absolute change of body weight after maintenance phase and body weight after weight loss intervention.

$\mathrm{N}$ weight loss $=491 ; \mathrm{N}$ weight regain $=356 . *$ P-value is adjusted with initial body weight,

\# P-value was corrected for weight loss during LCD and mean body weight pre and post LCD. 
CHAPTER 5

The association between vitamin $\mathrm{D}$ receptor polymorphisms and tissue-specific insulin resistance in human obesity

Supplemental Table S7. The association between VDR polymorphisms and change of tissue-specific insulin resistance index following weight loss.

\begin{tabular}{|c|c|c|c|c|c|c|c|c|c|c|c|c|c|}
\hline \multirow[b]{2}{*}{ Taql rs731236 } & \multicolumn{5}{|c|}{ Change of HIRI ${ }^{+}$} & \multicolumn{4}{|c|}{ Change of $\mathrm{MISI}^{\ddagger}$} & \multicolumn{4}{|c|}{ Change of Adipo-IR } \\
\hline & $\begin{array}{l}\text { Geno- } \\
\text { type }\end{array}$ & $\mathbf{N}$ & Mean & SE & $\begin{array}{c}P \\
\text {-value }\end{array}$ & $\mathbf{N}$ & Mean & SE & $\begin{array}{c}P \\
\text {-value }\end{array}$ & $\mathbf{N}$ & Mean & SE & $\begin{array}{c}P \\
\text {-value }\end{array}$ \\
\hline Co-dominant & $\begin{array}{l}\text { AA } \\
\text { GA } \\
\text { GG }\end{array}$ & $\begin{array}{r}139 \\
175 \\
61 \\
\end{array}$ & $\begin{array}{l}-7.7 \\
-6.0 \\
-8.6\end{array}$ & $\begin{array}{l}1.0 \\
1.0 \\
1.4\end{array}$ & 0.16 & $\begin{array}{r}135 \\
167 \\
62 \\
\end{array}$ & $\begin{array}{l}0.00 \\
0.00 \\
0.00\end{array}$ & $\begin{array}{l}0.01 \\
0.0 \\
0.01\end{array}$ & 0.73 & $\begin{array}{r}143 \\
189 \\
58 \\
\end{array}$ & $\begin{array}{l}-1.4 \\
-2.2 \\
-2.8\end{array}$ & $\begin{array}{l}0.3 \\
0.5 \\
0.9\end{array}$ & 0.67 \\
\hline Dominant & $\begin{array}{l}\mathrm{AA} \\
\mathrm{GA}+\mathrm{GG}\end{array}$ & $\begin{array}{l}139 \\
236\end{array}$ & $\begin{array}{l}-7.6 \\
-6.7 \\
\end{array}$ & $\begin{array}{l}1.0 \\
0.8\end{array}$ & 0.26 & $\begin{array}{l}135 \\
229 \\
\end{array}$ & $\begin{array}{l}0.00 \\
0.00\end{array}$ & $\begin{array}{l}0.01 \\
0.0\end{array}$ & 0.55 & $\begin{array}{l}143 \\
247 \\
\end{array}$ & $\begin{array}{l}-1.4 \\
-2.3\end{array}$ & $\begin{array}{l}0.3 \\
0.4\end{array}$ & 0.91 \\
\hline Recessive & $\begin{array}{l}\mathrm{AA}+\mathrm{GA} \\
\mathrm{GG}\end{array}$ & $\begin{array}{r}314 \\
61 \\
\end{array}$ & $\begin{array}{l}-6.7 \\
-8.6 \\
\end{array}$ & $\begin{array}{l}0.7 \\
1.4 \\
\end{array}$ & 0.28 & $\begin{array}{r}302 \\
62 \\
\end{array}$ & $\begin{array}{l}0.00 \\
0.00\end{array}$ & $\begin{array}{l}0.0 \\
0.01\end{array}$ & 0.49 & $\begin{array}{r}332 \\
58 \\
\end{array}$ & $\begin{array}{l}-1.8 \\
-2.8 \\
\end{array}$ & $\begin{array}{l}0.3 \\
0.9 \\
\end{array}$ & 0.42 \\
\hline Over-dominant & $\begin{array}{l}A A+G G \\
G A\end{array}$ & $\begin{array}{l}200 \\
175\end{array}$ & $\begin{array}{l}-7.7 \\
-6.0 \\
\end{array}$ & $\begin{array}{l}0.8 \\
1.0\end{array}$ & 0.08 & $\begin{array}{l}197 \\
167 \\
\end{array}$ & $\begin{array}{l}0.00 \\
0.00\end{array}$ & $\begin{array}{l}0.0 \\
0.0\end{array}$ & 0.95 & $\begin{array}{l}201 \\
189 \\
\end{array}$ & $\begin{array}{l}-1.8 \\
-2.2 \\
\end{array}$ & $\begin{array}{l}0.3 \\
0.5 \\
\end{array}$ & 0.50 \\
\hline Apal rs7975232 & $\begin{array}{c}\text { Geno- } \\
\text { type }\end{array}$ & $\mathbf{N}$ & Mean & SE & $\begin{array}{c}P \\
\text {-value }\end{array}$ & $\mathbf{N}$ & Mean & SE & $\begin{array}{c}P \\
\text {-value }\end{array}$ & $\mathbf{N}$ & Mean & SE & $\begin{array}{c}P \\
\text {-value }\end{array}$ \\
\hline Co-dominant & $\begin{array}{l}\text { CC } \\
\mathrm{CA} \\
\mathrm{AA} \\
\end{array}$ & $\begin{array}{r}135 \\
175 \\
65 \\
\end{array}$ & $\begin{array}{l}-7.7 \\
-6.2 \\
-8.1 \\
\end{array}$ & $\begin{array}{l}1.1 \\
1.0 \\
1.4 \\
\end{array}$ & 0.31 & $\begin{array}{r}131 \\
168 \\
65 \\
\end{array}$ & $\begin{array}{l}0.00 \\
0.00 \\
0.00 \\
\end{array}$ & $\begin{array}{l}0.01 \\
0.0 \\
0.01 \\
\end{array}$ & 0.80 & $\begin{array}{r}141 \\
188 \\
61 \\
\end{array}$ & $\begin{array}{l}-1.4 \\
-2.1 \\
-2.9 \\
\end{array}$ & $\begin{array}{l}0.3 \\
0.5 \\
0.9 \\
\end{array}$ & 0.59 \\
\hline Dominant & $\begin{array}{l}C C \\
C A+A A\end{array}$ & $\begin{array}{l}135 \\
240 \\
\end{array}$ & $\begin{array}{l}-7.7 \\
-6.7 \\
\end{array}$ & $\begin{array}{l}1.1 \\
0.8 \\
\end{array}$ & 0.29 & $\begin{array}{l}131 \\
233 \\
\end{array}$ & $\begin{array}{l}0.00 \\
0.00\end{array}$ & $\begin{array}{l}0.01 \\
0.0\end{array}$ & 0.56 & $\begin{array}{l}141 \\
249 \\
\end{array}$ & $\begin{array}{l}-1.4 \\
-2.3 \\
\end{array}$ & $\begin{array}{l}0.4 \\
0.4 \\
\end{array}$ & 0.96 \\
\hline Recessive & $\begin{array}{l}\mathrm{CC}+\mathrm{CA} \\
\mathrm{AA}\end{array}$ & $\begin{array}{r}310 \\
65 \\
\end{array}$ & $\begin{array}{l}-6.8 \\
-8.1 \\
\end{array}$ & $\begin{array}{l}0.7 \\
1.4 \\
\end{array}$ & 0.49 & $\begin{array}{r}299 \\
65 \\
\end{array}$ & $\begin{array}{l}0.00 \\
0.00\end{array}$ & $\begin{array}{l}0.0 \\
0.01\end{array}$ & 0.61 & $\begin{array}{r}329 \\
61 \\
\end{array}$ & $\begin{array}{l}-1.8 \\
-2.9 \\
\end{array}$ & $\begin{array}{l}0.3 \\
0.9 \\
\end{array}$ & 0.34 \\
\hline Over-dominant & $\begin{array}{l}C \mathrm{C}+\mathrm{AA} \\
\mathrm{CA}\end{array}$ & $\begin{array}{l}200 \\
175 \\
\end{array}$ & $\begin{array}{l}-7.8 \\
-6.2 \\
\end{array}$ & $\begin{array}{l}0.8 \\
1.0\end{array}$ & 0.12 & $\begin{array}{l}196 \\
148 \\
\end{array}$ & $\begin{array}{l}0.00 \\
0.00\end{array}$ & $\begin{array}{l}0.0 \\
0.0\end{array}$ & 0.87 & $\begin{array}{l}202 \\
188 \\
\end{array}$ & $\begin{array}{l}-1.9 \\
-2.1 \\
\end{array}$ & $\begin{array}{l}0.3 \\
0.5 \\
\end{array}$ & 0.45 \\
\hline $\begin{array}{l}\text { Bsml } \\
\text { rs1544410 }\end{array}$ & $\begin{array}{c}\text { Geno- } \\
\text { type }\end{array}$ & $\mathbf{N}$ & Mean & SE & $\begin{array}{c}P \\
\text {-value }\end{array}$ & $\mathbf{N}$ & Mean & SE & $\begin{array}{c}P \\
\text {-value }\end{array}$ & $\mathbf{N}$ & Mean & SE & $\begin{array}{c}P \\
\text {-value }\end{array}$ \\
\hline Co-dominant & $\begin{array}{l}\text { TT } \\
\text { TC } \\
\text { CC }\end{array}$ & $\begin{array}{r}110 \\
188 \\
77 \\
\end{array}$ & $\begin{array}{l}-7.6 \\
-6.8 \\
-7.1 \\
\end{array}$ & $\begin{array}{l}1.2 \\
0.9 \\
1.4\end{array}$ & 0.97 & $\begin{array}{r}110 \\
181 \\
73 \\
\end{array}$ & $\begin{array}{l}0.00 \\
0.00 \\
0.00\end{array}$ & $\begin{array}{l}0.01 \\
0.0 \\
0.01\end{array}$ & 0.11 & $\begin{array}{r}109 \\
202 \\
80 \\
\end{array}$ & $\begin{array}{l}-3.2 \\
-1.5 \\
-1.7 \\
\end{array}$ & $\begin{array}{l}0.7 \\
0.3 \\
0.3\end{array}$ & 0.49 \\
\hline Dominant & $\begin{array}{l}\text { TT } \\
\mathrm{TC}+\mathrm{CC}\end{array}$ & $\begin{array}{l}110 \\
265 \\
\end{array}$ & $\begin{array}{l}-7.6 \\
-6.8 \\
\end{array}$ & $\begin{array}{l}1.4 \\
0.7 \\
\end{array}$ & 0.81 & $\begin{array}{r}110 \\
254 \\
\end{array}$ & $\begin{array}{l}0.00 \\
0.00\end{array}$ & $\begin{array}{l}0.01 \\
0.0 \\
\end{array}$ & 0.09 & $\begin{array}{l}109 \\
281 \\
\end{array}$ & $\begin{array}{l}-3.2 \\
-1.5 \\
\end{array}$ & $\begin{array}{l}0.7 \\
0.2\end{array}$ & 0.54 \\
\hline Recessive & $\begin{array}{l}\mathrm{TT}+\mathrm{TC} \\
\mathrm{CC}\end{array}$ & $\begin{array}{r}298 \\
77 \\
\end{array}$ & $\begin{array}{l}-7.0 \\
-7.1 \\
\end{array}$ & $\begin{array}{l}0.7 \\
1.4 \\
\end{array}$ & 0.90 & $\begin{array}{r}291 \\
73 \\
\end{array}$ & $\begin{array}{l}0.00 \\
0.00\end{array}$ & $\begin{array}{l}0.0 \\
0.01\end{array}$ & 0.96 & $\begin{array}{r}310 \\
80 \\
\end{array}$ & $\begin{array}{l}-2.1 \\
-1.7 \\
\end{array}$ & $\begin{array}{l}0.3 \\
0.3 \\
\end{array}$ & 0.43 \\
\hline Over-dominant & $\begin{array}{l}\mathrm{TT}+\mathrm{CC} \\
\mathrm{TC}\end{array}$ & $\begin{array}{l}187 \\
188 \\
\end{array}$ & $\begin{array}{l}-7.4 \\
-6.7 \\
\end{array}$ & $\begin{array}{l}0.9 \\
0.9 \\
\end{array}$ & 0.90 & $\begin{array}{l}183 \\
181 \\
\end{array}$ & $\begin{array}{l}0.00 \\
0.00\end{array}$ & $\begin{array}{l}0.0 \\
0.0 \\
\end{array}$ & 0.08 & $\begin{array}{l}189 \\
201 \\
\end{array}$ & $\begin{array}{l}-2.5 \\
-1.5 \\
\end{array}$ & $\begin{array}{l}0.5 \\
0.3 \\
\end{array}$ & 0.24 \\
\hline $\begin{array}{l}\text { Fokl } \\
\text { rs10735810 }\end{array}$ & $\begin{array}{c}\text { Geno- } \\
\text { type }\end{array}$ & $\mathbf{N}$ & Mean & SE & $\begin{array}{c}P \\
\text {-value }\end{array}$ & $\mathbf{N}$ & Mean & SE & $\begin{array}{c}P \\
\text {-value }\end{array}$ & $\mathbf{N}$ & Mean & SE & $\begin{array}{c}P \\
\text {-value }\end{array}$ \\
\hline Co-dominant & $\begin{array}{l}\mathrm{GG} \\
\mathrm{GA} \\
\mathrm{AA}\end{array}$ & $\begin{array}{r}163 \\
161 \\
51 \\
\end{array}$ & $\begin{array}{l}-7.0 \\
-6.3 \\
-9.6 \\
\end{array}$ & $\begin{array}{l}1.0 \\
1.0 \\
1.7\end{array}$ & 0.22 & $\begin{array}{l}160 \\
158 \\
46\end{array}$ & $\begin{array}{l}0.01 \\
0.00 \\
0.00\end{array}$ & $\begin{array}{l}0.0 \\
0.0 \\
0.01\end{array}$ & 0.10 & $\begin{array}{r}171 \\
174 \\
45 \\
\end{array}$ & $\begin{array}{l}-1.9 \\
-2.2 \\
-1.4 \\
\end{array}$ & $\begin{array}{l}0.4 \\
0.5 \\
0.4\end{array}$ & 0.45 \\
\hline Dominant & $\mathrm{GG}$ & $\begin{array}{l}163 \\
212 \\
\end{array}$ & $\begin{array}{l}-7.0 \\
-7.1 \\
\end{array}$ & $\begin{array}{l}1.0 \\
0.8\end{array}$ & 0.91 & $\begin{array}{l}160 \\
204\end{array}$ & $\begin{array}{l}0.01 \\
0.01\end{array}$ & $\begin{array}{l}0.0 \\
0.0 \\
\end{array}$ & 0.06 & $\begin{array}{l}171 \\
219 \\
\end{array}$ & $\begin{array}{l}-1.9 \\
-2.0 \\
\end{array}$ & $\begin{array}{l}0.4 \\
0.4\end{array}$ & 0.29 \\
\hline Recessive & $\begin{array}{l}\text { GG+GA } \\
\mathrm{AA}\end{array}$ & $\begin{array}{r}324 \\
51 \\
\end{array}$ & $\begin{array}{l}-6.7 \\
-9.6 \\
\end{array}$ & $\begin{array}{l}0.7 \\
1.7 \\
\end{array}$ & 0.10 & $\begin{array}{r}318 \\
46 \\
\end{array}$ & $\begin{array}{l}0.00 \\
0.00 \\
\end{array}$ & $\begin{array}{l}0.0 \\
0.01\end{array}$ & 0.30 & $\begin{array}{r}345 \\
45 \\
\end{array}$ & $\begin{array}{l}-2.1 \\
-1.4 \\
\end{array}$ & $\begin{array}{l}0.3 \\
0.4\end{array}$ & 0.31 \\
\hline Over-dominant & $\begin{array}{l}\text { GG+AA } \\
\text { GA }\end{array}$ & $\begin{array}{l}214 \\
161 \\
\end{array}$ & $\begin{array}{l}-7.6 \\
-6.3 \\
\end{array}$ & $\begin{array}{l}0.8 \\
1.0 \\
\end{array}$ & 0.30 & $\begin{array}{l}206 \\
158 \\
\end{array}$ & $\begin{array}{l}0.01 \\
0.00 \\
\end{array}$ & $\begin{array}{l}0.0 \\
0.0 \\
\end{array}$ & 0.13 & $\begin{array}{l}216 \\
174 \\
\end{array}$ & $\begin{array}{l}-1.8 \\
-2.2 \\
\end{array}$ & $\begin{array}{l}0.3 \\
0.5 \\
\end{array}$ & 0.69 \\
\hline
\end{tabular}

Abbreviations: Adipo-IR, adipose tissue insulin resistance index; HIRI, hepatic insulin resistance index; MISI, muscle insulin sensitivity index. For each index, $P$-value was adjusted with baseline HIRI, MISI, and Adipo-IR, respectively. (†) $\mathrm{N}=375 ;$; ( $) \mathrm{N}=364$; (\#) $\mathrm{N}=390$. 
CHAPTER 5

The association between vitamin $\mathrm{D}$ receptor polymorphisms and tissue-specific insulin resistance in human obesity

Supplemental Table S8. The association between VDR polymorphisms and change of tissue-specific insulin resistance index following weight maintenance (regain).

\begin{tabular}{|c|c|c|c|c|c|c|c|c|c|c|c|c|c|}
\hline \multirow[b]{2}{*}{ TaqI rs731236 } & \multicolumn{5}{|c|}{ Change of $\mathrm{HIRI}^{+}$} & \multicolumn{4}{|c|}{ Change of $\mathrm{MISI}^{\ddagger}$} & \multicolumn{4}{|c|}{ Change of Adipo-IR } \\
\hline & $\begin{array}{l}\text { Geno- } \\
\text { type }\end{array}$ & $\mathbf{N}$ & Mean & SE & $\begin{array}{c}P \\
\text {-value }\end{array}$ & $\mathbf{N}$ & Mean & SE & $\begin{array}{c}P \\
\text {-value }\end{array}$ & $\mathbf{N}$ & Mean & SE & $\begin{array}{c}P \\
\text {-value }\end{array}$ \\
\hline \multirow{3}{*}{ Co-dominant } & $\mathrm{AA}$ & 99 & 6.0 & 1.4 & \multirow{3}{*}{0.30} & 76 & 0.00 & 0.0 & \multirow{3}{*}{0.21} & 51 & -0.1 & 0.3 & \multirow{3}{*}{0.85} \\
\hline & $\mathrm{GA}$ & 110 & 7.2 & 1.5 & & 85 & 0.01 & 0.0 & & 55 & -0.4 & 0.6 & \\
\hline & GG & 42 & 5.4 & 2.1 & & 40 & 0.01 & 0.0 & & 19 & 0.1 & 1.1 & \\
\hline \multirow[t]{2}{*}{ Dominant } & $\mathrm{AA}$ & 99 & 6.0 & 1.4 & \multirow{2}{*}{0.38} & 76 & 0.00 & 0.0 & \multirow{2}{*}{0.09} & 51 & -0.1 & 0.3 & \multirow{2}{*}{0.62} \\
\hline & $\mathrm{GA}+\mathrm{GG}$ & 152 & 6.7 & 1.3 & & 125 & 0.01 & 0.0 & & 74 & -0.3 & 0.5 & \\
\hline \multirow[t]{2}{*}{ Recessive } & $A A+G A$ & 209 & 6.7 & 1.1 & \multirow{2}{*}{0.38} & 161 & 0.01 & 0.0 & \multirow{2}{*}{0.72} & 106 & -0.3 & 0.4 & \multirow{2}{*}{0.65} \\
\hline & GG & 42 & 5.4 & 2.1 & & 40 & 0.02 & 0.0 & & 19 & 0.1 & 1.1 & \\
\hline \multirow[t]{2}{*}{ Over-dominant } & $A A+G G$ & 141 & 5.8 & 1.2 & \multirow{2}{*}{0.13} & 116 & 0.00 & 0.0 & \multirow[b]{2}{*}{0.16} & 70 & -0.1 & 0.3 & \multirow[b]{2}{*}{0.88} \\
\hline & $\mathrm{GA}$ & 110 & 7.2 & 1.5 & & 85 & 0.01 & 0.0 & & 55 & -0.4 & 0.6 & \\
\hline Apal rs7975232 & $\begin{array}{c}\text { Geno- } \\
\text { type }\end{array}$ & $\mathbf{N}$ & Mean & SE & $\begin{array}{c}P \\
\text {-value }\end{array}$ & $\mathbf{N}$ & Mean & SE & $\begin{array}{c}P \\
\text {-value }\end{array}$ & $\mathbf{N}$ & Mean & SE & $\begin{array}{c}P \\
\text {-value }\end{array}$ \\
\hline \multirow{3}{*}{ Co-dominant } & $\mathrm{CC}$ & 97 & 6.1 & 1.4 & \multirow{3}{*}{0.32} & 76 & 0.00 & 0.0 & & 51 & -0.1 & 0.3 & \\
\hline & CA & 109 & 7.3 & 1.5 & & 84 & 0.01 & 0.0 & 0.15 & 54 & -0.3 & 0.7 & 0.94 \\
\hline & AA & 45 & 5.1 & 2.0 & & 41 & 0.01 & 0.0 & & 20 & -0.2 & 1.0 & \\
\hline Dominant & $\mathrm{CC}$ & 97 & 6.1 & 1.4 & & 76 & 0.00 & 0.0 & & 51 & -0.1 & 0.3 & \\
\hline & $\mathrm{CA}+\mathrm{AA}$ & 154 & 6.7 & 1.2 & 0.43 & 125 & 0.01 & 0.0 & 0.09 & 74 & -0.3 & 0.6 & 0.83 \\
\hline Recessive & $\mathrm{CC}+\mathrm{CA}$ & 206 & 6.7 & 1.1 & & 160 & 0.00 & 0.0 & & 105 & -0.2 & 0.4 & \\
\hline & $\mathrm{AA}$ & 47 & 5.1 & 2.0 & 0.37 & 41 & 0.01 & 0.0 & 0.91 & 20 & -0.2 & 1.0 & 0.75 \\
\hline Over-dominant & $\mathrm{CC}+\mathrm{AA}$ & 142 & 5.8 & 1.2 & & 117 & 0.00 & 0.0 & & 71 & -0.1 & 0.3 & \\
\hline & $\mathrm{CA}$ & 109 & 7.3 & 1.5 & 0.14 & 84 & 0.01 & 0.0 & 0.08 & 54 & -0.3 & 0.7 & 0.98 \\
\hline Bsml rs1544410 & $\begin{array}{c}\text { Geno- } \\
\text { type }\end{array}$ & $\mathbf{N}$ & Mean & SE & $\begin{array}{c}P \\
\text {-value }\end{array}$ & $\mathbf{N}$ & Mean & SE & $\begin{array}{c}P \\
\text {-value }\end{array}$ & $\mathbf{N}$ & Mean & SE & $\begin{array}{c}P \\
\text {-value }\end{array}$ \\
\hline & TT & 75 & 6.7 & 1.8 & & 65 & 0.01 & 0.0 & & 36 & -0.7 & 0.9 & \\
\hline Co-dominant & $\mathrm{TC}$ & 121 & 6.4 & 1.4 & 0.96 & 93 & 0.00 & 0.0 & 0.67 & 62 & 0.2 & 0.4 & 0.60 \\
\hline & $\mathrm{CC}$ & 55 & 6.1 & 1.7 & & 43 & 0.00 & 0.0 & & 27 & -0.3 & 0.4 & \\
\hline Dominant & TT & 78 & 6.7 & 1.8 & & 65 & 0.01 & 0.0 & & 36 & -0.7 & 0.9 & \\
\hline & $\mathrm{TC}+\mathrm{CC}$ & 179 & 6.3 & 1.1 & 0.88 & 136 & 0.00 & 0.0 & 0.38 & 89 & 0.0 & 0.3 & 0.36 \\
\hline Recessive & $\mathrm{TT}+\mathrm{TC}$ & 201 & 6.5 & 1.1 & & 158 & 0.00 & 0.0 & & 98 & -0.2 & 0.4 & \\
\hline & $\mathrm{CC}$ & 56 & 6.1 & 1.7 & 0.78 & 43 & 0.01 & 0.0 & 0.63 & 27 & -0.3 & 0.4 & 0.92 \\
\hline Over-dominant & $\mathrm{TT}+\mathrm{CC}$ & 130 & 6.4 & 1.3 & 02 & 108 & 0.01 & 0.0 & 067 & 63 & -0.6 & 0.6 & 027 \\
\hline & $\mathrm{TC}$ & 121 & 6.4 & 1.4 & 0.93 & 93 & 0.00 & 0.0 & $0.6 /$ & 62 & 0.2 & 0.4 & 0.31 \\
\hline $\begin{array}{l}\text { Fokl } \\
\text { rs10735810 }\end{array}$ & $\begin{array}{c}\text { Geno- } \\
\text { type }\end{array}$ & $\mathbf{N}$ & Mean & SE & $\begin{array}{c}P \\
\text {-value }\end{array}$ & $\mathbf{N}$ & Mean & SE & $\begin{array}{c}P \\
\text {-value }\end{array}$ & $\mathbf{N}$ & Mean & SE & $\begin{array}{c}P \\
\text {-value }\end{array}$ \\
\hline & GG & 109 & 7.8 & 1.4 & & 92 & 0.00 & 0.01 & & 53 & -0.0 & 0.5 & \\
\hline Co-dominant & GA & 109 & 5.3 & 1.4 & 0.33 & 86 & 0.01 & 0.01 & 0.12 & 61 & -0.4 & 0.5 & 0.77 \\
\hline & AA & 33 & 5.7 & 2.6 & & 23 & 0.02 & 0.01 & & 11 & -0.2 & 1.1 & \\
\hline Dominant & GG & 109 & 7.8 & 1.4 & & 92 & 0.00 & 0.01 & & 53 & -0.0 & 0.5 & \\
\hline & $\mathrm{GA}+\mathrm{AA}$ & 142 & 5.4 & 1.3 & 0.15 & 109 & 0.01 & 0.01 & 0.08 & 72 & -0.3 & 0.5 & 0.47 \\
\hline Recessive & $\mathrm{GG}+\mathrm{GA}$ & 218 & 6.6 & 1.0 & & 178 & 0.01 & 0.0 & & 114 & -0.2 & 0.4 & \\
\hline & $\mathrm{AA}$ & 33 & 5.7 & 2.6 & 0.38 & 23 & 0.02 & 0.01 & 0.14 & 11 & -0.2 & 1.1 & 0.78 \\
\hline Over-dominant & $G G+A A$ & 142 & 7.3 & 1.2 & & 115 & 0.00 & 0.0 & & 64 & -0.1 & 0.4 & \\
\hline & $\mathrm{GA}$ & 109 & 5.3 & 1.4 & 0.40 & 80 & 0.01 & 0.0 & 0.38 & 61 & -0.4 & 0.5 & 0.59 \\
\hline
\end{tabular}

Abbreviations: Adipo-IR, adipose tissue insulin resistance index; HIRI, hepatic insulin resistance index; MISI, muscle insulin sensitivity index. For each index, $P$-value was corrected for the changes of HIRI, MISI, and Adipo-IR values during LCD, and mean of HIRI, MISI, Adipo-IR pre and post LCD, respectively. (†) N=251; (‡) N=192; (\#) N=125. 


\section{CHAPTER 6}

The effect of vitamin D supplementation on insulin sensitivity:

a systematic review and meta-analysis

Adriyan Pramono, Johan W.E. Jocken, Ellen E. Blaak, Marleen A. van Baak

\section{Published in:}

Diabetes Care 2020 Jul; 43(7): 1659-1669

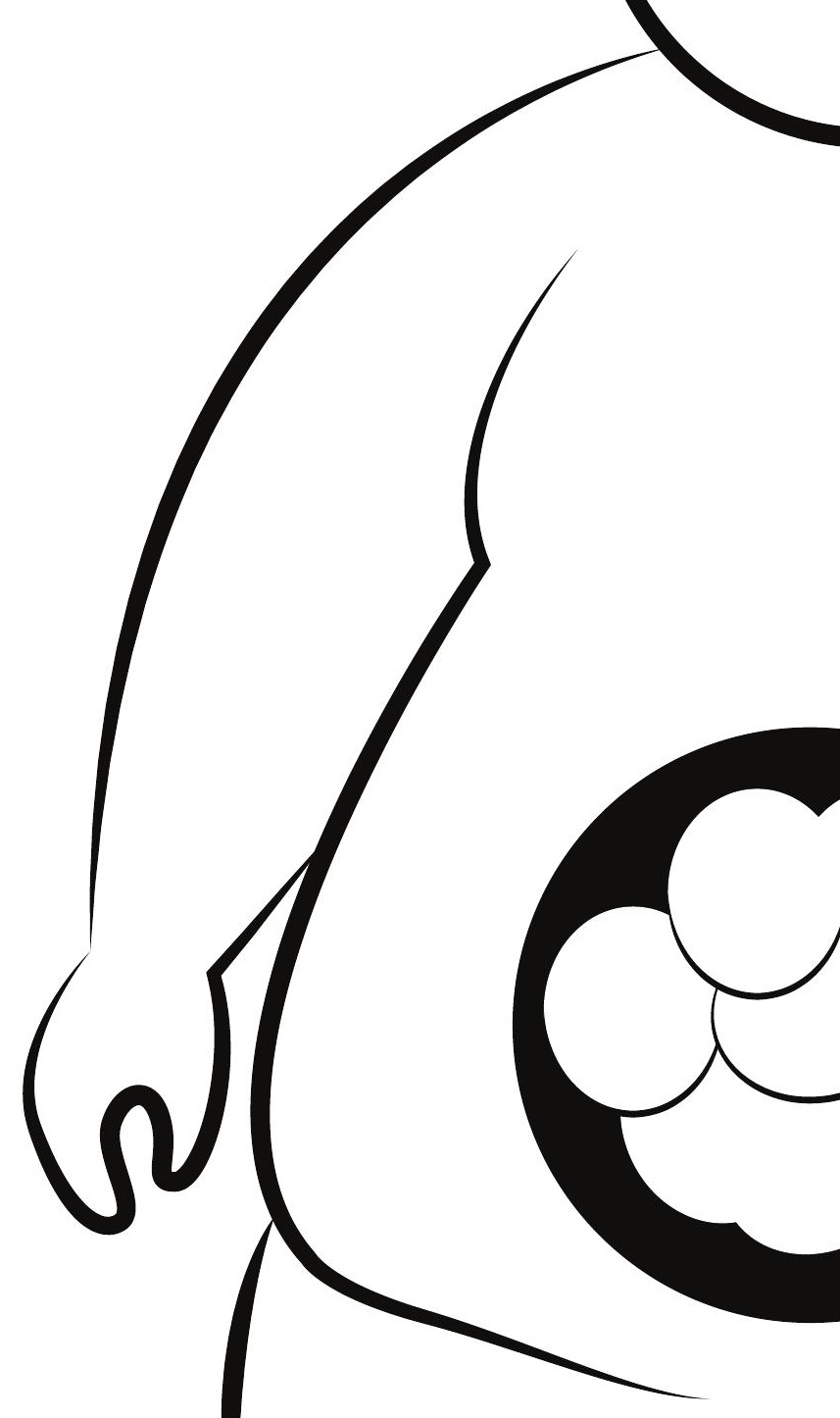




\begin{abstract}
Background: Vitamin D has been suggested to affect peripheral insulin sensitivity. Evidence regarding the effect of vitamin $D$ supplementation on insulin sensitivity is still conflicting.
\end{abstract}

Purpose: This meta-analysis aimed to assess the effect of vitamin D supplementation on insulin sensitivity in humans with or at risk of insulin resistance.

Data source and study selection: PubMed, Web of Science, Embase, CINAHL, and Cochrane library were systematically searched for randomized controlled trials (RCTs) from 1980 until 31 December 2018, reporting treatment effects of vitamin D supplementation on insulin sensitivity.

Data extraction: The main outcome of interest was the change in insulin sensitivity, derived from the gold standard hyperinsulinemic euglycemic clamp or the Matsuda index derived from Oral Glucose Tolerance Test (OGTT) and insulin sensitivity index from Intravenous Glucose Tolerance Test (IVGTT). We extracted data on the standardized mean difference (SMD) between the vitamin D treatment and placebo groups in change from baseline of insulin sensitivity.

Data synthesis: Eighteen RCTs were included in this meta-analysis comparing vitamin $D$ supplementation $(n=612)$ with placebo $(n=608)$. Vitamin $D$ supplementation had no effect on insulin sensitivity (SMD: $-0.01 ; 95 \% \mathrm{Cl}:-0.12,0.10 ; \mathrm{P}=0.87, \mathrm{I}^{2}=0 \%$ ). Visual inspection of funnel plot symmetry did not suggest potential publication bias.

Limitations: The number of individuals who participated in the included studies was relatively small possibly due to the invasive character of the measurement (e.g. clamp).

Conclusions: This meta-analysis provides no evidence that vitamin D supplementation has a beneficial effect on peripheral insulin sensitivity in people with or at risk of insulin resistance. 


\section{Introduction}

The International Diabetes Federation (1) has reported that the worldwide diabetes prevalence in the adult population reached 8.8\% (424.9 million people) in 2017. The majority (87-91\%) of these diabetes cases concerns type 2 diabetes. Type 2 diabetes has become a major public health concern due to its complications. It decreases quality of life and increases mortality risk (2). Additionally, about 7.3\% of the adult population (352.1 million people) suffers from prediabetes (1). Prediabetes is defined by increased fasting glucose and/or impaired glucose tolerance (postprandial hyperglycemia), which are both strongly associated with obesity (3). Moreover, postprandial hyperglycemia is a major risk factor for developing type 2 diabetes (4).

Obesity, prediabetes, and type 2 diabetes are often characterized by low circulating levels of vitamin D (vitamin D deficiency) (5). Indeed, based on cross sectional studies, vitamin D deficiency has been linked with an impaired insulin sensitivity in humans (6). Furthermore, people with low vitamin D levels (7) may be at greater risk to develop type 2 diabetes. Of interest, the vitamin $D$ receptor, which mediates the function of vitamin $D$, is also expressed in insulin-sensitive tissues (including adipose tissue, muscle, and pancreas) (8-10). Therefore, currently non-skeletal functions of vitamin D in insulin-sensitive organs are being investigated.

Several plausible mechanisms have been proposed to explain a potential role of vitamin $D$ in improving insulin sensitivity $(6,11)$. In adipose tissue, vitamin $D$ may affect lipid metabolism (12) and may reduce inflammation (13). Vitamin D may affect pancreatic insulin secretion via protection of beta-cells from local inflammation (14). Vitamin D may also affect insulin secretion, which is mediated by a calcium-dependent mechanism (15). In addition, it has been demonstrated that vitamin $D$ affects skeletal muscle metabolism, insulin sensitivity and lipid composition $(16,17)$. Thus, increasing circulating vitamin D concentration might be expected to have beneficial effects on tissue energy and substrate metabolism thereby contributing to an improvement of whole-body insulin sensitivity.

In recent years, several meta-analyses (18-23) have been conducted to investigate the effect of vitamin D supplementation on whole-body insulin sensitivity. However, the findings from these reports are inconsistent. From the six meta-analyses published between 2015 and 2018, 4 studies (18-21) indicated insufficient evidence/no effect on glycemic control and insulin resistance whereas 2 studies $(22,23)$ indicated sufficient evidence for an improvement of glycemic control and insulin sensitivity. Moreover, these meta-analyses have been focusing only on glucose homeostasis under fasting conditions by studying parameters such as homeostatic model assessment of insulin resistance (HOMA-IR), fasting glucose, fasting insulin, and Glycated haemoglobin $1 \mathrm{c}(\mathrm{HbA1c})$ as main outcome measures. Of importance, the skeletal muscle is considered as an important organ in peripheral insulin sensitivity as it affects $70-90 \%$ of total glucose disposal under postprandial conditions (non-fasting conditions) $(24,25)$. Studies have shown that vitamin D may affect skeletal muscle substrate metabolism and insulin sensitivity $(16,17)$. Thus, increasing circulating vitamin $\mathrm{D}$ concentration by means of supplementation might be expected to have beneficial effects during postprandial conditions by improving skeletal muscle glucose handling/ insulin sensitivity. Therefore, we undertook a systematic review and meta-analysis of RCTs to delineate the impact of vitamin D supplementation on insulin sensitivity derived from the gold standard hyperinsulinemic euglycemic clamp or from a multi-sampled oral or 
intravenous glucose tolerance tests (OGTT or IVGTT) as well as the postprandial glucose concentrations (OGTT) in humans with or at risk of insulin resistance.

\section{Methods}

\section{Literature search strategy and study selection}

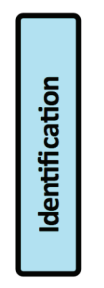

Records identified through database searching $(n=1321)$

PubMed (434); Embase (392); Cochrane (204); Web of Science (205); CINAHL (86)
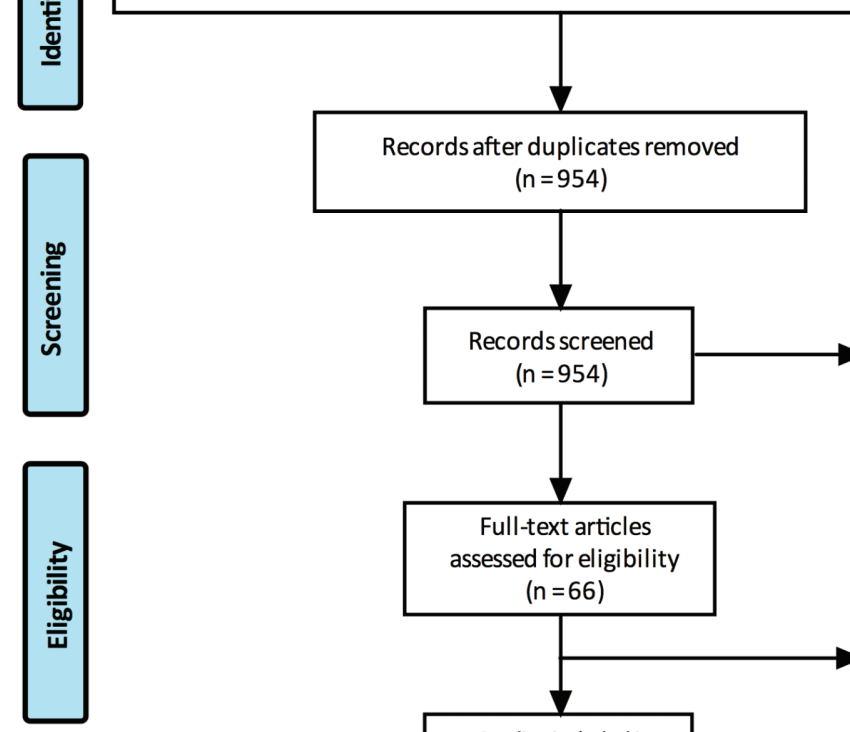

Full-text articles assessed for eligibility $(n=66)$
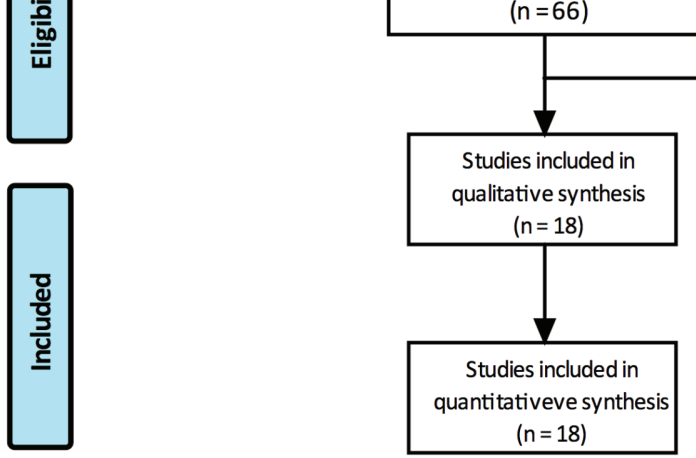

Records excluded with reasons $(n=888)$ - protocols - conference abstracts - observational studies -reviews/guidlines - did not meet PICOS criteria

Figure 1. Flowchart diagram for study selection of systematic review (based on Preferred Reporting Items for Systematic Reviews and Meta-Analysis/PRISMA guideline)

We conducted our systematic review and meta-analysis according to the Preferred Reporting Items for Systematic Reviews and Meta-Analyses (PRISMA) guidelines (26). The protocol for our systematic review was registered at the International Prospective Register of Systematic Reviews, PROSPERO (registration CRD42018092961). The main outcome of interest was the change in insulin sensitivity, derived from a gold standard hyperinsulinemic euglycemic clamp or in the form of the Matsuda Index derived from OGTT and/or insulin 
sensitivity index derived from intravenous glucose tolerance test (IVGTT), subsequent to vitamin $\mathrm{D}$ administration in individuals with or at risk of insulin resistance. The secondary outcome was the change in 2-hour postprandial glucose concentration and/or area under the curve (AUC) glucose during an OGTT.

A comprehensive literature search's [PubMed/Medline (Medical Literature Analyses and Retrieval System Online), Cochrane library, Web of Science, Embase database (OVID) and The Cumulative Index to Nursing and Allied Health Literature (CINAHL) was performed to identify articles from 1980 until 31 December 2018. The main keywords used were overweight, obesity, prediabetes, type 2 diabetes mellitus, vitamin D, insulin sensitivity, insulin resistance, blood glucose. These keywords were combined with Boolean operators (e.g. OR, AND, NOT), and all Fields or Medical subject subheading (MeSH) terms. This set of search terms was slightly modified when searching in every database due to a different system and technical limitations (Supplemental Table S1).

Eligible studies met the PICOS (Patients/participants, Intervention, Comparison/ control group, Outcome, and Study Design) criteria: (1) study was a randomized controlled trial; (2) study population consisted of individuals with elevated (risk for) insulin resistance (overweight, obesity, prediabetes, polycystic ovary syndrome (PCOS), and type 2 diabetes without complications); (3) participants were $\geq 18$ years; (4) interventions were vitamin D supplementation vs the appropriate placebo; (5) vitamin D supplementation dose was daily, weekly, or monthly; (6) trial length was $\geq 2$ months; (7) serum 25(OH)D level was measured; (8) insulin sensitivity was measured by Matsuda index derived from an OGTT and/or insulin sensitivity index derived from IVGTT, or by a hyperinsulinemic euglycemic clamp at the beginning and at the end of the trial; and (9) study was published in English.

Following the search, duplicates were removed. A total of 18 studies were included in this systematic review (Figure 1). Exclusion criteria were as follows: (1) non clinical trial studies; (2) studies without outcome of insulin sensitivity derived from multi-sampled oral glucose tolerance test or hyperinsulinemic euglycemic clamp; (3) study populations with end-stage renal disease (kidney disease), cancers, gestational diabetes, Non-alcoholic steatohepatitis (NASH), cardiovascular diseases complications, infectious diseases; (4) intervention periods of $<2$ months; (5) vitamin $D$ supplementation provided as a single dose; and (6) study performed in children and/or adolescents ( $<18$ years).

Titles and abstracts were screened by two authors (A.P. and M.A.v.B.). Final study selection, based on the inclusion criteria, was done by two authors (A.P. and M.A.v.B.) and approved by another author (E.E.B.). Any disagreements between the authors were resolved through discussion with the fourth author (J.W.E.J.).

\section{Data extraction and management}

Data were extracted by two authors (A.P., M.A.v.B.). Data extracted from each study included the following items: first author, reference, year of publication, country of study, study design, inclusion criteria, sample size, form of vitamin D, dose and frequency of vitamin D supplementation, any co-supplementation (e.g. diet or calcium), treatment control group, duration of supplementation, participants' characteristics [ $\mathrm{n}$, sex (\% male), age, BMI, ethnicities], comorbidities, baseline and follow-up serum 25(OH)D levels and outcome measures (e.g. M value or glucose infusion rate (GIR) or insulin-mediated glucose uptake derived from clamp, Matsuda index, Insulin sensitivity index, $2 \mathrm{~h}$ glucose or AUC 
glucose from an OGTT)] (Table 1). The corresponding author of an eligible publication was contacted by e-mail for additional data when relevant. Any further necessary calculations on study data, such as converting measurement units or calculating standard deviation (SD), was conducted by the first author (A.P.) and checked by another author (M.A.v.B.). Serum $25(\mathrm{OH}) \mathrm{D}$ levels were collated in $\mathrm{nmol} / \mathrm{L}$; a multiplication factor of 2.456 was used to convert 25(OH)D levels from $\mathrm{ng} / \mathrm{mL}$ to $\mathrm{nmol} / \mathrm{L}$. 2-hour glucose tolerance test glucose concentrations (2h-glucose) were collated in $\mathrm{mmol} / \mathrm{L}$; we used a multiplication factor of 0.0555 to convert glucose levels from $\mathrm{mg} / \mathrm{dL}$ to $\mathrm{mmol} / \mathrm{L}$, as appropriate (27).

\section{Quality assessment}

The quality of selected RCTs was assessed independently by two authors (A.P., M.A.v.B.) using the risk of bias checklist (RoB) from the Cochrane Collaboration (28). The quality assessments of the checklist included (1) bias from randomization process (random sequence generation and allocation concealment), (2) bias due to deviations from intended interventions (blinding of participants and personnel), (3) bias due to missing outcome data, (4) bias from measurements of the outcome, (5) bias from selection of reported result, and other sources of bias. Each criterion could be answered in three ways: "low risk" (adequate information), "unclear risk" (if there was unclear information), and "high risk" (if there was a high concern). Study quality and the risk of bias in the eligible RCTs was systematically assessed using software Review Manager 5.3 (The Nordic Cochrane Centre, The Cochrane Collaboration, Copenhagen, Denmark, 2014).

\section{Data synthesis and statistical analysis}

To calculate the effect size of each study, we used the mean change and SD of the outcome measures from baseline to the end of the intervention in the control and intervention groups (29). When the outcome measure was reported as mean and $95 \%$ confidence interval $[\mathrm{CI}]$ or mean and standard error of mean (SEM), values were estimated using Cochrane Review Manager 5.3 software (The Nordic Cochrane Centre, The Cochrane Collaboration, Copenhagen, Denmark, 2014) (30). If the outcome measures were reported in median, range or $25^{\text {th }}-75^{\text {th }}$ percentiles (P25-P75), mean and standard SD values were estimated using formulas published by Wan et al (31). If the outcome measures were only reported in figures, we used software to estimate the value. SDs of the mean difference were estimated using the following formula: $S D=$ square root [(SD pre-treatment $)^{2}+(S D$ post-treatment $\left.)^{2}\right)-(2 \mathrm{R} * \mathrm{SD}$ pre-treatment $* \mathrm{SD}$ post-treatment $\left.)\right]$. Because the pretestposttest correlation coefficients $(r)$ were not reported in studies, an $r$ value of 0.5 was assumed throughout this meta-analysis (30). If a study included more than two intervention groups (e.g. two different doses of vitamin D), which were compared with one placebo (control) group, the number of subjects of the control group was divided by the number comparisons. If the outcome measurement was performed at multiple time-points after the intervention period, we only used first time-point after the intervention (29).

The effect size is reported as standardized mean difference with its $95 \%$ confidence interval $(\mathrm{Cl})(26,32)$. Standardized mean difference is used as a summary statistic in metaanalysis when the studies all assess the same outcome but measure it in a variety of ways (in this study for example, all studies measured insulin sensitivity but use different methodology 
i.e. clamp or Matsuda index or insulin sensitivity index). A random-effects model was used to estimate outcomes. Heterogeneity was assessed using the $\mathrm{I}^{2}$ (I square) statistic, indicating what proportion of the variation in observed effects across studies is due to the variation in true effects, with values above $60 \%$ indicating substantial heterogeneity. A p-value < 0.05 is considered statistically significant (29). The analysis was performed and generated using Cochrane Review Manager 5.3 software (The Nordic Cochrane Centre, The Cochrane Collaboration, Copenhagen, Denmark, 2014). The PRISMA checklist was used as a guide for checking the quality of our systematic review (Supplemental Table S2).

\section{Publication Bias}

Publication bias was analyzed by visual inspection of the funnel plots.

\section{Meta regression and sensitivity analysis}

If the heterogeneity was $>60 \%$, additional analyses were conducted. Metaregression analysis and sensitivity analysis using the leave-one-out method (removing one study each time and repeating the analysis) were applied to gain insight into the source of the heterogeneity (29).

\section{Results}

\section{Study characteristics}

In total, 18 RCTs (33-50) published between 2011 and 2018 with 1220 participants were included in the current meta-analysis. Characteristics of the studies are summarized in Table 1. The studies were conducted in the United States of America $(n=5)$, Canada $(n=1)$, Iran $(n=1)$, India $(n=1)$, Malaysia $(n=1)$, Australia $(n=2)$, The Netherlands $(n=1)$, Denmark $(n=1)$, Norway $(n=1)$, Finland $(n=1)$, Sweden $(n=1)$, Austria $(n=1)$, and Italy $(n=1)$. Most studies included both men and women, except two studies that included only women $(43,45)$ and two other studies that included only men $(44,50)$. Among the 18 studies, 8 enrolled several ethnic populations (multi-ethnicity) (33, 36-38, 40, 46-48), two enrolled individuals from African-American ethnicity $(34,44)$ two enrolled in Asians $(43,45)$, one enrolled participants from Middle-Eastern countries (35), and five studies did not provide information about ethnicity $(39,41,42,49,50)$. Sixteen trials were in participants with overweight, obesity, prediabetes, type 2 diabetes, or metabolic syndrome, two of these trials also included apparently healthy participants $(40,50)$, while participants in the two other trials had PCOS (Polycystic Ovary Syndrome) (45) or a history of GDM (Gestational Diabetes Mellitus) (43). Studies used different cut-offs for baseline vitamin D levels: nine studies (34, 37-40, 45-47) recruited individuals with vitamin D levels $<50 \mathrm{nmol} / \mathrm{L}$, and the others $(33,35,36,41,42,44$, 48-50) included individuals with vitamin D levels $<75 \mathrm{nmol} / \mathrm{L}$ at the beginning of trial (Table 1). Mean serum vitamin $D 25(\mathrm{OH}) \mathrm{D}$ concentrations at baseline varied from $19.2 \mathrm{nmol} / \mathrm{L}(45)$ to $59.9 \mathrm{nmol} / \mathrm{L}$ (33) in vitamin D-supplemented groups and $16.9 \mathrm{nmol} / \mathrm{L}$ (45) to 61.4 (33) in placebo groups. The mean oral dose of vitamin D was 4,608 IU per day (range 1,200 IU (37) to $12,695 \mathrm{IU}$ (36) per day), with the majority of studies providing daily doses $\leq 4000 \mathrm{IU}$ (33, $34,37-39,41,43,45,46,48-50)$. The duration of vitamin D supplementation ranged from 2 (42) to 12 months (44). 
CHAPTER 6

The effect of vitamin $\mathrm{D}$ supplementation on insulin sensitivity: a systematic review and meta-analysis

\begin{tabular}{|c|c|c|c|c|c|c|}
\hline 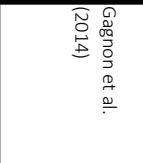 & 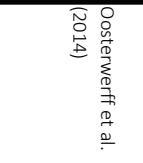 & 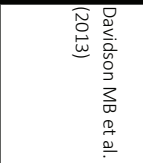 & 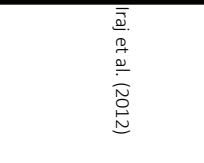 & 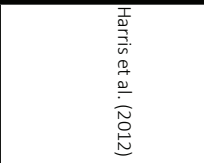 & 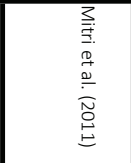 & 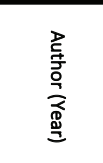 \\
\hline 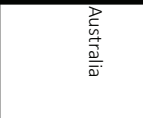 & 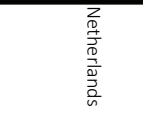 & $\stackrel{\check{c}}{\breve{s}}$ & $\overline{\mathrm{S}}$ & $\stackrel{\breve{s}}{\breve{s}}$ & 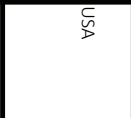 & 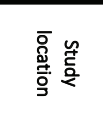 \\
\hline 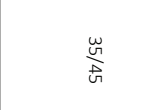 & $\frac{\stackrel{u}{\leftrightarrows}}{\vec{v}}$ & $\begin{array}{l}\text { जू } \\
\text { 今心 }\end{array}$ & $\frac{\tilde{N}}{\tilde{N}}$ & $\frac{\vec{\omega}}{\mathrm{f}}$ & $\underset{\underset{\sim}{\tilde{N}}}{\stackrel{\tilde{N}}{n}}$ & 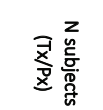 \\
\hline$\underset{\pi}{3}$ & $\underset{\pi}{3}$ & $\underset{\pi}{3}$ & $\underset{3}{3}$ & $\underset{\pi}{3}$ & $\underset{3}{3}$ & $\stackrel{\widetilde{\infty}}{x}$ \\
\hline 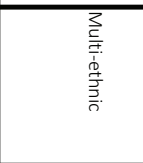 & 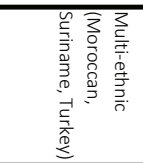 & 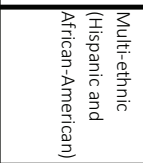 & 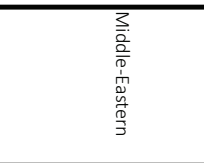 & 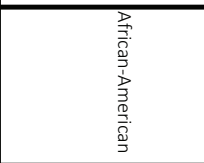 & 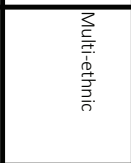 & 謇 \\
\hline $\begin{array}{l}\text { No } \\
\dot{0}\end{array}$ & $\underset{\sim}{\mathbb{N}}$ & $\stackrel{\mathbb{N}}{\mathbb{N}}$ & 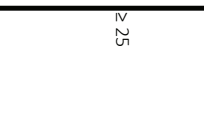 & 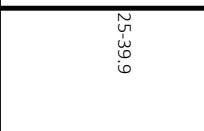 & 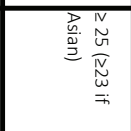 & 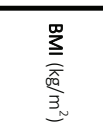 \\
\hline 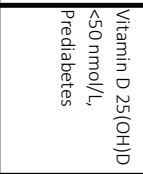 & 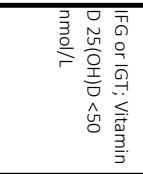 & 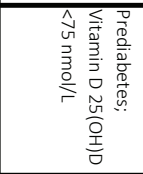 & 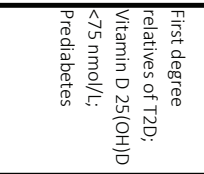 & 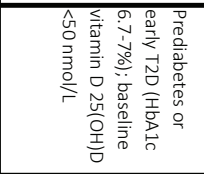 & 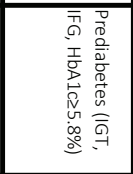 & 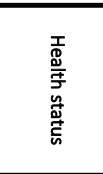 \\
\hline 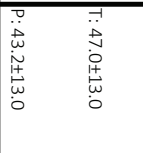 & 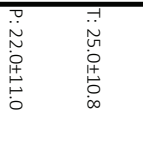 & 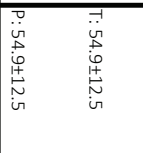 & 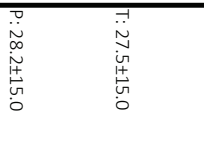 & 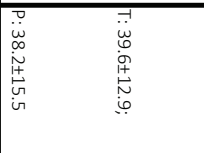 & 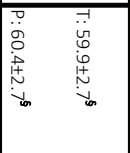 & 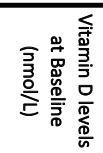 \\
\hline $\begin{array}{l}\vec{H} \\
\ddot{0} \\
6 \\
\dot{+} \\
\stackrel{+}{\sigma} \\
\dot{\sigma} \\
\dot{i r}\end{array}$ & 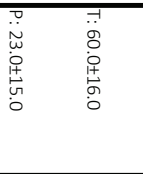 & 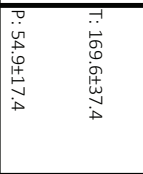 & 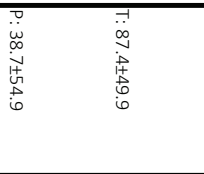 & 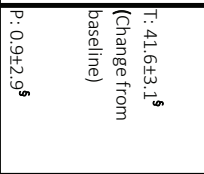 & 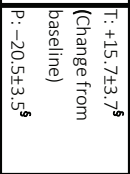 & 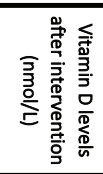 \\
\hline 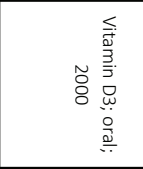 & 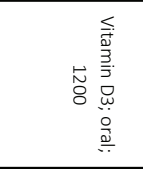 & 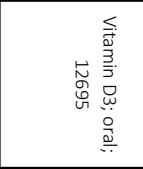 & 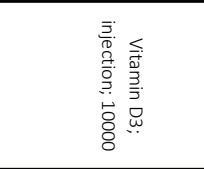 & 站 & 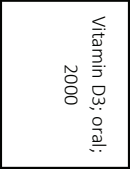 & 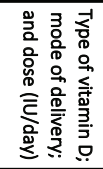 \\
\hline$\stackrel{\varrho}{\bar{D}}$ & 紊 & 䈉 & $\frac{\varrho}{\bar{D}}$ & $\frac{\pi}{\bar{D}}$ & 紊 & 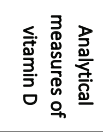 \\
\hline$a$ & D & $\omega$ & $\sim$ & $\omega$ & A & 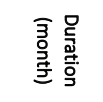 \\
\hline 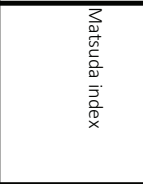 & 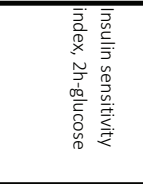 & 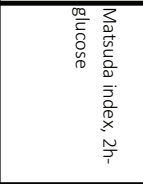 & 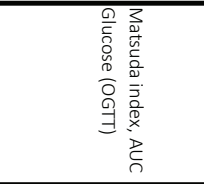 & 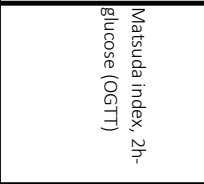 & 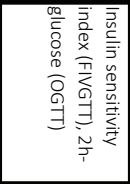 & 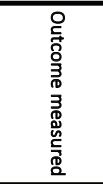 \\
\hline
\end{tabular}

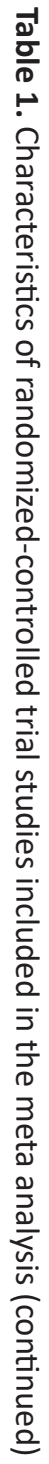




\begin{tabular}{|c|c|c|c|c|c|c|}
\hline 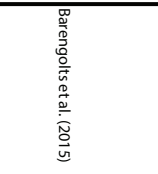 & 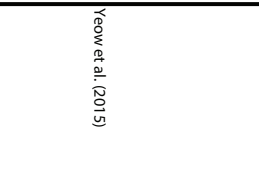 & 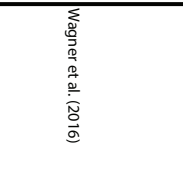 & 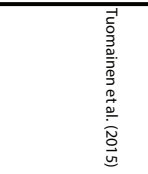 & 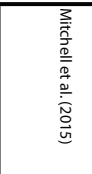 & 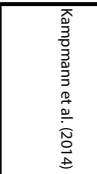 & 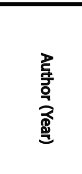 \\
\hline$\overline{\check{S}}$ & 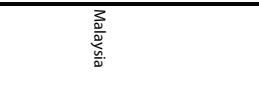 & 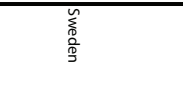 & 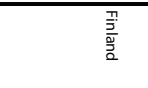 & $\overline{5}$ & 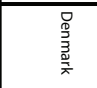 & 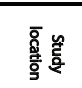 \\
\hline$\stackrel{\infty}{\stackrel{\infty}{\infty}}$ & $\underset{\omega}{\vec{\omega}}$ & $\underset{N}{\tilde{N}}$ & 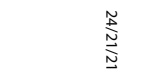 & $\begin{array}{l}\text { 总 } \\
\text { ò }\end{array}$ & $\stackrel{\stackrel{\circ}{\stackrel{\infty}{!}}}{\underline{\underline{s}}}$ & 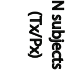 \\
\hline 3 & $\pi$ & $z_{t r}$ & $z_{T}$ & $z_{\pi}$ & $\underset{\pi}{3}$ & 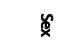 \\
\hline 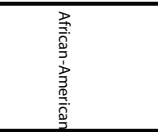 & $\begin{array}{l} \\
\frac{2}{3} \\
\frac{2}{3}\end{array}$ & $\overline{\text { z }}$ & 긲 & 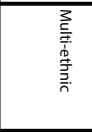 & 긲 & $\frac{\text { 睪 }}{\frac{0}{2}}$ \\
\hline $\begin{array}{l}\tilde{\infty} \\
\dot{\omega} \\
\dot{\omega}\end{array}$ & $\begin{array}{l}\tilde{w} \\
\dot{w}\end{array}$ & $\stackrel{⿱ 中}{\sim}$ & $\underset{\sim}{N}$ & 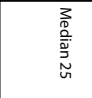 & $\underset{\sim}{N}$ & $\begin{array}{l}\text { 楚 } \\
\text { 唁 } \\
\text { 惫 }\end{array}$ \\
\hline 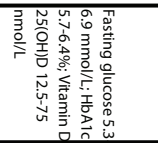 & 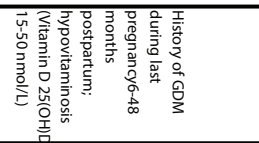 & 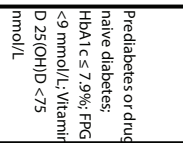 & 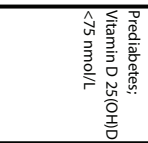 & 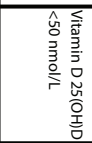 & 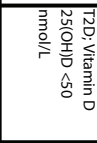 & 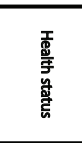 \\
\hline 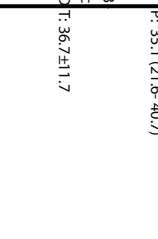 & 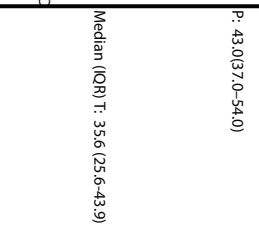 & 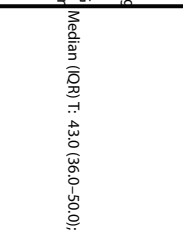 & 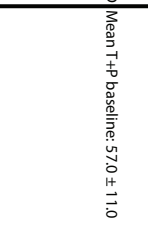 & 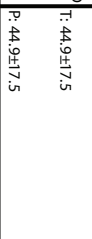 & 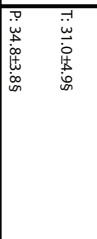 & 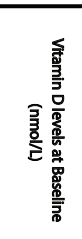 \\
\hline 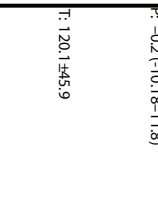 & 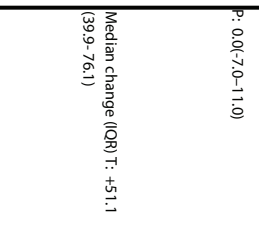 & 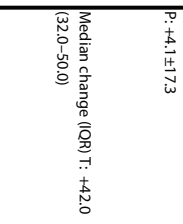 & 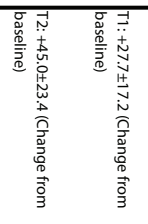 & 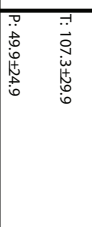 & 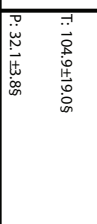 & 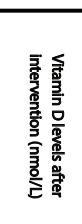 \\
\hline 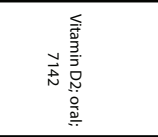 & 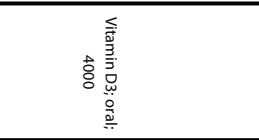 & 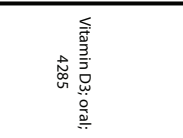 & 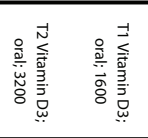 & 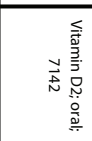 & 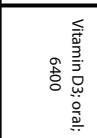 & 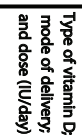 \\
\hline$\frac{f}{5}$ & $\stackrel{m}{\frac{m}{s}}$ & $\frac{\rho}{5}$ & 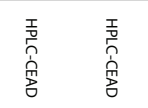 & 翌 & 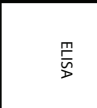 & 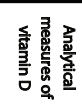 \\
\hline$\vec{N}$ & $a$ & N & u & $\omega$ & $\omega$ & 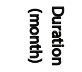 \\
\hline 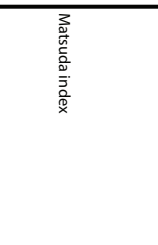 & 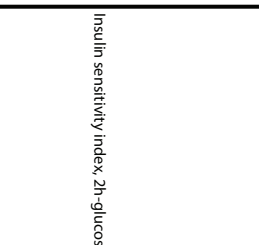 & 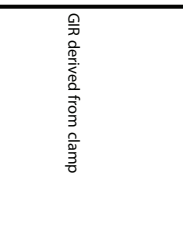 & 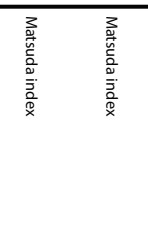 & 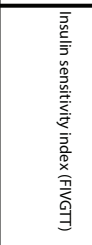 & 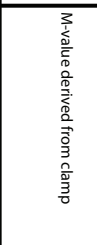 & 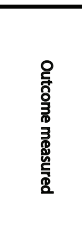 \\
\hline
\end{tabular}


CHAPTER 6

The effect of vitamin D supplementation on insulin sensitivity: a systematic review and meta-analysis

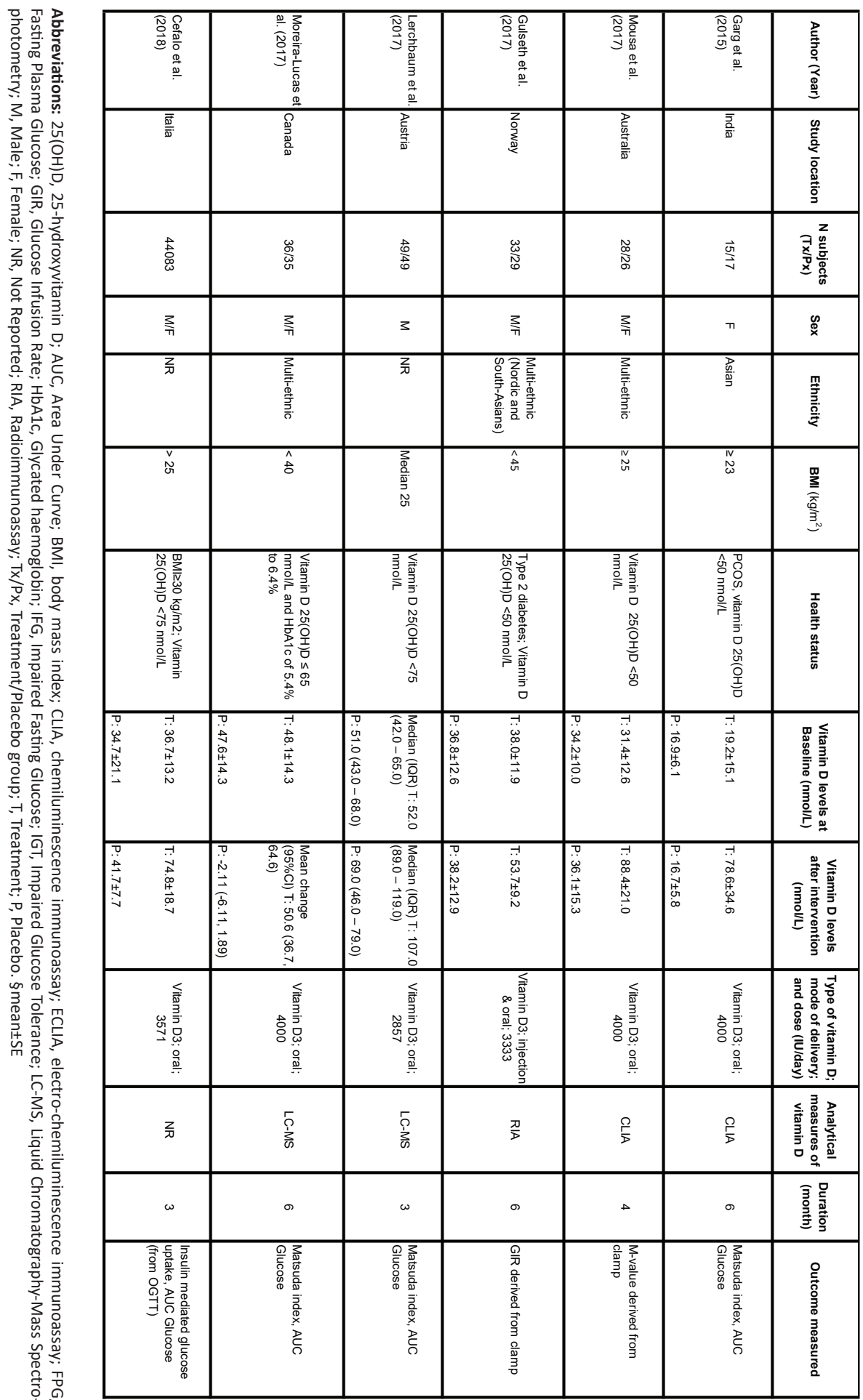

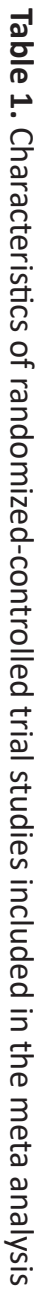




\section{The effect of vitamin D supplementation on insulin sensitivity}

There were 18 studies with sufficient data to be included in the meta-analysis to estimate the overall effect of vitamin $D$ supplementation on insulin sensitivity derived from a clamp $(39,42,46,47,49)$ or indices of insulin sensitivity derived from an oral or intravenous glucose tolerance test $(33-38,40,41,43-45,48,50)$. The total number of included individuals was 1220; of these, 612 received vitamin D supplementation, and 608 patients received placebo. From the 13 studies that used the Matsuda index derived from OGTT and/or insulin sensitivity index from IVGTT (33-38, 40, 41, 43-45, 48, 50), none reported a significant change (increase or decrease) in insulin sensitivity after vitamin $D$ supplementation compared with placebo. Furthermore, among those five studies in which the outcome of insulin sensitivity was derived from a clamp $(39,42,46,47,49)$, only one study (Cefalo et al (49)) reported a statistically significant improvement of insulin sensitivity.

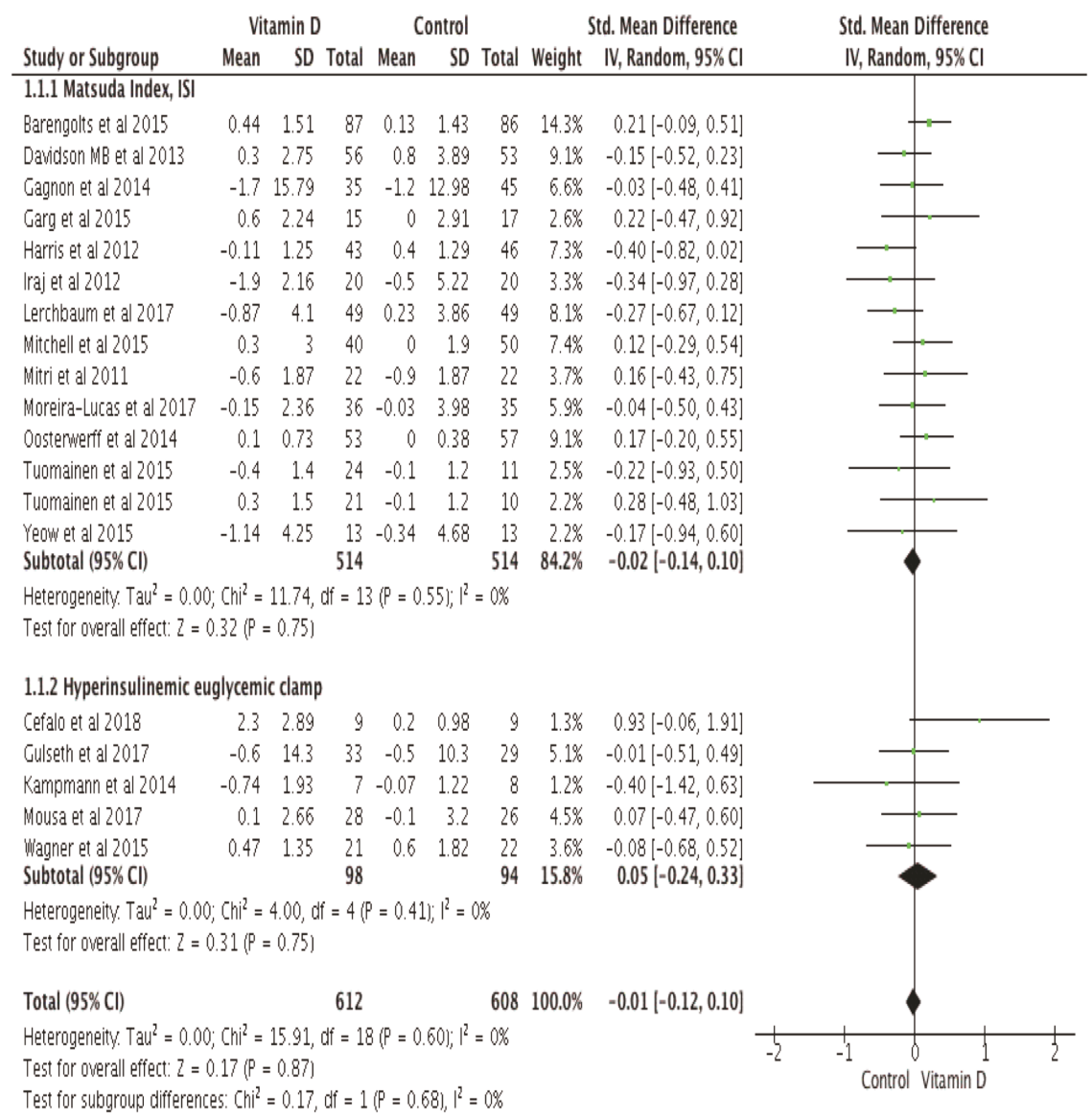

Figure 2. Forest plot of the effect of vitamin D supplementation on insulin sensitivity. Horizontal lines span individual study $95 \%$ confidence intervals (CI). Diamonds represent the combined study standardized mean value and the corresponding $95 \% \mathrm{Cl}$ values. 
Based on a random-effect meta-analysis, comparing the standardized mean difference of the change in insulin sensitivity from baseline between the vitamin Dsupplemented and placebo groups, the overall effect on insulin sensitivity was not significant after vitamin $\mathrm{D}$ supplementation (standardized mean difference: $-0.01,95 \% \mathrm{Cl}:-0.12$ to 0.10 , $\mathrm{P}=0.87 ; \mathrm{I}^{2}=0 \%, \mathrm{P}=0.60$ ) (Figure 2).

\section{The effect of vitamin D supplementation on postprandial glucose concentrations}

There were 12 studies that reported $2 \mathrm{~h}$-glucose concentrations ( 6 studies) $(33,34$, $36,41-43)$ or AUC Glucose (6 studies) $(35,37,45,48-50)$ as an outcome measure. A metaanalysis of these data including 745 individuals $(n=379$ treated with vitamin $D$ and $n=$ 366 with placebo) was performed to compare the mean change in $2 \mathrm{~h}$-glucose and/or AUC Glucose between the beginning and the end of study. Vitamin D supplementation had no effect on post-prandial glucose with a standardized mean difference of 0.09 ( $95 \% \mathrm{Cl}:-0.08$ to $0.25, \mathrm{P}=0.29 ; \mathrm{I}^{2}=18 \%, \mathrm{P}=0.26$ ) (Figure $3 \mathrm{~A}$ ).

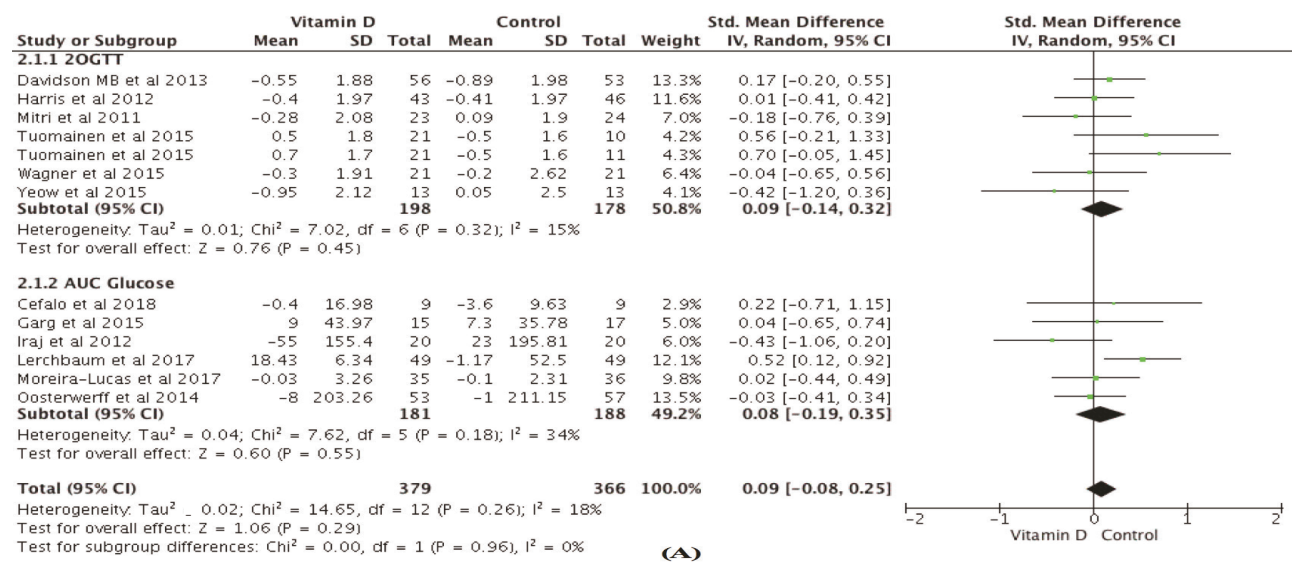

$(3 A)$

Figure 3A. Forest plots of the effect of vitamin D supplementation on postprandial glucose, Horizontal lines span individual study $95 \%$ confidence intervals $(\mathrm{Cl})$. Diamonds represent the combined study standardized mean value and the corresponding $95 \% \mathrm{Cl}$ values.

\section{The effect of vitamin D supplementation on serum vitamin D levels}

All eighteen trials ( $\mathrm{n}=1223 ; 613$ individuals treated with vitamin $\mathrm{D}$ and 610 individuals with placebo) reported the change in serum vitamin $D$ level after the intervention. There was a significant increase in the serum vitamin D level in the vitamin $D$ supplementation groups compared with the control groups (standardized mean difference $=2.25 ; 95 \% \mathrm{Cl}: 1.90-2.60, \mathrm{p}<0.001)$ (Figure 3B) with considerable heterogeneity $\left(\mathrm{I}^{2}=81 \%\right.$; $\mathrm{p}<0.001)$. 


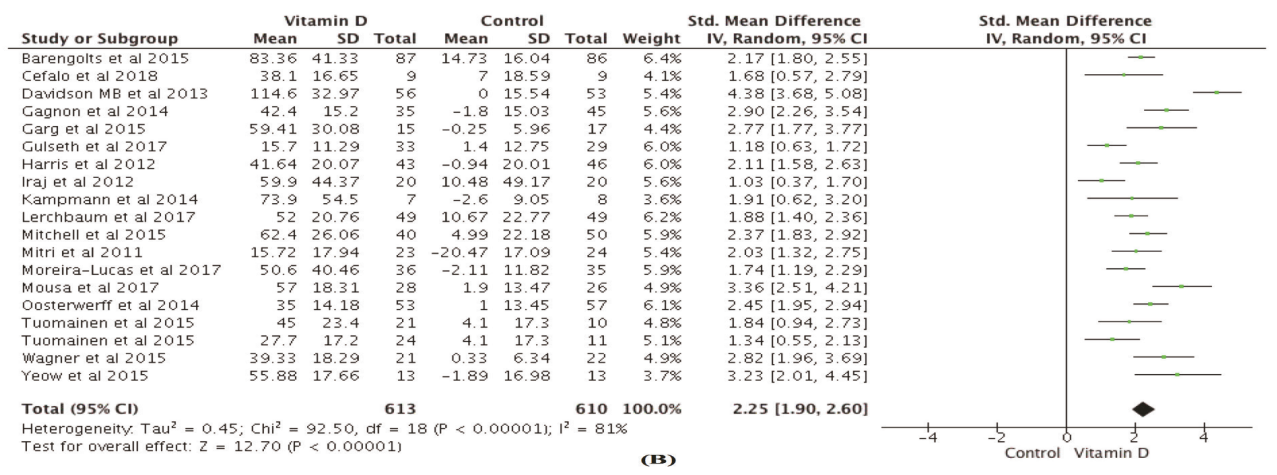

(3B)

Figure 3B. Forest plots of the effect of vitamin D supplementation on serum vitamin D levels, Horizontal lines span individual study $95 \%$ confidence intervals $(\mathrm{Cl})$. Diamonds represent the combined study standardized mean value and the corresponding $95 \% \mathrm{Cl}$ values.

\section{Risk of bias}

Most included studies had a low risk of bias according to randomization process (random sequence generation and allocation concealment), blinding participants (comparability of intervention groups and placebo (control) groups), incomplete outcome data (clear description of dropout/withdrawal/attrition rate). The blinding of outcome assessment was not clearly mentioned in some of studies (34-36, 41, 44, 45, 48, 49), resulted in unclear risk of detection bias. The overall quality assessment of the included trials in this meta-analysis is shown in Supplemental figures S1A-B.

\section{Publication bias}

The visual inspection of funnel plots of changes in insulin sensitivity, postprandial glucose and serum vitamin $D$ changes in this meta-analysis following vitamin $D$ supplementation did not indicate publication bias (Supplemental figures S2A-C).

\section{Meta regression and sensitivity analysis}

Regarding the change in serum vitamin D levels following supplementation, there was a considerable heterogeneity $\left(I^{2}=81 \%\right)$. A meta-regression analysis of dose or duration with standardized mean difference of serum vitamin $D$ levels showed that the dose of vitamin D supplementation may partly explain the heterogeneity (Supplemental Table S3). Further sensitivity analysis by leave-one-out analysis, shows that no single study is responsible for the heterogeneity of changes in serum vitamin D levels.

\section{Discussion}

We conducted a systematic review and meta-analysis of 18 RCTs to determine the effect of vitamin $D$ supplementation on insulin sensitivity in individuals with or at risk of 
insulin resistance. In this meta-analysis, vitamin D supplementation had no significant effect on insulin sensitivity derived from a hyperinsulinemic euglycemic clamp or the Matsuda Index derived from an OGTT and/or Insulin sensitivity index from IVGTT. Additionally, no significant changes in $2 \mathrm{~h}$ glucose or AUC glucose during an OGTT were observed following vitamin $\mathrm{D}$ supplementation.

In our analysis, study populations were often characterized by the presence of overweight or obesity (33-39, 41-44, 46-49), accompanied with baseline serum concentrations of $25(\mathrm{OH}) \mathrm{D}<50 \mathrm{nmol} / \mathrm{L}(33-44,46-50)$ or $<75 \mathrm{mmol}(35,36,41,42,44,49,50)$. Indeed, it has been described that human obesity often coincides with low circulating vitamin D 25(OH) D levels (5). Several mechanisms, such as uptake/sequestration of vitamin D within adipose tissue (51) and volumetric dilution due to increased body volume (52) may explain the link between obesity and low vitamin D levels. Furthermore, a comprehensive systematic review by Autier and colleagues suggests that the low serum vitamin $D$ levels could also be due to the chronic low grade inflammation which is an important characteristic of individuals with obesity and T2D (53). Thus, vitamin D supplementation in human overweight/obesity could be expected to increase serum vitamin D 25(OH)D levels. In this meta-analysis we showed that vitamin $D$ supplementation increased the mean vitamin $D 25(\mathrm{OH}) \mathrm{D}$ level of treatment group in all studies, although with considerable heterogeneity. Additional meta-regression analysis showed that some of the heterogeneity is explained by dose, but not by treatment duration. Nevertheless, in our meta-analysis, improving vitamin D 25(OH)D concentrations did not translate into an improvement in insulin sensitivity and glucose metabolism. In the present meta-analysis, we included only studies using standardized methodologies (non fasting measures of insulin sensitivity), either by multi-sampled OGTTs or IVGTTs (33-38, 40, $41,43-45,48,50)$ or the gold standard hyperinsulinemic euglycemic clamp $(39,42,46,47$, 49). Our meta-analysis, which shows no effect of vitamin $D$ supplementation on peripheral insulin sensitivity and postprandial glucose handling, supports several other findings which used fasting indices of insulin sensitivity (e.g. $\operatorname{HOMA-IR)}(18,19)$.

It has been shown that postprandial glycaemia is strongly associated with obesity (3), and predicts cardiovascular events among insulin resistant individuals $(4,54)$. Wood et al. (55) and Manson et al. (56). have shown that vitamin D supplementation did not result in the prevention of cardiovascular events. The most recent work by Pittas et al. (57) showed that vitamin D supplementation (4000 IU) did not result in a significantly lower risk of diabetes, assessed by 2 h OGTT in 2423 individuals. The skeletal muscle is a key organ for peripheral insulin sensitivity as it is responsible for the majority of glucose disposal during postprandial conditions $(24,58)$. Although effects of vitamin D on glucose responsiveness, insulin receptor substrate (59) and insulin sensitivity (17), muscle mitochondria biogenesis (16) as well as lipid metabolism (17) have been documented at the transcriptional and post-translational level in vitro, our analysis shows no effect on postprandial glucose concentrations suggests that these beneficial effects do not translate into beneficial effects at the functional level. Studies have shown that vitamin D may affect insulin secretion (15, 33) rather than insulin sensitivity per se. Vitamin $D$ may contribute to normalization of extracellular calcium, ensuring normal calcium flux through cell membranes and regulate the beta-cell calcium pool (15). Nevertheless, whether there is sufficient evidence that vitamin D supplementation may improve insulin secretion in postprandial condition (e.g. disposition index) needs further investigation. Furthermore, there is only one trial included in this meta analysis, by Cefalo et al. (49), which reported a significant increase of insulin 
sensitivity derived from a clamp after vitamin D supplementation. Of note, in that study vitamin $\mathrm{D}$ supplementation was combined with a low-calorie diet intervention, yet the sample size of this study was relatively small. Therefore, whether combining vitamin D supplementation with diet restriction may improve insulin sensitivity in humans with or at risk of insulin resistance needs further investigation in a well-controlled study.

When interpreting the results, several factors should be taken into consideration. The optimal time of intervention and dose that are necessary to evaluate the effects of vitamin $D$ supplementation on parameters related to glucose metabolism and insulin insulin sensitivity is not well established. We showed that neither dose nor treatment duration were associated with changes in insulin sensitivity and postprandial glucose. It also should be noted that the results could be affected by other factors such variation in age, season (19) and ethnicity (23) as well as tissue-specific metabolism and insulin resistance (60). A recent meta-analysis in type 2 diabetes populations by Li et al. (23) has suggested that vitamin D supplementation may have more beneficial effects in individuals from Middle eastern ethnicity as compared to other ethnicities, but some of the included studies on which this suggestion was based were of questionable quality. In this meta-analysis, we could not perform subgroup analysis based on ethnicity because 8 out of 18 trials $(33,36-38,40,46$ 48) were conducted in multi-ethnic populations, whereas 5 other studies $(39,41,42,49$, 50) did not report any information about ethnicity. In addition, the heterogeneity regarding the change in serum vitamin D levels may also be partly explained by compliance that was achieved during intervention, which we were unable to ascertain in more detail. Another limitation might be that the number of individuals who participated in the included studies was relatively small possibly due to the invasive and expensive character of the measurement (e.g. clamp). Despite the fact that the number of studies using clamps, the gold standard for the measurement of insulin sensitivity, was relatively small (only 5 studies), the outcome on insulin sensitivity derived from clamps was similar to the outcome based on the results from OGTTs and IVGTTs (13 studies). In addition, 3 studies that met our inclusion criteria and used a clamp (61-63) were published in 2019, after the window for being included in the meta analysis. After repeating the meta-analysis with in total 21 studies ( 3 studies in 2019 and the original 18 studies), the outcome did not change (Supplemental figures S3A-C). In conclusion, this systematic review provides no evidence that supplementation with vitamin $D$ has a beneficial effect on peripheral insulin sensitivity, as determined by hyperinsulinemic euglycemic clamp, the Matsuda or insulin sensitivity index, and postprandial glucose concentrations after an OGTT in people with, or at risk for insulin resistance.

\section{Acknowledgements}

A.P. is supported by Indonesia Endowment Fund for Education (LPDP) during the preparation of the manuscript. The funder had no role in the preparation, study design and analysis or the publication of the manuscript. Author contributions: A.P., E.E.B., J.W.E.J., and M.A.v.B designed the study. A.P. and M.A.v.B. searched databases and performed the selection of studies. A.P. analyzed the data, M.A.v.B checked the data analysis. A.P. wrote the manuscript. M.A.v.B., J.W.E.J., and E.E.B critically evaluated the review and meta-analysis, commented on it, and approved the last version. All authors reviewed and approved the final manuscript. E.E.B. are the guarantor of this study. 
CHAPTER 6

The effect of vitamin D supplementation on insulin sensitivity: a systematic review and meta-analysis

\section{Author disclosure}

All authors declare that they have no conflict of interest. 


\section{References}

1. International Diabetes Federation. IDF Diabetes Atlas - 8 th Edition. 2017.

2. Zheng Y, Ley SH, Hu FB. Global aetiology and epidemiology of type 2 diabetes mellitus and its complications. Nature reviews Endocrinology. 2018;14(2):88-98.

3. Blaak E, Antoine JM, Benton D, et al. Impact of postprandial glycaemia on health and prevention of disease. obesity reviews. 2012;13(10):923-84.

4. ADA. Prevention or delay of type 2 diabetes. Diabetes Care. 2015;38(Supplement 1):S31-S2.

5. Kabadi S, Lee B, Liu L. Joint effects of obesity and vitamin D insufficiency on insulin resistance and type 2 diabetes: results from the NHANES 2001-2006. Diabetes Care 2012;35(10):2048-54.

6. Pramono A, Jocken J, Blaak E. Vitamin D deficiency in the etiology of obesity related insulin resistance. Diabetes/metabolism research and reviews. 2019;35(5):e3146.

7. Gagnon C, Lu ZX, Magliano DJ, et al. Serum 25-hydroxyvitamin D, calcium intake, and risk of type 2 diabetes after 5 years. Diabetes care. 2011;34(5):1133-8.

8. Wamberg L, Christiansen T, Paulsen SK, et al. Expression of vitamin D-metabolizing enzymes in human adipose tissue - the effect of obesity and diet-induced weight loss. Int J Obes (Lond). 2013;37(5):651-7.

9. Girgis $\mathrm{CM}$, Mokbel N, Cha KM, et al. The vitamin D receptor (VDR) is expressed in skeletal muscle of male mice and modulates 25-hydroxyvitamin D (25OHD) uptake in myofibers. Endocrinology. 2014;155(9):3227-37.

10. Sherman $M H$, Ruth $T Y$, Engle DD, et al. Vitamin D receptor-mediated stromal reprogramming suppresses pancreatitis and enhances pancreatic cancer therapy. Cell. 2014;159(1):80-93.

11. Alvarez JA, Ashraf A. Role of vitamin D in insulin secretion and insulin sensitivity for glucose homeostasis. Int J Endocrinol. 2009;2010:1-18.

12. Larrick BM, Kim KH, Donkin SS, et al. 1,25-Dihydroxyvitamin D regulates lipid metabolism and glucose utilization in differentiated 3T3-L1 adipocytes. Nutrition research (New York, NY). 2018;58:72-83.

13. Karkeni E, Bonnet L, Marcotorchino J, et al. Vitamin D limits inflammation-linked microRNA expression in adipocytes in vitro and in vivo: A new mechanism for the regulation of inflammation by vitamin D. Epigenetics. 2018;13(2):156-62.

14. Altieri B, Grant WB, Casa SD, et al. Vitamin D and pancreas: the role of sunshine vitamin in the pathogenesis of Diabetes Mellitus and Pancreatic Cancer. Critical reviews in food science and nutrition. 2016:0.

15. Pittas AG, Harris SS, Stark PC, et al. The effects of calcium and vitamin D supplementation on blood glucose and markers of inflammation in nondiabetic adults. Diabetes Care. 2007;30(4):9806.

16. Ryan ZC, Craig TA, Folmes CD, et al. 1alpha,25-Dihydroxyvitamin D3 regulates mitochondrial oxygen consumption and dynamics in human skeletal muscle cells. J Biol Chem. 2016;291(3):1514-28.

17. Jefferson GE, Schnell DM, Thomas DT, et al. Calcitriol concomitantly enhances insulin sensitivity and alters myocellular lipid partitioning in high fat-treated skeletal muscle cells. Journal of physiology and biochemistry. 2017;73(4):613-21.

18. Seida JC, Mitri J, Colmers IN, et al. Clinical review: effect of vitamin D3 supplementation on improving glucose homeostasis and preventing diabetes: a systematic review and meta-analysis. J Clin Endocrinol Metab. 2014;99(10):3551.

19. Jamka M, Woźniewicz M, Jeszka J, et al. The effect of vitamin D supplementation on insulin and glucose metabolism in overweight and obese individuals: systematic review with meta-analysis. Sci Rep. 2015;5:1-12.

20. Poolsup N, Suksomboon N, Plordplong N. Effect of vitamin D supplementation on insulin resistance and glycaemic control in prediabetes: a systematic review and meta-analysis. Diabet Med. 2016;33(3):290-9. 
21. Wu C, Qiu S, Zhu X, et al. Vitamin D supplementation and glycemic control in type 2 diabetes patients: A systematic review and meta-analysis. Metabolism. 2017;73:67-76.

22. Mirhosseini N, Vatanparast H, Mazidi M, et al. The Effect of Improved Serum 25-Hydroxyvitamin D Status on Glycemic Control in Diabetic Patients: A Meta-Analysis. J Clin Endocrinol Metab. 2017;102(9):3097-110.

23. Li X, Liu Y, Zheng Y, et al. The Effect of Vitamin D Supplementation on Glycemic Control in Type 2 Diabetes Patients: A Systematic Review and Meta-Analysis. Nutrients. 2018;10(375):1-15.

24. Baron AD, Brechtel G, Wallace $P$, et al. Rates and tissue sites of non-insulin- and insulin-mediated glucose uptake in humans. The American journal of physiology. 1988;255(6 Pt 1):E769-74.

25. DeFronzo RA, Jacot $E$, Jequier $E$, et al. The effect of insulin on the disposal of intravenous glucose: results from indirect calorimetry and hepatic and femoral venous catheterization. Diabetes. 1981;30(12):1000-7.

26. Moher D, Liberati A, Tetzlaff J, et al. Preferred reporting items for systematic reviews and metaanalyses: the PRISMA statement. Plos Med. 2009;21(6(7)):e1000097.

27. Makariou SE, Elisaf M, Challa A, et al. No effect of vitamin D supplementation on cardiovascular risk factors in subjects with metabolic syndrome: a pilot randomised study. Archives of medical sciences Atherosclerotic diseases. 2017;2:e52.

28. Higgins JP, Altman DG, G $\varnothing$ tzsche PC, et al. The Cochrane Collaboration's tool for assessing risk of bias in randomised trials. Bmj. 2011;343:d5928.

29. Higgins JPT, Green S. Cochrane Handbook for Systematic Reviews of Interventions [internet]. 2011. Available from: http://handbook-5-1.cochrane.org

30. Higgins JPT, Green S. Cochrane handbook for systematic reviews of interventions version 5.0.2 [internet], 2009. Available from: https://handbook-5-1.cochrane.org/v5.0.2/

31. Wan X, Wang W, Liu J, et al. Estimating the sample mean and standard deviation from the sample size, median, range and/or interquartile range. BMC Medical Research Methodology. 2014;14(1):135.

32. Borenstein M, Hedges LV, Higgins JP, et al. Introduction to meta-analysis: John Wiley \& Sons; 2009.

33. Mitri J, Dawson-Hughes B, Hu FB, et al. Effects of vitamin D and calcium supplementation on pancreatic $\beta$ cell function, insulin sensitivity, and glycemia in adults at high risk of diabetes: the Calcium and Vitamin D for Diabetes Mellitus (CaDDM) randomized controlled trial. Am J Clin Nutr. 2011;94(2):486-94.

34. Harris SS, Pittas AG, Palermo NJ. A randomized, placebo-controlled trial of vitamin D supplementation to improve glycaemia in overweight and obese African Americans. Diabetes Obes Metab. 2012;14(9):789-94.

35. Iraj B, Aminorroaya A, Amini M. Does the intramuscular injection of vitamin D increase insulin resistance? J Res Pharm Pract. 2012;1(2):60.

36. Davidson $\mathrm{MB}$, Duran $\mathrm{P}$, Lee $\mathrm{ML}$, et al. High-dose vitamin $\mathrm{D}$ supplementation in people with prediabetes and hypovitaminosis D. Diabetes Care. 2013;36(2):260-6.

37. Oosterwerff MM, Eekhoff EM, Van Schoor NM, et al. Effect of moderate-dose vitamin D supplementation on insulin sensitivity in vitamin D-deficient non-Western immigrants in the Netherlands: a randomized placebo-controlled trial. Am J Clin Nutr. 2014;100(1):152-60.

38. Gagnon C, Daly RM, Carpentier A, et al. Effects of combined calcium and vitamin D supplementation on insulin secretion, insulin sensitivity and $\beta$-cell function in multi-ethnic vitamin $D$-deficient adults at risk for type 2 diabetes: a pilot randomized, placebo-controlled trial. PloS One. 2014;9(10):e109607.

39. Kampmann U, Mosekilde L, Juhl C, et al. Effects of 12 weeks high dose vitamin D3 treatment on insulin sensitivity, beta cell function, and metabolic markers in patients with type 2 diabetes and vitamin D insufficiency-a double-blind, randomized, placebo-controlled trial. Metabolism. 2014;63(9):1115-24. 
40. Mitchell DM, Leder BZ, Cagliero E, et al. Insulin secretion and sensitivity in healthy adults with low vitamin $\mathrm{D}$ are not affected by high-dose ergocalciferol administration: a randomized controlled trial. Am J Clin Nutr. 2015;102(2):385-92.

41. Tuomainen T-P, Virtanen JK, Voutilainen S, et al. Glucose metabolism effects of vitamin D in prediabetes: the VitDmet randomized placebo-controlled supplementation study. J Diabetes Res. $2015 ; 2015$.

42. Wagner $\mathrm{H}$, Alvarsson $\mathrm{M}$, Mannheimer $\mathrm{B}$, et al. No effect of high-dose vitamin $\mathrm{D}$ treatment on $\beta$-cell function, insulin sensitivity, or glucose homeostasis in subjects with abnormal glucose tolerance: A randomized clinical trial. Diabetes Care. 2016;39(3):345-52.

43. Yeow TP, Lim SL, Hor CP, et al. Impact of vitamin D replacement on markers of glucose metabolism and cardio-metabolic risk in women with former gestational diabetes-a double-blind, randomized controlled trial. PloS one. 2015;10(6):e0129017.

44. Barengolts E, Manickam B, Eisenberg Y, et al. Effect of high-dose vitamin D repletion on glycemic control in African-American males with prediabetes and hypovitaminosis D. Endocrine Practice. 2015;21(6):604-12.

45. Garg G, Kachhawa G, Ramot R, et al. Effect of vitamin D supplementation on insulin kinetics and cardiovascular risk factors in polycystic ovarian syndrome: a pilot study. Endocr Connect. 2015;4(2):108-16.

46. Mousa A, Naderpoor N, de Courten MP, et al. Vitamin D supplementation has no effect on insulin sensitivity or secretion in vitamin D-deficient, overweight or obese adults: a randomized placebocontrolled trial. Am J Clin Nutr. 2017;105(6):1372-81.

47. Gulseth HL, Wium C, Angel K, et al. Effects of Vitamin D Supplementation on Insulin Sensitivity and Insulin Secretion in Subjects With Type 2 Diabetes and Vitamin D Deficiency: A Randomized Controlled Trial. Diabetes Care. 2017:dc162302.

48. Moreira-Lucas TS, Duncan AM, Rabasa-Lhoret R, et al. Effect of vitamin D supplementation on oral glucose tolerance in individuals with low vitamin $D$ status and increased risk for developing type 2 diabetes (EVIDENCE): A double-blind, randomized, placebo-controlled clinical trial. Diabetes, Obesity and Metabolism. 2017;19(1):133-41.

49. Cefalo CM, Conte C, Sorice GP, et al. Effect of Vitamin D Supplementation on Obesity-Induced Insulin Resistance: A Double-Blind, Randomized, Placebo-Controlled Trial. Obesity. 2018;26(4):651-7.

50. Lerchbaum E, Pilz S, Trummer C, et al. Vitamin D and testosterone in healthy men: a randomized controlled trial. The Journal of Clinical Endocrinology \& Metabolism. 2017;102(11):4292-302.

51. Wortsman J, Matsuoka LY, Chen TC, et al. Decreased bioavailability of vitamin D in obesity. Am J Clin Nutr. 2000;72(3):690-3.

52. Drincic AT, Armas LA, Diest EE, et al. Volumetric dilution, rather than sequestration best explains the low vitamin D status of obesity. Obesity (Silver Spring). 2012;20:1444-48.

53. Autier $P$, Mullie $P$, Macacu A, et al. Effect of vitamin D supplementation on non-skeletal disorders: a systematic review of meta-analyses and randomised trials. The lancet Diabetes \& endocrinology. 2017;5(12):986-1004.

54. Rizza RA. Pathogenesis of fasting and postprandial hyperglycemia in type 2 diabetes: implications for therapy. Diabetes. 2010.

55. Wood AD, Secombes KR, Thies F, et al. Vitamin D3 supplementation has no effect on conventional cardiovascular risk factors: a parallel-group, double-blind, placebo-controlled RCT. J Clin Endocrinol Metab. 2012;97(10):3557-68.

56. Manson JE, Cook NR, Lee I-M, et al. Vitamin D supplements and prevention of cancer and cardiovascular disease. New England Journal of Medicine. 2019;380(1):33-44.

57. Pittas AG, Dawson-Hughes B, Sheehan P, et al. Vitamin D Supplementation and Prevention of Type 2 Diabetes. N Engl J Med. 2019.

58. DeFronzo RA, Ferrannini E, Sato Y, et al. Synergistic interaction between exercise and insulin on peripheral glucose uptake. The Journal of clinical investigation. 1981;68(6):1468-74. 
59. Maestro B, Campion J, Davila N, et al. Stimulation by 1,25-dihydroxyvitamin D3 of insulin receptor expression and insulin responsiveness for glucose transport in U-937 Human Promonocytic Cells. Endocrine Journal. 2000;47(4):383-91.

60. Trouwborst I, Bowser SM, Goossens GH, et al. Ectopic fat accumulation in distinct insulin resistant phenotypes; targets for personalized nutritional interventions. Frontiers in nutrition. 2018;5.

61. Scott D, Mousa A, Naderpoor N, et al. Vitamin D supplementation improves waist-to-hip ratio and fasting blood glucose in vitamin D deficient, overweight or obese Asians: a pilot secondary analysis of a randomised controlled trial. Journal of steroid biochemistry and molecular biology. 2019.

62. Wallace HJ, Holmes L, Ennis CN, et al. Effect of vitamin D3 supplementation on insulin resistance and $\beta$-cell function in prediabetes: a double-blind, randomized, placebo-controlled trial. American Journal of Clinical Nutrition. 2019;110(5):1138-47.

63. Lemieux P, Weisnagel SJ, Caron AZ, et al. Effects of 6-month vitamin D supplementation on insulin sensitivity and secretion: a randomised, placebo-controlled trial. Eur J Endocrinol. 2019;181(3):287-99. 


\section{Supplemental Tables}

Supplemental Table S1. The search terms for each database

\begin{tabular}{|c|c|c|}
\hline No & Database & Search terms \\
\hline 1 & PubMed & $\begin{array}{l}\text { ("overweight"[MeSH Terms] OR "overweight"[All Fields]) OR ("obesity"[MeSH } \\
\text { Terms] OR "obesity"[All Fields]) OR Obes[All Fields] OR "prediabetic state"[MeSH } \\
\text { Terms] OR ("prediabetic"[All Fields] AND "state"[All Fields]) OR "prediabetic } \\
\text { state"[All Fields] OR "prediabetes"[All Fields] OR ("diabetes mellitus, type } \\
\text { 2"[MeSH Terms] OR "type } 2 \text { diabetes mellitus"[All Fields] OR "diabetes mellitus, } \\
\text { type 2"[All Fields]) OR ("insulin resistance"[MeSH Terms] OR ("insulin"[All Fields] } \\
\text { AND "resistance"[All Fields]) OR "insulin resistance"[All Fields]) OR ("insulin } \\
\text { resistance"[MeSH Terms] OR ("insulin"[All Fields] AND "resistance"[All Fields]) } \\
\text { OR "insulin resistance"[All Fields] OR ("insulin"[All Fields] AND "sensitivity"[All } \\
\text { Fields]) OR "insulin sensitivity"[All Fields]) OR ("blood glucose"[MeSH Terms] OR } \\
\text { ("plasma blood"[All Fields] AND "glucose"[All Fields]) OR "blood glucose"[All Fields] } \\
\text { OR ("glucose"[All Fields] AND "blood"[All Fields]) OR "glucose, blood"[All Fields]) } \\
\text { AND ("vitamin d"[MeSH Terms] OR "vitamin d"[All Fields] OR "cholecalciferol"[All } \\
\text { Fields]) AND (Randomized Controlled Trial[ptyp] AND "humans"[MeSH Terms]) }\end{array}$ \\
\hline 2 & Cochrane & $\begin{array}{l}\text { (overweight OR obesity OR obese OR prediabetes OR type } 2 \text { diabetes mellitus) } \\
\text { AND (vitamin D OR vitamin D3 OR vitamin D2) AND (insulin sensitivity OR insulin } \\
\text { resistance) AND (glucose control OR blood glucose) }\end{array}$ \\
\hline 3 & Embase & $\begin{array}{l}\text { (blood glucose, insulin resistance, insulin sensitivity, non insulin dependent diabetes } \\
\text { mellitus, obesity, prediabetes, supplementation, vitamin d, cholecalciferol) } \\
\text { using a combination of multi-field search in all fields and EMTREE }\end{array}$ \\
\hline 4 & Web of Science & $\begin{array}{l}\text { (overweight OR obesity OR prediabetes OR type } 2 \text { diabetes mellitus) AND (vitamin } \\
\text { D OR vitamin D3 OR vitamin D2) AND (insulin sensitivity OR insulin resistance) AND } \\
\text { (plasma glucose OR OGTT) }\end{array}$ \\
\hline 5 & CINAHL & $\begin{array}{l}\text { (overweight OR obesity OR obese OR prediabetes OR type } 2 \text { diabetes mellitus) AND } \\
\text { (vitamin D OR } 25 \text { hydroxyvitamin D OR vitamin D3 OR vitamin D2) AND (insulin } \\
\text { sensitivity OR insulin resistance) AND (blood glucose OR glucose control) }\end{array}$ \\
\hline
\end{tabular}


CHAPTER 6

The effect of vitamin D supplementation on insulin sensitivity: a systematic review and meta-analysis

\section{Supplemental Table S2. The PRISMA (2009) Checklist}

\begin{tabular}{|c|c|c|c|}
\hline Section/topic & & Checklist item & $\begin{array}{l}\text { Reported } \\
\text { on page \# }\end{array}$ \\
\hline \multicolumn{4}{|l|}{ TITLE } \\
\hline Title & 1 & Identify the report as a systematic review, meta-analysis, or both. & 1 \\
\hline \multicolumn{4}{|l|}{ ABSTRACT } \\
\hline Structured summary & 2 & $\begin{array}{l}\text { Provide a structured summary including, as applicable: background; objectives; data sources; study eligibility criteria, } \\
\text { participants, and interventions; study appraisal and synthesis methods; results; limitations; conclusions and } \\
\text { implications of key findings; systematic review registration number. }\end{array}$ & \\
\hline \multicolumn{4}{|l|}{ INTRODUCTION } \\
\hline Rationale & 3 & Describe the rationale for the review in the context of what is already known. & 3 \\
\hline Objectives & & $\begin{array}{l}\text { Provide an explicit statement of questions being addressed with reference to participants, interventions, comparisons, } \\
\text { outcomes, and study design (PICOS). }\end{array}$ & \\
\hline \multicolumn{4}{|l|}{ METHODS } \\
\hline $\begin{array}{l}\text { Protocol and } \\
\text { registration }\end{array}$ & 5 & $\begin{array}{l}\text { Indicate if a review protocol exists, if and where it can be accessed (e.g., Web address), and, if available, provide } \\
\text { registration information including registration number. }\end{array}$ & \\
\hline Eligibility criteria & 6 & $\begin{array}{l}\text { Specify study characteristics (e.g., PICOS, length of follow-up) and report characteristics (e.g., years considered, } \\
\text { language, publication status) used as criteria for eligibility, giving rationale. }\end{array}$ & \\
\hline Information sources & 7 & $\begin{array}{l}\text { Describe all information sources (e.g., databases with dates of coverage, contact with study authors to identify } \\
\text { additional studies) in the search and date last searched. }\end{array}$ & \\
\hline Search & 8 & $\begin{array}{l}\text { Present full electronic search strategy for at least one database, including any limits used, such that it could be } \\
\text { repeated. }\end{array}$ & 5,6 \\
\hline Study selection & 9 & $\begin{array}{l}\text { State the process for selecting studies (i.e., screening, eligibility, included in systematic review, and, if applicable, } \\
\text { included in the meta-analysis). }\end{array}$ & \\
\hline $\begin{array}{l}\text { Data collection } \\
\text { process }\end{array}$ & 10 & $\begin{array}{l}\text { Describe method of data extraction from reports (e.g., piloted forms, independently, in duplicate) and any processes } \\
\text { for obtaining and confirming data from investigators. }\end{array}$ & 7,8 \\
\hline Data items & 11 & $\begin{array}{l}\text { List and define all variables for which data were sought (e.g., PICOS, funding sources) and any assumptions and } \\
\text { simplifications made. }\end{array}$ & 7,8 \\
\hline $\begin{array}{l}\text { Risk of bias in } \\
\text { individual studies }\end{array}$ & 12 & $\begin{array}{l}\text { Describe methods used for assessing risk of bias of individual studies (including specification of whether this was done } \\
\text { at the study or outcome level), and how this information is to be used in any data synthesis. }\end{array}$ & \\
\hline Summary measures & 13 & State the principal summary measures (e.g., risk ratio, difference in means). & 8,9 \\
\hline Synthesis of results & 14 & $\begin{array}{l}\text { Describe the methods of handling data and combining results of studies, if done, including measures of consistency } \\
\left(\text { e.g., } I^{2}\right) \text { for each meta-analysis. }\end{array}$ & \\
\hline
\end{tabular}

\begin{tabular}{|c|c|c|c|}
\hline Section/topic & \# & Checklist item & $\begin{array}{l}\text { Reported } \\
\text { on page \# }\end{array}$ \\
\hline $\begin{array}{l}\text { Risk of bias across } \\
\text { studies }\end{array}$ & 15 & $\begin{array}{l}\text { Specify any assessment of risk of bias that may affect the cumulative evidence (e.g., publication bias, selective } \\
\text { reporting within studies). }\end{array}$ & \\
\hline Additional analyses & 16 & $\begin{array}{l}\text { Describe methods of additional analyses (e.g., sensitivity or subgroup analyses, meta-regression), if done, indicating } \\
\text { which were pre-specified. }\end{array}$ & \\
\hline \multicolumn{4}{|l|}{ RESULTS } \\
\hline Study selection & 17 & $\begin{array}{l}\text { Give numbers of studies screened, assessed for eligibility, and included in the review, with reasons for exclusions at } \\
\text { each stage, ideally with a flow diagram. }\end{array}$ & $\begin{array}{r}9 \text { (and } \\
\text { Figure 1) }\end{array}$ \\
\hline Study characteristics & 18 & $\begin{array}{l}\text { For each study, present characteristics for which data were extracted (e.g., study size, PICOS, follow-up period) and } \\
\text { provide the citations. }\end{array}$ & 9 to 11 \\
\hline $\begin{array}{l}\text { Risk of bias within } \\
\text { studies }\end{array}$ & 19 & Present data on risk of bias of each study and, if available, any outcome level assessment (see item 12). & 12 \\
\hline $\begin{array}{l}\text { Results of individual } \\
\text { studies }\end{array}$ & 20 & $\begin{array}{l}\text { For all outcomes considered (benefits or harms), present, for each study: (a) simple summary data for each } \\
\text { intervention group (b) effect estimates and confidence intervals, ideally with a forest plot. }\end{array}$ & 10,11 \\
\hline Synthesis of results & 21 & Present results of each meta-analysis done, including confidence intervals and measures of consistency. & 10,11 \\
\hline $\begin{array}{l}\text { Risk of bias across } \\
\text { studies }\end{array}$ & 22 & Present results of any assessment of risk of bias across studies (see Item 15). & 12 \\
\hline Additional analysis & 23 & Give results of additional analyses, if done (e.g., sensitivity or subgroup analyses, meta-regression [see Item 16]). & 12 \\
\hline \multicolumn{4}{|l|}{ DISCUSSION } \\
\hline $\begin{array}{l}\text { Summary of } \\
\text { evidence }\end{array}$ & 24 & $\begin{array}{l}\text { Summarize the main findings including the strength of evidence for each main outcome; consider their relevance to } \\
\text { key groups (e.g., healthcare providers, users, and policy makers). }\end{array}$ & 12 to 14 \\
\hline Limitations & 25 & $\begin{array}{l}\text { Discuss limitations at study and outcome level (e.g., risk of bias), and at review-level (e.g., incomplete retrieval of } \\
\text { identified research, reporting bias). }\end{array}$ & 15 \\
\hline Conclusions & 26 & Provide a general interpretation of the results in the context of other evidence, and implications for future research. & 15 \\
\hline \multicolumn{4}{|l|}{ FUNDING } \\
\hline Funding & 27 & $\begin{array}{l}\text { Describe sources of funding for the systematic review and other support (e.g., supply of data); role of funders for the } \\
\text { systematic review. }\end{array}$ & 16 \\
\hline
\end{tabular}

From: Moher D, Liberati A, Tetzlaff J, Altman DG, The PRISMA Group (2009). Preferred Reporting Items for Systematic Reviews and Meta-Analyses: The PRISMA Statement. PLoS Med 6(7): e1000097. doi:10.1371/journal. pmed1000097. For more information, visit: www.prisma-statement.org 


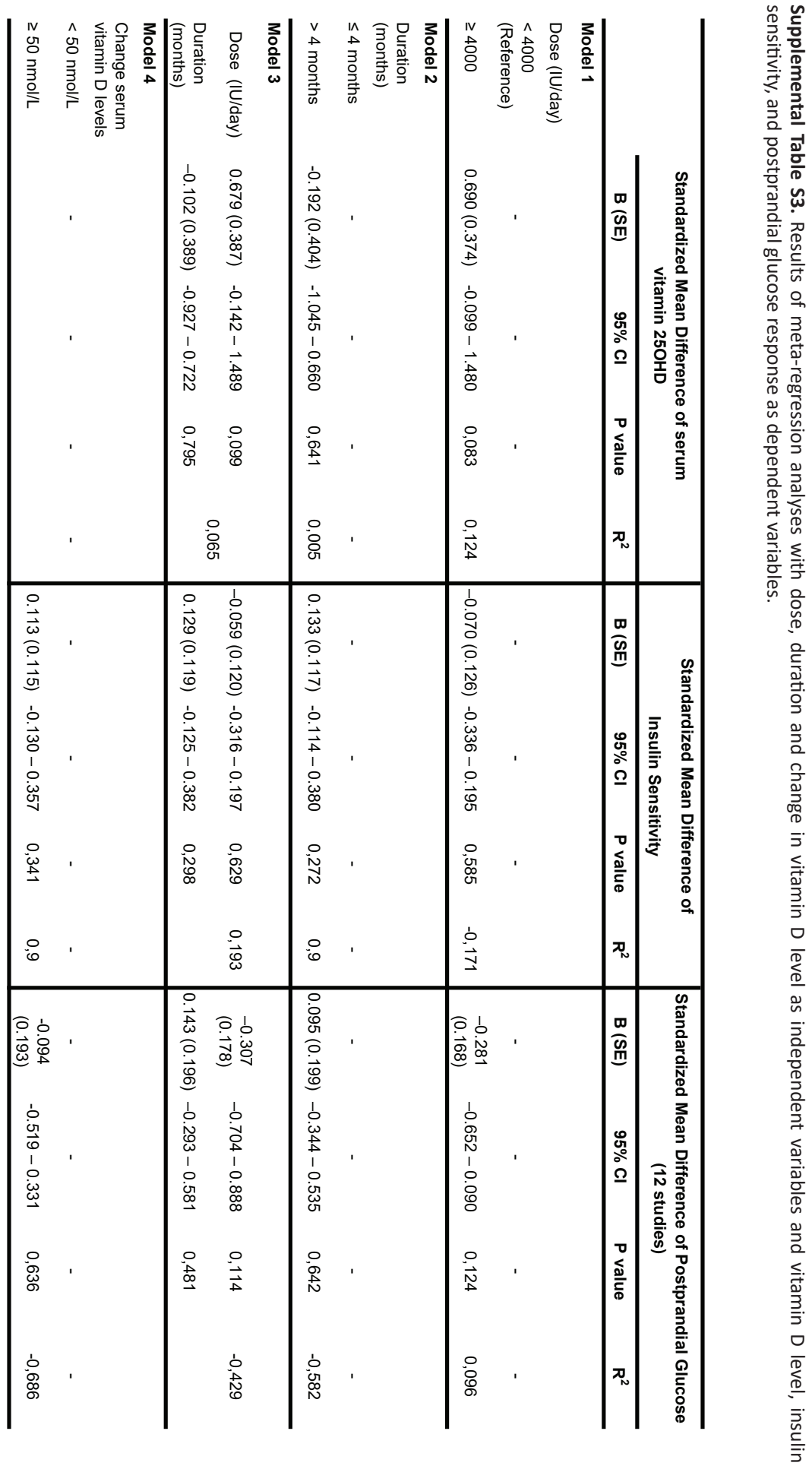




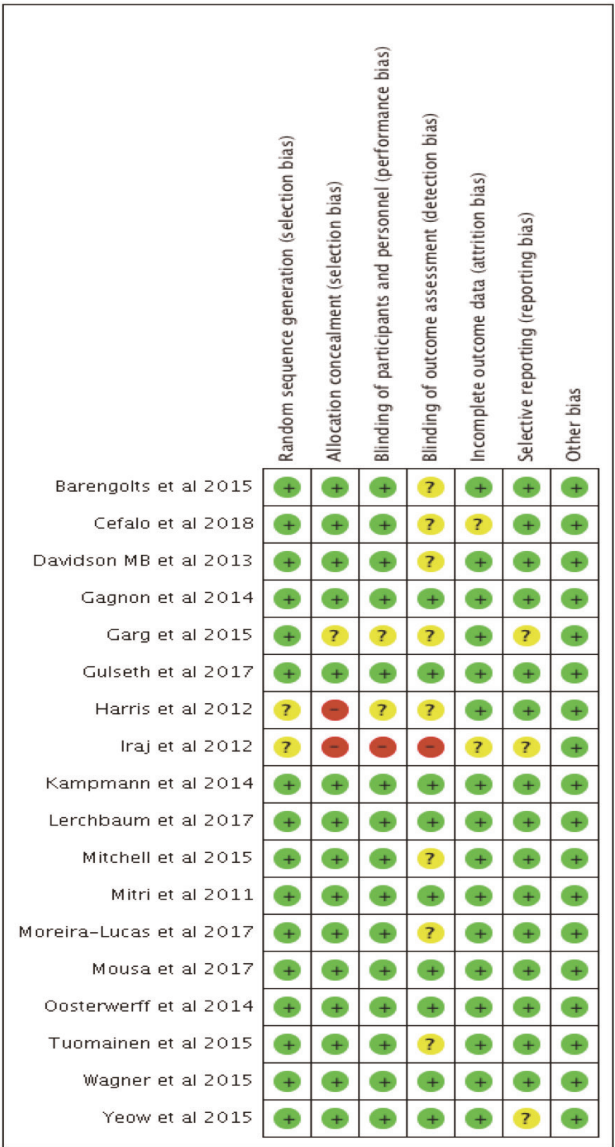

(A)

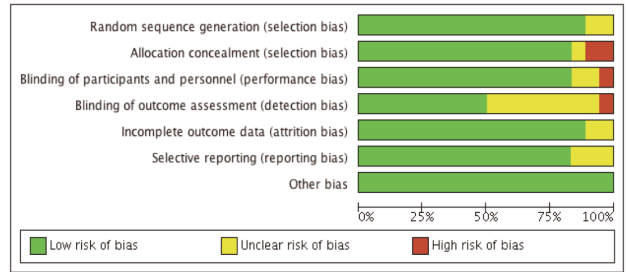

(B)

\section{Supplemental figures 1A-B}

Supplemental figures S1A-B. Risk of bias analysis (A) The analysis of the individual studies included in the systematic review and meta-analysis. Green dot = low risk of bias; yellow dot = unclear risk of bias; red dot $=$ high risk of bias (B) The summary of the risk of bias analysis. 
CHAPTER 6

The effect of vitamin D supplementation on insulin sensitivity: a systematic review and meta-analysis

(A)

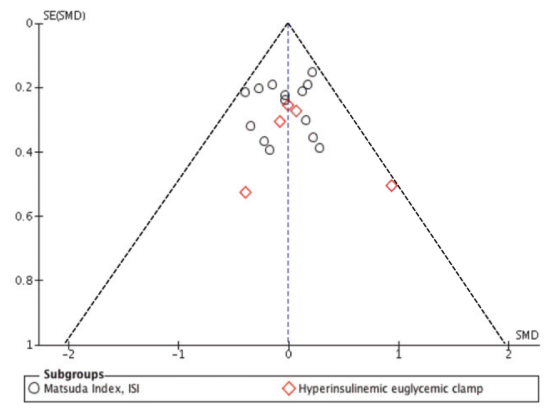

(B)

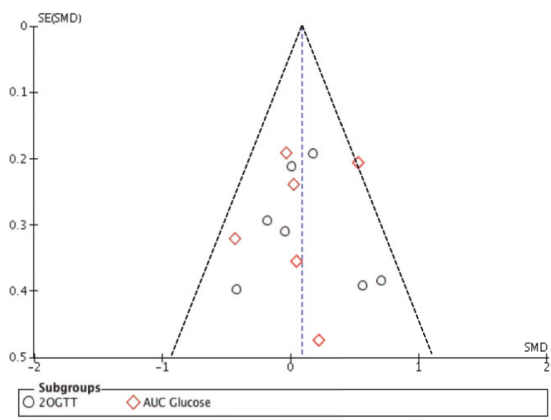

(C)

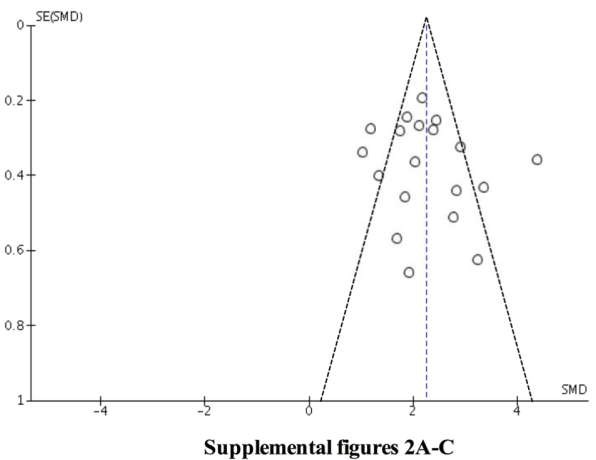

Supplemental figures S2A-C. Funnel plot of RCTs the effect of vitamin D supplementation on $(A)$ insulin sensitivity; (B) postprandial glucose; (C) serum vitamin D levels. Symmetrical funnel plots suggest publication bias is unlikely. RCTs, randomized controlled trials; SE(SMD) Standard Error of Standardized Mean Difference. 
Supplemental figures S3A-C. Forest plots and funnel plots after repeating the meta-analysis with in total 21 studies (additional 3 studies in 2019 and the original 18 studies) of the effect of vitamin D on: (S3A) insulin sensitivity; (S3B) postprandial glucose; (S3C) serum vitamin D levels.

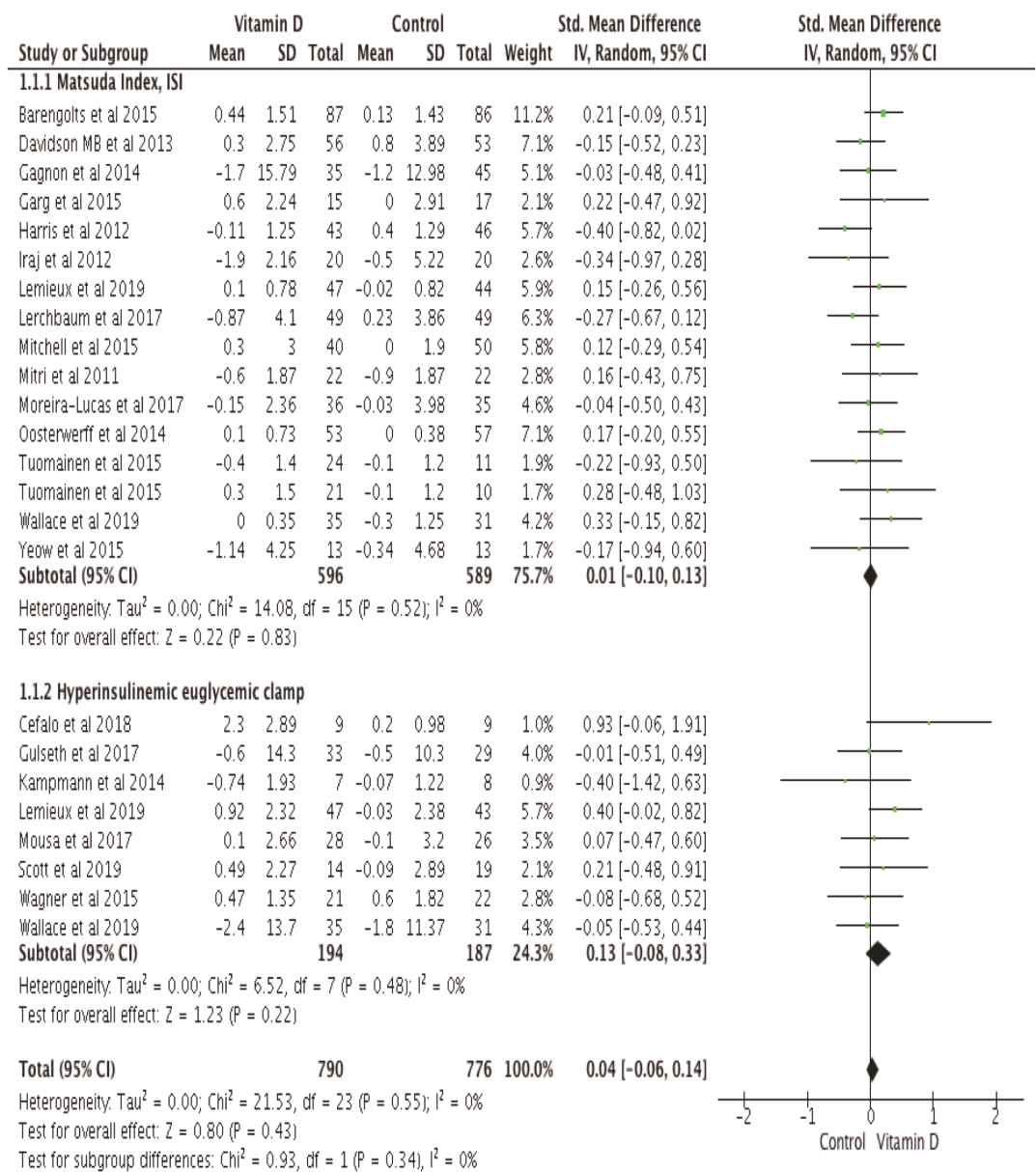

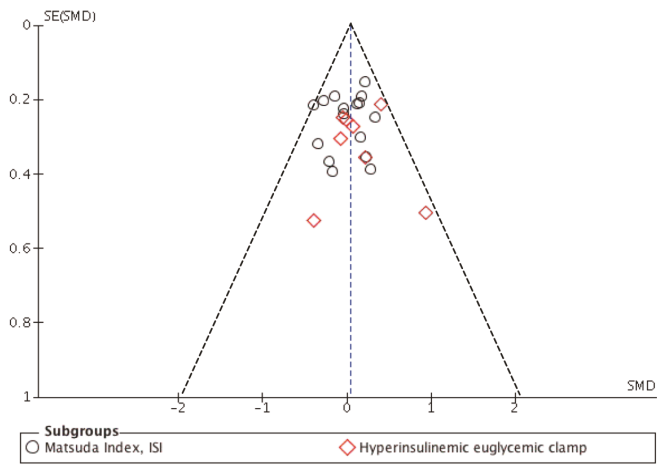

Supplemental figure S3A 


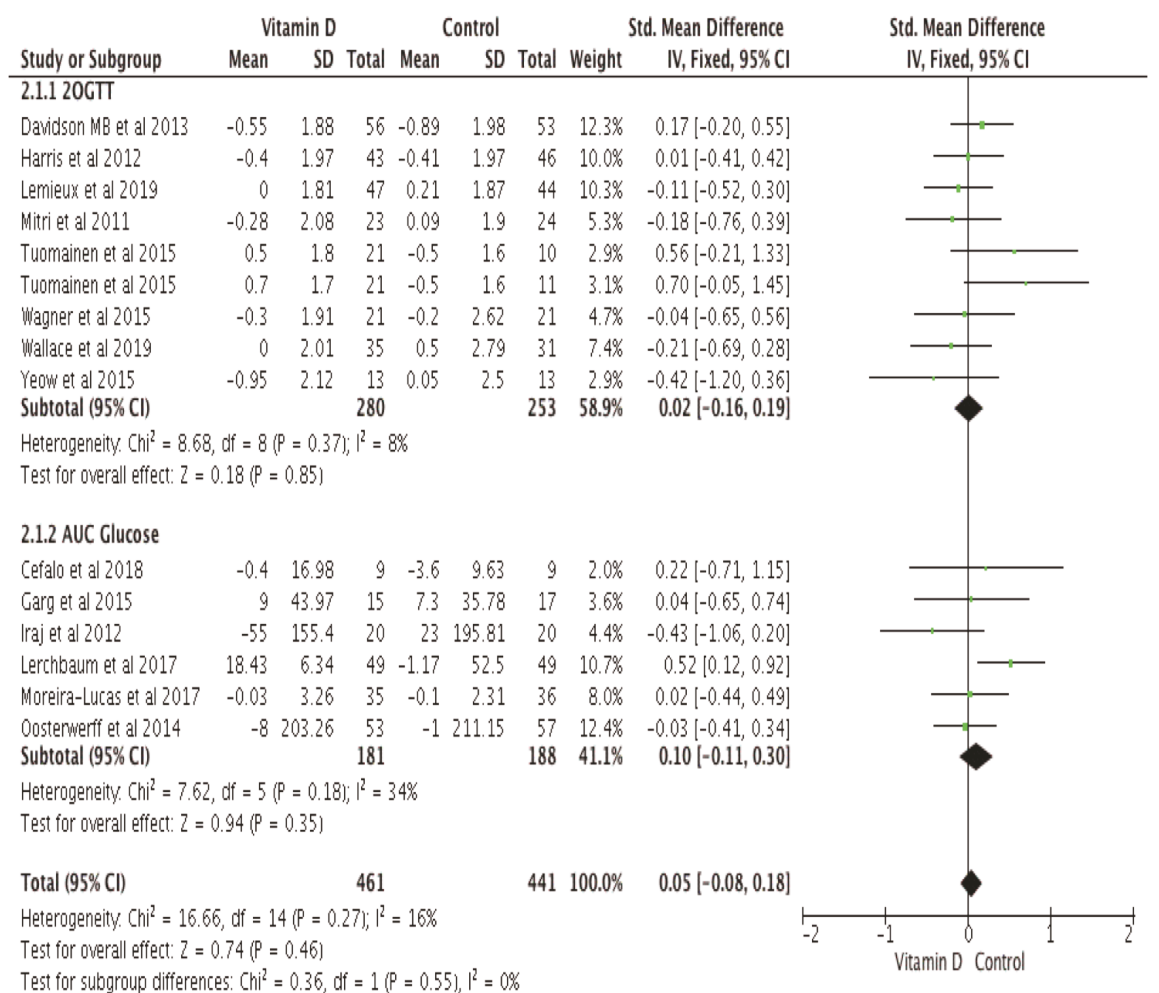

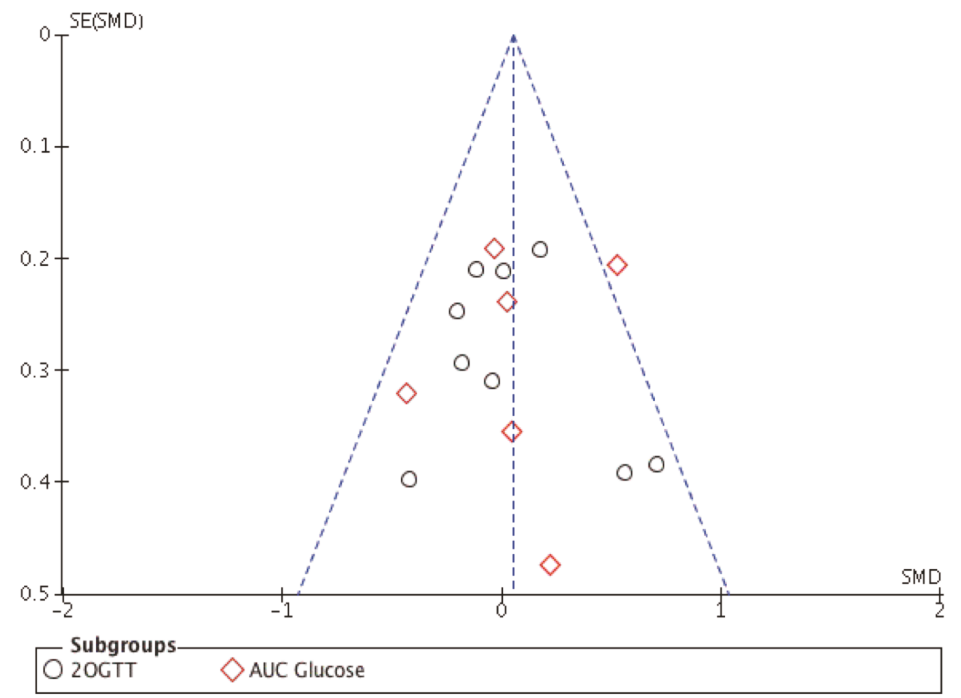

Supplemental figure S3B 


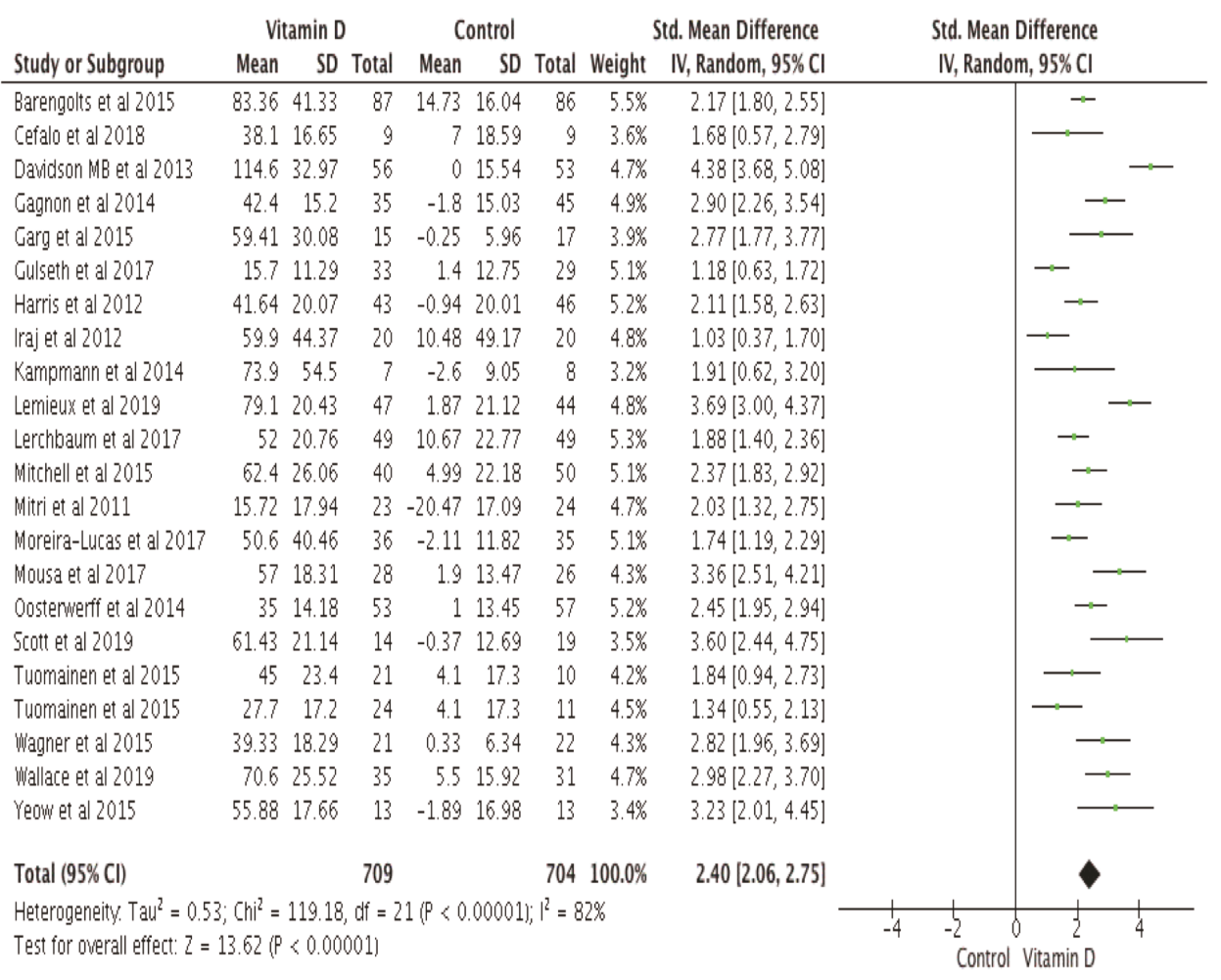

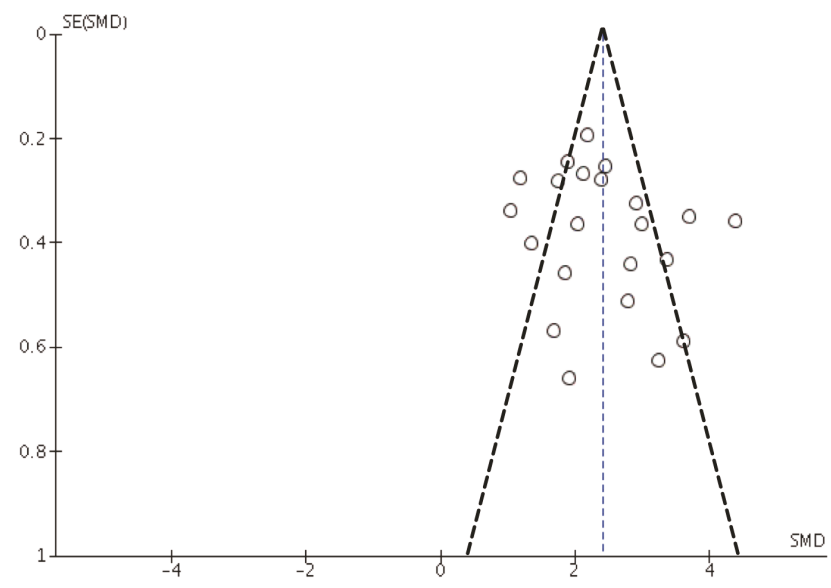

Supplemental figure S3C 
CHAPTER 7

General Discussion

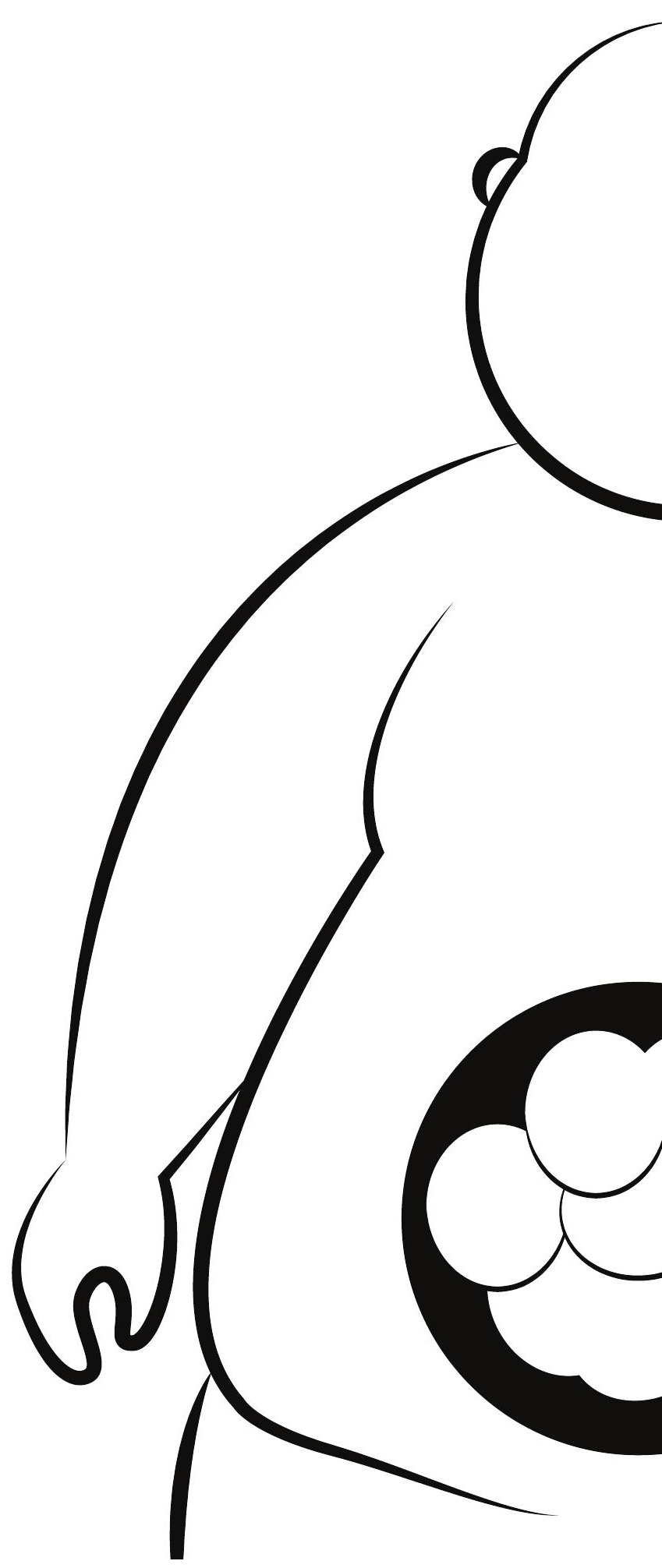




\section{General Discussion}

The increasing prevalence of obesity substantially leads to an increased risk for the development of insulin resistance, type 2 diabetes mellitus, cardiovascular diseases (hypertension and stroke), and certain types of cancer. In addition, obesity and obesityassociated health complications might contribute to a reduced quality of life (1). Obesity is often characterized by low vitamin $\mathrm{D} 25(\mathrm{OH}) \mathrm{D}_{3}$ concentrations (also known as vitamin $\mathrm{D}$ deficiency or hypovitaminosis $D$ ) as indicated by a recent population-based study reporting $42.5 \%$ vitamin $D$ deficiency among individuals with $\mathrm{BMI} \geq 30 \mathrm{~kg} / \mathrm{m}^{2}(2)$. The underlying mechanism linking vitamin $\mathrm{D} 25(\mathrm{OH}) \mathrm{D}_{3}$ and obesity is still unclear (3), whereas reports on the link between vitamin $1,25(\mathrm{OH})_{2} \mathrm{D}_{3}$ concentrations and obesity are inconsistent $(4$, 5). Additionally, in the past decades, insulin resistance and type 2 diabetes mellitus (T2D) have been linked with vitamin D deficiency (6). The US National Health Survey (NHNES) 2001-2006 showed that obese individuals with vitamin D deficiency had higher risk for the development and maintenance of insulin resistance as compared to obese individuals with sufficient vitamin D levels (7).

Therefore, in the present thesis we investigated whether and how vitamin $D$ is related to insulin sensitivity in human obesity. At first, we investigated whether uptake and release of vitamin D by abdominal SAT is impaired in obese individuals and may thereby possibly contribute to the reduced circulating vitamin D levels in vivo in human obesity (chapter 3). Next, we aimed to gather (mechanistic) insight into the association between circulating vitamin $\mathrm{D}$ metabolites $\left[25(\mathrm{OH}) \mathrm{D}_{3}\right.$ and $\left.1.25(\mathrm{OH})_{2} \mathrm{D}_{3}\right]$ and gene-expression of vitamin D-related metabolism within SAT and tissue-specific insulin sensitivity in overweight/obese humans (chapter 4). Furthermore, we examined whether genetic variation in the vitamin $D$ receptor is related to tissue-specific insulin sensitivity in overweight/obesity individuals in the large Pan-European dietary intervention trial (DiOGenes) (chapter 5). Finally, we conducted a meta-analysis of human randomized controlled-trials to investigate whether there is sufficient evidence that vitamin D may affect insulin sensitivity derived from the gold standard hyperinsulinemic euglycemic clamp or from the Matsuda or insulin sensitivity indices derived from OGTT or IVGTT respectively (chapter 6).

\section{Association of circulating vitamin $\mathrm{D}$, obesity and insulin resistance}

The prevalence of low circulating vitamin $D 25(\mathrm{OH}) \mathrm{D}_{3}$ levels $(<50 \mathrm{nmol} / \mathrm{L})$ has been reported to be about $40.7 \%$ in individuals with obesity and insulin resistance (2). In line with these data, about $45.7 \%$ of obese-insulin resistant individuals in our study (chapter 4 ) were classified as vitamin $D$ deficient. The above data suggest that vitamin $\mathrm{D} 25(\mathrm{OH}) \mathrm{D}_{3}$ deficiency is a commonly observed characteristic in obese insulin resistant individuals. However, it is unclear whether vitamin D deficiency is associated with obesity (BMI) or insulin resistance per se.

In chapter 4, we conducted a cross sectional analysis in overweight and obese individuals with either normal or impaired glucose metabolism to investigate whether obesity (BMI) is related to plasma vitamin $\mathrm{D}$ metabolites $\left[25(\mathrm{OH}) \mathrm{D}_{3}\right.$ and $1.25(\mathrm{OH})_{2} \mathrm{D}_{3}$ or the ratio between both in overweight/obese individuals. We demonstrated that $\mathrm{BMI}$ was negatively associated with circulating vitamin $\mathrm{D} 25(\mathrm{OH}) \mathrm{D}_{3}$ but not with the active metabolite of vitamin $\mathrm{D}\left[1.25(\mathrm{OH})_{2} \mathrm{D}_{3}\right]$. The association between $\mathrm{BMI}$ and vitamin $\mathrm{D} 25(\mathrm{OH}) \mathrm{D}_{3}$ remained 
significant after adjustment for age and sex. This finding is consistent with other findings, indicating an inverse correlation between plasma $25(\mathrm{OH}) \mathrm{D}_{3}$ concentration and $\mathrm{BMI}$ across age, different ethnicities and in a range of geographic locations (8-11).

In contrast to our findings, a previous study in individuals with a wide range of $\mathrm{BMI}$ (mean $\pm \mathrm{SD}=32.0 \pm 6.8$; estimated range from 18.4 to $45.6 \mathrm{~kg} / \mathrm{m}^{2}$ ) (12) and a recent study in middle-aged sedentary adults demonstrated a negative correlation between $\mathrm{BMI}$ and active metabolite of vitamin $D\left[1.25(\mathrm{OH})_{2} \mathrm{D}_{3}\right]$ independent of age and sex (5). These discrepancies could possibly be explained by the different BMI ranges of these studies (i.e., our cohort mean $\pm \mathrm{SD}=30.6 \pm 2.9$; range $25.5-38.6 \mathrm{~kg} / \mathrm{m}^{2}$ vs. The FIT-AGEING study (5) mean $\pm \mathrm{SD}=$ $26.7 \pm 3.8$; estimated range $19.1-34.3 \mathrm{~kg} / \mathrm{m}^{2}$ ).

In chapter 4, we extended our cross sectional analysis, to determine whether vitamin D metabolites relate to tissue-specific insulin sensitivity and whether these relationships are independent of BMI, age, and sex. We observed that none of vitamin D metabolites [25(OH) $\mathrm{D}_{3}$ nor $1,25(\mathrm{OH}) \mathrm{D}_{3}$ nor its ratio] were associated with hepatic, muscle nor adipose tissue insulin sensitivity derived from the gold standard two-steps hyperinsulinemic euglycemic clamp technique. Further correction for BMI did not change the outcome. In line, Ter Horst et al (4), also observed no association between vitamin $\mathrm{D} 25(\mathrm{OH}) \mathrm{D}_{3}$ and insulin sensitivity determined by a gold standard two-steps hyperinsulinemic euglycemic clamp in human obesity.

As mentioned above there is a large amount of observational studies that investigated the link between vitamin $D$ deficiency and insulin resistance, but the outcomes are inconsistent (chapter 2). Analyses of the National Health and Nutrition Examination Survey 1989-1994 (NHANES III) disclosed that serum $25(\mathrm{OH}) \mathrm{D}_{3}$ was inversely associated with diabetes risk and measures of insulin resistance in general population (13). Further cross-sectional analysis from population-based study (NHANES 2001-2006), has shown that the interaction between low serum $25(\mathrm{OH}) \mathrm{D}_{3}$ and high $\mathrm{BMI}$ may explain $47 \%$ of insulin resistance cases as assessed by HOMA-IR (7). Significant associations have been reported between circulating $25(\mathrm{OH}) \mathrm{D}_{3}$ and hyperglycemic clamp-induced insulin response in normal glucose tolerant (obese/overweight) individuals of various ethnic backgrounds (14). In contrast, a study conducted in a European populations with metabolic syndrome, showed that serum vitamin $\mathrm{D} 25(\mathrm{OH}) \mathrm{D}_{3}$ levels were not associated with insulin action and glucose metabolism derived by intravenous glucose tolerance test (IVGTT) after correction for BMI (15). In addition, other recent studies have shown no association between vitamin D 25(OH) $\mathrm{D}_{3}$ and HOMA-IR and Matsuda index after adjustment for BMI (15-18).

Of note, vitamin $\mathrm{D} 25(\mathrm{OH}) \mathrm{D}_{3}$ still needs to be hydroxylated to produce its hormonally active metabolite $1,25(\mathrm{OH})_{2} \mathrm{D}_{3}(19)$. Mechanistically, vitamin $\mathrm{D} 1,25(\mathrm{OH})_{2} \mathrm{D}_{3}$ may directly affect insulin signaling (20) and/or glucose stimulated pancreatic insulin secretion (21). However, as mentioned above, We observed no association between $1,25(\mathrm{OH}) \mathrm{D}_{3}$ markers of tissue insulin sensitivity in chapter 4 . In contrast, a recent observational study suggested $1,25(\mathrm{OH})_{2} \mathrm{D}_{3}$ is independent of age, sex, and BMI for features of metabolic syndrome (MetS) (22). However, data on the association of $1,25(\mathrm{OH})_{2} \mathrm{D}_{3}$ and metabolic markers is limited, possibly due to technical issues and vitamin $\mathrm{D} 1,25(\mathrm{OH})_{2} \mathrm{D}_{3}$ stability over longer period of time $(23,24)$.

Taken together, the majority data suggests that vitamin $D 25(\mathrm{OH}) \mathrm{D}_{3}$ deficiency is merely associated with BMI but not with indices of insulin resistance. Notably, studies using hyperinsulinemic euglycemic clamps, IVGTT as well as the Matsuda index do not report 
an association between vitamin $\mathrm{D} 25(\mathrm{OH}) \mathrm{D}_{3}$ deficiency and insulin resistance in line with our data in chapter 4 . Nevertheless, whether vitamin D deficiency is associated with insulin sensitivity in subgroups based on ethnicity, sex and metabolic health status needs to be studied further. Data on the association between $1,25(\mathrm{OH})_{2} \mathrm{D}_{3}, \mathrm{BMI}$ and insulin resistance is still inconsistent and warrant further investigation.

\section{Adipose tissue mass and metabolism in relation to vitamin $D$ deficiency (inactive and active metabolite)}

As reviewed in the chapter $\mathbf{2}$, an altered vitamin $\mathrm{D}$ metabolism within adipose tissue (25) and an increased sequestration of vitamin D in adipose tissue (26) may partly explained vitamin $D$ deficiency in obesity. Furthermore, the dilution of vitamin $D 25(\mathrm{OH}) \mathrm{D}_{3}$ due to a higher volume of distribution in obese individuals has been proposed as underlying mechanism for low serum $25(\mathrm{OH}) \mathrm{D}_{3}$ concentrations in obesity (27).

In chapter 2, we described that there is evidence showing that vitamin D-related metabolism is altered in obese SAT (25). Wamberg et al. observed a decreased RNA expression of 25-hydroxylase enzymes in SAT of obese compared with lean women (25). Interestingly, a recent study using the murine 3T3-L1 adipocyte model demonstrated that adipocytes are capable of converting vitamin $D_{3}$ precursor into vitamin $D 25(\mathrm{OH}) \mathrm{D}_{3^{\prime}}$, but this conversion occurs to a lesser extent in insulin resistant adipocytes due to a reduced expression of the 25-hydroxylation enzyme (28). Together, these data may suggest that large quantities of vitamin $D_{3}$ are stored as the native compound, presumably in body fat, and are only slowly released as vitamin $\mathrm{D} 25(\mathrm{OH}) \mathrm{D}_{3}$ due to less efficient 25 -hydroxylation in SAT in the obese insulin resistant state (29).

However, in chapter 4, further analysis revealed that the association between BMI and plasma vitamin $\mathrm{D} 25(\mathrm{OH}) \mathrm{D}_{3}$ levels in overweight and obese individuals did not change after adjustment for the SAT gene expression of the 25-hydroxylases CYP2J2, CYP27A1; and the 1-alpha-hydroxylase enzyme CYP27B1. Our study also did not find any associations between vitamin $\mathrm{D} 1.25(\mathrm{OH})_{2} \mathrm{D}_{3}$ levels and the expression of 25- or 1-alpha-hydroxylase enzymes within SAT. Thus, our results may suggest that BMI and adiposity and not an altered adipose tissue metabolism is the main determinant for circulating vitamin $\mathrm{D} 25(\mathrm{OH}) \mathrm{D}_{3}$ and $\mathrm{D}$ $1.25(\mathrm{OH})_{2} \mathrm{D}_{3}$ levels in overweight/obese individuals. However, we cannot exclude that other hydroxylase enzymes might be involved in vitamins $D$ metabolism in human SAT, which needs to be investigated in more detail in future research.

Of note, in chapter 4 we only investigated expression of vitamin D enzymes in the abdominal SAT. A study in obese women showed that the expression of the 25-hydroxylation enzymes (CYP27A1, CYP27B1) was higher in VAT compared to SAT and positively correlated with circulating vitamin $D 25(\mathrm{OH}) \mathrm{D}_{3}$ concentration (25). Therefore, whether vitamin $D$ $25(\mathrm{OH}) \mathrm{D}_{3}$ hydroxylation may be regulated differently depending on AT depot as well as the relative contribution of AT vitamin $D$ precursor (stored as native compound) to circulating $25(\mathrm{OH}) \mathrm{D}_{3}$ concentration in obese-insulin resistant state needs further investigation.

It was two decades ago, that Wortsman et al documented that vitamin $\mathrm{D}_{3}$ (a precursor for inactive vitamin $D$ metabolite $/ 25(\mathrm{OH}) \mathrm{D}_{3}$ ) is sequestered in adipose tissue of obese individuals (26). Furthermore, not only the precursor vitamin $D_{3}(30)$ but also the metabolite vitamin $\mathrm{D} 25(\mathrm{OH}) \mathrm{D}_{3}$ has been shown to accumulate in abdominal SAT (31). Of 
interest, an impaired release of vitamin $\mathrm{D}_{3}$ (pre-vitamin $\mathrm{D}$ ) and vitamin $\mathrm{D} 25(\mathrm{OH}) \mathrm{D}_{3}$ has been documented from subcutaneous adipocytes of obese donor compared lean ex vivo (28). This impairment of vitamin D release was co-existing with an impaired lipolytic response following beta-adrenergic stimulation in adipocytes from obese donors (28).

To investigate the contribution of vitamin $D$ metabolites from abdominal adipose tissue, we measured vitamin D metabolites using arterio-venous blood sampling across abdominal SAT in combination with AT blood flow measurements in chapter 3 . We did not observe significant in vivo vitamin $\mathrm{D} 25(\mathrm{OH}) \mathrm{D}_{3}$ release across SAT of lean or obese men following an overnight fast and during acute $ß$-adrenergic stimulation. However, we observed a blunted release of active vitamin D metabolite $1.25(\mathrm{OH})_{2} \mathrm{D}_{3}$ following $ß$-adrenergic stimulation in obese but not in lean men. Of interest, $1,25(\mathrm{OH})_{2} \mathrm{D}_{3}$ is a ligand for vitamin $\mathrm{D}$ receptor (VDR), and it has been shown that VDR expression is increased in abdominal SAT of individuals with obesity (32). In line, our data (chapter 4 ) showed a positive association between BMI and VDR expression in abdominal SAT. Taken together, it could be speculated that vitamin $D 1,25(\mathrm{OH})_{2} \mathrm{D}_{3}$ binds to a higher extent to VDR within SAT in individuals with obesity, resulting in less spillover/release of vitamin $D 1,25(\mathrm{OH})_{2} \mathrm{D}_{3}$ in the circulation in obese but not in lean individuals, which still needs further investigation.

The exact association between the impaired ß-adrenergic stimulated lipolysis and vitamin $D$ release and to what extent they are interconnected remains to be largely determined. Among the physiological factors stimulating release of free fatty acids (FFAs) from adipose tissue, exercise contributes to the greatest proportion (33). During exercise, lipolytic hormones (such as catecholamines and atrial natriuretic peptide (ANP)) $(34,35)$ and ATBF are increased (36). Several cross-sectional studies report a positive correlation between serum $25(\mathrm{OH}) \mathrm{D}_{3}$ concentrations and higher physical activity independent of $\mathrm{BMI}(37,38)$. Interestingly, a recent RCT (39) has observed an elevated serum $25(\mathrm{OH}) \mathrm{D}_{3}$ concentrations in lean individuals in response to 30 minutes cycling exercise. This increased circulating $25(\mathrm{OH})$ $\mathrm{D}_{3}$ was observed immediately post-exercise and even persisted for 24 hours. Therefore, whether exercise has an effect on $25(\mathrm{OH}) \mathrm{D}_{3}$ and $1.25(\mathrm{OH})_{2} \mathrm{D}_{3}$ concentrations - potentially via improved intracellular metabolism (e.g. hydroxylation) and mobilization of adipose tissuederived vitamin $D$ warrants further investigation.

Another type of intervention that induces lipolysis is weight loss induced via caloric restriction in lifestyle interventions (40). Recently, a 1-year lifestyle intervention in obese individuals resulted in a $26 \%$ increase in circulating $25(\mathrm{OH}) \mathrm{D}_{3}$ along with a $26 \%$ decrease in VAT and $18 \%$ decrease in SAT volume (37). This increased $25(\mathrm{OH}) \mathrm{D}$ level correlated inversely with changes in both SAT and VAT (37). Furthermore, an increased expression of the catabolizing enzyme CYP24A1 was observed in SAT of obese individuals following weight loss (25). As CYP24A1 degrades both $25(\mathrm{OH}) \mathrm{D}_{3}$ and $1.25(\mathrm{OH})_{2} \mathrm{D}_{3}(41)$, this may suggest a higher turnover of both $250 \mathrm{HD}_{3}$ and $1.25(\mathrm{OH})_{2} \mathrm{D}_{3}$ following weight loss. Further research is needed to understand vitamin D dynamics (uptake and release) across different adipose tissue depots and under physiological challenges like weight loss and exercise.

\section{Vitamin $D$ and insulin sensitivity}

Data from literatures regarding the effect of vitamin D supplementation on insulin sensitivity and glucose homeostasis are still inconsistent as reviewed in chapter $\mathbf{2}$. The majority of these meta-analyses have used a surrogate marker of insulin sensitivity such us 
HOMA-IR. In chapter 6, we conducted a systematic review and meta-analysis to determine the effect of vitamin D supplementation on insulin sensitivity in individuals with or at risk of insulin resistance.

As reviewed in chapter 2, mainly in vitro and animal data suggest a potential role of vitamin $D$ in insulin-sensitive organs. In adipose tissue, vitamin $D$ may affect lipid metabolism (42) and may reduce inflammation (43). Vitamin D may affect pancreatic insulin secretion via an immunometabolic protection of beta-cells (44) as well as calciumdependent mechanisms (45). In addition, it has been demonstrated that vitamin D affects skeletal muscle substrate and energy metabolism, insulin sensitivity and lipid composition $(46,47)$. More importantly, skeletal muscle affects $70-90 \%$ of postprandial glucose disposal and is therefore a key organ in in the regulation of glucose homeostasis and whole body insulin sensitivity.

Thus, increasing circulating vitamin D concentration by means of supplementation might be expected to have beneficial effects during fasting and postprandial conditions by improving skeletal muscle glucose handling/insulin sensitivity. However, in chapter 6, despite the fact that in all supplementation studies increased concentrations of serum vitamin D 25(OH)D were observed, our meta-analysis indicated no evidence that supplementation with vitamin $D$ has a beneficial effect on peripheral insulin sensitivity, as determined by hyperinsulinemic euglycemic clamp, the Matsuda or insulin sensitivity index nor on postprandial glucose levels. Furthermore, when we also take into account the 3 papers that were published since we complete our meta-analysis in 2019 (48-50) (that met our inclusion criteria and used a clamp), the results do not change (chapter 6). Thus, although mechanistic evidence of vitamin $D$ on glucose responsiveness, insulin receptor substrate (20) and insulin sensitivity (47), muscle mitochondria biogenesis (46) as well as lipid metabolism (47) have been documented at the transcriptional and post-translational level in vitro, our analysis indicate that these do not translate into beneficial functional in vivo effect on peripheral insulin sensitivity and postprandial glucose concentrations.

It might be argued that the participants from included studies (chapter 6) were not deficient enough to observe any major effects of vitamin D supplementation. In chapter 6 , the mean serum vitamin D 25(OH)D concentrations at baseline varied from $19.2 \mathrm{nmol} / \mathrm{L}$ to $59.9 \mathrm{nmol} / \mathrm{L}$ in vitamin D-supplemented groups and $16.9 \mathrm{nmol} / \mathrm{L}$ to 61.4 in placebo groups. Currently, there is a major discussion on the cut-off point for vitamin $D$ deficiency. Circulating $25(\mathrm{OH}) \mathrm{D}_{3}$ concentration $<25 / 30 \mathrm{nmol} / \mathrm{L}$ or $25-50 \mathrm{nmol} / \mathrm{L}$ are defined as severe deficient or deficient (51-53), whereas circulating $25(\mathrm{OH}) \mathrm{D}_{3}$ concentration between 50 to $75 \mathrm{nmol} / \mathrm{L}$ and $>75 \mathrm{nmol} / \mathrm{L}$ are considered as sufficient (52-55). However, the Endocrine Society defines vitamin D sufficient when circulating $25(\mathrm{OH}) \mathrm{D}_{3}$ levels $>75 \mathrm{nmol} / \mathrm{L}(51)$.

When we re-analyzed 9 out of 18 studies with mean baseline serum vitamin D levels $\leq 30 \mathrm{nmol} / \mathrm{L}$, the outcome remains unchanged, suggesting no evidence that vitamin D supplementation improves peripheral insulin sensitivity in individuals with a low vitamin D status. Most (but not all) RCTs included in our meta-analysis recruited participants with $\mathrm{BMI} \geq 25 \mathrm{~kg} / \mathrm{m}^{2}$ and almost all RCTs administrated vitamin $\mathrm{D}_{3}$ as supplementation. It has been suggested that large quantities of vitamin $\mathrm{D}_{3}$ may potentially be stored in body fat, and are only slowly released as vitamin $\mathrm{D} 25(\mathrm{OH}) \mathrm{D}_{3}(29)$. In these particular individuals, weight loss has been shown to increase $25(\mathrm{OH}) \mathrm{D}_{3}$ levels $(25,37)$, and potentially increases the availability of vitamin $\mathrm{D} 25(\mathrm{OH}) \mathrm{D}_{3}$ for muscle tissue. Therefore, combining vitamin $\mathrm{D}_{3}$ supplementation and weight loss in relation to effects on peripheral insulin sensitivity may 
warrant further investigation in more detail.

\section{The VDR gene expression, genetic variants and obesity-insulin resistance}

In chapter 2, we reviewed that there is strong evidence that vitamin D affects adipose tissue function via its transcription factor VDR, although the effects may vary between species and cell models used $(56,57)$. In chapter 4 , we observed that higher abdominal SAT VDR gene expression was associated with a reduced AT insulin sensitivity independent of BMI, age, sex, and explained $14 \%$ of the variance in AT insulin sensitivity. Recent cross sectional data, showed that $\mathrm{BMI}(32,58)$ and $\operatorname{HOMA-IR}(58,59)$ are positively associated with subcutaneous adipose tissue VDR gene expression. This relationship of higher VDR in AT and obesity might be a primary (genetic) defect or more secondary to the obese insulin resistant state and mediated by several factors, including vitamin $\mathrm{D}$ status and low-grade inflammation. Vitamin $\mathrm{D} 25(\mathrm{OH}) \mathrm{D}_{3}$ deficiency/insufficiency might lead to an inflammatory process $(60,61)$ which could subsequently promote VDR expression. Of interest, in vitro data reported that the inflammatory factor TNF-alpha can increase expression and activity of VDR in keratinocytes (62), indicating that VDR levels in abdominal SAT may be elevated in response to obesity-associated adipose tissue inflammation. However this needs to be investigated in more detail in human adipocytes.

Polymorphisms in the VDR gene, namely, Taql, Bsml, Apal, and Fokl, have been identified and may be associated with VDR activity and human obesity (63). In chapter 5, we investigated whether genetic variants of VDR are associated with obesity phenotypes in the DiOGenes study, a Pan-European multicenter, randomized, controlled dietary intervention study (64). In chapter 5, we showed that variants in VDR Taql and Apal are associated with elevated BMI, (contributing $0.9 \mathrm{~kg} / \mathrm{m} 2$ per risk allele), WC ( $3 \mathrm{~cm}$ per risk allele) or FM ( $2 \mathrm{~kg}$ per risk allele) at baseline. In concordance with these results, the VDR Taql was associated with a higher risk of obesity in Greek individuals with $\mathrm{BMI}<30$ and $\geq 30 \mathrm{~kg} / \mathrm{m}^{2}$ (contributing 3 $\mathrm{kg} / \mathrm{m}^{2}$ per risk allele) $(65)$. Our results are in line with some $(65-67)$, but not all studies $(68,69)$ and discrepancies between studies may be partly explained by individuals' characteristics (including differences in the range in BMI, WC, FM, sex, ethnicity).

In chapter 5, we also investigated whether VDR genetic variants are associated with tissue-specific IR and abdominal SAT gene expression (VDR gene and genes related AT remodeling, lipid metabolism, and inflammation). VDR polymorphisms were not associated with hepatic nor muscle insulin sensitivity index at baseline. However, the Fokl VDR polymorphism was associated with adipose tissue insulin resistance (Adipo-IR) as well as elevated circulating FFA (contributing $79 \mu \mathrm{mol} / \mathrm{L}$ per risk allele) at baseline (chapter 5). In line a recent meta-analysis showed that VDR polymorphisms may be associated with insulin resistance (i.e. HOMA-IR) only in Asian and dark-pigmented Caucasian but not in white Caucasian (70), which may suggest ethnic-differences. Currently, it is unclear whether the association between Fokl variants and Adipo-IR or FFA is related to circulating vitamin D concentration or vitamin D status, which warrants further investigation.

Furthermore, our eQTL analysis observed no major effect of VDR SNP variants on abdominal SAT VDR or VDR target gene transcription (chapter 5). This may suggest that VDR genetic variants are not a major determinant of VDR gene expression within abdominal SAT of overweight/obese individuals as observed in chapter $\mathbf{4}$. Finally, in chapter $\mathbf{5}$ we also did not find any effects of VDR variants on body weight change, and tissue-specific IR indices 
following weight loss and weight maintenance, suggesting that the VDR genetic variants may not relate to dietary intervention outcome. Of interest, the Fokl polymorphism is located on the exon in the coding region of the VDR gene, resulting in different translation initiation sites (TIS) and giving rise to a full-length VDR protein or a three amino acid shorter VDR protein variant $(71)$, having higher transcriptional activity $(72,73)$. Therefore, future studies need to investigate how these VDR variants affect functional VDR activity in human adipose tissue and other insulin sensitive tissues such as gut, liver and muscle.

Interestingly, a recent GWAS study in two independent cohorts has shown that genetic variation in VDR (rs7974353) is associated with overall microbial ß diversity (74). Further analysis indicated that Parabacteroides (phylum Bacteroidetes) and unclassified Enterococcaceae (phylum Firmicutes) were significantly correlated with the VDR gene expression in the gut enterocytes (74). The fact that VDR is highly expressed in intestinal tissue (mainly in enterocytes) (75), and that gut microbiota do not express VDR may suggest an indirect relationship between vitamin D, VDR expression and gut microbiota composition, which warrants further investigation.

\section{Main outcomes of this thesis and future perspectives}

The following gives an overview of the main outcomes of this thesis as well as several perspectives for future research,

1. We showed that BMI was inversely associated with vitamin D 25(OH)D3 concentrations which could not be explained by alterations in abdominal SAT vitamin D-metabolizing enzymes. In the present study, plasma vitamin D metabolites [25(OH)D3 and 1,25(OH)2D3] were not related to hepatic, muscle, and adipose tissue insulin sensitivity. These data suggest that BMI but not insulin resistance is the main determinant of vitamin D 25(OH)D3 concentrations in obesity (chapter 4 ).

2. A blunted catecholamine-mediated lipolysis was accompanied with a decreased 1,25(OH)2D3 but not vitamin $\mathrm{D} 25(\mathrm{OH}) \mathrm{D} 3$ release across abdominal SAT in obese men, but did not affect circulating 1,25(OH)2D3 concentration in obese men (chapter 3). Additionally, VDR expression in abdominal SAT was positively associated with BMI indicating an increased VDR expression in obesity (chapter 4). Whether a blunted 1,25(OH)2D3 release might be linked with an increased VDR expression in obese SAT still needs further investigation. Of interest, we showed that abdominal SAT VDR expression is negatively associated with AT insulin sensitivity (chapter 4 ). Whether this is a primary defect or more a secondary phenomenon of the obese insulin resistant state (e.g. low-grade inflammation) needs to be investigated in future research.

3. The VDR polymorphisms are unlikely to play a primary role in tissue-specific insulin resistance (chapter 5). However, VDR polymorphisms were associated with markers of adiposity including $\mathrm{BMI}, \mathrm{WC}$ and $\mathrm{FM}$. Of interest, a recent study from an Asian population (76) demonstrated that VDR polymorphisms, the fat mass and the obesity-associated FTO gene affected weight-loss following 6-months dietary and exercise intervention, indicating that VDR polymorphisms may interact with other gene polymorphisms in determining 
intervention-induced weight loss. Therefore, whether and how VDR genetic variants in combination with other risk alleles affect lifestyle interventioninduced weight loss needs further investigation.

4. Our systematic review and meta-analysis from RCTs (conducted between 1980 - 2019 year) using Matsuda Index, Insulin sensitivity Index, and gold standard hyperinsulinemic euglycemic clamp showed no effect of vitamin D supplementation on insulin sensitivity or postprandial glucose metabolism in individuals with or at risk of insulin resistance (chapter 6).

However, it is possible that vitamin D supplementation may have a beneficial effect on other cardiometabolic risk factor like low-grade inflammation. Recent systematic reviews and meta-analyses $(77,78)$ reported small, but significant, decreases in high-sensitivity C-reactive protein (hs-CRP) and Tumor Necrosis Factor alpha (TNF- $\alpha$ ) concentrations following vitamin D supplementation. It has been shown recently from a Mendelian Randomization study, that hs-CRP is one of 4 inflammatory biomarkers in 3 independent clusters (ILs, adhesion molecules, acute-phase proteins) which was inversely associated with serum $25(\mathrm{OH}) \mathrm{D}_{3}$ concentration (79). Further studies are warranted to investigate whether vitamin $D$ supplementation may have beneficial effects on obesityrelated inflammatory markers or might be beneficial in the prevention and treatment of immune-related disease like cancer and inflammatory bowel disease (IBD) $(80,81)$. In line, It has been recently suggested that vitamin D may also link to the gut metabolism relating to local gut inflammation and gut microbiota composition (82). A recent RCT suggested that vitamin D plays a role in maintaining the intestinal permeability and reducing systemic CRP concentrations (83). Further, there appears to be a bi-directional interplay between the gut microbiota, vitamin $D$ and intestinal inflammation (84). The available evidence suggests that the gut microbiome is responsive to both vitamin $D$ deficiency and/or supplementation. However, the precise nature of the mechanisms in the context of obesity related metabolic disorders is unclear and further investigations are warranted.

Finally, recent findings suggest that the effect of vitamin $D$ supplementation on metabolic health may be affected by VDR genetic variants $(85,86)$. Several studies also indicate beneficial effects on metabolic health by combining vitamin D supplementation and other modes of intervention such as lifestyleinduced weight loss (i.e. diet and exercise) (87-89). Therefore, further studies with more personalized (sub-group, i.e. carrier and non-carriers of VDR SNPs) approaches and combining vitamin D supplementation with other modes of intervention might provide new strategies towards a more personalized approach for treatment and prevention of insulin resistance in humans. 


\section{References}

1. Blüher M. Obesity: global epidemiology and pathogenesis. Nature Reviews Endocrinology. 2019:1.

2. Parva NR, Tadepalli S, Singh $P$, et al. Prevalence of vitamin D deficiency and associated risk factors in the US population (2011-2012). Cureus. 2018;10(6).

3. Pourshahidi LK. Vitamin D and obesity: current perspectives and future directions. Proceedings of the Nutrition Society. 2015;74(2):115-24.

4. Ter Horst KW, Versteeg RI, Gilijamse PW, et al. The vitamin D metabolites 25(OH)D and 1,25(OH)2D are not related to either glucose metabolism or insulin action in obese women. Diabetes Metab. 2016;42(6):416-23.

5. De-la-O A, Jurado-Fasoli L, Castillo MJ, et al. Relationship between 1, 25-Dihydroxyvitamin D and Body Composition in Middle-Aged Sedentary Adults: The FIT-AGEING Study. Nutrients. 2019;11(11):2567.

6. Alvarez JA, Ashraf A. Role of vitamin D in insulin secretion and insulin sensitivity for glucose homeostasis. Int J Endocrinol. 2009;2010:1-18.

7. Kabadi S, Lee B, Liu L. Joint effects of obesity and vitamin D insufficiency on insulin resistance and type 2 diabetes: results from the NHANES 2001-2006. Diabetes Care 2012;35(10):2048-54.

8. Palacios C, Gil K, Pérez CM, et al. Determinants of vitamin D status among overweight and obese Puerto Rican adults. Annals of Nutrition and Metabolism. 2012;60(1):35-43.

9. Shafinaz I, Moy F. Vitamin D level and its association with adiposity among multi-ethnic adults in Kuala Lumpur, Malaysia: a cross sectional study. BMC public health. 2016;16(1):232.

10. Walsh JS, Bowles S, Evans AL. Vitamin D in obesity. Current opinion in endocrinology, diabetes, and obesity. 2017;24(6):389-94.

11. Man REK, Li L-J, Cheng C-Y, et al. Prevalence and determinants of suboptimal vitamin $D$ levels in a multiethnic Asian population. Nutrients. 2017;9(3):313.

12. Konradsen $\mathrm{S}, \mathrm{Ag} \mathrm{H}$, Lindberg F, et al. Serum 1, 25-dihydroxy vitamin D is inversely associated with body mass index. European journal of nutrition. 2008;47(2):87-91.

13. Scragg $R$, Sowers M, Bell C. Serum 25-hydroxyvitamin D, diabetes, and ethnicity in the Third National Health and Nutrition Examination Survey. Diabetes care. 2004;27(12):2813-8.

14. Chiu KC, Chu A, Go VLW, et al. Hypovitaminosis D is associated with insulin resistance and $\beta$ cell dysfunction. Am J Clin Nutr. 2004;79(5):820-5.

15. Gulseth HL, Gjelstad IMF, Tierney AC, et al. Serum vitamin D concentration does not predict insulin action or secretion in European subjects with the metabolic syndrome. Diabetes Care. 2010;33(4):923-5.

16. Marques-Vidal P, Vollenweider P, Guessous I, et al. Serum vitamin D concentrations are not associated with insulin resistance in Swiss adults. J Nutr. 2015;145(9):2117-22.

17. Esteghamati A, Aryan Z, Esteghamati A, et al. Vitamin D deficiency is associated with insulin resistance in nondiabetics and reduced insulin production in type 2 diabetics. Horm Metab Res. 2015;47(04):273-9.

18. Kayaniyil $S$, Vieth $R$, Retnakaran $R$, et al. Association of vitamin $D$ with insulin resistance and $\beta$-cell dysfunction in subjects at risk for type 2 diabetes. Diabetes care. 2010;33(6):1379-81.

19. Bikle DD. Vitamin D metabolism, mechanism of action, and clinical applications. Chem Biol. 2014;21(3):319-29.

20. Maestro B, Campion J, Davila N, et al. Stimulation by 1,25-dihydroxyvitamin D3 of insulin receptor expression and insulin responsiveness for glucose transport in U-937 Human Promonocytic Cells. Endocrine Journal. 2000;47(4):383-91.

21. Pittas AG, Lau J, Hu FB, et al. The role of vitamin D and calcium in type 2 diabetes. A systematic review and meta-analysis. The Journal of Clinical Endocrinology \& Metabolism. 2007;92(6):201729. 
22. Bea JW, Jurutka PW, Hibler EA, et al. Concentrations of the vitamin D metabolite 1, $25(\mathrm{OH}) 2 \mathrm{D}$ and odds of metabolic syndrome and its components. Metabolism. 2015;64(3):447-59.

23. Casetta B, Jans I, Billen J, et al. Development of a Method for the Quantification of $1 \alpha, 25$ (OH) 2-Vitamin D3 in Serum by Liquid Chromatography Tandem Mass Spectrometry without Derivatization. European Journal of Mass Spectrometry. 2010;16(1):81-9.

24. Dirks NF, Martens F, Vanderschueren D, et al. Determination of human reference values for serum total 1, 25-dihydroxyvitamin D using an extensively validated 2D ID-UPLC-MS/MS method. The Journal of steroid biochemistry and molecular biology. 2016;164:127-33.

25. Wamberg L, Christiansen T, Paulsen SK, et al. Expression of vitamin D-metabolizing enzymes in human adipose tissue - the effect of obesity and diet-induced weight loss. Int J Obes (Lond). 2013;37(5):651-7.

26. Wortsman J, Matsuoka LY, Chen TC, et al. Decreased bioavailability of vitamin D in obesity. Am J Clin Nutr. 2000;72(3):690-3.

27. Drincic AT, Armas LA, Diest EE, et al. Volumetric dilution, rather than sequestration best explains the low vitamin D status of obesity. Obesity (Silver Spring). 2012;20:1444-48.

28. Di Nisio A, De Toni L, Sabovic I, et al. Impaired release of vitamin D in dysfunctional adipose tissue: new cues on vitamin D supplementation in obesity. J Clin Endocrinol Metab. 2017.

29. Heaney RP, Armas LA, Shary JR, et al. 25-Hydroxylation of vitamin D3: relation to circulating vitamin D3 under various input conditions. The American journal of clinical nutrition. 2008;87(6):173842.

30. Didriksen A, Burild A, Jakobsen J, et al. Vitamin D3 increases in abdominal subcutaneous fat tissue after supplementation with vitamin D3. European Journal of Endocrinology. 2015;172(3):235-41.

31. Martinaityte I, Kamycheva E, Didriksen A, et al. Vitamin D stored in fat tissue during a 5-year intervention affects serum 25-hydroxyvitamin D levels the following year. The Journal of Clinical Endocrinology \& Metabolism. 2017;102(10):3731-8.

32. Jonas MI, Kuryłowicz A, Bartoszewicz Z, et al. Vitamin D Receptor Gene Expression in Adipose Tissue of Obese Individuals is Regulated by miRNA and Correlates with the Pro-Inflammatory Cytokine Level. International journal of molecular sciences. 2019;20(21):5272.

33. Polak J, Bajzova M, Stich V. Effect of exercise on lipolysis in adipose tissue. Future Lipidology. 2008;3(5):557-72.

34. Jocken JW, Blaak EE. Catecholamine-induced lipolysis in adipose tissue and skeletal muscle in obesity. Physiol Behav. 2008;94(2):219-30.

35. Moro C, Pillard F, De Glisezinski I, et al. Sex differences in lipolysis-regulating mechanisms in overweight subjects: effect of exercise intensity. Obesity. 2007;15(9):2245-55.

36. Thompson $\mathrm{D}$, Karpe $\mathrm{F}$, Lafontan $\mathrm{M}$, et al. Physical activity and exercise in the regulation of human adipose tissue physiology. Physiol Rev. 2012;92(1):157-91.

37. Gangloff A, Bergeron J, Pelletier-Beaumont E, et al. Effect of adipose tissue volume loss on circulating 25-hydroxyvitamin D levels: results from a 1-year lifestyle intervention in viscerally obese men. Int J Obes. 2015;39(11):1638-43.

38. Chin K, Zhao D, Tibuakuu M, et al. Physical activity, vitamin D, and incident atherosclerotic cardiovascular disease in whites and blacks: the ARIC study. The Journal of Clinical Endocrinology \& Metabolism. 2017;102(4):1227-36.

39. Sun X, Cao ZB, Taniguchi H, et al. Effect of an Acute Bout of Endurance Exercise on Serum 25(OH) D Concentrations in Young Adults. J Clin Endocrinol Metab. 2017;102(11):3937-44.

40. Hansen M, Lund MT, Gregers E, et al. Adipose tissue mitochondrial respiration and lipolysis before and after a weight loss by diet and RYGB. Obesity. 2015;23(10):2022-9.

41. Jones G, Prosser DE, Kaufmann M. 25-Hydroxyvitamin D-24-hydroxylase (CYP24A1): its important role in the degradation of vitamin D. Archives of biochemistry and biophysics. 2012;523(1):9-18.

42. Larrick BM, Kim KH, Donkin SS, et al. 1,25-Dihydroxyvitamin D regulates lipid metabolism and glucose utilization in differentiated 3T3-L1 adipocytes. Nutrition research (New York, NY). 
2018;58:72-83.

43. Karkeni E, Bonnet L, Marcotorchino J, et al. Vitamin D limits inflammation-linked microRNA expression in adipocytes in vitro and in vivo: A new mechanism for the regulation of inflammation by vitamin D. Epigenetics. 2018;13(2):156-62.

44. Altieri B, Grant WB, Casa SD, et al. Vitamin D and pancreas: the role of sunshine vitamin in the pathogenesis of Diabetes Mellitus and Pancreatic Cancer. Critical reviews in food science and nutrition. 2016:0.

45. Pittas AG, Harris SS, Stark PC, et al. The effects of calcium and vitamin D supplementation on blood glucose and markers of inflammation in nondiabetic adults. Diabetes Care. 2007;30(4):9806.

46. Ryan ZC, Craig TA, Folmes CD, et al. 1alpha,25-Dihydroxyvitamin D3 regulates mitochondrial oxygen consumption and dynamics in human skeletal muscle cells. J Biol Chem. 2016;291(3):1514-28.

47. Jefferson GE, Schnell DM, Thomas DT, et al. Calcitriol concomitantly enhances insulin sensitivity and alters myocellular lipid partitioning in high fat-treated skeletal muscle cells. Journal of physiology and biochemistry. 2017;73(4):613-21.

48. Jorde R, Sollid ST, Svartberg J, et al. Vitamin D 20,000 IU per Week for Five Years Does Not Prevent Progression From Prediabetes to Diabetes. J Clin Endocrinol Metab. 2016;101(4):1647-55.

49. Kawahara T. Eldecalcitol, a vitamin $D$ analog, for diabetes prevention in impaired glucose tolerance (DPVD study). Am Diabetes Assoc; 2018.

50. Pittas AG, Dawson-Hughes B, Sheehan P, et al. Vitamin D Supplementation and Prevention of Type 2 Diabetes. N Engl J Med. 2019.

51. Holick MF, Binkley NC, Bischoff-Ferrari HA, et al. Evaluation, treatment, and prevention of vitamin D deficiency: an Endocrine Society clinical practice guideline. J Clin Endocrinol Metab. 2011;96(7):1911-30.

52. European Food Safety Association. Dietary reference values for vitamin D. EFSA Journal. 2016;14(10):4547-145.

53. Lips P, Cashman KD, Lamberg-Allardt C, et al. Management of Endocrine Disease: Current vitamin D status in European and Middle East countries and strategies to prevent vitamin D deficiency; a position statement of the European Calcified Tissue Society. European journal of endocrinology. 2019;1(aop).

54. Institute Of Medicine. Dietary Reference Intake for Calcium and Vitamin D. Washington DC: National Academy Press (US); 2011.

55. Balvers MG, Brouwer-Brolsma EM, Endenburg S, et al. Recommended intakes of vitamin D to optimise health, associated circulating 25 -hydroxyvitamin D concentrations, and dosing regimens to treat deficiency: workshop report and overview of current literature. Journal of nutritional science. 2015;4.

56. Narvaez $\mathrm{CJ}$, Matthews $\mathrm{D}$, Broun E, et al. Lean phenotype and resistance to diet-induced obesity in vitamin $D$ receptor knockout mice correlates with induction of uncoupling protein-1 in white adipose tissue. Endocrinology. 2009;150(2):651-61.

57. Wong KE, Kong J, Zhang W, et al. Targeted expression of human vitamin D receptor in adipocytes decreases energy expenditure and induces obesity in mice. J Biol Chem. 2011;286(39):33804-10.

58. Yuzbashian $E$, Asghari $G$, Hedayati $M$, et al. Determinants of vitamin $D$ receptor gene expression in visceral and subcutaneous adipose tissue in non-obese, obese, and morbidly obese subjects. J Steroid Biochem Mol Biol. 2018.

59. Nguyen VT, Li X, Elli EF, et al. Vitamin D, inflammation, and relations to insulin resistance in premenopausal women with morbid obesity. Obesity. 2015;23(8):1591-7.

60. Chang E, Kim Y. Vitamin D insufficiency exacerbates adipose tissue macrophage infiltration and decreases AMPK/SIRT1 activity in obese rats. Nutrients. 2017;9(4):338.

61. Abbas MA. Physiological functions of Vitamin D in adipose tissue. J Steroid Biochem Mol Biol. 2016;165(Pt B):369-81. 
62. Ziv E, Koren R, Zahalka MA, et al. TNF- $\alpha$ increases the expression and activity of vitamin D receptor in keratinocytes: role of c-Jun N-terminal kinase. Dermato-endocrinology. 2016;8(1):e1137399.

63. Ruiz-Ojeda FJ, Anguita-Ruiz A, Leis R, et al. Genetic factors and molecular mechanisms of vitamin D and obesity relationship. Annals of Nutrition and Metabolism. 2018;73:89-99.

64. Larsen TM, Dalskov S, van Baak M, et al. The Diet, Obesity and Genes (Diogenes) Dietary Study in eight European countries - a comprehensive design for long-term intervention. Obes Rev. 2010;11(1):76-91.

65. Vasilopoulos Y, Sarafidou T, Kotsa K, et al. VDR Taql is associated with obesity in the Greek population. Gene. 2013;512(2):237-9.

66. Bienertova-Vasku J, Zlamal F, Pohorala A, et al. Allelic variants in vitamin D receptor gene are associated with adiposity measures in the central-European population. BMC Med Genet. 2017;18(1):90.

67. Al-Daghri NM, Guerini FR, Al-Attas OS, et al. Vitamin D receptor gene polymorphisms are associated with obesity and inflammosome activity. PloS one. 2014;9(7):e102141.

68. Maria CR, Carrillo-Avila JA, Jacqueline SR, et al. Genetic association analysis of vitamin D receptor gene polymorphisms and obesity-related phenotypes. Gene. 2018;640:51-6.

69. Vimaleswaran KS, Cavadino A, Berry DJ, et al. Genetic association analysis of vitamin D pathway with obesity traits. International journal of obesity (2005). 2013;37(10):1399-406.

70. Han Ff, Lv YI, Gong LI, et al. VDR Gene variation and insulin resistance related diseases. Lipids Health Dis. 2017;16(157):1-12.

71. Whitfield GK, Remus LS, Jurutka PW, et al. Functionally relevant polymorphisms in the human nuclear vitamin D receptor gene. Molecular and cellular endocrinology. 2001;177(1-2):145-59.

72. Colin EM, Weel AE, Uitterlinden AG, et al. Consequences of vitamin $D$ receptor gene polymorphisms for growth inhibition of cultured human peripheral blood mononuclear cells by 1, 25-dihydroxyvitamin D3. Clin Endocrinol (Oxf). 2000;52(2):211-6.

73. Alimirah F, Peng X, Murillo G, et al. Functional significance of vitamin D receptor Fokl polymorphism in human breast cancer cells. PloS one. 2011;6(1):e16024.

74. Wang J, Thingholm LB, Skieceviciene J, et al. Genome-wide association analysis identifies variation in vitamin $D$ receptor and other host factors influencing the gut microbiota. Nat Genet. 2016;48(11):1396-406.

75. Kong J, Zhang Z, Musch MW, et al. Novel role of the vitamin D receptor in maintaining the integrity of the intestinal mucosal barrier. American journal of physiology Gastrointestinal and liver physiology. 2008;294(1):G208-16.

76. Gulati S, Misra A, Tiwari R, et al. The influence of polymorphisms of fat mass and obesity (FTO, rs9939609) and vitamin D receptor (VDR, Bsml, Taql, Apal, Fokl) genes on weight loss by diet and exercise interventions in non-diabetic overweight/obese Asian Indians in North India. Eur J Clin Nutr. 2020;74(4):604-12.

77. Mirhosseini N, Rainsbury J, Kimball SM. Vitamin D supplementation, serum 25 (OH) D concentrations and cardiovascular disease risk factors: a systematic review and meta-analysis. Frontiers in cardiovascular medicine. 2018;5:87.

78. Mousa A, Naderpoor N, Teede H, et al. Vitamin D supplementation for improvement of chronic low-grade inflammation in patients with type 2 diabetes: a systematic review and meta-analysis of randomized controlled trials. Nutrition reviews. 2018;76(5):380-94.

79. Palaniswamy S, Gill D, De Silva NM, et al. Could vitamin D reduce obesity-associated inflammation? Observational and Mendelian randomization study. The American Journal of Clinical Nutrition. 2020.

80. Liu W, Zhang L, Xu H-J, et al. The anti-inflammatory effects of vitamin $\mathrm{D}$ in tumorigenesis. International journal of molecular sciences. 2018;19(9):2736.

81. Fletcher J, Cooper SC, Ghosh S, et al. The role of vitamin D in inflammatory bowel disease: mechanism to management. Nutrients. 2019;11(5):1019. 
82. Gubatan J, Moss AC. Vitamin D in inflammatory bowel disease: more than just a supplement. Current opinion in gastroenterology. 2018;34(4):217-25.

83. Raftery $\mathrm{T}$, Martineau AR, Greiller $\mathrm{CL}$, et al. Effects of vitamin $\mathrm{D}$ supplementation on intestinal permeability, cathelicidin and disease markers in Crohn's disease: results from a randomised double-blind placebo-controlled study. United European gastroenterology journal. 2015;3(3):294302.

84. Waterhouse $M$, Hope $B$, Krause $L$, et al. Vitamin $D$ and the gut microbiome: a systematic review of in vivo studies. European journal of nutrition. 2019;58(7):2895-910.

85. Neyestani TR, Djazayery A, Shab-Bidar S, et al. Vitamin D Receptor Fok-I polymorphism modulates diabetic host response to vitamin $D$ intake: need for a nutrigenetic approach. Diabetes care. 2013;36(3):550-6.

86. Al-Daghri NM, Mohammed AK, Al-Attas OS, et al. Vitamin D Receptor Gene Polymorphisms Modify Cardiometabolic Response to Vitamin D Supplementation in T2DM Patients. Sci Rep. 2017;7:8280.

87. Cefalo CM, Conte C, Sorice GP, et al. Effect of Vitamin D Supplementation on Obesity-Induced Insulin Resistance: A Double-Blind, Randomized, Placebo-Controlled Trial. Obesity. 2018;26(4):651-7.

88. Lotfi-Dizaji L, Mahboob S, Aliashrafi S, et al. Effect of vitamin D supplementation along with weight loss diet on meta-inflammation and fat mass in obese subjects with vitamin $D$ deficiency: $A$ double-blind placebo-controlled randomized clinical trial. Clinical endocrinology. 2019;90(1):94101.

89. Duggan C, de Dieu Tapsoba J, Mason C, et al. Effect of vitamin D3 supplementation in combination with weight loss on inflammatory biomarkers in postmenopausal women: a randomized controlled trial. Cancer Prevention Research. 2015;8(7):628-35. 


\section{APPENDIX}

Summary/Ringkasan, Valorization, Acknowledgements, About the author, PhD portofolio

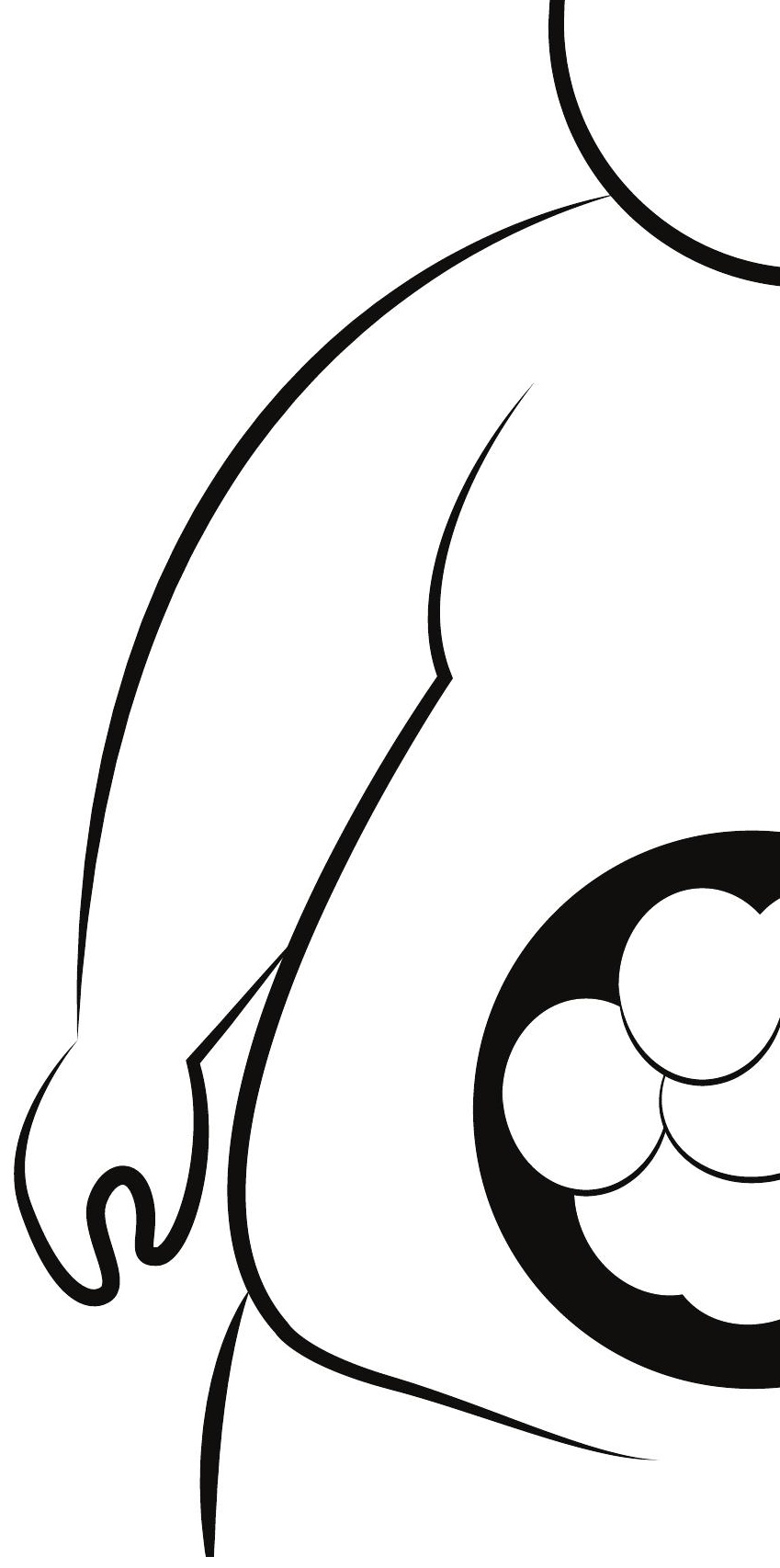




\section{SUMMARY}

Currently, the global prevalence of obesity has doubled over decades across socioeconomic and demographic status. At the same time, vitamin D insufficiency and deficiency are major public health issue worldwide, where the prevalence of vitamin D deficiency was estimated high in obesity regardless of ethnicity, age and sex. Evidence from observational studies suggests a negative correlation between body mass index (BMI) and circulating vitamin $D 25(\mathrm{OH}) \mathrm{D}_{3}$ levels. Up to now, the vitamin $\mathrm{D}$ status in the general population is based on circulating vitamin $\mathrm{D} 25(\mathrm{OH}) \mathrm{D}_{3}$ (inactive metabolite) concentrations. Furthermore, vitamin $\mathrm{D}$ deficiency has also been reported to relate to whole-body insulin resistance. Of note, the development of insulin resistance is caused by a complex inter-organ crosstalk, including several insulin sensitive tissues such as the liver, the skeletal muscle, and the adipose tissue (AT). In this thesis, we aimed to investigate the link between vitamin D status and (tissue-specific) insulin sensitivity in human obesity.

Chapter $\mathbf{2}$ provides an extensive literature review of studies that have examined the effects of vitamin D on glucose and lipid metabolism, as well as inflammation in insulin sensitive tissues such as the liver, skeletal muscle, AT, pancreas, and the gastro-intestinal tract. The majority of the data about the effects of vitamin $D$ in these tissues were derived from animal or in vitro studies, with often inconsistent findings. From human observational studies, more evidence supports the association between vitamin $D$ and obesity-related insulin resistance. However, from human randomized clinical trials (RCTs), evidence for a causal role is debatable. Most of RCTs used surrogate markers such as Homeostatic model assessment of insulin resistance (HOMA-IR) to define insulin resistance and did not take into account ethnic differences. Based on our extensive literature review we concluded that vitamin $D$ deficiency may be associated with obesity through several mechanisms including sequestration in the AT, an impaired vitamin D related metabolism within AT, and a blunted release of vitamin D from AT. However, the link between vitamin D with (tissue-specific) insulin sensitivity warrants further investigation, using more standardized (state-of-the-art) methodologies such as hyperinsulinemic-euglycemic clamps or insulin sensitivity indices derived from an OGTT.

Sequestration of vitamin D metabolites in the excessive amount of AT in conditions of increased adiposity is one of the mechanisms that may explain the low circulating vitamin $\mathrm{D} 25(\mathrm{OH}) \mathrm{D}_{3}$ levels in human obesity. Vitamin $\mathrm{D}$ is a fat-soluble vitamin, and ex vivo evidence from obese AT donors suggests that vitamin D release from the AT obese is blunted following lipolytic stimulation with adrenaline. Therefore, we hypothesized that in human obesity the often observed blunted catecholamine-mediated lipolysis coincides with a blunted release of vitamin $\mathrm{D}$ metabolites in vivo. Therefore, in chapter 3 , we analyzed vitamin $\mathrm{D}$ (inactive) $25(\mathrm{OH}) \mathrm{D}_{3}$ and (active) $1.25(\mathrm{OH})_{2} \mathrm{D}_{3}$ fluxes across the abdominal subcutaneous adipose tissue (SAT) of obese compared to lean men, in relation to changes in circulating vitamin D levels and local AT lipolysis. We observed that both net glycerol release (marker of lipolysis) and net release of the active vitamin $\mathrm{D}$ metabolite $1,25(\mathrm{OH})_{2} \mathrm{D}_{3}$ across abdominal SAT during ß-adrenergic stimulation were significantly reduced in obese as compared to lean men, suggesting a blunted vitamin $\mathrm{D} 1,25(\mathrm{OH})_{2} \mathrm{D}_{3}$ release and an impaired lipolysis across abdominal SAT in obese men in vivo. In contrast, no significant release of the inactive vitamin D metabolite $25(\mathrm{OH}) \mathrm{D}_{3}$ across SAT was observed in lean or obese men following an 
overnight fast or during ß-adrenergic stimulation, possibly indicating an impaired AT vitamin $D$ metabolism (hydroxylation of $25(\mathrm{OH}) \mathrm{D}_{3}$ ) in human obesity. Total adipose tissue mass may be an important determinant of circulating vitamin $D$ levels as it has been proposed that a sequestration of vitamin $D$ in the expanded adipose tissue mass may be a responsible factor for the vitamin D deficiency in obesity. Additionally, an altered vitamin D metabolism in AT may also contribute to vitamin $D$ deficiency and insulin resistance.

In chapter 4, we investigated (1) whether obesity (BMI) is related to circulating vitamin $D$ levels (active, inactive and ratio), and whether alterations in plasma vitamin $D$ metabolites may be mediated by an altered AT expression of VDR or vitamin D-metabolizing (hydroxylation) enzymes; (2) whether plasma vitamin D and AT expression of VDR relates to tissue-specific (adipose tissue, liver and skeletal muscle) insulin sensitivity determined by a 2-step hyperinsulinemic-euglycemic clamp with a [6,6- $\left.{ }^{2} \mathrm{H}_{2}\right]$-glucose tracer; (3) Finally, we investigated whether an altered AT vitamin $D$ metabolism may relate to AT insulin sensitivity. We demonstrated that (1) BMI was negatively associated with of plasma $25(\mathrm{OH}) \mathrm{D}_{3}$ but not with plasma $1,25(\mathrm{OH})_{2} \mathrm{D}_{3}$, nor its ratio; (2) Plasma vitamin $\mathrm{D} 25(\mathrm{OH}) \mathrm{D}_{3}$ deficiency was neither related to changes in SAT vitamin D-metabolizing enzymes nor SAT VDR gene expression; (3) plasma $25(\mathrm{OH}) \mathrm{D}_{3}, 1,25(\mathrm{OH})_{2} \mathrm{D}_{3}$, and the active/inactive metabolite ratio were not significantly associated with hepatic, peripheral or AT insulin sensitivity; (4) Interestingly, SAT VDR gene expression was negatively associated with AT insulin sensitivity (as indicated by $\%$ suppression of systemic FFA). Therefore, future studies are needed to unravel the molecular mechanisms by which nuclear and membrane-bound VDR interacts with insulin action and lipolysis in abdominal SAT.

Twin and familial studies from past decades have demonstrated a nontrivial heritability of both obesity and circulating vitamin D concentrations. Moreover, several large-scale genome-wide association studies (GWAS) have discovered associations with key vitamin $D$ enzymes and serum levels of vitamin D. Therefore, we hypothesized that VDR genetic variants may be associated with adiposity, whole body insulin resistance and the development of T2D. However, whether these VDR variants may also affect AT vitamin D metabolism and human SAT at the transcriptional level is unknown. In chapter 5, we tested the hypothesis that VDR genetic variants are associated with obesity phenotypes, tissuespecific insulin resistance and changes in the SAT transcriptome. Therefore, we included 553 overweight/obesity men and women from DiOGenes study, a multi-center, randomized double-blind controlled dietary intervention trial in 8 European countries. We estimated hepatic insulin resistance (HIRI) and muscle insulin sensitivity (MISI) using insulin and glucose concentrations from a 5 time-points oral glucose tolerance test (OGTT) and adipose tissue insulin resistance (Adipo-IR) from fasting insulin and free fatty acids levels. We found that Taql and Apal genetic variants were associated with markers of adiposity including BMI, WC, and Fat Mass. However, the VDR genetic variants were not associated with HIRI or MISI. Variants in FokI VDR were associated with Adipo-IR as well as elevated circulating FFA. However, cis and trans eQTL analysis demonstrated no major effects of these VDR polymorphisms on the SAT transcriptome, indicating that the putative mechanisms of action remain to be determined. The VDR polymorphisms did not relate to changes in body weight and insulin resistance as result of the dietary intervention.

Several plausible mechanisms to explain a potential role of vitamin D in improving insulin sensitivity have been described in chapter 2, including its effects on skeletal muscle substrate metabolism, insulin sensitivity and lipid composition. Importantly, the skeletal 
muscle is recognized as key organ in peripheral insulin sensitivity as it affects $70-90 \%$ of total glucose disposal under postprandial conditions (non-fasting conditions). Based on the conclusions derived from our review in chapter 2, we conducted a systematic review and meta-analysis on the effect of vitamin D supplementation on insulin sensitivity in individuals with or at risk of insulin resistance (Chapter 6 ). We systematically searched and performed a meta-analysis from studies (published between 1980 and 2018) that met the PICOS (Patients/ participants, Intervention, Comparison/control group, Outcome, and Study Design) criteria: (1) study was a randomized controlled trial; (2) study population consisted of individuals with elevated (risk for) insulin resistance (overweight, obesity, prediabetes, polycystic ovary syndrome (PCOS), and type 2 diabetes without complications); (3) participants were $\geq 18$ years; (4) interventions were vitamin D supplementation vs the appropriate placebo; (5) vitamin D supplementation dose was daily, weekly, or monthly; (6) trial length was $\geq 2$ months; (7) serum 25(OH)D level was measured; (8) insulin sensitivity was measured by Matsuda index derived from an OGTT and/or insulin sensitivity index derived from IVGTT, or by a hyperinsulinemic-euglycemic clamp at the beginning and at the end of the trial. This systematic review (chapter 6 ) provides no evidence that supplementation with vitamin $D$ has a beneficial effect on peripheral insulin sensitivity, as determined by the hyperinsulinemiceuglycemic clamp, the Matsuda or insulin sensitivity index, and postprandial glucose concentrations after an OGTT in people with, or at risk for insulin resistance.

In conclusion, we found that BMI but not insulin sensitivity (in the liver, muscle, or adipose tissue) is the main determinant of circulating vitamin $D 25(\mathrm{OH}) \mathrm{D}_{3}$ concentration. However, the VDR gene expression in abdominal SAT is associated with adipose tissue insulin sensitivity, Whether this is a primary defect or more a secondary phenomenon of the obese insulin resistant state (e.g. chronic low-grade inflammation) needs to be investigated in future research. Furthermore, a blunted vitamin $\mathrm{D} 1,25(\mathrm{OH})_{2} \mathrm{D}_{3}$ release and an impaired lipolysis across abdominal SAT in obese men was observed in vivo following ß-adrenergic stimulation. Further studies are still needed to investigate whether this impaired release of vitamin $D$ $1,25(\mathrm{OH})_{2} \mathrm{D}_{3}$ might be linked with changes in the VDR expression in abdominal SAT of obese individuals or possibly due to an impaired AT vitamin D metabolism (i.e. hydroxylation) in human obesity. In addition, The VDR polymorphisms are unlikely to play a primary role in tissue-specific insulin resistance. Finally, our meta-analysis showed no effect of vitamin D supplementation on insulin sensitivity or postprandial glucose metabolism in individuals with or at risk of insulin resistance. Nevertheless, it is possible that vitamin D supplementation may have a beneficial effect on other cardio-metabolic risk factor like chronic low-grade inflammation and may have beneficial effects on gut microbiota composition/diversity and intestinal health. Further studies with more specific approaches by taking into account genetic variations of the VDR and combining vitamin D supplementation with other modes of intervention might provide new strategies towards a more personalized approaches for treatment and prevention of insulin resistance in humans. 


\section{RINGKASAN}

Prevalensi obesitas di dunia telah berlipat ganda tanpa memandang status sosialekonomi dan demografis. Pada saat yang sama, kekurangan vitamin D juga merupakan masalah kesehatan masyarakat. Prevalensi kekurangan vitamin D diperkirakan tinggi pada orang dengan obesitas tanpa memandang etnis, usia dan jenis kelamin. Bukti dari studi observasional menunjukkan korelasi negatif antara indeks massa tubuh (IMT) dan kadar vitamin $\mathrm{D} 25(\mathrm{OH}) \mathrm{D}_{3}$ darah. Kekurangan vitamin $\mathrm{D}$ juga dilaporkan berhubungan dengan resistensi insulin. Perkembangan resistensi insulin dapat terjadi secara spesifik di beberapa organ yang sensitif terhadap insulin seperti hati, otot, dan jaringan adiposa. Dalam tesis ini, kami bertujuan untuk menyelidiki hubungan antara status vitamin $D$ dan sensitivitas insulin yang spesifik (di otot, hati, dan adiposa) pada orang yang obesitas.

Bab 2 berisi tinjauan literatur yang luas mengenai berbagai studi yang telah meneliti efek vitamin $D$ pada metabolisme glukosa dan lemak, serta inflamasi pada organ yang sensitif terhadap insulin seperti hati, otot, adiposa, pankreas, dan saluran pencernaan. Sebagian besar data-data tersebut berasal dari studi pada hewan coba atau studi in vitro (menggunakan sel model), dengan temuan yang tidak konsisten. Dari studi pengamatan di manusia, terdapat cukup bukti yang mendukung hubungan antara vitamin $D$ dan resistensi insulin terkait obesitas. Akan tetapi, dari uji klinis acak pada manusia (randomized control trial/RCT), peran vitamin D terhadap resistensi insulin masih diperdebatkan. Sebagian besar RCT menggunakan biomarker tidak langsung seperti penilaian model homeostasis resistensi insulin (HOMA-IR) untuk menentukan resistensi insulin. Berdasarkan tinjauan literatur kami yang luas, kami menyimpulkan bahwa kekurangan vitamin D mungkin dapat dikaitkan dengan obesitas melalui beberapa mekanisme termasuk sekuestrasi vitamin D di jaringan adiposa, gangguan metabolisme vitamin $D$ di jaringan adiposa, dan gangguan/hambatan pelepasan vitamin $\mathrm{D}$ dari jaringan adiposa. Namun, hubungan antara vitamin $\mathrm{D}$ dengan sensitivitas insulin yang spesifik (di jaringan adiposa, otot, dan hati) memerlukan investigasi lebih lanjut, menggunakan metodologi yang lebih terstandarisasi (mutakhir) seperti teknik hyperinsulinemic-euglycemic clamp atau indeks sensitivitas insulin yang berasal dari beberapa tahap pengambilan glukosa darah setelah tes oral cairan glukosa (oral glucose tolerance test).

Sekuestrasi vitamin D metabolit dalam jumlah berlebihan di adiposa yang terjadi seiring peningkatan adipositas (penumpukan jaringan lemak/adiposa) diduga menjadi salah satu mekanisme yang dapat menjelaskan rendahnya sirkulasi vitamin $D 25(\mathrm{OH}) \mathrm{D}_{3}$ pada obesitas. Vitamin $\mathrm{D}$ adalah vitamin yang larut dalam lemak, dan studi ex vivo dari jaringan adiposa laki-laki pendonor yang obesitas menunjukkan bahwa terjadi hambatan pelepasan vitamin $\mathrm{D}$ setelah distimulasi dengan adrenalin. Kami menduga bahwa pada secara in vivo, orang yang obesitas mengalami gangguan pelepasan lemak yang dimediasi katekolamin, bersamaan dengan itu juga terjadi hambatan pelepasan vitamin $\mathrm{D}$ metabolit dari jaringan adiposa. Dalam bab 3, kami menganalisis vitamin $\mathrm{D} 25(\mathrm{OH}) \mathrm{D}_{3}$ dan $1,25(\mathrm{OH})_{2} \mathrm{D}_{3}$ fluks dari jaringan adiposa subkutan di bagian perut laki-laki yang obesitas dibandingkan dengan laki-laki normal. Kami mengamati bahwa pelepasan gliserol (salah satu penanda proses pelepasan lemak/lipolisis) dan pelepasan vitamin $\mathrm{D} 1,25(\mathrm{OH})_{2} \mathrm{D}_{3}$ dari jaringan adiposa subktan selama stimulasi beta agonis isoprenaline secara signifikan lebih rendah pada laki-laki yang obesitas dibandingkan dengan laki-laki normal, mengindikasikan terjadi 
hambatan pelepasan lemak dan vitamin $\mathrm{D} 1,25(\mathrm{OH})_{2} \mathrm{D}_{3}$ pada obesitas. Sebaliknya, tidak ada pelepasan signifikan dari metabolit vitamin $\mathrm{D} 25(\mathrm{OH}) \mathrm{D}_{3}$ dari jaringan adiposa subkutan di bagian perut pada laki-laki obesitas atau normal, setelah puasa semalam atau selama stimulasi beta agonis isoprenaline. Hal ini mungkin mengindikasikan gangguan metabolisme vitamin $\mathrm{D}$ (hidroksilasi $25(\mathrm{OH}) \mathrm{D}_{3}$ ) di jaringan adiposa pada orang yang obesitas. Total massa jaringan adiposa mungkin merupakan determinan penting dari kadar vitamin $\mathrm{D}$ darah, dan mungkin merupakan faktor yang bertanggung jawab atas defisiensi vitamin $\mathrm{D}$ pada obesitas. Gangguan metabolisme vitamin D pada obesitas mungkin juga berkontribusi terhadap defisiensi vitamin $D$ dan resistensi insulin.

Dalam bab 4, kami menyelidiki (1) apakah obesitas (dilihat dari Indeks Massa Tubuh/IMT) terkait dengan sirkulasi kadar vitamin D (metabolit yang aktif, tidak aktif dan rasionya), dan apakah perubahan kadar vitamin $D$ dimediasi oleh ekspresi gen enzimenzim dalam metabolism vitamin D serta reseptor vitamin D; (2) apakah kadar vitamin D tubuh dan ekspresi gen enzim-enzim vitamin $D$ serta gen reseptor vitamin $D$ di jaringan adipose berhubungan dengan sensitivitas insulin di berbagai jaringan (jaringan adiposa, hati, dan otot). Sensitivitas insulin di jaringan spesifik tersebut diukur dengan teknik gold standard hyperinsulinemic-euglycemic clamp dengan pelacak radio-isotop glukosa yang stabil $\left[6,6-{ }^{2} \mathrm{H}_{2}\right]$-glukosa; (3) Kami juga menyelidiki apakah enzim-enzim metabolisme vitamin $D$ di jaringan adiposa juga berhubungan dengan sensitivitas insulin yang spesifik di hati, otot, dan jaringan adiposa. Kami menunjukkan bahwa (1) IMT berhubungan negatif dengan kadar $25(\mathrm{OH}) \mathrm{D}_{3}$ tetapi tidak dengan vitamin $\mathrm{D} 1,25(\mathrm{OH})_{2} \mathrm{D}_{3}$, atau rasionya; (2) Kekurangan vitamin $\mathrm{D} 25(\mathrm{OH}) \mathrm{D}_{3}$ tidak berhubungan dengan ekspresi gen enzim-enzim metabolisme vitamin D atau ekspresi gen reseptor vitamin D; (3) Kadar vitamin D $25(\mathrm{OH}) \mathrm{D}_{3}, 1,25(\mathrm{OH})$ ${ }_{2} \mathrm{D}_{3}$, dan rasionya tidak berhubungan dengan sensitivitas insulin yang spesifik di hati, otot, atau jaringan adiposa; (4) Menariknya, ekspresi gen reseptor vitamin D berhubungan negatif dengan sensitivitas insulin di jaringan adiposa. Oleh karena itu, studi yang lebih detail diperlukan untuk mengungkap mekanisme molekuler bagaimana reseptor vitamin $\mathrm{D}$ berinteraksi dengan aksi insulin, serta pemecahan lemak khususnya di jaringan adiposa.

Studi genetik, dari beberapa dekade terakhir telah menunjukkan heritabilitas nontrivial dari obesitas dan konsentrasi vitamin D. Selain itu, beberapa studi asosiasi genomik skala besar (GWAS) menunjukkan hubungan dengan variasi genetic dari enzim-enzim vitamin $\mathrm{D}$ dan kadar vitamin $\mathrm{D}$ darah. Oleh karena itu, kami berhipotesis bahwa variasi genetik reseptor vitamin $D$ mungkin juga berhubungan dengan adipositas, resistensi insulin seluruh tubuh serta diabetes tipe 2. Namun, apakah variasi reseptor vitamin D ini mempengaruhi transkripsi berbagai gen di jaringan adiposa pada manusia belum diketahui. Dalam bab 5, kami menguji hipotesis bahwa varian genetik reseptor vitamin D terkait dengan obesitas, resistensi insulin yang spesifik di hati, otot, dan jaringan adiposa, serta mempengaruhi transkripsi genetik di jaringan adiposa dari bagian abdomen (perut). Kami menganalisis 553 pria dan wanita yang kelebihan berat badan / obesitas dari studi DiOGenes, sebuah studi klinis intervensi diet di 8 negara Eropa. Kami menganalisis resistensi insulin di hati (hepatic insulin resistance index/HIRI) dan sensitivitas insulin di otot (muscle insulin sensitivity index/ MISI) berdasarkan konsentrasi insulin dan glukosa dari uji toleransi glukosa oral (OGTT) 5 titik waktu $(0,30,60,90,120$ menit) serta resistensi insulin jaringan adiposa (adipose tissue insulin resistance index/Adipo-IR) berdasarkan kadar insulin puasa dan asam lemak bebas dalam darah puasa. Kami menemukan bahwa varian genetik Taql dan Apal berhubungan dengan marker adipositas termasuk IMT, lingkar pinggang, dan massa lemak. Tidak ada 
varian genetik reseptor vitamin D yang berhubungan dengan HIRI atau MISI. Varian genetik Fokl resptor vitamin D berhubungan dengan Adipo-IR serta peningkatan kadar asam lemak bebas. Namun, analisis cis- dan trans- eQTL tidak menunjukkan ada pengaruh dari variasi genetik reseptor vitamin $D$ ini pada transkripsi genetik di jaringan adiposa, menunjukkan bahwa mekanisme keterkaitan varian genetik reseptor vitamin $D$ dengan resistensi insulin di jaringan adiposa masih harus diteliti lebih lanjut. Pada studi kami, variasi genetik reseptor vitamin $\mathrm{D}$ juga tidak berhubungan dengan perubahan berat badan dan resistensi insulin setelah di intervensi diet.

Beberapa mekanisme mungkin dapat menjelaskan potensi vitamin D dalam meningkatkan sensitivitas insulin telah dijelaskan pada Bab 2, termasuk efeknya pada aksi reseptor insulin, komposisi lemak, dan metabolisme di jaringan otot. Lebih utamanya adalah otot merupakan organ kunci dalam sensitivitas insulin di jaringan tepi (perifer) karena mempengaruhi $70-90 \%$ dari total penggunaan glukosa di bawah kondisi postprandial (kondisi non-puasa). Berdasarkan ulasan kami di Bab 2, kami melakukan tinjauan sistematis dan meta-analisis tentang efek suplementasi vitamin $D$ pada sensitivitas insulin pada individu dengan atau berisiko resistansi insulin (Bab 6). Kami secara sistematis mencari dan melakukan meta-analisis dari studi (diterbitkan antara 1980 dan 2018) yang memenuhi kriteria PICOS (Patients/ pasien/peserta penelitian, Intervention/intervensi yang diberikan, Control/kelompok pembanding/plasebo, Outcomes/hasil/luaran yang diukur, dan Study design/desain penelitian) kriteria: (1) desain studi adalah RCT; (2) populasi penelitian terdiri dari individu dengan/berisiko resistensi insulin (obesitas, prediabetes, sindrom ovarium polikistik (PCOS), dan diabetes tipe 2 tanpa komplikasi); (3) pasien berusia $\geq 18$ tahun; (4) intervensi adalah suplementasi vitamin D vs plasebo yang sesuai; (5) dosis suplemen vitamin D adalah harian, mingguan, atau bulanan; (6) lama studi adalah $\geq 2$ bulan; (7) kadar vitamin D 25(OH)D diukur; (8) sensitivitas insulin diukur dengan indeks Matsuda yang berasal dari OGTT atau indeks sensitivitas insulin yang berasal dari tes toleransi glukosa intravenous (IVGTT), atau hyperinsulinemic-euglycemic clamp di awal dan di akhir percobaan. Tinjauan sistematis dan meta analisis ini (bab 6) menunjukkan tidak ada efek suplementasi vitamin D terhadap sensitivitas insulin, yang diukur oleh metode gold standard hyperinsulinemiceuglycemic clamp, indeks Matsuda atau indeks sensitivitas insulin, serta tidak berefek menurunkan konsentrasi glukosa postprandial setelah OGTT pada orang dengan/berisiko mengalami resistensi insulin.

Sebagai kesimpulan, kami menemukan bahwa IMT (bukan sensitivitas insulin di hati, otot, atau jaringan adiposa) merupakan determinan utama kadar vitamin $\mathrm{D} 25(\mathrm{OH}) \mathrm{D}_{3}$. Selanjutnya, ekspresi gen reseptor vitamin $D$ pada jaringan adipose subkutan berhubungan dengan sensitivitas insulin di jaringan adiposa, Perlu diteliti lebih lanjut apakah kaitan tersebut merupakan gangguan primer atau lebih merupakan fenomena sekunder dari keadaan resisten insulin pada orang obesitas (misalnya sebagai akibat peradangan kronis tingkat rendah). Terjadi hambatan pelepasan vitamin $\mathrm{D} 1,25(\mathrm{OH})_{2} \mathrm{D}_{3}$ dan gangguan lipolisis pada jaringan adipose subkutan pada laki-laki obesitas secara in vivo setelah stimulasi katekolamin. Penelitian lebih lanjut masih diperlukan untuk menyelidiki apakah hambatan pelepasan vitamin $\mathrm{D} 1,25(\mathrm{OH})_{2} \mathrm{D}_{3}$ ini mungkin terkait dengan perubahan ekspresi reseptor vitamin $\mathrm{D}$ pada jaringan adiposa subkutan pada obesitas atau mungkin karena gangguan metabolisme vitamin D pada obesitas. Kemudian, variasi genetik reseptor vitamin D tidak berperan utama dalam resistensi insulin di jaringan hati, adiposa dan otot. Pada metaanalisis, tidak ada efek suplementasi vitamin D terhadap sensitivitas insulin atau penurunan 
kadar glukosa postprandial pada individu dengan atau berisiko resistansi insulin. Namun, suplementasi vitamin D mungkin memiliki efek terhadap faktor risiko kardio-metabolik lainnya seperti kemungkinan menurunkan peradangan kronis dan mungkin memiliki efek terhadap keanekaragaman mikrobiota usus serta kesehatan intestinal (usus). Studi lebih lanjut dengan pendekatan yang lebih spesifik dengan mempertimbangkan variasi genetik metabolisme vitamin $\mathrm{D}$ dan kombinasi berbagai intervensi mungkin memberikan strategi baru menuju pendekatan yang lebih personal untuk pencegahan resistensi insulin pada manusia. 


\section{VALORIZATION}

Obesity prevalence is increasing worldwide and often coincides with circulating vitamin $\mathrm{D}$ deficiency and whole-body insulin resistance. The present thesis describes how obesity-related phenotypes, vitamin D concentrations as well as vitamin D-related genes link to insulin resistance. The valorization potential of the work described in this thesis will be discussed in terms of societal and economic relevance, the implications for the scientific community and health care professionals, activities/products, including future planning and realization.

\section{Societal and Economic Relevance}

Obesity is associated with type 2 diabetes mellitus, cardiovascular diseases (mainly heart disease and stroke), diabetes, musculoskeletal disorders (especially osteoarthritis - a highly disabling degenerative disease of the joints), some types of cancers, depression and a reduced quality of life (1), and more recently it was identified as a major risk factor for fatal COVID-19 (2). Obesity is a chronic metabolic disorder resulting from an energy imbalance, by which a long-term positive energy balance leads to the storage of excess energy as body fat (3). Furthermore, obesity is often characterized with vitamin D deficiency. Putative mechanisms, linking obesity, vitamin $D$, and insulin resistance are described in this thesis, including obesity, vitamin D deficiency, adipose tissue dysfunction, and tissue-specific insulin sensitivity.

Our study showed that the prevalence of vitamin $\mathrm{D} 25(\mathrm{OH}) \mathrm{D}_{3}$ deficiency [based on Endocrine Society cut-off value $<50 \mathrm{nmol} / \mathrm{L}$ ] in our study was about $45.7 \%$, and BMI is the main determinant of vitamin $\mathrm{D} 25(\mathrm{OH}) \mathrm{D}_{3}$ concentration in individuals with overweight/ obesity (chapter 4), indicating that obesity-associated vitamin D deficiency could be recognized as an important public health concern. Ensuring sufficient circulating vitamin $D$ $25(\mathrm{OH}) \mathrm{D}_{3}$ level is essential to maintain general health but also may be of importance in the management of obesity, and the prevention of insulin resistance and T2D.

Oral and intravenous vitamin $\mathrm{D}$ supplementation have been suggested to effectively increase circulating vitamin $\mathrm{D} 25(\mathrm{OH}) \mathrm{D}_{3}$ level. Our meta-analysis showed that vitamin $\mathrm{D}$ supplementation is an effective means to increase circulating vitamin $D 25(\mathrm{OH}) \mathrm{D}_{3}$ level, despite substantial heterogeneity (chapter 6). However, more research is needed to study the efficacy and bioavailability of different types (and routes of administration) of vitamin D supplementation to more effectively increase serum vitamin D levels in overweight/obesity.

We did not find any associations between circulating vitamin D levels with hepatic, muscle, and adipose tissue insulin sensitivity assessed by hyperinsulinemic-euglycemic clamp (chapter 4). Furthermore, our meta-analysis showed no beneficial effect of vitamin D supplementation on the improvement of insulin sensitivity (chapter 6), suggesting no direct causality between vitamin $\mathrm{D}$ deficiency and whole body and tissue specific insulin resistance in human obesity.

Our study using arterio-venous difference techniques across abdominal subcutaneous adipose tissue (SAT) showed that there was an impaired release of active vitamin $D$ metabolite in obese men (chapter $\mathbf{3}$ ). In addition, we observed that VDR expression in abdominal SAT is increased in obesity and associated with adipose tissue insulin sensitivity 
(chapter 4). This may suggest that adipose tissue may be a key target organ to improve vitamin $D$ metabolism in the context of human obesity. Furthermore, currently a project on exercise-mediated Vitamin D mobilization sequestered in the human adipose tissue (Vita-DEx project) is ongoing (4). If exercise might be beneficial to mobilize vitamin $D$ from adipose, then this may have implications regarding the management/treatment of a low vitamin D status in obesity.

\section{Scientific Community}

The content of the chapters in this thesis have been presented at national scientific meetings (i.e. NASO spring meeting and ADDRM meeting) and international conferences (The $25^{\text {th }}$ and $26^{\text {th }}$ European Congress on Obesity). The results have also been discussed to health professionals and colleagues inside and outside the scientific community with the purpose to discuss the medical and societal consequences of obesity and vitamin $D$ deficiency. Moreover, the studies described in this thesis have been published or will become available to the scientific community through publication in peer-reviewed journals.

The findings presented in this thesis, may be of value for health care professionals (e.g. physicians and dieticians). Given that fact that the incidence of vitamin D deficiency is considerable high (>40\%) among obese individuals, this may possibly have consequences for recommended nutritional intake. However, a recent RCT reported $750 \mathrm{~g} /$ week of salmon was not sufficient to prevent a decrease in serum 25-hydroxyvitamin $D[25(\mathrm{OH})$ $D_{3}$ ] in autumn in South-Western Norway in adults with overweight/obesity (5). These data suggest that increasing vitamin $D$ intake from diet only, may not be adequate to improve circulating vitamin $\mathrm{D} 25(\mathrm{OH}) \mathrm{D}_{3}$ level in obese individuals. Furthermore, although Vitamin D supplementation increased circulating vitamin $D$ levels $25(\mathrm{OH}) \mathrm{D}_{3}$ levels, nevertheless, this did not translate to improved whole-body insulin sensitivity (chapter 6). Therefore, a combination mode of interventions (e.g. exercise and nutrition) and more personalized strategies should be explored in future research.

\section{Activities/Products and Innovation}

In this thesis, we combined state-of-the-art methodology including: hyperinsulinemic-euglycemic clamp, adipose tissue gene expression using qRT-PCR, plasma vitamin D and vitamin D fluxes analysis using gold standard LC/MS-MS measurement, adipose tissue blood flow measurements (i.e. xenon washout technique), arterio-venous balance technique, PCR-based genetic variant analysis in combination with subcutaneous adipose tissue transcriptomic, which together gave important insights in obesity related vitamin D metabolism. Furthermore, we have also conducted a systematic review and meta-analysis in this thesis, providing one of the highest levels of evidence in human clinical research to date.

\section{Planning and Realization}

The causal relationship between vitamin $\mathrm{D}$ and obesity related metabolic health is still under debate. Although, from studies described in this thesis, the direct link between vitamin $D$ 
and overall metabolic health (non-skeletal function) may not be mediated by tissue-specific insulin signaling/sensitivity pathways. However, the link between Vitamin D and metabolic health may be partly mediated via its effects on gut microbiota composition/diversity and gut health (6). This is supported by the presence of VDR expression in human enterocytes and from a recent genome wide association study that suggests a potential link between VDR variants and gut microbiota diversity (7). However, future studies are needed to investigate in more detail the relationship between vitamin $D$, gut microbiota, gut health, and its effects on host metabolic health.

Results from this thesis should encourage future Vitamin D research, for instance, how genetic variants (chapter 5) in vitamin D metabolisms (VDR and CYP) may influence the metabolic outcome of vitamin D supplementation. This will pave the way for studies with more personalized (sub-group, i.e. carrier and non-carriers of VDR SNPs) approaches. In addition, combining vitamin $\mathrm{D}$ supplementation with other modes of intervention (i.e. exercise / dietary intervention induced weight loss) might provide new strategies towards a more personalized approach for obesity related vitamin $D$ deficiency treatment.

Last but not least, while obesity has been suggested as one of the major comorbidities of covid-19 (2), vitamin D deficiency is a common feature in obesity, and may also be a determinant of covid-19 outcome. More studies warrant to explore the link between vitamin D deficiency, obesity, and covid-19 which is highly relevant given the current pandemic our society and scientific community is dealing with. 


\section{References:}

1. Blüher M. Obesity: global epidemiology and pathogenesis. Nature Reviews Endocrinology. 2019:1.

2. Klang E, Kassim G, Soffer S, et al. Morbid Obesity as an Independent Risk Factor for COVID-19 Mortality in Hospitalized Patients Younger than 50. Obesity (Silver Spring). 2020.

3. Frühbeck G, Busetto $L$, Dicker $D$, et al. The $A B C D$ of obesity: an EASO position statement on a diagnostic term with clinical and scientific implications. Obesity facts. 2019;12(2):131-6.

4. Hengist A, Perkin O, Gonzalez J, et al. Mobilising vitamin D from adipose tissue: The potential impact of exercise. Nutrition Bulletin. 2019.

5. Bratlie M, Hagen IV, Helland A, et al. Five salmon dinners per week were not sufficient to prevent the reduction in serum vitamin $D$ in autumn at $60^{\circ}$ north latitude: a randomised trial. The British journal of nutrition. 2020;123(4):419-27.

6. Waterhouse $M$, Hope $B$, Krause $L$, et al. Vitamin D and the gut microbiome: a systematic review of in vivo studies. European journal of nutrition. 2019;58(7):2895-910.

7. Wang J, Thingholm LB, Skieceviciene J, et al. Genome-wide association analysis identifies variation in vitamin $D$ receptor and other host factors influencing the gut microbiota. Nat Genet. 2016;48(11):1396-406. 


\section{ACKNOWLEDGEMENTS}

Nutrition and metabolism are strongly connected. Continuous works from scientist troops all around the world have contributed almost a real time explanation of biological mechanisms that has never been thought before. It took more than 7000 miles far away from my "comfort zone" to learn and take on board into this fascinating subject. Of course I would not made it by myself, therefore I want to thank all the people that made this journey possible.

First, I would like to express my utmost gratitude to my promotor, prof. Ellen Blaak. She granted me with an acceptance in NUTRIM School of Translational Research and Metabolism 4 years ago, and patiently admitted to discuss my research proposal prior to my departure in Maastricht. Thank you for your support, guidance, and precious advices during my PhD study.

Next to her, there is my daily supervisor that guided me in detail - Dr. Johan Jocken. You exposed me to so many biological mechanisms (particularly adipose tissue and its physiology) more than anyone before. I hope you don't mind with my hundred door knockings at your room to ask or discuss on my research progress. Your comments have always been constructive and encouraging. Thank you for always boosting up my confidence through this far.

Thank you to prof. Edwin C. Mariman, prof. Luc van Loon, prof. Lisette de Groot, prof. Marjolein Visser, prof. Jogchum Plat, Dr. Simone Eussen, and Dr. Susan Coort for taking a time and willingness to review my thesis, and being present at the official PhD defence.

To $(E m)$ prof. Marleen van Baak, thank you to supervise me on meta-analysis manuscript, for the handbook that I borrowed alongside the entire study and our valuable discussions.

My paranymphs, Kenneth and Bobby, thank you for every helps you both done to make sure my defence ceremony would run smoothly. Amidst this challenging corona time, I really appreciate your willingness to organize the details.

To Gijs, Ruth, and Emanuel, thank you for all interesting discussion during the research and literature meeting, as well as warm conversations in the coffee corner. Gijs, thank you for introduced me with NASO spring meeting, a semi-formal national's meeting with exciting presentations.

I want to thank Nicole and Yvonne who help me a lot with technical support. Thank you for your assistance during the cell culture trial and extra help with qPCR assays. Yvonne, thanks for the 'fingers sport' pipetting training also he glycerol assay.

To all my former and current colleagues: Rudi, Kenneth Verbouwen, Max, Birgitta, Mattea, Kenneth Pasmans, Rens, Manuel, Inez \& Kelly (our representative in NUTRIM PhD 
council), Qing, Lars, Jacco, Michelle, Dilemin, Mirella, and loannis thanks a bunch for the friendship and supports during my PhD. To my roommate Wesley, sadly this 2020 we can't talk Formula-1 race like before. To Jehad and Sultan thanks for chats during lunch time. I wish you all a success and bright future wherever you may find yourself.

Gabby, during you busy time, many thanks to provide me the DIOGENES data. Desiree thanks for connected me to Human Resource (KCIS) FHML and helped along my moving to The Netherlands. To secretariat of Human Biology Department - the C\&C Claudia and Cleo, thanks for the daily helps especially when I forgot to bring my room key $(;)$, and also with the administration of my PhD promotion.

To all the peoples in Human Biology Department, thank you for every moments I have here. I am proud and more than honoured to be part of this big family. I will cherish those memories forever.

My journey far away from home would be blunt and dull without full dose of laughs and supports from Indonesian Student Association (PPI Maastricht) circa 2016-2020; Dave, Rafael, Puji, Wimba, Rajan, Syifaul, Tari, Adel, Ika, Lina, Tika, Ipeh, Fasya, Herma, Ipam, Bu Carla, Arip, Astin, Dexon, Nael, Josua, Malia, Radit Ghent, Herwansyah, Tricia, Bona, Nunu, Tari. Also to all BUDI-LN 2016 PhD scholars whom I cannot mention one by one, thank you for many warm gatherings in all over the Netherlands. I wish you success in your future endeavours.

Dear my "extended" family and friends in Limburg; Ari-Andin, Iging-Desti, FerdiNia, Wisnu-Yuli, Untung-Nora, Arin-Dani, Aep-Patrice, Armand-Upie, Arip-Mei, Misbah-Upi, Fauzan-Masni, Cici-Haris, Eli, Yuke, Wanda, Titin, Ibu Ati, Riyani, Farida, Tante Inne, Louise, Abdurrahim-Priscilla, and other families heel erg bedankt for series of tasty delicious yet comfort Indonesian foods as well as your support and companionship during every season of life.

To Ferdi Cayani, Dr. Titut, Widagdo, Galuh, Fadel, Indri-Fajar, Farid, Rina, Yusta and Rovan thanks for the great time we had when exploring several places all across NL. From free picking flowers at Nationale Tulpen Dag to walking across 3 nations in one minute at Drielandenpunt.

Sincere gratitude to Indonesian Ministry of Research, Technology, and Higher Education together with Indonesian Endowment Fund of Education (LPDP) that has granted me a scholarship and made this PhD journey possible. Many thanks to Dr. Ani Margawati, Dr.Diana Nur Afifah, Dr. Gemala Anjani, and collagues in Deparment Nutrition Science, Faculty of Medicine Univeritas Diponegoro; Nuryanto, Syauqy, Ayusta, Binar, Etika, Deny, Dieny, Ninik, Fahmy, Nissa, Nurmasari, Hartanti, Ayu, Rachma, Dewi. To Kristina and Fifi thank you for helping me with administrative bureaucracy during my leave. To prof. Sulchan and prof. Hertanto thank you for providing me a recommendation upon my scholarship application. To prof. Tri Nur thank you to guide my early introduction with Maastricht University. 
My steps wouldn't be this far without wholehearted support and continuous prayers from my parent, inlaws, and family in Indonesia. Terimakasih Ibu, Bapak, Mama, Papa, Mita, Helmi, Bestari, dan Fajri. Thanks for the endless phone and videocalls that make 11.329 kilometers distance just in the fingertip.

And last to the most valuable thing in my life, my little family, thank you for the unconditional love and supports. My dearest wife - Fauzia Ramadhaniyanti, you set aside your medical career and general practices to get along with me and wander the world. We buckled up into this PhD rollercoaster together. It was not always smooth and pleasant ride but I'm blessed we kept holding each other through it. The coolness of my sight, my beloved children Fadhlan and Fathima, thanks for thousands of cuddling and hug. You both are reason for Papa to keep moving forward. Let us sign up into other ride. May Allah SWT always guide and bless our life. 


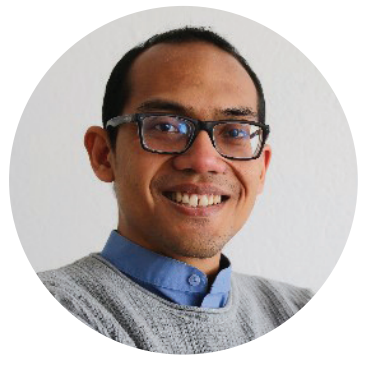

ADRIYAN PRAMONO

Research Group: NIMO-Lab

(Nutrition, Integrative Metabolism, \& Obesity)

Research Department: Department of Human Biology, Maastricht UMC+

Research School: NUTRIM School of Nutrition and Translational Research in Metabolism

PhD Period: $2016-2020$

Promotor: Prof. Ellen E Blaak

Co-promotor: Dr. Johan W.E. Jocken

\section{ABOUT THE AUTHOR}

Adriyan Pramono was born on July 4, 1985, in Semarang. He did his bachelor of nutrition in the Faculty of Medicine, Diponegoro University, Semarang, Indonesia in 2003 and graduated in 2007. In 2008 while working as a research assistant, he continued his master degree in nutrition science and graduated in 2010. He then continued with several short courses which were mainly conducted in SEAMEO-RECFON (Southeast Asian Ministry Education Organization - Regional Center Food and Nutrition), University of Indonesia, Jakarta where he had the opportunity to meet the expert in nutrition such as Prof. Rosalind S Gibson, and a leader such as the CEO of General Electric Indonesia, Handry Santriago.

Since 2012, he has been appointed as junior faculty in the Department of Nutrition Science, Faculty of Medicine, Diponegoro University. Between 2012 and 2016, he was actively involved in the educational duties, university research, and community empowerment.

In September 2016, he started his PhD program at the Department of Human Biology, NUTRIM School of Nutrition and Translational Research in Metabolism, Maastricht University Medical Center+, The Netherlands under the supervision of Prof. Ellen Blaak and Dr. Johan Jocken. Here in the NIMO-Lab research group, he studied about vitamin $D$ and its relation to insulin sensitivity in human obesity, using humans cohort with overweight/ obesity, state-of-the-art methodology including a 2 step hyperinsulinemic-euglycemic clamp, LC/MS-MS, arteriovenous difference, and gene expression analysis of abdominal adipose tissue.

During his PhD, he received awards; Travel Grant from LPDP (Indonesia Endowment Fund for Education) in 2018 and EASO (European Association for the Study of Obesity) in 2019 for presenting in The $25^{\text {th }}$ and $26^{\text {th }}$ European Congress on Obesity.

After his PhD, Adriyan will continue his carrier in Indonesia. He would like to continue his research focusing on vitamin $\mathrm{D}$ related metabolism, whole dietary pattern and metabolic health in overweight and obesity. He would like to do both fundamental and translational research as well as systematic reviews and meta-analysis. 


\section{PHD PORTFOLIO}

\section{LIST OF PUBLICATION}

- $\quad$ Pramono, A., Jocken, J. W. E., Essers, Y. P. G., Goossens, G. H., \& Blaak, E. E. (2019). Vitamin $D$ and Tissue-Specific Insulin Sensitivity in Humans With Overweight/Obesity. The Journal of clinical endocrinology and metabolism, 104(1), 49. https://doi.org/10.1210/ic.2018$\underline{00995}$

- $\quad$ Pramono, A., Jocken, J. W. E., \& Blaak, E. E. (2019). Vitamin D deficiency in the etiology of obesity related insulin resistance. Diabetes/ metabolism research and reviews, e3146: https://doi.org/10.1002/dmrr.3146

- $\quad$ Pramono, A., Jocken, J. W. E., Goossens, G. H., \& Blaak, E. E. (2019). Vitamin D release across abdominal adipose tissue in lean and obese men: The effect of ß-adrenergic stimulation. Physiological Reports 7(24): e14308: DOI: $10.14814 /$ phy2.14308

- $\quad$ Adriyan Pramono, Johan W.E. Jocken, Marleen A. van Baak, Ellen E. Blaak. The Effect of vitamin D supplementation on insulin sensitivity: a systematic review and meta-analysis. Diabetes Care 2020 Jul; 43(7): 1659 - 1669 (https://doi. org/10.2337/dc19-2265)

- Adriyan Pramono, Johan W.E. Jocken, M.A Adriaens, M.F. Hjorth, A. Astrup, W.M. Saris, E.E. Blaak. The association between vitamin $D$ receptor polymorphisms and tissue-specific insulin resistance in human obesity. Submitted

\section{SELECTED ORAL/POSTER PRESENTATION}

2018:

- The Netherlands Association for the Study of Obesity (NASO) Spring meeting, Utrecht 19 April 2018

- $\quad$ The $25^{\text {th }}$ European Congress on Obesity (ECO), Vienna, Austria 23-26 May 2018

- $\quad$ Annual NUTRIM Symposium, Maastricht 21 November 2018

2019:

- The Netherlands Association for the Study of Obesity (NASO) Spring meeting, Utrecht 3 April 2019

- $\quad$ The $26^{\text {th }}$ European Congress on Obesity (ECO), Glasgow, Scotland 28 April- 1 May 2019

- $\quad$ Annual NUTRIM Symposium, Maastricht, 27 November 2019

\section{AWARD}

- $\quad$ Travel Grant for ECO 2018 in Vienna, Austria from LPDP (Indonesia Endowment Fund for Education)

- Travel Grant for ECO 2019 in Glasgow, Scotland from EASO (European Association for the Study of Obesity)

\section{COURSES}

- $\quad$ Research Writing for PhD I - II (Biomedical Sciences)

- $\quad$ Presentation Course for PhD

- Biostatistics Part II - Regression Analysis

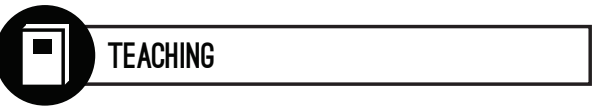

- Involved in the supervision of bachelor thesis 
